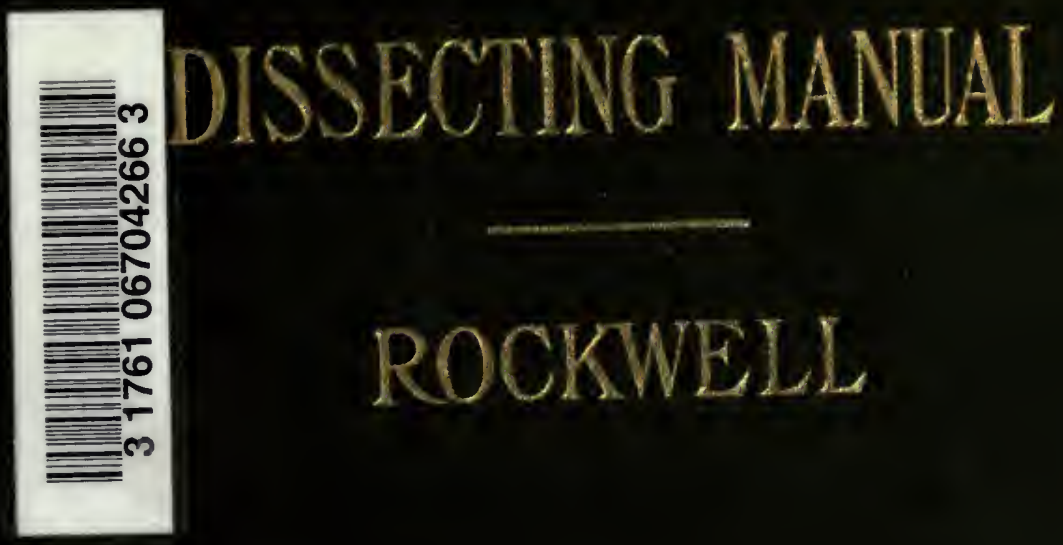



Withe ther Compeliments

afthe Preblisters.

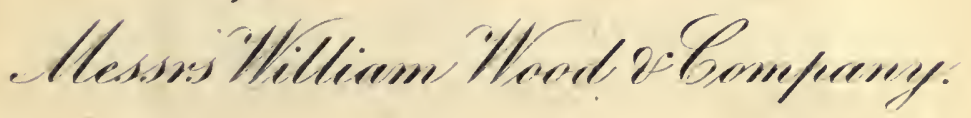

st. Fifitu Stronese.

- Ventylorl.

Prices: = net 
。

a

. 
Digitized by the Internet Archive in 2007 with funding from Microsoft Corporation 



\section{DISSECTING MANUAL}

BASED ON

\section{CUNNINGHAM'S ANATOMY}

BY

\section{W. H. ROCKWELL, JR., M.D.}

Formerly Assistant Demonstrator of Anatomy in the College of Physiclans and Surgeons, Columbla University, New York

\section{NEW YORK \\ WILLIAM WOOD \& COMPANY \\ MDCCCCV}

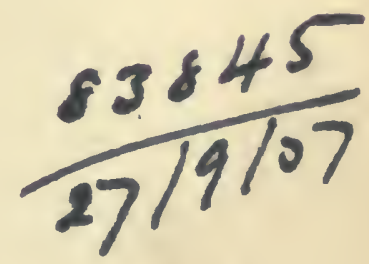


COPYRIGHT, I905, By WILLIAM WOOD AND COMPANY. 


\section{PREFACE.}

As this manual is intended for dissecting-room use, the body has been considered as divided into the five parts usual in the dissecting-room, viz., head and neck, thorax, upper extremity, abdomen and pelvis, and lower extremity. Each of these parts has been subdivided as much as possible, with regard to the avoidance of excessive repetitions, and described completely. The spinal cord has been described under the heading of the cranial cavity, because it seemed best to include it with the brain. A special subdivision has been made of the scalp, because of the necessity of early removal of the skull cap in order to preserve the brain. In the text the name of each muscle has been begun with a capital, e.g., Pectoralis major. Because of the great irregularity in origin and course of the smaller arteries, only their distribution has been fully described, as a rule. Cunningham's Anatomy has been followed strictly throughout, and the bracketed numerals at the end of each paragraph refer to the corresponding page in the last edition of that Anatomy, e.g., [104]. The bracketed numerals in the body of any paragraph refer to pages in this manual, e.g., (page 47).

$$
\text { W. H. ROCKWELL, JR. }
$$

August, 1905. 



\title{
TABLE OF CONTEN'TS.
}

\author{
HEAD AND NECK.
}

Bones of the skull .

PAGL

Cranium as a whole . . . . . . . . . . . 5

Cranium in transverse section . . . . . . . . . . 14

Cranium in sagittal section . . . . . . . . . . . . 16

Cervical vertebræ . . . . . . . . . . . . . . 18

Articulations . . . . . . . . . . . . . . . . . . 19

Scalp . . . . . . . . . . . . . . . . 23

Fascia and muscles . . . . . . . . . . 23

Nerves . . . . . . . . . . . . . . 23

Arteries and veins . . . . . . . . . . . . 24

Cranial cavity . . . . . . . . . . . . . 25

Meninges . . . . . . . . . . . . 25

Brain . . . . . . . . . . . . 26

Medulla . . . . . . . . . . . . . 26

Pons Varolii . . . . . . . . . . . 28

Fourth ventricle . . . . . . . . . . . 28

Cerebellum . . . . . . . . . . 30

Mid-brain . . . . . . . . . . . 32

Fore-brain . . . . . . . . . . . . . 33

Cerebral hemispheres . . . . . . . . . 37

Nerves . . . . . . . . . . . . . 45

Arteries . . . . . . . . . . . . . . 47

Veins . . . . . . . . . . . . . 49

Spinal cord . . . . . . . . . . . . . 50

Orbit . . . . . . . . . . . . . 52

Muscles . . . . . . . . . . . . . 53

Nerves . . . . . . . . . . . . 53

Arteries and veins . . . . . . . . . 55

Eyeball . . . . . . . . . . . . . . . 56

Anterior aspect of head and neck . . . . . . . . . 59

Fascia . . . . . . . . . . . . . 59

Muscles . . . . . . . . . . . . . . 60

Cervical nerves . . . . . . . . . . . . 66 
TABLE OF CON'TENTS.

PAGE

Arteries . . . . . . . . . . . . . . . 78

Veins . . . . . . . . . . . . . . 83

Lymphatics . . . . . . . . . . . . . 84

Mouth and pharynx . . . . . . . . . . 85

Salivary glands . . . . . . . . . . . . 88

Larynx . . . . . . . . . . . • • . . 89

Thyroid body . . . . . . . . . . . . 94

Nasal fossæ . . . . . . . . . . . . . . 94

External ear . . . . . . . . . . . . . . . 95

Middle ear . . . . . . . . . . . . . . . 97

Internal ear . . . . . . . . . . . . . . 100

Posterior aspect of neck . . . . . . . . . . . . 103

Fascia and superficial muscles . . . . . . . . 103

Deep muscles . . . . . . . . . . . . . . . 104

Nerves . . . . . . . . . . . . . . 105

Vessels . . . . . . . . . . . . . . 106

THORAX.

Bones . . . . . . . . . . . . . . . 107

Articulations . . . . . . . . . . . . . . 110

Fascià . . . . . . . . . . . . . . . . 113

Muscles . . . . . . . . . . . . . . . 114

Nerves . . . . . . . . . . . . . . . 118

Heart . . . . . . . . . . . . . . . . . . 124

Arteries . . . . . . . . . . . . . . . . . 128

Veins . . . . . . . . . . . . . . . . 133

Lymphatics . . . . . . . . . . . . . . . . 135

Respiratory system . . . . . . . . . . . . 136

Glandular structures . . . . . . . . . . . . . . 139

UPPER EXTREMITY.

Bones . . . . . . . . . . . . . . . . 141

Articulations . . . . . . . . . . . . . . . . 149

Shoulder and arm . . . . . . . . . . . . . . 157

Fascia . . . . . . . . . . . . . . 157

Muscles . . . . . . . . . . . . . . 158

Nerves . . . . . . . . . . . . . . 160

Arteries . . . . . . . . . . . . . . . 165

Veins . . . . . . . . . . . . . . 167

Lymphatics . . . . . . . . . . . . . 168

[vi] 


\section{TABLE OF CONTEN'TS.}

Forearm, wrist, and hand . . . . . . . . . . . 168

Fascia . . . . . . . . . . . . . . 168

Muscles . . . . . . . . . . . . . . . 170

Nerves . . . . . . . . . . . . . . 175

Arteries . . . . . . . . . . . . . . . 178

Veins . . . . . . . . . . . . 180

\section{ABDOMEN AND PELVIS.}

Bones . . . . . . . . . . . . . . . . . . 182

Articulations . . . . . . . . . . . . . . . . . . 187

Fasciæ and muscles . . . . . . . . . . . . . . 190

Nerves . . . . . . . . . . . . . . . . . . 198

Arteries . . . . . . . . . . . . . . . . 206

Veins . . . . . . . . . . . . . . . . 212

Lymphatics . . . . . . . . . . . . . . . . . 214

Digestive system . . . . . . . . . . . . . . . . . 216

Peritoneum . . . . . . . . . . . . . . . . . 226

Ürogenital system . . . . . . . . . . . . . . . . .231

Male reproductive organs . . . . . . . . . . . . . 235

Female reproductive organs . . . . . . . . . . . . 241

Ductless glands . . . . . . . . . . . . . . . . . 248

\section{LOWER EXTREMITY.}

Bones . . . . . . . . . . . . . . . . . . . 250

Articulations . . . . . . . . . . . . . . . . . . 259

Thigh and buttock . . . . . . . . . . . . 270

Fascia . . . . . . . . . . . . . 270

Muscles . . . . . . . . . . . . . . . . . . 272

Nerves . . . . . . . . . . . . . . . 278

Arteries . . . . . . . . . . . . . . . . . 288

Veins . . . . . . . . . . . . . 291

Lymphatics . . . . . . . . . . . . . . 292

Leg and foot . . . . . . . . . . . . . . 293

Fascia . . . . . . . . . . . . . . . . 293

Muscles . . . . . . . . . . . . . . . . . 294

Nerves . . . . . . . . . . . . . . . . . 299

Arteries . . . . . . . : . . . . . . . . . .303

Veins . . . . . . . . . . . . . . . 306

Lymphatics . . . . . . . . . . . . 306 



\section{DISSECTING MANUAL.}

\section{HEAD AND NECK.}

\section{BONES OF THE SKULL.}

The skull comprises the bony envelope of the brain, and the bones of the face; the hyoid bone is usually described with it. The cranium is the skull minus the inferior maxilla. Because it is so found in dissecting, it will be described as a whole, following brief descriptions of the shape and position of the bones forming it.

[103]

The frontal bone occupies the front of the cranium and consists of three parts. The frontal part is shell-like, corresponds to the forehead, and rises above the orbital arches. The orbital part is horizontal and consists of two orbital plates, which extend backward from the orbital arches and are separated in their posterior halves by a notch (ethmoidal). The nasal part helps form the roof of the nasal fossæ.

[103]

The two parietal bones form the top of the cranial vault and lie bchind the frontal; they are quadrilateral.

[107]

The occipital bone occupies the lower and back part of the cranium and consists of three parts which surround the foramen magnum. The squamous (tabular) part is the expanded curved plate behind the foramen; its superior borders unite in the superior angle, and end laterally in the lateral angles. The lateral (condylic) portions lie on either side of the foramen, while the basilar part lies in front of it.

The two temporal bones lie on either side of the cranium 


\section{DISSECTING MANUAL.}

between the sphenoid and occipital, below the parietals; each consists of three parts, squamous, tympanic, and petro-mastoid. The squamous part is thin, shell-like, and vertical. The tympanic part lies below the squamous and forms the lower part of the external auditory meatus. The petro-mastoid part joins the inner aspect of the squamous and tympanic parts and extends behind their junction as a nipple-like (mastoid) process. Its petrous portion is an elongated and three-sided pyramid, which is attached by its base to the inner aspect of the squamous and tympanic parts postero-inferiorly, and extends nearly horizontally inward and forward.

[114]

The sphenoid bone lies at the base in front of the occipital mesially and the temporals at either side. It somewhat resembles a bat and presents a cubical body with three pairs of processes. The lesser (orbital) wings are small and flattened triangular plates which extend horizontally outward from the fore and upper part of the body. The greater (temporal) wings are large and, as seen from above, crescentic plates which extend outward from the lower part of the body, between the frontal and temporal bones. The pterygoid processes each consist of two plates (external and internal pterygoid); these descend vertically from the roots of the great wing and under surface of the lateral part of the body on each side and are fused in front, except inferiorly.

[122]

The ethmoid bone lies in front of the sphenoid, occupying the ethmoidal notch of the frontal and projecting below this. It is cubical and consists of two cellular (lateral masses) parts, which are united superiorly to a mesial (vertical) plate by a thin horizontal lamina (cribriform plate).

[128]

The two superior maxillary bones form the upper jaw; each consists of a hollow pyramidal body with four surfaces and four processes. The malar (zygomatic) process springs from the outer surface high up; the frontal (nasal) process is a plate ascending vertically from the upper and fore part; the alveolar process is a curved projection from the under surface; 


\section{BONES OF THE SKULL.}

and the palatal process is a plate running horizontally inward from the inner side of the body and alveolar process.

[131]

The two malar bones (cheek bones) lie on the outer sides of the orbital fossæ, upon the superior maxillæ. Each has four angles, or processes.

[135]

The two nasal bones are elongated and quadrilateral plates which form the bridge of the nose.

[137]

The two lachrymal bones are thin and quadrangular scales which lie on each inner orbital wall, just behind the nasal process of the superior maxilla.

[138]

The two inferior tubinated bones are elongated and shelllike laminæ which lie along the lower part of the outer wall of each nasal fossa.

The vomer is irregularly quadrilateral and lies below the sphenoid at the back of the nasal septum.

[140]

The two palate bones lie below the sphenoid and help form the back of the hard palate and outer walls of the nasal fossæ. Each consists of two plates, horizontal and vertical, which are united like the letter $\mathrm{L}$, the horizontal plate running inward; a tuberosity runs backward and outward from the angle between the plates. Two processes, orbital and sphenoidal, surmount the front and back parts respectively of the top of the vertical plate:

The inferior maxilla (mandible) has a horizontal and horseshoe-shaped body from which two rami project vertically upward, behind. Body. Externally this presents, in the midline in front, a vertical ridge (symphysis) which divides inferiorly to enclose a triangular area (mental protuberance); the inferior angles of the protuberance are prominent (mental tubercles). On its outer surface, on each side, a faint ridge (external oblique line) runs from the mental tubercle to the anterior border of the ramus; just above the centre of the ridge is the foramen (mental) of the inferior dental canal. The upper border presents the tooth sockets; these of the canine and incisors produce ridges; between the canine ridge and the 


\section{DISSECTING MANUAL.}

symphysis is a hollow (incisor fossa). The inferior border is rounded. On the internal surface, on each side, a ridge (mylohyoid; internal oblique line) runs, from behind and above, downward and forward to the lower part of the symphysis; below the ridge posteriorly is a fossa for the submaxillary gland; at the junction of both ridges, in the midline anteriorly, is a raised tubercle with two, or two pairs of laterally placed, spines (mental, or genial spines).

Ramus.-This ascends from the back of the body; its posterior border forms an angle, usually everted, with the base of the body. Its outer surface may present obliquely curved ridges. Its inner surface presents mesially a foramen (inferior dental) which is overhung in front by a projection (lingula); a groove (mylo-hyoid) descends from the foramen behind the lingula. Superiorly the ramus supports two processes which are separated by a wide notch (sigmoid). The condyle is the posterior process; it is convex, elongated transversely, and supported on a neck which is compressed antero-posteriorly; on the inner side of the neck is a depression for the External pterygoid. The coronoid process is a triangular elevation which lies in front, its anterior border joining that of the ramus; behind this border, on the inner side, is a triangular groove whose inner border joins the internal oblique line.

The hyoid bone lies in the neck, between the mandible and the larynx; it has a U-shaped body with four processes (cornua). The body is compressed antero-posteriorly; its anterior surface presents a median vertical ridge; its posterior surface is concave; its upper border is broad and bounded in front by a transverse ridge, and behind by a thin edge. From each end of the body a process (great cornu) curves upward and backward, being compressed laterally but expanded at its end. A small process (lesser cornu) projects upward, backward, and slightly outward from the upper surface, on each side, at the junction of the body and the great cornu; it is often partly cartilaginous. 


\section{BONES OF THE SKULL.}

\section{The Cranium As a Whole.}

Anterior Aspect (norma frontalis). - This includes the frontal, malar, nasal, and superior maxillary bones; it presents the orbital fossæ, one lying on each side, with the orifice of the nasal fossa between and below them.

Frontal Region. - This is convex and limited laterally by two ridges (temporal lines); it is formed by the frontal bone, which presents inferiorly the arched upper (orbital) margins of the orbits. Each orbital margin presents a (supra-orbital) notch, or foramen, near its inner third; externally it is thin and sharp and ends in a (external angular) process which joins a (frontal) process of the malar; internally it is rounded and ends in another (internal angular) process which joins a (frontal) process of the superior maxilla. The space between the internal angular processes is the root of the nose and may present the remains of a mesial suture between the original halves of the frontal. It also presents, just above the naso-frontal suture, a median prominence (glabella) from which a (supraorbital) ridge runs outward on each side above the orbit; above each ridge is a fulness (frontal eminence).

Orbital Fossa. - This is a four-sided pyramid whose base is the orbital aperture; its apex is directed backward and inward, so that the axes of both foss $x$ converge behind. The margin of the aperture is formed above by the orbital margin of the frontal; in the outer, and half the lower, part by the sharp (orbital) margin of the malar; and in the inner, and half the lower, part by the frontal process and sharp (orbital) margin of the body of the superior maxilla. A narrow cleft (sphenoidal fissure) runs outward and slightly upward, from the apex, between the wings of the sphenoid; above and internal to its inner end is a small (optic foramen) opening between the roots of the lesser wing of the sphenoid.

The roof is concave and formed in front by the orbital plate of the frontal, and behind by the lesser wing of the sphenoid. 


\section{DISSECTING MANUAL.}

It is separated from the inner wall by a rather horizontal suture; and from the outer wall by the sphenoidal fissure bchind and sutures in front. On the inner boundary, in the frontoethmoidal suture, are two foramina (anterior and posterior ethmoidal canals). A depression, or spine, for the pulley of the Superior oblique, lies just behind the inner part of the orbital margin of the frontal, while a shallow fossa, for the lachrymal gland, lies under cover of the external angular process of the frontal.

The floor is formed by the orbital plate of the superior maxilla, the orbital surface of the malar, and posteriorly a small triangular area on the orbital process of the palate bone. Externally a cleft (spheno-maxillary fissure) separates the superior maxilla from the great wing of the sphenoid. Internally the floor is separated from the inner wall by a line of sutures which end anteriorly, opposite the lachrymal bone, at the canal (lachrymal). A canal (infra-orbital) runs sagittally under the floor to the face; posteriorly its roof is deficient and a groove leads from it to the spheno-maxillary fissure. [149]

The outer wall is formed by the great wing of the sphenoid and orbital surface of the malar. It is limited below by the spheno-maxillary fissure posteriorly; and above by the sphenoidal fissure posteriorly and a line of sutures anteriorly. One or two small (orbital) canals run through the malar bone anteriorly to the temporal fossa.

[151]

The inner wall is formed, from before backward, by the frontal process of the superior maxilla, the lachrymal, the side (os planum) of the lateral mass of the ethmoid, and part of the side of the body of the sphenoid. It is limited above and below by lines of sutures. The lachrymal bone presents a mesial vertical ridge (lachrymal crest), and in front of this a hollow (lachrymal groove), for the lachrymal sac, which is completed by the frontal process of the superior maxilla; a canal for the nasal duct descends from the groove to the nasal fossa.

[151] 
Skeleton of the Face.-Anteriorly this is formed by the superior maxillæ, which are united below the nasal aperture. The malar bones lie externally on the malar processes of the superior maxillæ, while the nasal bones are wedged in between their frontal processes above. The tooth sockets produce ridges of which the eanine is the most prominent; internal to this is a shallow (incisive) fossa over the incisors, while external to it and higher up is a deeper (canine) fossa. Just below the orbital margin is the orifice (infra-orbital foramen) of the infraorbital canal. The body of the superior maxilla contains a large pyramidal cavity (antrum of Highmore). The alveolar processes are curved and project from the under surface of each body; they contain the teeth and form together the alveolar arch.

[151]

The nasal aperture is pyriform. Its margins are formed below by the free edges of the bodies and frontal processes of the superior maxillx, and above by those of the nasal bones. At the eentre of its lower margin is an outstanding process (anterior nasal spine).

[152]

Lateral Aspect (norma lateralis).- This includes the frontal, parietal, occipital, sphenoid, temporal, malar, and superior maxilla. A vertical (coronal) suture unites the frontal and parietal. Another (lambdoid) unites the occipital and parietal; it joins (at the asterion) the occipito-mastoid and parietomastoid sutures. The spheno-parietal suture forms (at the pterion) the crosspicce of an $\mathrm{H}$-shaped suture surrounding the end of the great wing of the sphenoid. A ridge (temporal crest), often double, curves upward and backward from the external angular process of the frontal, across (at the stephanion) the coronal suture, then downward over the parietal toward the posterior inferior angle, and then (supramastoid crest) forward on the temporal to become the posterior root of the zygoma. An elevation (parietal eminence) is seen near the centre of the parietal, above the temporal crest. The malar presents an external foramen (malar canal) leading into the orbit, and a 


\section{DISSEC'TING MANUAL.}

process (temporal) running backward. The protuberance and curved lines of the occipital will be described with the "posterior aspect."

$[152]$

Temporal Fossa.-This lies above the level of the zygomatic arch, enclosed by the temporal crest. It is limited inferiorly; in front by the free border of the great wing of the sphenoid, which bounds the spheno-maxillary fissure above; and behind by a ridge (pterygoid) which crosses the sphenoid and squamous temporal to become the anterior root of the zygoma. Anteriorly a foramen (temporal canal) in the angle of the malar, behind its frontal and orbital processes, leads into the orbit.

A process (zygomatic) springs from the front and lower part of the squamous temporal by a broad attachment whose surfaces are horizontal; anteriorly it twists till its surfaces are vertical and joins the temporal process of the malar, completing the zygomatic arch. Posteriorly its upper edge (posterior root) runs back over the external auditory meatus as the supramastoid crest, while its lower edge (anterior root) turns inward as the pterygoid ridge (infra-temporal crest). On the under side of the anterior root is a transverse ridge (articular eminence), and over the outer side of this, at the divergence of the roots, is a rounded prominence (tubercle). A conical process (post-glenoid tubercle, or "middle root") descends from the posterior root in front of the auditory meatus.

Behind the articular eminence is a hollow (glenoid fossa); an oblique (Glaserian) fissure divides this into anterior articular and posterior non-articular parts; in the inner end of the fissure is a scale of bone, and behind this is the orifice of the canal of Huguier (iter chordæ anterius). A process (alar spine) of the sphenoid lies just internal to the articular portion of the fossa. A flat (tympanic) plate forms the back of the fossa; its lower edge is a crest (vaginal process) which splits to enclose a descending rod (styloid process) of bone; its outer edge (external auditory process) bounds the external auditory 


\section{BONES OF THE SKULL.}

meatus below and in front; a fissure (auricular) for Arnold's nerve separates the plate from the mastoid and squamous temporal behind. The external auditory meatus curves inward and slightly forward, with its convexity upward, to the tympanum. Behind this the mastoid process, a large and nipple-like process, projects downward; it usually presents a (mastoid) foramen, in the occipito-mastoid suture, for a vein.

Zygomatic Fossa.-This is a deep hollow in front of the anterior root of the zygoma and below the infra-temporal crest (pterygoid ridge). The postero-external (zygomatic) surface of the superior maxilla forms the anterior wall, being limited externally by the sharp lower border of its malar process, and superiorly by the lower border of the spheno-maxillary fissure; it presents foramina (posterior dental canals) leading to the upper molars, and also a projection (tubercle) behind the last molar. The external pterygoid plate of the sphenoid, which forms the inner wall, is separated from the superior maxilla above by a narrow and vertical cleft (pterygo-maxillary fissure), and below by the tuberosity of the palate bone; the posterior border of the plate is thin and may have spiny points. [156]

The under (zygomatic) surface of the great wing of the sphenoid overhangs the fossa, extending from the alar spine to the spheno-maxillary fissure and outward to the pterygoid ridge: it presents an oval hole (foramen ovale) just behind the root of the pterygoid plate, and behind this a smaller orifice (foramen spinosum) close to the alar spine. Part of the roof is formed by a small triangular area on the squamous temporal between the articular eminence and anterior root of the $\mathrm{zy}$ goma. At the back of the fossa are the styloid and vaginal processes of the sphenoid. Internally the fossa communicates with the orbit and spheno-maxillary fossa, by the sphenomaxillary and pterygo-maxillary fissures respectively; these fissures join at right angles in an $\mathrm{L}$.

Spheno-maxillary Fossa.-This corresponds to the angular interval between the spheno-maxillary and pterygo-maxillary 


\section{DISSECTING MANUAL.}

fissures, and lies between the superior maxilla and root of the pterygoid process of the sphenoid. The vertical plate of the palate bone forms its inner wall, and presents a large (sphenopalatine) foramen leading between the orbital and sphenoidal processes of the palate bone into the nose. The body of the sphenoid and orbital plate of the palate bone form its roof. Opening into it above and behind are the foramen rotundum, Vidian canal, and pterygo-palatine eanal from without inward, while below are the upper end of the posterior palatine canal and the orifices of the accessory posterior palatine canals. [158]

Posterior Aspect (norma occipitalis).-This includes the parietal and occipital bones and the mastoid portions of the temporals. The interparietal (sagittal) suture meets (at the lambda) the occipito-parietal (lambdoid) suture; separated ossicles (Wormian bones) may be found in the lambdoid suture. A (parietal) foramen is found on each parietal not far above the lambda and close to the sagittal suture; the point on the suture between the foramina is the obelion. At the centre of the tabular part of the occipital is a projection (external occipital protuberance) from which a ridge (superior curved line) runs outward on each side to the lateral angle (at the asterion); just above this ridge is another faint one (highest curved line). A mesial ridge (external occipital crest) descends from the protuberance to the foramen magnum; from its centre a ridge (inferior eurved line) runs outward on each side, parallel to the others.

[159]

Superior Aspect (norma verticalis).-The sagittal- (interparietal) suture joins the coronal (fronto-parietal) in front (at the bregma) and the lambdoid (occipito-parietal) behind (at the lambda). The temporal ridge crosses the coronal suture (at the stephanion). The vault is rounded and its highest point (vertex) is in the sagittal suture.

[159]

Inferior Aspect or Base (norma basalis).-This is best described in detail, from before backward. The hard palate is a horseshoe-shaped plate in front, formed by the palatal proc- 


\section{BONES OF THE SKULL.}

esses of the superior maxilla and the horizontal plates of the palate bones. The alveolar processes (superior alveolar arch) of the superior maxillæ bound it in front and at the sides; its posterior border presents a mesial (posterior nasal) spine between two thin and free lunated edges. It presents a mesial sagittal (middle palatine) suture in which a pit (anterior palatine canal, or fossa) lies just behind the incisor teeth. At the bottom of the pit are two pairs of foramina, one pair (foramina of Stenson) lying side by side, and the other (foramina of Scarpa) lying mesially in front and behind. The suture (transversc palatine) between the superior maxillæ and palate bones bends backward on each side to a foramen (posterior palatine canal) just internal to the root of the wisdom tooth; a groove runs forward from this foramen along the inner side of the alveolar arch and may have a sharp inner edge. A transverse ridge lies close to the posterior border.

[160]

The malar bones lie external to the hard palate, on the maxillx, and curve backward (temporal processes) to complete the zygomatic arches.

[160]

The pterygoid processes of the sphenoid lie on either side of the posterior nares, separated from the superior maxillæ by the tuberosities of the palate bones; each tuberosity presents two foramina (posterior, and external accessory, palatine canals) just behind the posterior palatine canal. Each pterygoid process consists of two vertical plates, external and internal, which are separated by a (pterygoid) fossa; the anterior edges of the plates coalcsce superiorly but are separated inferiorly by the tuberosity of the palate bone. The posterior free edge of the internal plate ends below in a hook-like (hamular) proccss which curves backward and outward; it bifurcates above to enclose a (scaphoid) fossa, whose inner margin ends on the body of the sphenoid in a projection (pterygoid tubercle) which extends backward; just above and external to the tubercle is a foramen (Vidian canal). The internal plate curves inward on the body of the sphenoid, as a lipped edge (vaginal process) 


\section{DISSECTING MANUAL.}

which joins the ala of the vomer; just external to this union is the orifice of a canal (pterygo-palatine) which runs betwcen the vaginal process and the sphenoidal process of the palate bone.

[163]

The posterior nares open into the nasal fossæ; they are quadrilateral and separated by the vomer. They are bounded below by the horizontal plates of the palate bones, at the sides by the internal pterygoid plates, and above by the vaginal processes of the sphenoid externally and the alæ of the vomer internally.

[163]

The zygomatic fossa (see page 9) lie external to the pterygoid processes; each extends between the malar and superior maxilla in front, and the zygomatic process and its anterior root at the side and behind. The spheno-maxillary fissure separates the roof and anterior wall. Between the great wing of the sphenoid and petrous temporal is a narrow cleft (sphenopetrosal fissure) which is closed by a synchondrosis; this forms a groove, for the cartilaginous part of the Eustachian tube, which runs from the root of the internal pterygoid plate to the inner side of the base of the alar spine, and there enters an osseouis canal, in the petrous bone, leading to the tympanum. An osseous partition (cochleariform process) divides the canal into an upper portion for the Tensor tympani, and a lower part for the osseous part of the Eustachian tube. Just in front of the alar spine is a small foramen (spinosum); in front of this is a larger one (foramen ovale).

[164]

The basi-occipital (basilar part of the occipital) extends from the body of the sphenoid to the foramen magnum; at its centre is an elevation (pharyngeal tubercle) from which a ridge curves outward and backward on each side. Between the front part of the basi-occipital, the root of the pterygoid process, and the apex of the petrous temporal is an irregular opening (foramen lacerum medium) whose lower part is occupied by fibro-cartilage. Into this the Vidian canal opens anteriorly; and the carotid canal postero-externally, lying in the apex of 


\section{BONES OF THE SKULL.}

the petrous temporal. A fissure (petro-occipital) runs backward from the foramen, between the basi-occipital and petrous temporal; it is closed by cartilage and opens behind into an irregular orifice (jugular foramen) between the petrous temporal and jugular process of the occipital. A projection (processus intra-jugulare) from the jugular process may divide the jugular foramen. The jugular fossa is the excavated part of the foramen which is formed by the petrous bone; in its outer part, or its outer border, is a foramen (for Arnold's nerve); the lower orifice of the carotid canal lies just in front of it, separated by a ridge which presents a foramen (for Jacobson's nerve).

[164]

External to the jugular foramen is the styloid process, enclosed by the vaginal process (see page 8); the foramen (stylomastoid) of the aqueductus Fallopii is just behind the root of the styloid process. At the base of the inner surface of the mastoid process is a deep (Digastric) groove, and just internal to this is a shallow groove for the occipital artery. A stout bar (jugular process) extends outward from the back part of each occipital condyle to the petrous temporal. The condyles are oval, flat transversely but convex antero-posteriorly, and bound the sides of the anterior half of the foramen magnum; they end anteriorly in rounded thickenings. Just external to the front part of each condyle is a fossa (anterior condylic) which is pierced posteriorly by a foramen (anterior condylic); just bchind each condyle is another fossa (posterior condylic) which may be pierced by a foramen (posterior condylic). The foramen magnum is large and oval; its extreme anterior and posterior edges are the basion and opisthion.

[165]

The nuchal surface of the tabular part of the occipital lies behind the foramen magnum; it is limited posteriorly by a ridge (superior curved line) running transversely outward on each side from a central eminence (external occipital protuberance). A mesial ridge (external occipital erest) descends from the protuberance to the foramen magnum; from its centre 
a ridge (inferior curved line) runs transversely outward on each side.

[165]

\section{The Cranium in Transverse Section.}

Deep Surface of $\nabla$ ault. - There is a mesial sagittal groove for the superior longitudinal sinus, with depressions on each side for Pacchionian bodies. The parietal foramina lie on either side of the sagittal suture just in front of the lambda. The meningeal arteries groove the frontal and parietal. [167]

Upper Surface of Base.-This is divided into three fossæ.

Anterior Fossa.-This lies in front of the posterior edges of the lesser wings of the sphenoid. Its fioor is formed mesially, from before backward, by the ethmoid and body of the sphenoid; and laterally by the orbital plates of the frontal and lesser wings of the sphenoid. Anteriorly a ridge (frontal crest) on the frontal, which descends from a groove (frontal sulcus), is separated by an orifice (foramen cæcum) from a mesial longitudinal eminence (crista galli) of the ethmoid. A groove (for the olfactory lobe) lies on either side of the crista galli and presents many foramina (cribriform plate) leading to the nose; on its outer side are two (anterior and posterior ethmoidal) foramina leading to the orbit.

[167]

Middle Fossa.-This extends from the lesser wings of the sphenoid to the superior borders of the petrous bones. Its floor is formed by the body and great wings of the sphenoid, the squamous temporal, and the superior surface of the petrous temporal. From before backward in the midline the body of the sphenoid presents, first a transverse (optic) groove which leads into the orbit on each side through a foramen (optic) between the roots of the lesser wing. Behind this is a transverse elevation (olivary eminence) from the back of whose outer ends little spurs (middle clinoid processes) may project. Behind this it presents a depression (sella turcica, or pituitary fossa) which is overhung behind by a sloping ridge (dorsum 


\section{BONES OF THE SKULL.}

sellæ); the angles of the ridge project anteriorly and externally as tubercles (posterior clinoid processes).

[169]

More laterally the posterior angles of the lesser sphenoidal wings project (anterior clinoid processes) backward. Just behind the optic foramen an S-shaped (carotid) groove descends on the side of the body of the sphenoid to an orifice (carotid canal), in the apex of the petrous temporal, which opens into the foramen lacerum medium, an irregular aperture. Just external to this foramen is an oval one (foramen ovale), and just external to and behind this is a small one (foramen spinosum). There is a large cleft (sphenoidal fissure) anteriorly between the wings of the sphenoid; just below its inner end is an opening (foramen rotundum) into the spheno-maxillary fossa; behind this foramen is a small one (foramen Vesalii).

[169]

The superior, or anterior, surface of the petrous temporal presents near its apex a depression for the Gasserian ganglion. Near its centre is an elevation (arcuate eminence) over the superior semicircular canal. Just in front of this is a slit-like opening (hiatus Fallopii), of the aqueductus Fallopii, which presents two foramina at its bottom; a groove leads from the hiatus to the foramen lacerum medium. Just external to the hiatus is a small foramen, for the lesser superficial petrosal nerve. Behind this, and in front of the eminence, is the thin roof (tegmen tympani) of the tympanum.

[169]

Posterior Fossa.-This is the largest and lies behind the posterior clinoid processes and superior borders of the petrous bones. The foramen magnum pierces the floor in the midline; on either side of this is a foramen (anterior condylic); overhanging and external to this is a rounded bridge of bone (tuberculum jugulare). External to this is an irregular opening (jugular foramen), which may be divided by a projection (processus intra-jugulare). Behind this, and close to the foramen magnum, there may be another foramen (posterior condylic).

[170]

The petrous temporal presents on its posterior surface the 
orifice of a canal (internal auditory meatus), which runs outward and slightly downward and ends blindly; its fundus presents a horizontal ridge (falciform crest), the orifice of the aqueductus Fallopii, and foramina for the auditory nerve (see page 102). External to and above the meatus is a depression (floccular fossa) for a process of dura mater; below and external to this is a foramen (of the aqueductus vestibuli) which may be concealed by a scale of bone. A groove (for the superior petrosal sinus) occupies the superior border of the petrous temporal, while another (for the inferior petrosal sinus) runs along the suture between the basi-occipital and petrous temporal to the jugular foramen.

The squamous part of the occipital presents a mesial elevation (internal occipital protuberance); a ridge (internal occipital crest) descends from this to the foramen magnum and is grooved (for the occipital sinus); another ridge ascends from the protuberance and presents a groove (sagittal sulcus) at one side (for the superior longitudinal sinus). From each side of the protuberance a groove (for the lateral sinus) runs forward and outward to the posterior inferior angle of the parietal, and then downward and inward on the mastoid, the posterior surface of the petrous temporal, and then the occipital, to the jugular foramen: it presents the inner orifice of the mastoid foramen; its upper lip limits the posterior fossa laterally and posteriorly. These sinuses meet (torcular Herophili) at one side of the occipital protuberance.

\section{The Cranium in Sagittal Section.}

Nasal Fossæ.-These are deepest at their centre. The floor of each is formed by the palate process of the superior maxilla and the horizontal process of the palate bone. The roof consists of the nasal, frontal, cribriform plate of the ethmoid, body of the sphenoid, sphenoidal turbinal, sphenoidal process of the palate, and ala of the vomer. The outer wall consists of the nasal, nasal process of the superior maxilla, lachrymal, lateral 


\section{BONES OF THE SKULL.}

mass of the ethmoid, vertical plate of the palate, inferior turbinate, and internal pterygoid plate of the sphenoid. The anterior opening (ariterior naris) of each fossa is half heart-shaped and looks somewhat downward; the posterior opening (posterior naris) is smaller, rhomboidal, and also looks somewhat downward.

[173]

On the outer wall are seen three longitudinal and shell-like laminæ, of which the upper two are processes (superior, and middle turbinated) of the ethmoid while the lower is the inferior turbinated bone; they roof over the channels on the wall, respectively the superior, middle, and inferior meatus. The inferior meatus receives the canal for the nasal duct, anteriorly and high up; in the front of its floor, near the midline, is a foramen (anterior palatine canal). The middle meatus slopes downward and backward; from it a passage (infundibulum) ascends to the frontal sinus and some ethmoidal cells; near its centre is an opening into the antrum of Highmore. The superior meatus receives the openings of the posterior ethmoidal cells; it presents a foramen (spheno-palatine) posteriorly. [168]

The nasal septum is cartilaginous in front and bony behind. The bony part consists chiefly of the vomer below and the vertical plate of the ethmoil above; and partly of the nasal crests of the superior maxillæ and palate bones below, and those of the nasal bones, the nasal process of the frontal, and the ethmoidal crest and rostrum of the sphenoid above. It is usually deflected to one side.

The sphenoidal sinus is in the body of the sphenoid and is divided by a mesial septum; each part opens into a depression (spheno-ethmoidal recess) in the roof of the nasal fossa; it is closed anteriorly by a hollow and three-sided pyramidal bone (sphenoidal turbinal). The ethmoidal sinuses lie between the orbits and the sicles of the upper parts of the nasal fossæ. A sinus in the orbital process of the palate bone opens into either the sphenoidal sinus or some of the posterior ethmoidal sinuses. The maxillary sinus (antrum of Highmore) is pyram- 


\section{DISSECTING MANUAL.}

idal, and occupies the body of the superior maxilla. The frontal sinuses lie, one on either side, between the inner and outer tables of the frontal, over the root of the nose and extending outward.

[174]

\section{CERVICAL VERTEBRA.}

General Characteristics.-There are seven cervical vertebræ. The bodies are widest transversely, and highest behind; transversely the upper surface is concave, and the lower surface convex. The pedicles spring from the sides of the bodies behind; the superior and inferior notches are nearly equal in depth. The laminx are long and wide. The spinal foramen is triangular. The transverse processes each consist of two parts; these enclose the vertebrarterial foramen and end in two tubercles (anterior and posterior), separated above by a groove. The spinous processes are short, bifid, and directed downward. The articular processes lie on the junction of the pedicles and laminx; the superior facets are circular and look upward and backward, the inferior downward and forward.

[76]

Atlas (First Vertebra).- This has neither body nor spinous process, but consists of two lateral masses united by two arches. Each lateral mass is elongated and approximated to its fellow in front; on its upper surface is an oval facet, concave antero-posteriorly and inclined inward; on its under surface there is a circular facet. The anterior arch is compressed laterally; mesially it is thickened and presents a prominence (anterior tubercle) in front, and a circular facet (for the odontoid process) behind. On the inner surface of each lateral mass is a tubercle for the transverse ligament; on the outer side the transverse process arises by two roots, enclosing the foramen, but its end is not bifid. The posterior arch arises from both the lateral mass and the posterior root oi the transverse process; on its upper surface anteriorly is a transverse groove; mesially it is thickened and has a projection (posterior tubercle) behind. 


\section{ARTICULATIONS.}

Axis (Second Vertebra).-This is characterized by a toothlike process (odontoid) ascending from the upper surface of the body; it is constricted below and tapers bluntly above; anteriorly it has an oval facet (for the anterior arch of the atlas), and posteriorly, at its neck, a groove for the transverse ligament. The anterior surface of the body has a raised triangular surface ending above in a ridge. The pedicles are grooved below but concealed above by the articular processes. The laminæ are thick, and end in a bifid spinous process which is grooved below. The inferior articular processes follow the cervical type: the superior are nearly flat and circular, and look upward and slightly outward. The transverse process turns down and is not bifid.

[79]

Vertebra Prominens (Seventh Vertebra).-This is characterized by its prominent spinous process, whose end is not bifid. The transverse processes are longer than the others; the vertebrarterial foramen is small, or absent.

[80]

\section{ARTICULATIONS.}

Temporo-mandibular Joint.- This is an arthrodial diarthrosis between the condylar head of the mandible and the articular part of the glenoid fossa of the temporal. The articular surfaces are dissimilar in size and shape; the condylar part is cylindrical with its long axis running outward and forward; the glenoid part is concavo-convex antero-posteriorly and includes the eminentia articularis. There is a complete capsule (capsular ligament) whose outer wall is thickened (external lateral ligament) and divisible into anterior and posterior portions attached above to the root tubercle and lower border of the zygoma, and below to the outer side and posterior border of the neck of the mandible; the fibres run downward and backward. A horizontal interarticular fibro-cartilage (discus articularis) divides the joint in two compartments; its edges are attached to the capsule; it is widest across, thickest behind, and thinnest (often perforated) mesially. A synovial mem- 


\section{DISSECTING MANUAL.}

brane lines each compartment. An accessory band (internal lateral ligament) lies internal to, but separate from, the eapsule, attached above to the spine of the great wing of the sphenoid, and below to the lower and hinder (lingula) border of the inferior dental foramen of the mandible.

[267]

Non-articular Cranial Ligaments.-There are the following:

Stylo-mandibular.-A specialized portion of deep cervical fascia running from the anterior aspect of the tip of the styloid process to the posterior border of the angle of the mandible, between the Masseter and Internal pterygoid.

[269]

Pterygo-spinous. - A membrane extending from the upper part of the posterior free margin of the external pterygoid plate, backward to the spine of the sphenoid; there is an interval between its upper border and the floor of the skull.

[269]

Stylo-hyoid.-A downward continuation of the styloid process, attached to the lesser cornu of the hyoid.

[269]

Articulations between the Cranium and Spine.-The joints are diarthrodıal, between the biconvex oceipital condyles and the biconcave superior articular facets of the atlas; each has a thin and complete capsular ligament; a synovial membrane lines each capsule. The supplementary ligaments are as follows:

[266]

Anterior Occipito-atloid.-A thin membrane attached below to the anterior arch of the atlas, and above to the anterior half of the margin of the foramen magnum; it is continuous laterally with the capsule, and presents mesially a thickened band running from the anterior tubercle of the atlas to the basiocciput.

[266]

Posterior Occipito-atloid.-A thin membrane attached below to the posterior arch of the atlas, and above to the posterior half of the margin of the foramen magnum; laterally it is continuous with the capsule.

Posterior Occipito-axoid.-A prolongation of the posterior common ligament, running from the posterior surface of the 


\section{ARTICULATIONS.}

body of the axis to the basilar groove of the occipital and, laterally, the margin of the foramen magnum.

[266]

Ligamentum Cruciatum Atlantis (subjacent to the preceding).- This is formed by (crus transversum) the superficial fibres of the transverse ligament of the atlas, and also mesial longitudinal fibres running from them downward (crus inferius) to the posterior surface of the body of the axis, and upward (crus superius) to the posterior surface of the basi-occiput, just under the preceding.

[267]

Check or Lateral Odontoid. - A rounded band on each side, running from the summit of the odontoid process to the tubercle on the inner side of the occipital condyle.

[267]

Middle Odontoid.-A band ascending from the apex of the odontoid process to the centre of the anterior margin of the foramen magnum.

[267]

\section{Intercentral Articulations of the Cervical Vertebræ.-} These are amphiarthrodial and comprise the following structures:

[261]

Intervertebral Discs.-These are closely adherent to the bodies, and each consists of a pulpy centre surrounded by fibres connecting the vertebræ, mostly oblique and parallel. They are thickest in front.

Anterior Common Ligament.-A broad band descending from the front of the axis, attached to the margins of the bodies of the vertebræ and to the intervertebral dises; some fibres connect adjoining vertebræ, others those farther apart. [263]

Posterior Common Ligament.-A broad band in the spinal canal, running downward from the back of the body of the axis and expanding over each intervertebral dise; it is attached to the dises and also to the whole adjacent margins of the vertebræ.

[263]

Interneural Articulations of the Cervical Vertebræ.These are true arthrodial diarthroses, between the facets on the articular processes. Each joint has a thin but complete 


\section{DISSEC'TING MANUAL.}

capsule lined by a synovial mombrane. There are also accessory ligaments, distinct from the capsule, as follows:

[263]

Ligamenta Subflava.-A layer of yellow elastic fibres running from the front of each lamina, just above its lower border, to the back of the lamina next below; it extends laterally to the capsule; mesially, it joins its fellow at the root of the spinous process.

[263]

Interspinous Ligaments.-These are layers of interlacing fibres springing from near the tips of two adjacent spines and radiating to their opposing margins; they extend from base to tip.

[263]

Supraspinous Ligaments.-These are longitudinal bands of fibres of varying lengths, in continuity with the preceding, connecting the tips of the spines; they also project backward from the spines between the muscles as a mesial elastic partition (ligamentum nuch(e) attached above to the occipital crest; the free posterior margin of this partition extends from the spine of the vertebra prominens to the external occipital protuberance.

[264]

Atlo-axoid Articulation.-There are two arthrodial diarthroses between the articular processes; and a rotary diarthrosis between the facet on the front of the odontoid process and that on the back of the anterior arch. Each has a complete capsule with its synovial membrane. Each capsule connecting the articular processes presents a band (accessory ligament) running, within the canal, from the lateral mass of the atlas to the top of the body of the axis. The additional ligaments are as follows:

[265]

Anterior Atlo-axoid.-A thin membrane running from the anterior arch of the atlas to the front of the body of the axis; a prolongation of the anterior common ligament thickens it mesially.

[265]

Posterior Atlo-axoid.-A layer replacing the ligamenta subflava and running from the posterior arch of the atlas to the upper border of the neural arch of the axis.

[265] 


\section{SCALP.}

Transverse Ligament of the Atlas.-A strong band eonnecting the tubereles on the inner surfaces of the lateral masses of the atlas. It develops a fibrocartilaginous plate where it arches behind the odontoid process, and this joint has a separate synovial membrane.

[265]

\section{SCALP.}

Fascia.-The superficial fascia adheres to the skin and aponeurosis. The deep fascia (epicranial aponeurosis) is attached to the superior eurved line of the oceipital (between the Occipito-frontalis bellies), the mastoid process, and the temporal ridge.

$[399,401]$

\section{Muscles.}

Occipito-frontalis.-Posterior Belly. Origin; outer twothirds of superior curved line of occipital. Insertion; epicranial aponeurosis. Anterior Belly (blending with its fellow). Origin; epicranial aponeurosis. Insertion; Orbicularis palpebrarum; Corrugator supercilii.

[401]

Retrahens Aurem.-Origin; mastoid process. Insertion; deep surface of pinna.

[402]

Attollens Aurem.-Origin; temporal fascia. Insertion; top of root of pinna.

[402]

Attrahens Aurem.-Origin; temporal fascia. Insertion; top of root of pinna.

[402]

\section{NERVES.}

Ophthalmic.-The supra-orbital branch, aseending from the supra-orbital notch, supplies the forehead and scalp. The supra-trochlear branch, ascending from the inner canthus, supplies the forehead.

[679]

Superior Maxillary. - The temporal branch ascends from a malar foramen to the temple.

[681]

Inferior Maxillary. - The auriculo-temporal branch ascends 
in front of the ear to supply the temple, scalp, pinna and external auditory meatus.

[683]

Great Occipital.-This ascends past the occipital protuberance to supply the scalp posteriorly.

Small Occipital.-This ascends, midway between the occipital protuberance and the ear, to (auricular branches) the ear and (mastoid and occipital branches) scalp.

[618]

Great Auricular.-The branches ascend to (auricular) the pinna, and (mastoid) the scalp behind it.

[618]

Facial.-The posterior auricular branch divides behind the ear into a branch (auricular) to the Retrahens aurem and intrinsic muscles of the pinna, and another (occipital) to the posterior belly of the Occipito-frontalis. Temporal branches of the pes anserinus (temporo-facial division) ascend in front of the ear to the Attrahens aurem, Attollens aurem, and anterior belly of the Occipito-frontalis.

[687]

\section{Arteries.}

Occipital.-This ascends near the occipital protuberance; its terminal branches (internal and external) ramify on the back of the scalp; a twig (parietal) enters the parietal foramen.

[807]

Posterior Auricular.-This divides behind, the ear into auricular and mastoid branches.

[808]

Superficial Temporal.-This ascends in front of the ear and divides into terminal branches (anterior and posterior) which ramify over the vertex.

[809]

Ophthalmic.-The supra-orbital branch ascends from the supra-orbital notch to the forehead. The frontal branch asscends from the inner canthus to the scalp.

[815]

\section{VIINS.}

The occipital drains the occipito-parietal region and descends with the occipital artery. The posterior auricular drains the posterior temporo-parietal region and descends 


\section{CRANIAL CAVITY.}

behind the ear. The superficial temporal drains the temporoparietal region and descends in front of the ear. The frontal and supra-orbital drain the forehead and unite (angular vein) at the inner canthus.

[879]

\section{CRANIAL CAVITY.}

\section{Meninges.}

The brain is enclosed, from without inward, by the dura, arachnoidea, and pia.

Dura Mater.-This is a dense membrane, smooth internally but rough externally, which is attached loosely to the vault, except along the sutures, but firmly to the floor. In places its layers separate to form venous sinuses. Four septa project from its deep surface, viz.: The falx cerebri, sickle-shaped, separates the cerebral hemispheres. It is narrow in front and attached to the crista galli; broad behind and attached to the tentorium in the midline, enclosing the straight sinus; convex above and attached to the vault, enclosing the superior longitudinal sinus; and concave and free below, enclosing the inferior longitudinal sinus.

[597]

The tentorium cerebelli, crescentic and horizontal, separates the cerebrum and cerebellum. It is convex behind and attached to the occipital, enclosing the lateral sinuses; attached laterally to the parietal and, enclosing the superior petrosal sinus, the superior border of the petrous bone; and free and concave (incisura tentorii) anteriorly. Prolongations of the free and attached margins cross beyond the apex of the petrous bone and are attached respectively to the anterior and posterior clinoid processes. The falx cerebelli, sickle-shaped, separates the cerebellar hemispheres. It is free anteriorly but attached above to the tentorium and below to the occipital, bifurcating to enclose the oceipital sinuses. The diaphragma selle covers the pituitary fossa; the infundibulum pierces its centre. Between the dura and arachnoidea is the subdural space. [599] 


\section{DISSECTING MANUAL.}

Arachnoidea.- This is a delicate membrane which dips into the Sylvian and great longitudinal fissures only. The subarachnoid space, between the arachnoidea and pia, contains cerebro-spinal fluid; it communicates with the lateral ventricles at the end of each descending horn, and with the fourth ventricle at the foramen of Magendie and the tip of each lateral recess: A fine meshwork connects it with the pia and develops interspaces (cisternæ subarachnoidales).

[600]

The Pacchionian bodies are small purplish protrusions from the arachnoidea, and attached by a stalk, which invaginate but do not pierce the dura. They occur chiefly in or beside the superior longitudinal sinus, occasionally in other sinuses.

[602]

Pia Mater.-This is a delicate vascular membrane enveloping the brain closely and lining all sulci except the smaller cerebellar ones. The tela choroidea inferior is the portion covering the ependymal roof of the fourth ventricle; prolongations from it (choroid plexuses) invaginate the ependyma. The velum interpositum or tela choroidea superior is a triangular double layer, or fold, passing through the transverse fissure, between the fornix and the optic thalami and roof of the third ventricle, to (apex) the foramina of Monro; prolongations from it (choroid plexuses) invaginate the roof of the third ventricle and, along its margins, the walls of the lateral ventricles.

[603]

\section{The Brain.}

This consists of the medulla, pons, cerebellum, mid-brain, and cerebrum; it has a convex superior surface and an irregular inferior surface or base.

\section{Medulla.}

This extends from the foramen magnum to the pons, continuing the spinal cord; it is under an inch long and widest above. It consists of a lower closed part and an upper open 


\section{CRANIAL CAVITY.}

part, is divided by median fissures, and each half is subdivided by lateral furrows into three areas. The central canal traverses the closed part and expands above into the fourth ventricle.

[481]

Fissures.-The antero-median ends at the pons in a blind pit (foramen cæcum of Vicq d'Azyr); the crossed pyramidal tracts cross (decussation of pyramids) its lower part. The postero-median extends half-way to the pons and then opens into the ventricle. The antero-lateral extends to the pons, giving origin to the hypoglossal roots. The postero-lateral extends to the pons, giving origin, from below upward, to the eleventh, tenth, and ninth cranjal nerve roots.

[482]

Areas.-The anterior is a prominence (pyramid) between the antero-median and antero-lateral fissures, narrow below, expanded above, and slightly constricted just below the pons. The lateral, between the antero- and postero-lateral furrows, is narrow below but expands above into an oval prominence (olivary eminence) produced by the inferior olivary nucleus. The posterior lies between the postero-lateral furrow and the postero-median fissure and margin of the ventricular floor. Its upper half is the restiform body, a bundle of fibres inclining outward and finally bending backward as the inferior cerebellar peduncle. Its lower half presents three longitudinal prominences, from within outward the funiculus gracilis, funiculus cuneatus, and funiculus of Rolando; these are produced respectively by the gracile and euneate nuclei, and substantia gelatinosa Rolandi, and end above in enlargements, the clava, cuneate tubercle, and tubercle of Rolando. [483]

Superficial Arcuate Fibres.-The anterior emerge from the antero-median, or antero-lateral fissure, or pyramid, cross over or below the olivary eminence, and chiefly enter the restiform body. The posterior pass from the cuneate and gracile nuclei to the restiform body of the same side.

[485]

Internal Structure.-White matter is chiefly superficial. Gray matter is superficial on the ventricular floor; internally 


\section{DISSEC'TING MANUAL.}

it forms nuclei, a network (formatio reticularis), and a layer about the central canal.

[489]

\section{Pons VaroliI.}

This is a convex white prominence above the medulla which, except the restiform portion, it enters and mostly passes through. The ventral surface consists of transverse white fibres which are gathered on each side in a bundle (middle cerebellar peduncle); it is convex and presents a mesial groove between prominences produced by the pyramidal tracts. The fifth nerve emerges laterally, nearer the upper than the lower border, between the pons and middle peduncle. At the lower border the sixth nerve emerges at the outer border of the pyramid, the seventh just in front of the restiform, and the eighth on the ventral aspect of the restiform.

[4S6]

The dorsal surface presents the upper half of the floor of the fourth ventricle, and the superior cerebellar peduncles; the latter converge in ascending, finally overhanging the floor, and pass under the inferior corpora quadrigemina to the mid-brain.

[486]

Internal Structure.-The larger ventral part consists chiefly of superficial transverse white fibres (middle peduncles), of longitudinal deep white bundles (pyramidal tracts) passing to the crura cerebri, and of gray nuclei (pontis) between them. The tegmental (dorsal) part consists chiefly of gray matter (nuclei and formatio reticularis), partly of longitudinal white bundles (superior peduncles and nerve roots).

[499]

\section{Fourth Ventricle.}

This is a rhomboidal cavity bounded by the superior peduncles above, and the clavæ, cuneate tubercles and restiform bodies below; it is continuous with the central canal and Sylvian aqueduct. A narrow prolongation (lateral recess) curves outward, from each lateral angle, around the upper part of the restiform body. 


\section{CRANIAL CAVITY.}

Floor.-This is a lozenge-shaped area, covered by central gray matter and an ependymal layer, the upper half formed by the pons and the lower by the medulla: its lower end tapers (ealamus scriptorius) between the elavæ. A median groove bisects it; each lateral half is divided into upper and lower triangular portions by transverse fibres (striæ acusticæ) running from the mesial groove across the upper part of the restiform body. Lower portion: Each is divided into three areas by grooves prolonging the sides of a triangular depression (inferior fovea) lying, apex upward, just below the striæ. These areas are mesial (trigonum hypoglossi), inferior (trigonum vagi), and external (trigonum acustici); the latter has an eminenee (acustic area) at its base. Upper portion: Alongside the median groove is a ridge (eminentia teres) continuous with the trigonum hypoglossi; outside this, just above the strix, is a slight depression (fovea superior) whence a shallow grayish depression (locus cœruleus) extends toward the aqueduct; outside of and below the fovea is an elevated extension of the area acustica.

[487]

Roof.-The upper part is formed by the superior medullary velum and, slightly, superior peduncles. The lower part is formed above by the inferior medullary velum and below by ependyma supported on pia. A thin white lamina passes a short distance over the ependyma at (obex) the calamus scriptorius, and also (ligula) along each lateral boundary; it runs upward from the elava over the cuneate tuberele and then outward over the restiform body, bounding the lateral recess bclow and sometimes becoming continuous with the infcrior medullary velum. An orifice (foramen of Magendic) pierces the epithelial and pial roofs mesially, just above the calamus scriptorius; another is found at the tip of each lateral recess.

[511]

The choroid plexuses are vascular infoldings of pia which invaginate the epithelial roof, one on each side, along the midline, and project into the cavity; an offshoot is prolonged into 


\section{DISSECTING MANUAL.}

each lateral recess. All choroid plexuses, being covered by ependyma, are really outside the ventricles.

\section{Cerebellum.}

This lies behind the pons and medulla and consists of a median portion (vermis) and two lateral portions (hemispheres). The latter are separated in front and behind by notches (anterior and posterior notches); the posterior notch is the smaller and narrower. Numerous curved and parallel sulci mark the surfaces; the largest sulcus (great longitudinal fissure) begins in front, enclosing the peduncles, runs around the circumference, and divides the cerebellum into upper and lower parts. The superior surface presents a median ridge (superior vermis, or monticulus cerebelli) which is highest in front; from this it slopes to the margins of the hemispheres. The inferior surface presents the convex hemispheres separated by a mesial hollow (vallecula); at the bottom of the hollow is a median ridge (vermis inferior) which is separated from the hemisphere on each side by a furrow (sulcus valleculæ).

[505]

The longer and deeper furrows divide the vermis and hemispheres into lobules. Each lobule of the vermis, except the lingula, is continuous on each side with a corresponding lobule of the hemisphere, and the three lobules together form a lobe. The arrangement of the lobules is as follows, from before backward.

\section{Upper Surface.}

Hemisphere.

Superior Vermis. ..Lingula

Alæ..................................

Anterior crescentic lobule....... Culmen monticuli

Posterior crescentic lobule. . . . . . . . Clivus monticuli

Postero-superior lobule........... Folium cacuminis

Lower Surface.

IIemisphere.

Inferior Vermis.

Flocculus..................... Nodule

Tonsil....................... Uvula

Biventral lobule.................. Pyramid

Postero-inferior lobule........... Tuber valvulæ 


\section{CRANIAL CAVITY.}

Lobes on the Upper Surface.-The lingula consists of a few gray folia prolonged from the superior vermis upon the upper surface of the superior medullary velum and hidden in the anterior notch. The lobus centralis consists of the lobulus centralis (a small mass in the anterior notch) and the alæ (two expansions prolonged round the notch). The lobus culminis consists of the eulmen monticuli (the highest part of the vermis) and the anterior crescentic lobules. The lobus clivi consists of the clivus monticuli and posterior crescentic lobules. The lobus cacuminis consists of the folium cacuminis and posterior superior lobules. The crescentic lobules together form the lobulus quadrangularis.

[506]

Lobes on the Lower Surface.-The lobus noduli consists of the nodule and the flocculi; the latter are two small masses lying on the upper surface of the middle peduncles and conneeted with the nodule by the inferior medullary velum. The lobus uvuloe consists of the uvula (a triangular elevation) and the tonsils; the latter are rounded and lie internal to the biventral lobules, each connected with the uvula, across the sulcus valleculæ, by a gray ridge (furrowed band). The lobus pyramidalis consists of the pyramid and the biventral lobules; the latter lie just behind each floceulus, and are connected with the pyramid, across the sulcus valleculæ, by a faint ridge. The lobus tuberis consists of the tuber valvulx and the posterior inferior lobules; each of the latter is divided by three fissures into four parts, of which the two anterior form the lobulus gracilis, and the two posterior form the lobulus semilunaris inferior.

[507]

Internal Structure.-It consists of gray matter covering a central white mass; the white matter of the vermis is the corpus trapezoides. On antero-posterior section, the branching white stems projecting from the central white mass into the lobes form the arbor vito cerebelli. At the centre of the white core of each hemisphere lies a corrugated gray capsule (corpus dentatum) with an opening (hilum) supero-internally. In 


\section{DISSECTING MANUAL.}

each half of the central white mass are three small gray nuclei, viz.: the embolus (nucleus emboliformis), just internal to the hilum of the corpus dentatum; the nucleus globosus, internal to the embolus; and the nucleus fastigii (roof nucleus), in the corpus trapezoides, close to the midline.

[509]

Peduncles.-All pass through the great horizontal fissure and into the white core. The middle, the largest and most external, come from the pons; the superior emerge at the inner side of the preceding, and cross the pons to the mid-brain; the inferior emerge between the others, bend sharply and descend as the restiform bodies.

[510]

Medullary Vela.-These are two thin laminæ, prolonged from the white core, which pass through the great horizontal fissure in contact, and then diverge. The superior (valve of Vieussens) passes upward under the lingula, stretching between and continuous with the inner dorsal edges of the superior peduncles; the trochlear nerves emerge from its dorsal surface near the quadrigeminal bodies. The inferior, curving forward and downward over the nodule, soon ends in a free and thickened crescentic edge; laterally it stretches to the flocculi.

[511]

\section{Mid-Brain.}

This is short and narrow; it connects the cerebrum with the pons and cerebellum. The corpora quadrigemina are two pairs of rounded eminences, on its dorsum, separated by two grooves, longitudinal and transverse; the inferior pair are the smaller but better defined. A white band (inferior brachium) runs, from each lower body, upward under the internal geniculate body to, chiefly, the optic thalamus; another (superior brachium), from each upper body, runs upward between the thalamus and internal geniculate body to the external geniculate body, and, slightly, lateral root of the optic tract. At the upper end of the longitudinal groove is a depression for the pineal body; a white band (frenulum veli) runs from its lower end to the valve of Vieussens; the transverse groove 


\section{CRANIAL CAVITY.}

continues between the brachia. The corpus geniculatum internum is a small oval eminence on the side of the upper part of the mid-brain, under the optic thalamus.

[531]

Crura Cerebri.-These form the main bulk of the mid-brain and appear on the base as two diverging rope-like strands. A dark gray layer (substantia nigra), convex ventrally, divides each crus into a dorsal tegmental part (tegmentum) passing under the thalamus, and a ventral part (crusta) passing outside of the thalamus to the internal capsule. Two grooves on each crus indicate this division; the outer one (sulcus lateralis mesencephali) is continuous with the groove between the superior and middle peduncle; the inner one (sulcus oculomotorius) gives origin to the oculomotor nerve. A few faint fibres of the lateral fillet emerge from the sulcus lateralis and curve over the superior peduncle to the inferior quadrigeminal body. The aqueduct of Sylvius is a canal running through the tegmentum in the midline, from the fourth to the third ventricle, and lying nearest the dorsal surface; it is triangular on section below, T-shaped above, and surrounded by a thick layer of Sylvian gray matter continuous with that on the ventricular floors.

[532]

Internal Structure.-The crusta are bundles of white fibres. The tegmentum consists chiefly of formatio reticularis, and partly of longitudinal white bundles; it presents an elongated and cylindrical reddish mass (red nucleus) at its upper part, on each side of the midline, ventral to the aqueduct. Quadrigeminal bodies; the inferior are gray matter with white matter externally; the superior each present, from without inward, a white layer (stratum zonale) and three gray layers (stratum cinereum, stratum opticum, and stratum lemnisci). [533-541]

Fore-brain.

Optic Thalami.-These are two large ovoid gray masses which are separated by the third ventricle but lie close together anteriorly. The external (lateral) surface is connected 


\section{DISSECTING MANUAL.}

with the internal capsule by a reticulated layer (external medullary lamina); the inferior (ventral) surface joins the subthalamic tegmental region, corpus mammillare, and, anteriorly, tuber cinereum.

The superior (dorsal) surface is convex, free, and covered by a thin white layer (stratum zonale). It is bounded externally by a groove occupied by the tænia semicircularis; and internally by the trigonum habenulæ behind, and a sharp edge (tænia thalami) of ependyma and the stria medullaris in front; the two latter structures join the pineal stalk. A faint groove running from the inner border, behind the anterior extremity, to the outer part of the posterior extremity, divides this surface into two areas; the inner lies under the velum interpositum and includes the prominent posterior extremity (pulvinar); the outer is covered by ependyma, forms part of the floor of the lateral ventricle, and includes the prominent anterior extremity (anterior tubercle) which helps form the foramen of Monro.

The internal (mesial) surface is free, covered by ependyma and central gray matter, and helps form the wall of the third ventricle; a gray band joins it anteriorly (middle commissure) to the opposite thalamus. The corpus geniculatum externum is an oval prominence, below and external to the pulvinar, which is closely connected with the optic tract and formed of alternate gray and white laminæ. Internal structure: A vertical white layer divides the thalamus into three nuclei; the lateral one lies external to the lamina and includes the pulvinar; the mesial one lies internal to the lamina; and the anterior one forms the anterior tubercle and extends a short distance between the others.

[544]

Subthalamic Tegmental Region.-The structures under the thalamus consist chiefly of prolongations from the mid-brain, tegmentum, red nucleus, superior peduncles, and substantia nigra; they end below the corpus mammillare. Also a small gray mass (corpus subthalamicum, or nucleus of Luys) lying on 


\section{CRANIAL CAVITY.}

the dorsum of the crusta replaces the substantia nigra anteriorly.

[546]

Pineal Body.-This is a conical, reddish body lying in a depression between the superior quadrigeminal bodies. At its base is a hollow stalk divided, by a recess of the third ventricle, into a ventral part folded round the posterior commissure, and a dorsal part curving outward on each side to join the tænia thalami and stria medullaris. Trigonum habenulæ: This is a small triangular depression between the pineal stalk, superior quadrigeminal body, and optic thalamus. Stria medullaris: This is a white band on the thalamus, under the tænia thalami; posteriorly it partly ends in the ganglion habenulæ, and partly crosses in the dorsum of the pineal stalk (commissura habenularum) to the opposite ganglion habenulæ; anteriorly it divides, near the anterior pillar of the fornix, into a dorsal part running upward to the fornix, and a ventral part running downward to nerve cells. Commissura posterior: This is a slender white band which crosses the midline, between the pineal stalk and orifice of the Sylvian aqueduct.

[547]

Interpeduncular Space.-This is a deep lozenge-shaped interval between the crura cerebri, optic tracts, and optic chiasm. The locus perforatus posticus, a layer of central gray matter with many foramina, forms the floor of the posterior angle; delicate white bands (tænia pontis) pass from it, around the crura cerebri, to the pons. The corpora mammillaria are two small and round white bodies lying side by side just in front of the preceding; they consist of gray matter, covered by white matter from the fornix. The tuber cinereum is an elevated area of central gray matter which stretches from the corpora mammillaria to the optic chiasm. From its fore part the stalk (infundibulum) of the pituitary body projects downward, being hollowed above by a recess of the third ventricle. The pituitary body is small, oval, and formed by two lobes; the posterior, which receives the infundibulum, is chiefly con- 


\section{DISSECTING MANUAL.}

nective tissue; the anterior is larger and resembles the thyroid body.

$[475,548]$

Lamina Cinerea.-This is a thin layer running from the optic chiasm to the rostrum of the corpus callosum. Anterior commissure: This is a round white bundle which connects the olfactory and the temporal lobes; it crosses the midline just in front of the anterior pillars of the fornix, where it is connected anteriorly with the laminæ cinerea; it projects into the third ventricle, covered by ependyma.

$[549,588]$

Third Ventricle.-This is a vertical cleft between the thalami, extending from the pineal body to the lamina cinerea, and deepest anteriorly. The floor consists, from before backward, of the tuber cinereum, corpora mammillaria, locus perforatus posticus, and, slightly, tegmenta of crura cerebri; the Sylvian aqueduct opens on it below the posterior commissure. The front wall is the lamina cinerea, extending from the optic chiasm to the anterior commissure. The roof is the ependyma stretching between the tæniæ thalami; a choroid plexus, from the velum interpositum, invaginates it along each side of the midline, and projects downward.

[550]

The lateral wall is chiefly the mesial surface of the thalamus; it presents anteriorly a bulging ridge, running downward and backward, produced by the anterior pillar of the fornix. The foramen of Monro leads into the lateral ventricle at the upper and fore part; it is bounded posteriorly by the thalamus (anterior tubercle) and anteriorly by the anterior pillar of the fornix; a groove (sulcus of Monro), a fotal relic, leads from the foramen of Monro to the Sylvian aqueduct.

[550]

The middle commissure crosses the ventricle just in front of its middle. A funnel-shaped diverticulum leads through the tuber cinereum into the infundibulum; another (recessus opticus) runs above the optic chiasm; another (recessus pinealis) runs above the posterior commissure, into the pineal stalk; another (recessus suprapinealis) runs into the ependyma above the preceding.

[550] 


\section{CRANIAL CAVITY.}

\section{Cerebral Hemispheres.}

The great longitudinal fissure separates them completely in front and behind but is interrupted mesially below by the corpus callosum. Each hemisphere has an external, an internal (mesial), and an inferior surface; the Sylvian fissure divides the latter into an anterior (orbital) and a posterior (tentorial) area. Each hemisphere has four borders; supero-mesial, between the external and internal surfaces; supereiliary, between the external and orbital surfaces; infero-lateral, between the external and tentorial surfaces; and internal occipital, between the internal and tentorial surfaces. Each has an anterior (frontal pole) and posterior (occipital pole) extremity, and a forward projection (temporal pole), on the under surface, under the Sylvian fissure. Each consists of gray matter (cortex) covering a white medullary centre in whose basal part are large gray nuclei (corpus striatum).

[553]

On the surfaces are convolutions (gyri) separated by fissures (sulci); incomplete fissures are merely superficial; complete fissures involve the whole wall and produce elevations on the ventricular wall. Certain arbitrarily chosen interlobar fissures (fissure of Sylvius, fissure of Rolando, parieto-oceipital, calloso-marginal, collateral, and limiting sulcus of Reil) divide the surface into lobes, the frontal, parietal, occipital, temporal, and insula (Island of Reil).

Fissure of Sylvius.- The stem begins at the locus perforatus anticus, in a depression (vallecula Sylvii) on the inferior surface, runs outward to (Sylvian point) the outer surface and divides at once into three limbs. The posterior horizontal limb runs backward and slightly upward for two or three inches and then (ascending terminal piece) turns upward; the anterior horizontal limb runs horizontally forward for threefourths of an inch; the ascending limb runs upward and slightly forward for an inch.

[555]

Limiting Sulcus of Reil.-This surrounds the island of 
Reil; it is triangular, apex downward, and consists of three parts, upper, lower, and anterior. The opercula insula are brain folds overlapping the insula; from behind forward they consist of the temporal, fronto-parietal, frontal, and orbital opercula; their margins are the limbs of the Sylvian fissure.

Fissure of Rolando.-This begins in the supero-mesial border just behind its midpoint, winds downward and forward on the outer surface, and ends above the centre of the posterior Sylvian limb. It bends (superior genu), with the concavity forward, between its upper and middle thirds, and again (inferior genu), with the concavity backward, lower down and in front. The upper end runs a short way backward on the mesial surface.

Parieto-occipital Fissure.-The internal portion begins in the supero-mesial border an inch and a half to two inches in front of the occipital pole, descends almost vertically on the mesial surface, and joins the calcarine fissure just in front of its centre. The external portion runs for about half an inch outward on the external surface.

Collateral Fissure.-Beginning near the occipital pole this runs forward on the tentorial surface toward the temporal pole; a shallow sulcus (incisura temporalis), which is rarely continuous with it, prolongs its course round the end of the temporal lobe.

[559]

Calloso-marginal Fissure.-Beginning near the locus perforatus anticus, below the genu of the corpus callosum, this curves around in front of the genu on the mesial surface, then runs backward to just behind the middle of this surface, and then upward into the supero-mesial border just behind the upper end of the fissure of Rolando.

[560]

Frontal Lobe.-This is bounded on the outer surface by the fissure of Rolando behind and the posterior Sylvian limb below, on the mesial surface by the calloso-marginal fissure, and on the inferior surface by the Sylvian stem. External sur- 


\section{CRANIAL CAVITY.}

face: In front of the fissure of Rolando is the anterior central convolution, which is vertical and placed behind the precentral sulci; of the latter the superior is short and vertical, while the inferior has a vertical and a horizontal part. Anteriorly two horizontal sulci, the superior and inferior frontal, mark off three gyri, the superior, middle, and inferior frontal; the sulcus paramedialis and sulcus frontalis medius divide the superior and middle gyri respectively into upper and lower parts; the anterior Sylvian limbs divide the inferior gyrus, from behind forward, into the pars basilaris, pars triangularis and pars orbitalis.

[560]

Mesial surface: This comprises the gyrus marginalis, which lies between the supero-mesial border and calloso-marginal fissure; one or two curved sulci usually appear anteriorly; the posterior part (paracentral lobule) is partly cut off and presents the end of the fissure of Rolando. Orbital surface: The gyrus rectus lies between the mesial border and olfactory sulcus (for the olfactory tract and bulb). Externally three orbital gyri (internal, anterior, and posterior) are marked off by the orbital sulcus; this is $\mathrm{H}$-shaped and formed by three limbs, internal, transverse, and external.

[561]

Parietal Lobe.-This is bounded on the outer surface: in front by the fissure of Rolando; below by the posterior Sylvian limb and an imaginary prolongation of it backward; and behind by the external parieto-occipital fissure and an imaginary prolongation of it downward to an identation (præoccipital notch) on the infero-lateral border. The mesial surface is the quadrate lobule (præcuneus); this lies between the parieto-occipital fissure and upturned end of the calloso-marginal fissure, and is bounded below by a variable postlimbic sulcus.

[562]

External Surface.-This presents a T-shaped sulcus (intraparietal) formed by four, usually connected, sulci as follows: vertically in front are the superior and inferior postcentral sulci; and running backward from between these is the ramus hori- 


\section{DISSECTING MANUAL.}

zontalis, prolonged by the ramus occipitalis. The intraparietal sulcus divides the surface into a superior and an inferior parietal gyrus lying above and below it; and a posterior central convolution lying in front of it, behind the fissure of Rolando. The posterior Sylvian limb and the superior and inferior temporal sulci divide the inferior parietal gyrus respectively into the supra-marginal, angular, and postparietal gyri.

[563]

Occipital Lobe.-This is the pyramidal hinder part of the hemisphere. The mesial surface is marked off by the internal parieto-occipital fissure; this joins a fissure (calcarine) running forward from the occipital pole to end just below the splenium; the surface above the calcarine fissure is a triangular gyrus (cuneus); that below it is the gyrus lingualis. The inferior surface, which is marked off by an arbitrary line from the prroccipital notch to the isthmus of the limbic lobe, is the posterior part of the occipito-temporal gyrus. The external surface is marked off by the external parieto-occipital fissure and its imaginary prolongation to the præoccipital notch; superiorly it presents the sulcus occipitalis transversus, a bifurcation of the ramus occipitalis; lower down a horizontal sulcus (occipitalis lateralis) is seen.

[564]

Temporal Lobe.-The external surface is bounded above by the posterior Sylvian limb and its imaginary prolongation, and behind by the imaginary prolongation of the external parieto-occipital fissure; two horizontal sulci, the first and second temporal, divide it into the superior, middle, and inferior temporal gyri. The inferior surface is bounded in front by the Sylvian stem, internally by the collateral fissure, and posteriorly by the arbitrary line from the præoccipital notch to the isthmus of the limbic lobe. It consists of the front part of the occipito-temporal gyrus and part of the inferior (third) temporal gyrus; these are separated by the occipito-temporal sulcus. It has also an upper opercular surface hidden in the Sylvian fissure.

[567] 


\section{CRANIAL CAVITY.}

Island of Reil or Insula.-This is a triangular area, apex downward, lying at the bottom of the Sylvian fissure; at the apex (limen insulæ), where the limiting sulcus of Reil is absent, its gray matter is continuous with the locus perforatus anticus. Radiating sulci divide it into diverging gyri; the suleus centralis insulæ, in the same plane and direction as the fissure of Rolando, divides it into a frontal and a parieto-limbic portion.

[567]

Limbic Lobe.-This curves, on the mesial surface, around the corpus callosum; the olfactory tract roots connect its ends at the locus perforatus anticus; its upper part is the callosal gyrus, and its lower the hippocampal gyrus. The callosal convolution runs from the locus perforatus anticus, upward around the genu, backward on the upper surface, and downward around the splenium of the corpus callosum; a portion (isthmus) which is narrowed by the calcarine fissure joins it to the hippocampal gyrus. The calloso-marginal sulcus separates it from the marginal gyrus, the postlimbic from the præcuneus, and the callosal from the corpus callosum. The hippocampal convolution runs forward to the crus cerebri, then folds back on itself and ends in a recurved hook-like tip (uncus). It is bounded externally by the collateral fissure and incisura temporalis, and internally by the dentate fissure; posteriorly the calcarine fissure separates the isthmus from a portion joining the gyrus lingualis. A white layer (substantia reticularis alba) covers it.

[568]

The dentate fissure, continuous with the collateral, begins behind the splenium, separates the hippocampal gyrus from the gyrus dentatus, and ends in the uneus. It produces the hippocampus major; hidden in it are the following structures. The gyrus dentatus is a free notched edge of gray matter extending from near the splenium into the cleft of the uncus, whence it emerges as a delicate band (frenulum Giacomini) crossing the uneus; the fimbrio-dentate sulcus separates this gyrus from the fimbria, lying deeper.

[569] 
Olfactory Lobe.-This comprises a posterior lobule (locus perforatus anticus), a small triangular gray area in front of the optic tract; and an anterior lobule composed of the trigonum olfactorium, area of Broca, and olfactory bulb, tract, and roots. The olfactory tract is a narrow white band which expands anteriorly (olfactory bulb) and lies in the olfactory sulcus; posteriorly it divides in two diverging roots which enclose a small triangular gray area (trigonum olfactorium). The mesial root curves inward behind a small area (area of Broca) to the callosal gyrus; the lateral root runs backward and outward over the locus perforatus anticus and disappears; a few fibres (the occasional middle root) may arise from the tract posteriorly and enter the trigonum.

[569]

Corpus Callosum.-This is an arched commissure, convex above and concave below, which unites the inner surfaces of the hemispheres for nearly half their length and lies nearest their anterior extremities. In the hemispheres its fibres diverge widely (radiatio corporis callosi), those from the body and upper part of the splenium forming a definite layer(tapetum), and those from the rest of the splenium running backward in a bundle (forceps major). Its thick posterior end (splenium) is tightly folded on itself below. Its thinner anterior end (genu) also bends on itself ; the lower part (rostrum) is separated from the upper by an interval, thins out rapidly and joins the lamina cincrea. The body is still thinner.

[570]

The upper surface is covered by a thin cortical gray layer; it presents a mesial furrow between two delicate bands (stria longitudinalis medialis), and a similar band (stria longitudinalis lateralis) on each side. Posteriorly the striæ and gray matter join the gyrus dentatus; anteriorly the mesial striæ diverge, as gyri geniculi, and are connected, through the cortex, with the locus perforatus anticus. The under surface is attached mesially to the fornix and septum lucidum; elsewhere it is mostly free, covered by ependyma, and roofs over the lateral ventricles. 


\section{CRANIAL CAVITY.}

Fornix.-This consists of two arched lateral halves which are joined (body). mesially but separated (pillars) elsewhere. The body is triangular, apex forward, with sharp lateral margins and lies on the velum interpositum. Its upper surface is adherent posteriorly to the corpus callosum (body); and in front of this to the septum lucidum mesially while laterally, covered by ependyma, it helps floor the lateral ventricle. The anterior pillars are two rounded and slightly divergent strands which curve, from the front of the body, downward in front of the foramina of Monro to end in the corpora mammillaria. The posterior pillars are two flattened bands which diverge from the posterior angles of the body; they adhere at first to the corpus callosum and then curve behind the thalami into the descending horns of the ventricles; here each furnishes a white covering (alveus) for the hippocampus major, and also passes, as the fimbria, to the tip of the uncus, being attached by its outer border along the inner border of the hippocampus major. Transverse fibres run between the posterior pillars, on the corpus callosum, forming the lyra.

Septum Lucidum.-This is a vertical triangular partition between the lateral ventricles, in the gap between the fornix and corpus callosum. It is composed of two thin laminæ separated by an isolated cleft (Fifth ventricle).

[573]

Lateral Ventricle.-This cavity in each hemisphere has a body and three horns; it communicates with the third ventricle at the foramen of Monro. The body extends from this foramen to the splenium, being closed externally by the junction of roof and floor; its roof is the corpus callosum and its inner wall the septum lucidum and attachment of the fornix to the corpus callosum. The floor, from within outward, presents the caudate nucleus, groove with the tænia semicircularis, optic thalamus, choroid plexus, and margin of the fornix. The anterior horn is triangular on section and runs forward and outward, being bounded in front by the callosal genu; its inner wall is the septum lucidum and its roof the corpus 


\section{DISSECTING MANUAL.}

callosum; the caudate nucleus projects onto its floor. The posterior horn curves backward and inward, tapering; the callosal tapetum forms its roof and outer wall. On its inner wall are two curved elevations, the upper (bulb of the cornu) being formed by the forceps major, and the lower (calcar avis) by the calcarine fissure. The ventricle is triangular (trigonum ventriculi) in the angle between the diverging posterior and descending horns.

[573]

The descending horn runs backward and outward, then downward around the thalamus, and then forward almost to the temporal pole. Its roof, formed chiefly by the tapetum, presents prolongations of the tænia semicircularis and tail of the caudate nucleus, and also at its tip a bulging (amygdaloid tubercle) produced by the amygdaloid nucleus. The floor presents internally a curved elevation (hippocampus major), produced by the dentate fissure, which is narrowed behind, thickened at its anterior end, and partly covered by the choroid plexus; the fimbria is attached to its inner border. A smooth elevation (eminentia collateralis), produced by the collateral fissure, lies in the trigonum ventriculi, and occasionally another (eminentia collateralis anterior), produced by the anterior part of the collateral fissure, is seen external to the hippocampus major.

[576]

An arched cleft (choroid fissure), which is normally closed by a layer of ependyma attached to its margins, opens into the whole body and descending horn between the fornix and thalamus, and between the fimbria and roof. Through it the choroid plexus, which is derived from the edge of the velum interpositum, projects into the ventricle, invaginating the ependyma.

[578]

Caudate Nucleus.- This is an arched gray mass with a large head which projects into the anterior horn of the lateral ventricle, a narrower part which is seen on the floor of the body, and a long thin tail which curves onto the roof of the descending horn to join the amygdaloid nucleus. Lenticular Nucleus. 


\section{CRANIAL CAVITY.}

- This is a gray mass lying external to the caudate nucleus but directly continuous with it below. Two vertical white laminæ (external and internal medullary) divide it into three zones, of which the outer is the putamen, while the two inner form the globus pallidus. The caudate and lenticular nuclei form the corpus striatum.

[579]

Claustrum.-This is a thin gray lamina in the white matter, between the lenticular nucleus and cortex of the island of Reil. The tænia semicircularis is a band arising mostly from the amygdaloid nucleus. Running backward on the roof of the descending horn it then curves forward on the floor of the body of the lateral ventricle, just internal to the caudate nucleus; then running through the foramen of Monro it descends both in front of and behind the anterior commissure to the locus perforatus anticus.

[582]

The external capsule is a thin white lamina between the putamen and claustrum; it joins the internal capsule in front. The internal capsule is a broad white band directly continuous with the crusta of the crus cerebri below, but radiating (corona radiata) to the cortex above. It separates the lenticular nucleus from the thalamus, tænia semicircularis, and caudate nucleus, and is bent on itself opposite the tænia semicircularis, with the angle (genu) directed inward. The portion (about one-third) in front of the genu is the anterior limb; the remainder is the posterior limb.

[583]

\section{NeRves.}

Exit of Cranial Nerves.-The olfactory arise from the bulb and descend through the cribriform plate. The optic tracts unite, over the optic groove, in the optic chiasm, from which the optic nerve runs on each side through the dura and the optic foramen. The oculo-motor pierces the dura between the free and attached borders of the tentorium, runs uppermost in the outer wall of the cavernous sinus, and divides in the sphenoidal fissure into upper and lower branches. The trochlear 


\section{DISSECTING MANUAL.}

pierces the free border of the tentorium external to the oculomotor and runs below it in the outer wall of the cavernous sinus, and then runs through the sphenoidal fissure above the ocular muscles.

[675-677]

The trigeminal roots both pierce the dura beneath the petrous attachment of the tentorium. The large (sensory) root develops a large ganglion (Gasserian) in a depression at the apex of the petrous bone. Three branches arise from the front of the ganglion, viz.: the ophthalmic, which runs in the outer wall of the cavernous sinus below the trochlear and divides in the sphenoidal îssure into three branches, lachrymal, frontal, and nasal; the superior maxillary, which runs below the cavernous sinus and through the foramen rotundum; and the inferior maxillary, which runs through the foramen ovale. The small (motor) root runs under the ganglion and through the foramen ovale.

[678]

The abducent pierces the dura beside the dorsum sellæ, runs on the inner wall of the cavernous sinus, external to the carotid artery, and then continues lowermost through the sphenoidal fissure. The facial, with the pars intermedia below it, runs through the internal auditory meatus and into the aqueduct of Fallopius. The auditory runs through the internal auditory meatus below the facial and pars intermedia and divides into two trunks. Its upper (vestibular) trunk is continuous with the mesial root, gets fibres from the pars intermedia, sends a branch to the geniculate ganglion, and splits into three branches which run through the lamina cribrosa to the utricle and the superior and external semicircular canals. Its inferior (cochlear) trunk is continuous with the lateral root, sends branches to the saccule and posterior semicircular canals, and runs (cochlear nerve) through the lamina cribrosa to the modiolus and spiral lamina of the cochlea.

[686-688]

The glosso-pharyngeal runs through the jugular foramen in the anterior dural eompartment. The pneumogastric and spinal accessory run through the jugular foramen in the dural 


\section{CRANIAL CAVITY.}

compartment behind the preceding; the spinal portion of the spinal accessory enters the cranium through the foramen magnum. The hypoglossal root bundles both pierce the dura separately and unite in the anterior condyloid foramen or after leaving the skull.

[689-696]

In the cavernous sinus the ophthalmic communicates with the oculo-motor, trochlear, and abducent; all of them communicate with the sympathetic cavernous plexus.

Meningeal Nerves.-Superior maxillary: a recurrent branch arises in the cranium. Inferior maxillary: recurrent branch enters through the foramen spinosum. Ophthalmic: a recurrent branch arises in the cavernous sinus. Vagus: a meningeal branch arises from the root ganglion. Hypoglossal: a recurrent branch. Cervical plexus: a meningeal branch ascends on the hypoglossal.

\section{Arteries.}

Internal Maxillary. - The middle meningeal entêrs by the foramen spinosum, ascends in a groove on the great wing of the sphenoid, and divides. Branches: petrosal, entering the hiatus Fallopii; gasserian, to that ganglion; tympanic, entering the petro-squamous suture or Tensor tympani canal; orbital, entering the sphenoidal fissure; anterior terminal, ascending past the antero-inferior angle of the parietal; posterior terminal, running backward over the squamous part of the temporal. The small meningeal enters by the foramen ovale. [810]

Internal Carotid.-This traverses the carotid canal to the apex of the petrous bone, crosses the foramen lacerum medium, runs in the outer wall of the cavernous sinus to the lower root of the small wing of the sphenoid, ascends to the brain, and divides into the anterior and middle cerebral. Branches in canal: tympanic, piercing the posterior wall; Vidian, entering the Vidian canal. Branches in cranium: cavernous, to that sinus; gasserian, to the ganglion; pituitary, to the pituitary body; meningeal; ophthalmic, running under the optic nerve 


\section{DISSECTING MANUAL.}

and through the optic foramen; posterior communicating, to the posterior cerebral artery; anterior choroidal, entering the choroidal fissure below.

[813-817]

Anterior Cerebral.-This curves round the genu of the corpus callosum into the great longitudinal fissure. Branches: anterior communicating, to the opposite anterior cerebral; anteromesial, entering the base of the brain; internal orbital, to the inner orbital surface; anterior, middle, and posterior internal frontal, to the mesial surface. Middle cerebral: This occupies the fissure of Sylvius. Branches: internal and external striate, entering the base of the brain; inferior external orbital, to the outer orbital surface; ascending frontal and ascending parietal, ascending on either side of the fissure of Rolando; temporal, running over the upper temporal gyri; parieto-temporal, running backward.

[817]

Vertebral.-This enters at the foramen magnum, ascends inward on the medulla and joins the opposite vertebral at the lower border of the pons, forming the basilar. Branches: meningeal, to the dura; posterior spinal, descending beside the medulla and cord; anterior spinal, joining its fellow and then descending in the antero-median fissure; posterior inferior cerebellar, curving round the medulla to enter the vallecula cerebelli.

[818]

Basilar.-This occupies the mesial groove of the pons and divides at its upper border into the posterior cerebrals. Branches: transverse, crossing the pons; auditory, accompanying the auditory nerves; anterior inferior cerebellar, to the lower surfaces of the hemispheres; superior cerebellar, to the upper surfaces. Each posterior cerebral runs backward on the tentorial surface, being joined by the posterior communicating branch of the internal carotid. Branches: posteromesial and postero-lateral, entering the base on the inner and outer sides of the crus; posterior choroidal, to the choroidal fissure above; anterior and posterior temporal, to the occipitotemporal region in front and behind; calcarine, running in the 


\section{CRANIAL CAVITY.}

calcarine fissure; parieto-occipital, running in the parietooccipital fissure.

[820]

Circle of Willis.-This is an irregularly polygonal arterial anastomosis at the base of the brain formed by the anterior communicating, anterior cerebral, posterior communicating, and posterior cerebral arteries.

[821]

\section{Veins.}

Unpaired Sinuses.-The superior longitudinal begins at the crista galli, runs in the attached margin of the falx cerebri and, diverging slightly to the right (or left), becomes the right (or left) lateral sinus at the level of the internal occipital protuberance; a dilatation (torcula Herophili) at its end is connected with a similar dilatation of the straight and opposite lateral sinuses. The inferior longitudinal occupies the posterior two-thirds of the free margin of the falx cerebri and joins the vena magna Galeni behind, forming the straight sinus. The straight sinus occupies the attachment of the falx cerebri to the tentorium and joins the left (or right) lateral sinus. The circular sinus surrounds the pituitary body and is usually formed by two channels connecting the cavernous sinuses. The $b a$ silar is a plexus, on the basilar part of the occipital, connecting the cavernous, or inferior petrosal sinuses.

[883]

Paired Sinuses. - Lateral: Each runs in a groove, outward in the outer border of the tentorium to the posterior inferior angle of the parietal, then downward on the mastoid, and forward across the jugular process to join the internal jugular in the jugular foramen. Occipital: Each runs in the lower attached border of the falx cerebelli, to the lateral sinus of the same side, or (uniting) either lateral sinus. Cavernous: Each begins at the sphenoidal fissure, runs alongside the body of the sphenoid, and divides, at the apex of the petrous bone, into the superior and inferior petrosal. Superior petrosal: Each runs from the cavernous to the lateral sinus in the attached margin of the tentorium, along a groove on the petrous bone. 


\section{DISSECTING MANUAL.}

Inferior petrosal: Each runs from the eavernous sinus along the lower border of the petrous bone and margin of the basilar part of the occipital, to join the internal jugular in the jugular foramen. Spheno-parietal: Each lies on the under surface of the small wing of the sphenoid and ends in the cavernous sinus. [886]

Cranial Veins.-The diploic veins drain the diploe and usually join a sinus. The vence comites accompany their arteries and usually join a sinus. The vence Galeni are two lateral veins which run between the layers of the velum interpositum from apex to base and join (vena magna) to end in the straight sinus. Emissary veins communicate with the exterior of the cranium, viz.: from the superior longitudinal sinus through the foramen excum and parietal foramina; from the lateral sinus through the mastoid and posterior condylar foramina; and from the cavernous sinus through the carotid canal and foramen ovale (or Vesalii), and through the ophthalmic vein to the angular vein.

[880]

\section{The Spinal Cord.}

Spinal Cord.-This is eylindrical, slightly flattened in front and behind, and lies in the spinal canal. Beginning at the foramen magnum, where it is continuous with the medulla, it extends to the body of the first (lower border) or second (upper border) lumbar vertebra; there it forms a tapered end (conus medullaris) which is prolonged by a narrow thread (filum terminale) attached to the back of the coccyx. Its girth is uniform in most of the dorsal region, but is gradually increased between (cervical enlargement) the upper end of the cord and the second dorsal vertebra, being most marked at the fifth or sixth cervical vertebra; it also increases (lumbar enlargement) below the tenth dorsal vertebra, being most marked at the twelfth and then tapering rapidly. Three membranes surround it. The pia mater, the most internal, is fibrous, invests it closely and sends septa into it. The arachnoid, next externally, is delicate and scparated from the pia by the subarach- 


\section{CRANIAL CAVITY.}

noid space, which contains cerebrospinal fluid. The dura mater, the most external, is dense and fibrous, and extends considerably below the conus medullaris. The ligamenta denticulata are two lateral, wing-like structures which support the cord and extend from its sides to the inner surface of the dura where they are attached by a series of pointed processes.

[452]

Fissures and Columns of the Cord.-The antero-median fissure runs the whole length in the midline anteriorly and penetrates slightly less than one-third of the diameter; the pia dips into it. The postero-median fissure runs the whole length in the midline posteriorly and penetrates half-way; it is very narrow and receives no pia. These two fissures divide the cord in halves; in the lumbar region they become of nearly equal depth. Near the postero-median fissure, on each side, is a shallow groove (postero-lateral sulcus) running the whole length; the posterior nerve roots emerge at its bottom. It divides each lateral half into a small posterior column and a large antero-lateral column; the latter is arbitrarily divided, by the line of anterior nerve roots, into a lateral column and an anterior column. In the cervical region a distinct posterior paramedian groove, nearer the postero-median than the posterolateral furrow, divides the posterior column into a column of Burdach (funiculus cuneatus) externally, and a column of Goll (funiculus gracilis) internally; this groove is gradually lost in the dorsal region.

[454]

Thirty-one pairs of spinal nerves arise from the spinal cord; they are named according to their place of exit from the spinal canal. In passing down in the canal, below the conus medullaris, to reach their places of exit they form a large bundle (cauda equina) which encloses the filum terminale.

[453]

Internal Structure of Cord.-The white matter is external and the gray matter internal. On transverse section the gray matter forms a crescentic mass, with the concavity outward, in each lateral half; a transverse band (posterior gray commissure) connects the crescents and forms the bottom of the 


\section{DISSEC'TING MANUAL.}

postero-median fissure. The white matter of the halves is connected by a transverse band (anterior white commissure) forming the bottom of the antero-median fissure.

[456]

The anterior end of each gray crescent is the anterior cornu; this is constricted (cervix) near the commissure but is thickened (caput) at its end, which does not reach the surface; the anterior nerve roots arise from it. The posterior end of each is the posterior cornu; this is narrower, constricted (cervix) near the commissure, enlarged (caput) outwardly, and ends in a point (apex) which almost touches the bottom of the posterolateral furrow; its apex is somewhat translucent and consists of substantia gelatinosa Rolandi: the posterior nerve roots arise from it. The lateral horn is a projection outward from the concavity of each crescent, opposite the gray commissure, and most marked in the upper dorsal region; it blends above and below with the anterior horn. In the cervical region the anterior horns are very large, while the posterior are narrow. In the dorsal region both horns are narrow, but especially the posterior. In the lumbar region the difference is less marked as the posterior horns widen out.

[456]

The white matter of each lateral half is in three columns; the posterior lies behind the posterior horn, the lateral column occupies the concavity of the crescent, and the anterior lies in front of the anterior horn. The central canal runs throughout the cord, in the gray commissure, and ends, in the conus medullaris, in an expansion (ventriculus terminalis). The filum terminale is in two parts; the filum terminale externum is the part which has pierced the dura, and is a mere fibrous thread; the filum terminale internum is the part within the dura, consists largely of pia, and, in its upper half, contains the end of the central canal, surrounded by gray matter.

[459]

\section{The Orbit.}

The eyeball with its muscles, vessels, and nerves lies in a mass of fat. A smooth membrane (capsule of Tenon) sur- 


\section{CRANIAL CAVITY.}

rounding its posterior two-thirds is pierced by the optic nerve and muscle tendons.

$[405]$

\section{Muscles.}

Levator Palpebræ Superioris (the uppermost).-Origin; margin of the foramen. Insertion; (mainly) upper border of tarsal cartilage; (slightly) Orbicularis palpebrarum, skin of upper lid, conjunctiva, upper border of orbital margin.

[405]

Recti.-All arise from a membranous ring which surrounds the optic foramen and is separable into superior and inferior common tendons; all are inserted in the sclerotic just behind the corneal margin. Superior rectus: Origin; the superior tendon: Insertion; eyeball in its vertical plane just internal to its axis. Inferior rectus : Origin; the inferior tendon: Insertion, eyeball in its vertical plane. Internal rectus : Origin; the inferior tendon: Insertion; eyeball in its transverse plane. External rectus: Origin; (upper head) the superior tendon; (lower head) the inferior tendon. Insertion; eyeball in its transverse plane.

Obliquus Superior.-Origin; margin of optic foramen between the Recti superior and internus. Course; its narrow tendon runs through a fibrous pulley (trochlea) attached to the roof of the orbit and then bends outward under the Superior rectus tendon. Insertion; sclerotic between the Recti superior and externus, midway between the cornea and entrance of the optic nerve.

[406]

Obliquus Inferior.-Origin; floor of orbit antero-internally, external to the naso-lachrymal groove. Course; under the Inferior rectus and between the eyeball and the External rectus. Insertion; sclerotic between the Recti, superior and externus, posterior to the Superior oblique.

[406]

\section{Nerves.}

Ophthalmic.-The lachrymal runs through the outer angle of the sphenoidal fissure above the muscles and forward below 


\section{DISSECTING MANUAL.}

the periosteum to the lachrymal gland, conjunctiva, and skin at outer canthus; it communicates with the orbital (superior maxillary) and temporal (facial). The frontal runs through the sphenoidal fissure and then above the muscles, dividing into the supra-orbital and supra-trochlear. The supra-orbital runs through the supra-orbital groove to the skin of the forehead, eyelid, and scalp, communicating with the temporal (facial). The supra-trochlear runs over the Superior oblique tendon and under the inner side of the supra-orbital arch to the inner canthus and skin of the forehead and root of the nose, communicating with the infra-trochlear (nasal).

The nasal runs through the sphenoidal fissure between the heads of the External rectus and between the divisions of the oculo-motor; then running inward above the optic nerve and Internal rectus, below the Superior rectus and Superior oblique, and through the anterior ethmoidal foramen, it crosses the cribriform plate, descends through the nasal fissure to the nose and divides into nasal branches. Branches: Long root of ciliary ganglion, arising external to the optic nerve; Long ciliary, two branches arising above the optic nerve and running beside it to the eyeball. Infra-trochlear, arising internal to the optic nerve and running under the pulley of the Superior oblique to the skin of the eyelids and root of the nose. Internal nasal, to the front of the septum. External nasal, supplying the front of the outer nasal wall and then running between the nasal bone and lateral cartilage to the skin on the lower part of the nose.

[680]

Ciliary or Lenticular Ganglion.-This is small and reddish and lies between the optic nerve and External rectus, in front of the oph thalmic artery. Roots : Short (motor), derived from the inferior division of the oculo-motor. Long (sensory), derived from the nasal branch of the ophthalmic. Sympathetic, derived from the cavernous plexus and may fuse with the preceding. Branches: Short ciliary, twelve to fifteen nerves which run above and below the optic nerve to the eyeball.

[680] 


\section{CRANIAL CAVITY.}

Oculo-motor.-Both branches run through the sphenoidal fissure between the heads of the External rectus, separated by the nasal nerve; the superior branch supplies the Superior rectus and Levator palpebræ superioris; the inferior branch supplies the Internal rectus, Inferior rectus, and Inferior oblique and gives off the short root of the ciliary ganglion.

[676]

Trochlear.-Running through the sphenoidal fissure above the muscles, this enters the superior surface of the Superior oblique.

[677]

Abducent.-Running through the sphenoidal fissure between the heads of the External rectus and below the nasal and oculo-motor, this enters the inner surface of the External rectus.

[686]

Superior Maxillary.--The orbital branch runs through the sphenoidal fissure and then along the outer wall of the orbit and through the orbital canal of the malar; it communicates with the lachrymal.

[681]

Optic.-Running through the optic foramen above the ophthalmic artery, this enters the eyeball.

[675]

\section{Arteries.}

Ophthalmic.-This runs through the optic foramen and forward over the optic nerve to the inner side of the orbit, and divides into the frontal and nasal. Branches: Posterior ciliary, running beside the optic nerve to the eyeball. Central artery of retina, running in the optic nerve. Recurrent, passing through the sphenoidal fissure to the dura. Lachrymal, to the gland. Muscular. Anterior ciliary, to the eyeball in front. Supra-orbital, running through the supra-orbital notch to the forehead. Anterior and posterior ethmoidal, passing through the ethmoidal canals. Palpebral, to the eyelids. Nasal, to the nose. Frontal, to the forehead.

[815]

VEINS.

Ophthalmic.-This runs through the sphenoidal fissure between the heads of the External rectus and joins the cavern- 


\section{DISSECTING MANUAL.}

ous sinus. Its branches are the arterial venæ comites except the frontal, which joins the angular vein.

[879]

\section{The Eyeball.}

This is composed of segments of two spheres, the anterior (corneal) being of shorter radius than the posterior (scleral); the centres (anterior and posterior poles) of the curvatures are joined by the sagittal axis while the equator is midway between them.

[724]

Outer Coat.-The cornea, the anterior sixth, is a transparent laminated structure, covered externally by epithelium continuous with that on the conjunctiva. The sclera, the posterior five-sixths, is an opaque structure; externally it is whitish and separated from the capsule of Tenon by the suprascleral lymphatic space; internally it is brownish and firmly attached to the choroid at the entrance of the optic nerve, but only loosely attached elsewhere by a fine meshwork (lamina fusca), being separated from it by a lymph space (spatium perichoroideale). Posteriorly the sclera is pierced (lamina cribrosa) by the optic nerve and ciliary vessels and nerves; just behind its equator are two orifices above, and two below, for veins. A circular canal (Schlemm) lies deeply in the corneo-scleral junction and communicates with the anterior chamber and scleral veins.

[725]

Middle Coat. - The choroid is a vascular and dark brown, or black, structure lying between the sclera and retina; it is pierced by the optic nerve and adheres to the retina. The ciliary body, which connects the choroid with the circumference of the iris, presents the following structures: orbicularis ciliaris, a narrow zone with many ridges, lying next to the choroid; ciliary processes, about seventy radial thickenings; and ciliary muscle, composed of radial fibres externally and circular fibres internally. The \&ris is a contractile diaphragm which divides the space between the cornea and lens into two parts, the anterior and posterior chambers. It consists of 


\section{CRANIAL CAVITY.}

radial muscle (Dilator pupillæ) fibres externally; and of circular (Sphincter pupillæ) fibres internally, surrounding an almost circular aperture (pupil) lying just to the nasal side of its centre. The ciliary arteries form an anastomosing circle (circulus arteriosus major) around its outer or ciliary margin; and another circle (circulus arteriosus minor) around the margin of the pupil.

[727]

Inner Coat.-The retina is a delicate membrane composed of an outer pigmented layer attached to the choroid; and of an inner nervous layer, the retina proper, which is in contact with the hyaloid membrane of the vitreous body but is only attached to this at the entrance of the optic nerve and near the ciliary processes. It seems to end in a serrated border (ora serrata) just behind the ciliary body, but the pigmented layer, thinned out, is really prolonged onto the ciliary body and the iris. It presents internally, at the posterior pole, a small yellowish spot (macula lutea) which is depressed (fovea centralis) centrally; and also, at the entrance of the optic nerve, a whitish area (optic disc) which is depressed (optic cup) centrally but elevated (colliculus nervi optici) at the edge. It consists of ten layers which are only separable microscopically.

[731]

Refracting Media.-The vitreous body is a transparent jellylike substance lying between the retina and lens; it is concave anteriorly (fossa patellaris) and enclosed in a thin transparent (hyaloid) membrane. The hyaloid membrane is thickened (zonula of Zinn) in front of the ora serrata, presenting grooves for the ciliary processes and splitting into two layers; the posterior layer is the thinner and covers the fossa patellaris; the anterior layer (suspensory ligament) blends with the front of the capsule of the lens. A lymph space (canal of Petit) runs around the lens behind the suspensory ligament. The crystalline lens is a biconvex transparent body lying between the iris and vitreous body, and enclosed in a thin transparent capsule. It is formed by concentric laminæ and consists of a soft outer 


\section{DISSECTING MANUAL.}

part (substantia corticalis), and a dense central part (nucleus lentis). The centres of its surfaces are its anterior and posterior poles; its circumference is known as its equator. The aqueous humor is a watery fluid which fills the anterior and posterior chambers.

[735]

Eyelids.--These are two skin folds, separated by a fissure (palpebral) which ends in inner and outer angles (canthi); in the triangular space (lacus lacrimalis) between them internally is seen a pale red body (caruncula lacrimalis); a papilla (lachrymal) lies on the margin of each lid at the outer limit of the lacus lacrimalis. Mucous membrane (conjunctiva) lines the lids, forms a vertical fold (plica semilunaris) between the eyeball and caruncula, and also passes onto the eyeball. A fibrous plate (tarsal plate) is found in each lid. The external tarsal ligament is attached to the malar bone; and the internal to the nasal process of the superior maxilla in front of the lachrymal groove; their free ends divide and are attached to the ends of the tarsal plates. Membranous expansions (superior and inferior palpebral ligaments) run from each margin of the orbit to the corresponding tarsal plate; they fuse externally with the external tarsal ligament, but pass internally behind the internal tarsal ligament to the lachrymal bone behind the lachrymal sac. Meibomian glands lie behind the tarsal plates and open on the margins of the lids, behind the lashes.

[738]

Lachrymal Apparatus.-The lachrymal gland is an oval body lying in the upper and outer part of the orbital cavity; it consists of two portions partly separated by an expansion of the Levator palpebræ superioris tendon. The orbital portion is the larger and lies in the fossa lacrimalis of the frontal; its ducts receive those of the palpebral portion and empty on the upper eyelid close to the line (fornix) of reflexion of the conjunctiva. The palpebral portion lies below and in front, projecting into the upper eyelid. The lachrymal canals begin by minute orifices (puncta lacrimalia) at the apices of the lach- 


\section{ANTERIOR ASPECT OF HEAD AND NECK.}

rymal papillæ and run in the margins of the lids. The upper one first ascends and then runs inward; the lower one first descends and then runs inward; each one is dilated (ampulla ductus lacrimalis) where it bends. They open close together into the outer and fore part of the lachrymal sac just below its middle. The lachrymal sac is a small reservoir lying in the groove between the lachrymal bone and the nasal process of the superior maxilla; its lower end narrows into the nasal duct. The nasal duct descends from the sae and opens into the inferior meatus of the nose; its lower orifice is often guarded by a fold (valve, or plica lacrimalis of Hasner) of mucous membrane.

[740]

\section{ANTERIOR ASPECT OF HEAD AND NECK.}

Superficial Fascia.-On the face it is thin and loose below the cyelids, and continuous with a fatty pad between the Buccinator and Masseter. On the neck it is separated from the deep fascia by the Platysma.

Deep Fascia.-On the face proper it is almost non-existent, but forms a thin masseteric fascia posteriorly and then thickens as the parotid capsule. Over the Temporal it forms the temporal fascia, which is continuous with the epicranial aponeurosis and is attached above to the temporal ridge and below, splitting in two layers, to the zygoma.

In the neck it is attached below to the sternum, first rib, clavicle, and scapula; and above to the superior curved line of the occipital, mastoid process, lower border of the mandible, and (behind the pharynx and parotid) styloid and vaginal processes of the temporal, great wing of the sphenoid, and basilar process of the occipital. A continuous layer covers the neck, surrounds the Trapezius and deep muscles behind, helps form the earotid sheath, and splits to enclose the Sterno-mastoid; at the lower end of the latter it is attached in two layers to the front and back of the episternal notch. Septal layers, contin- 


\section{DISSECTING MANUAL.}

uous with and entering into the carotid sheaths, form compartments; a layer enclosing the infrahyoid muscles runs in front of the trachea to the hyoid bone; another runs in front of the trachea and encloses the hyoid body; another runs between the trachea and osophagus; another (prevertebral layer) runs between the prevertebral muscles and the pharynx and œsophagus.

[400]

\section{Muscles.}

Platysma Myoides (a thin quadrilateral sheet).-Origin; clavicle; pectoral deep fascia. Insertion; (anterior fibres) opposite Platysma; (middle fibres) lower border of mandible, Depressor labii inferioris, Depressor anguli oris; (posterior fibres) Risorius.

[401]

Muscles of Face.

Orbicularis Palpebrarum.-This transversely oval sphincter occupies the eyelids and is divisible into an external portion, whose coarse fibres spread onto the forehead, temple, and cheek; and an internal portion whose finer fibres lie in the eyelids under the skin. It is attached internally to the inner tarsal ligament and the borders of the naso-lachrymal groove. The fibres in the margin of each lid form a separate ciliary bundle. The posterior fibres running from the posterior edge of the naso-lachrymal groove to the tarsal ligaments behind the lachrymal sac form the Tensor tarsi.

[402]

Corrugator Supercilii.-Origin; nasal eminence. Insertion; Orbicularis palpebrarum.

[403]

Pyramidalis Nasi.-Origin; Occipito-frontalis; skin over the glabella. Insertion; a membrane covering the nose. [403]

Compressor Naris.-Origin; superior maxilla. Insertion; a membrane covering the nose.

[403]

Dilatores Naris.-These are two weak slips, one in front and one behind, on the outer side of the edge of the nostril. 


\section{ANTERIOR ASPEC'T OF HEAD AND NECK.}

Depressor Alæ Nasi.-Origin; upper part of incisor fossa. Course; splits into two parts. Insertion; ala and septum of nose.

Levator Labii Inferioris Alæque Nasi.-Origin; root of nasal process of superior maxilla. Insertion; Orbicularis oris; ala of nose.

[403]

Orbicularis Oris.-This sphincter surrounds the lips. Its mesial fibres are attached above to the septum of the nose and the incisor fossa, and below to the lower jaw on each side of the symphysis; they radiate outward to the rest of the muscle. Laterally its upper fibres join the Buccinator and Depressor anguli oris, and its lower fibres the Buccinator and Levator anguli oris.

[403]

Levator Labii Superioris.-Origin; superior maxilla above the infra-orbital foramen. Insertion; skin of upper lip; Orbicularis oris.

[403]

Levator Anguli Oris.-Origin; canine fossa. Insertion; Orbicularis oris; skin at angle of mouth.

[403]

Zygomaticus Minor.-Origin; malar bone. Insertion; Orbicularis oris.

[404]

Zygomaticus Major.-Origin; malar portion of zygoma. Insertion; Orbicularis oris; skin at angle of mouth.

[404]

Risorius.-Origin; masseteric fascia. Insertion; Orbicularis oris; skin at angle of mouth.

[404]

Depressor Anguli Oris.-Origin; Platysma; external oblique line of lower jaw. Insertion; Orbicularis oris; skin at angle of mouth.

[404]

Depressor Labii Inferioris.-Origin; lower jaw. Insertion; Orbicularis oris; skin of lower lip.

[404]

Levator Menti.-Origin; incisor fossa. Insertion; skin of chin.

Buccinator.-Origin; alveolar arches of both jaws; pterygomandibular ligament. Insertion; Orbicularis oris, the middle fibres decussating at the angle of the mouth but the upper and lower fibres passing directly to it.

[404] 


\section{DISSECTING MANUAL.}

Muscles of Mastication.

Masseter-Origin; inner surface and anterior two-thirds of lower border of zygoma. Insertion; outer surface of ramus of lower jaw and coronoid process.

[407]

Temporal.-Origin; whole temporal fossa; temporal fascia. Insertion; anterior border of ramus and deep surface of coronoid process of lower jaw.

[408]

External Pterygoid.-Origin; (upper head) under surface of great wing of sphenoid; (lower head) outer surface of external pterygoid plate. Insertion; a depression in front of neck of lower jaw; inter-articular fibro-cartilage and capsule of temporo-maxillary joint.

[408]

Internal Pterygoid.-Origin; deep surface of external pterygoid plate; tuberosity of upper jaw. Insertion; triangular impression on inner surface of lower jaw, between the angle and mylo hyoid groove.

Muscles of Neck.

Sterno-cleido-mastoid.-Origin; (sternal head) anterior surface of manubrium sterni; (clavicular head) upper surface of inner third of clavicle. Insertion; mastoid process; superior curved line of occipital.

[410]

Muscles of Hyoid Bone.

Omo-hyoid.-Origin (posterior belly); superior border of scapula; suprascapular ligament. Course; forward and upward to an intermediate tendon, and then upward. Insertion (anterior belly); body of hyoid bone.

[411]

Sterno-hyoid.-Origin; back of presternum and first costal cartilage; clavicle. Insertion; body of hyoid internal to preceding.

Sterno-thyroid.-Origin; back of presternum and first costal cartilage. Insertion; oblique line of thyroid cartilage. It has a tendinous intersection. 


\section{ANTERIOR ASPECT OF HEAD AND NECK.}

Thyro-hyoid.-Origin; oblique line of thyroid cartilage. Insertion; body of hyoid.

Digastric.-Origin (posterior belly); digastric groove under mastoid process. Course; at first downward and forward to an intermediate tendon (which is held to the body of the hyoid by a band of cervical fascia), then upward and forward. Inscrtion (anterior belly); oval impression on lower border of mandible close to symphysis.

[413]

Stylo-hyoid.-Origin; styloid process of temporal. Insertion; body of hyoid, by two slips which enclose the Digastric tendon.

[413]

Mylo-hyoid.-Origin; lower three-fourths of mylo-hyoid ridge of lower jaw. Insertion; upper body of body of hyoid; the median raphe extending from the hyoid almost to the chin.

Genio-hyoid.-Origin; lower genial tubercle on back of symphysis of lower jaw. Insertion; body of hyoid.

[414]

\section{Muscles of Tongue.}

Genio-hyo-glossus. - Origin; upper genial tubercle behind symphysis of lower jaw. Insertion; body of hyoid bone; tongue from base to tip.

Hyo-glossus. - Origin; body and great cornu of hyoid. Insertion; side of tongue.

Stylo-glossus.-Origin; lower end of styloid process; stylomandibular ligament. Insertion; side and under surface of tongue.

[414]

Palato-glossus.-Origin; under surface of soft palate. Insertion; side of tongue.

Intrinsic Muscles.--Superior lingualis: This extends on the dorsum from base to tip. Inferior lingualis: This is a cylindrical band on the under surface, between the Hyo-glossus and Genio-hyo-glossus; some fibres are attached to the hyoid bone. Transverse fibres: These run from the median raphe to the dor- 


\section{DISSECTING MANUAL.}

sum and sides, between the two preceding. Vertical fibres: These run from the dorsum to the sides.

\section{Muscles of Pharynx.}

Superior Constrictor.-Origin; lower half of posterior border of internal pterygoid plate; pterygo-mandibular ligament; mylo-hyoid ridge of lower jaw; mucosa of floor of mouth. Insertion; pharyngeal spine of occipital; a median raphe in the posterior pharyngeal wall.

Middle Constrictor.-Origin; stylo-hyoid ligament; both cornua of hyoid bone. Insertion; median raphe.

Inferior Constrictor.-Origin; oblique line of thyroid cartilage; side of cricoid cartilage. Insertion; the median raphe, the lower fibres blending with the œsophagus.

[417]

Stylo-pharyngeus.-Origin; root of styloid process internally. Course; between the Superior and Middle constrictors. Insertion; superior and posterior borders of thyroid cartilage; pharyngeal wall, becoming continuous with the Palatopharyngeus.

Palato-pharyngeus.-Origin; (postero-superior layer) opposite Palato-pharyngeus, the fibres being continuous; (antero-inferior layer) posterior border of hard palate. Insertion; posterior border of thyroid cartilage; pharyngeal aponeurosis as far as lower border of Inferior constrictor.

[417]

Muscles of Soft Palate.

Azygos Uvulæ.-This consists of two narrow slips arising from the posterior nasal spine and aponeurosis of the soft palate; they run backward between the layers of the Palatopharyngeus, unite, and end in the uvula.

Levator Palati.-Origin; under surface of apex of petrous bone; lower part of cartilaginous Eustachian tube. Course; between the layers of the Palato-pharyngeus. Insertion; aponeurosis of soft palate.

[418]

Tensor Palati.-Origin; scaphoid fossa and alar spine of [64] 


\section{ANTERIOR ASPECT OF HEAD AND NECK.}

sphenoid; outer side of cartilaginous Eustachian tube. Insertion (by a tendon hooking round the hamular process); posterior border of hard palate and aponeurosis of soft palate beneath the preceding.

[419]

Lateral and Prevertebral Muscles of Neck.

Scalenus Anticus.-Origin; anterior tubercles of transverse processes of third, fourth, fifth, and sixth cervical vertebræ. Insertion; scalene tubercle and ridge on first rib.

[419]

Scalenus Medius.-Origin; posterior tubercles of transverse processes of second to sixth cervical vertebræ. Insertion; first rib.

[420]

Scalenus Posticus.-Origin; posterior tubercles of fourth, fifth, and sixth cervical transverse processes. Insertion; outer side of second rib.

Rectus Capitis Anticus Major.-Origin; anterior tubercles of transverse processes of third, fourth, fifth, and sixth cervical vertebræ. Insertion; basilar process of occipital, antero-external to pharyngeal spine.

[420]

Rectus Capitis Anticus Minor.-Origin; anterior arch of atlas. Insertion; basilar process.

Longus Colli.-Vertical portion: Origin; bodies of first three thoracic and last three cervical vertebræ: Insertion; bodies of second, third, and fourth cervical vertebræ. Lower oblique portion: Origin; bodies of first three thoracic vertebræ: Insertion; anterior tubercles of fifth and sixth cervical vertebræ. Upper oblique portion: Origin; anterior tubercles of transverse processes of third, fourth, and fifth cervical vertebra: Insertion; anterior tubercle of atlas.

[421]

Rectus Capitis Lateralis.-Origin; transverse process of atlas. Insertion; under surface of ex-occipital bone. [422]

Triangles of Neck. - The Sterno-mastoid divides each side of the neck into two triangles, anterior and posterior. The posterior belly of the Omo-hyoid subdivides the posterior triangle into two triangles, the occipital above and the clavicular 


\section{DISSECTING MANUAL.}

(subclavian) below. The Digastric and the anterior belly of the Omo-hyoid subdivide the anterior triangle into three triangles, the digastric above, the carotid mesially, and the muscular below.

\section{Cervical Nerves.}

Cervical Plexus.-This is formed by the anterior primary divisions of the first four cervical nerves; they emerge from the spinal canal behind the vertebral artery and form loops on the Rectus capitis lateralis and Scalenus medius under the Sterno-mastoid. The branches, which arise from the loops, are superficial (ascending and descending) and deep (external and internal).

[617]

Superficial Branches (cutaneous).-These pass under the Sterno-mastoid to the posterior triangle. Ascending series: The small occipital (C. 2 and 3) ascends along the posterior border of the Sterno-mastoid, pierces the deep fascia and divides into the following branches: auricular, to the pinna; mastoid and occipital, to the scalp; and cervical, to the upper neck. It communicates with the great occipital, great auricular, and posterior auricular. The great auricular (C. 2 and 3) ascends on the Sterno-mastoid and divides below the ear into the following branches: mastoid, to the scalp; auricular, to the lower part of the pinna; and facial, to the lower part of the cheek. It communicates with the small occipital, posterior auricular, and (in the parotid gland) facial. The superficial cervical (C. 2 and 3) runs across the Sterno-mastoid to its anterior border and divides into upper and lower branches for the neck in front. It communicates with the infra-mandibular branch of the facial. Descending series (C. 3 and 4): A trunk descends in the posterior triangle and divides into the following branches, which pierce the deep fascia above the clavicle. The sternal run over the clavicle internally, to supply the neck and chest down to the end of the manubrium. The clavicular run over the clavicle mesially, to supply the chest down to the nipple. 


\section{ANTERIOR ASPEC'T OF HEAD AND NECK.}

The acromial run through or over the Trapezius insertion, and over the clavicle externally, to supply the shoulder down to the lower third of the Deltoid.

[617-619]

Deep Branches (muscular and communicating).-External series. These run toward the posterior triangle as follows: To (C. 2) the deep surface of the Sterno-mastoid, communicating under it with the spinal accessory. To (C. 3 and 4) the Trapezius, communicating under it, and in the posterior triangle, with the spinal accessory. To (C. 3 and 4) the Scaleni, medius and posticus, and outer surface of the Levator anguli scapulæ. Internal series. These run toward the anterior triangle as follows: To (C. 1 to 4 ) the sympathetic superior cervical ganglion. To (loop between C. 1 and 2) all the Recti, the vagus (inconstant), and the hypoglossal; the latter branch sends a meningeal branch upward on the hypoglossal and then, probably, entirely constitutes its descendens hypoglossi branch and its branches to the Thyro-hyoid, Genio-hyoid, and (possibly) intrinsic muscles of the tongue. To (C. 2, 3, and 4) the Intertransversales, Longus colli, and Rectus capitis anticus major. To (C. 4) the upper part of the Scalenus medius. The descending cervical (C. 2 and 3) are two long branches which join in front of the internal iugular and form a loop (ansa hypoglossi) with the descendens hypoglossi in front of the carotid sheath; branches of the loop supply the Omo-hyoid, Sterno-thyroid, and Sterno-hyoid; the latter branch may continue behind the sternum to join the cardiac plexus, or the phrenic.

[619]

Phrenic.-This is derived mainly from the fourth cervical and partly from the third (either directly or through the nerve to the Sterno-hyoid) and the fifth (cither directly or through the nerve to the Subclavius); it often communicates with the cervical sympathetic system. Its roots unite, descend upon the Scalenus anticus, and pass between the subclavian vessels on their way to the diaphragm.

[621]

Brachial Plexus.-This is formed by the anterior primary 
divisions of the fifth, sixth, seventh, and eighth cervical nerves and most of the first thoracic; it often gets a branch from the fourth cervical and sometimes one from the second thoracic; the latter always enters the intercosto-humeral. The fifth and sixth cervical communicate with the middle cervical ganglion of the sympathetic, and the seventh and eighth cervical with the inferior ganglion. The plexus appears in the posterior triangle between the Scaleni, anticus and medius. It quickly unites in primary cords, the first cord being formed by the fifth and sixth cervical, the second by the seventh cervical, and the third by the eighth cervical and first thoracic. At the same time each cervical nerve begins to divide into two trunks, dorsal and ventral. The whole plexus is described with the upper extremity.

Supraclavicular Branches.-Anterior series: To (C. 5, 6, 7, and 8 ; arising from them at the spinal foramina) the Scalenus anticus and Longus colli. To (C. 5) the phrenic, but it may be absent or of different origin. To (arising from the front of the first cord) the Subclavius, crossing the subclavian artery. Posterior series: To (C. 5, 6, 7, and 8, arising at the foramina) the Scaleni, medius and posticus. The posterior scapular (arising from the back of C. 5 at the foramen) pierces the Scalenus medius and descends to the posterior border of the scapula. The long thoracic (arising from the back of C. 5, 6, and 7 at the foramina) pierces the Scalenus medius and descends behind the plexus to the side of the chest. The suprascapular (arising from the back of the first cord) descends above the plexus and runs through the suprascapular foramen.

[624]

\section{Cranial Nerves.}

Olfactory.-About twenty nerves descend through the cribriform plate of the ethmoid to supply the upper part of the nasal septum and the outer wall of the nasal fossa.

[675]

Ophthalmic.-Terminal branches of the lachrymal supply the conjunctiva and skin at the outer canthus of the eye; they 


\section{ANTERIOR ASPECT OF HEAD AND NECK.}

communicate, on the face, with temporal branches of the facial. The supra-orbital emerges at the supra-orbital foramen and ascends to the forehead; it supplies the frontal sinus, upper eyelid, and the forehead and scalp as far back as the vertex; it communicates with temporal branches of the facial. The supra-trochlear emerges under the inner side of the supraorbital arch and supplies the skin of the mesial part of the forehead, the root of the nose, and the inner canthus of the eye. The nasal enters the nasal cavity through the nasal fissure and divides; the internal branch supplies the mucous membrane on the upper and fore part of the septum; the external branch supplies the outer wall and then runs between the nasal bone and lateral cartilage to supply the skin on the lower part and tip of the nose, communicating with the infraorbital. The infra-trochlear branch of the nasal emerges at the inner angle of the orbit and supplies the eyelids and skin on the root of the nose, communicating with the infra-orbital branches of the facial.

[679]

Superior Maxillary.-Emerging from the foramen rotundum, this runs across the spheno-maxillary fossa and through the spheno-maxillary fissure, entering the orbit as the infraorbital nerve; it then continues through the infra-orbital canal and foramen to the face.

[681]

Branches in the Spheno-maxillary Fossa.-The spheno-palatine are the two short roots of Meckel's ganglion. The posterior dental descends in the pterygo-maxillary fissure and runs forward along the outer side of the upper alveolar arch to the gums and molars, piercing the bone. The orbital runs through the spheno-maxillary fissure and along the outer wall of the orbit, communicating with the lachrymal. Then passing through the orbital canal of the malar it divides into two branches: the malar branch supplies the skin over the malar; the temporal branch supplies the front of the temple; both communicate with the facial.

[681]

Branches in the Infra-orbital Canal. - The middle and anterior 


\section{DISSEC'TING MANUAL.}

dental both descend in bony canals, in the wall of the antrum, to the alveolar arch and supply the incisors, canine, and premolars; they communicate with the posterior dental. Branches on the Face.-The nerve divides into three sets of radiating branches, viz.: palpebral, to the lower eyelid; nasal, to the side of the nose; and labial, to the cheek and upper lip. All these communicate with the facial, thus forming the infraorbital plexus.

[682]

Meckel's (Spheno-palatine) Ganglion.-This lies in the upper part of the spheno-maxillary fossa below the superior maxillary nerve and is small and reddish-gray. Roots: The sensory are the spheno-palatine branches of the superior maxillary. The motor and sympathetic are the Vidian nerve, which is formed by the (motor) great superficial petrosal, from the facial geniculate ganglion, and the (sympathetic) great deep petrosal from the carotid plexus.

[682]

Branches. - The pterygo-palatine runs backward in the pterygo-palatine canal to the mucosa on the roof of the pharynx. The large posterior palatine descends in the large posterior palatine canal to the mucosa of the soft and hard palate; a branch (inferior nasal) arising in the canal goes to the mucosa on the lower part of the outer nasal wall. The small posterior palatine descends in the small posterior palatine canal and through the tuberosity of the palate bone to the mucosa of the soft palate, uvula, and tonsil. The accessory posterior palatine twigs descend in accessory posterior palatine canals to the mucosa of the tonsil, soft palate, and uvula. The superior nasal runs through the spheno-palatine foramen to the upper and posterior part of the outer nasal wall. The orbital twigs ascend to the orbital periosteum. The naso-palatine runs through the spheno-palatine foramen and across the roof of the nose, then passes downward and forward on the septum, grooving the vomer, and through the foramen of Scarpa (the left nerve in front) and then runs backward; it supplies the mucosa of the roof and septum of the nose, and that of the 


\section{ANTERIOR ASPECT OF HEAD AND NECK.}

hard palate; it communicates with its fellow and the large posterior palatine.

[683]

Inferior Maxillary.-Emerging from the foramen ovale, the roots unite in a nerve which soon divides into anterior and posterior trunks. Before dividing it gives off a recurrent branch which runs through the foramen spinosum to the dura; and also a branch to the Internal pterygoid, which supplies the motor root of the otic ganglion.

[683]

The anterior trunk descends under the External pterygoid and separates into the following branches: One to the deep surface of the External ptergyoid. One running above the External pterygoid and through the sigmoid notch of the mandible to the Masseter. Two ascending above the External pterygoid to the Temporal. One (buccal nerve) running between the hearls of the External pterygoid to the Buccinator and usually sending a branch to the Temporal; this nerve is sensory and supplies the cheek and inside of the mouth, piercing the Buccinator; it communicates with the facial.

[683]

The posterior trunk descends beneath the External pterygoid and, after giving off the auriculo-temporal, divides into the lingual and inferior dental.

[684]

The auriculo-temporal arises by two roots which embrace the middle meningeal artery and then unite. Running backward uncler the External pterygoid and between the internal lateral ligament and neck of the jaw bone, it ascends through the parotid gland and then over the zygoma and in front of the ear, where it divides into terminal branches for the temple and scalp. It also gives branches to the temporo-maxillary joint, parotid gland, and external auditory meatus. It receives branches, at its roots, from the otic ganglion, and communicates with the facial in the parotid gland and superfieially on the temple.

[684]

The lingual descends beneath the External pterygoid, then runs forward between the Internal pterygoid and the ramus of the mandible, and then passes under the floor of the mouth, 


\section{DISSEC'TING MANUAL.}

between the Mylo-hyoid and Hyo-glossus, but under Wharton's duct, to the side of the tongue. It communicates with the hypoglossal, while the chorda tympani of the facial joins it under the External pterygoid. It supplies the mucous membrane on the outer wall and floor of the mouth and the anterior two-thirds of the side and dorsum of the tongue.

[684]

The inferior dental runs between the internal lateral ligament and ramus of the mandible, and then through the inferior dental foramen and canal, where it supplies the molars, and divides into two branches, mental and incisor. The incisor branch supplies the canine and incisors. The mental branch runs through the mental foramen to the skin on the chin and lower lip, communicating with the facial. A mylohyoid branch arises before the nerve enters the inferior dental foramen; it descends in a groove on the ramus of the lower jaw to enter the superficial surface of the Mylo-hyoid and also supply the anterior belly of the Digastric.

[685]

Submaxillary Ganglion.- - This lies on the Hyo-glossus, just under the lingual nerve, and is reddish and very small. Roots: The afferent root comes from the lingual; and the efferent from the fibres of the chorda tympani in the lingual. The sympathetic root comes from the plexus on the facial. Branches: These supply the submaxillary gland and duct, and also (by fibres which rejoin the lingual) the sublingual gland. [685]

Otic Ganglion.-This lies under the inferior maxillary nerve, just below the foramen ovale. Roots: The motor comes from the (inferior maxillary) nerve to the Internal pterygoid; and the sympathetic from the plexus on the middle meningeal artery. The sensory is the small superficial petrosal nerve from the tympanic plexus (facial and glosso-pharyngeal). Branches: These go to (motor) the Tensor tympani and Tensor palati; and to (communicating) the Vidian, chorda tympani, and roots of the auriculo-temporal.

[685]

Facial.-After traversing the internal auditory meatus, where the pars intermedia sends branches to it and also to the 


\section{ANTERIOR ASPECT OF HEAD AND NECK.}

auditory, it runs through the Fallopian aqueduct.' Here it at first bends backward on the inner side of the tympanum and then descends in the inner wall of the tympanic antrum. Then emerging at the stylo-mastoid foramen it runs forward in the parotid gland, over the external carotid artery and temporomaxillary vein, and spreads out in the pes anserinus. [686]

The geniculate ganglion is an oval swelling on the nerve where it bends in the aqueduct; it communicates with the auditory. Branches: The large superficial petrosal runs through the hiatus Fallopii and joins the great deep petrosal over the foramen lacerum medium, forming the Vidian; this runs through the Viclian canal to Meckel's ganglion. The external superficial petrosal (inconstant) goes to the middle meningeal plexus of the sympathetic. A small branch joins the tympanic branch of the glosso-pharyngeal in the temporal bone, forming the small superficial petrosal, which joins the otic ganglion.

[686]

Branches of Facial in the Aqueduct (from the lower part).A branch supplies the Stapedius and another joins the auricular (vagus). The chorda tympani runs through the iter chordæ posterius, across the drum and handle of the malleus, in the tympanum, and then through the iter chordæ arterius, and joins the lingual below the External pterygoid; it supplies a root to the submaxillary ganglion, communicates with the otic ganglion, and supplies (taste?) the anterior two-thirds of the side and dorsum of the tongue.

[687]

Branches in the Neck.-A branch supplies the Stylo-hyoid, and another the posterior belly of the Digastric; the latter may communicate with the glosso-pharyngeal. The posterior auricular ascends over the mastoid process and divides into an auricular branch to the Retrahens aurem and intrinsic muscles of the pinna, and an occipital branch to the posterior belly of the Occipito-frontalis; it communicates with the great auricular, small occipital, and auricular (vagus).

[687]

Branches in the Parotid Gland.-The nerve communicates 


\section{DISSECTING MANUAL.}

with the great auricular and auriculo-temporal and spreads out (pes anserinus) in two divisions. The temporo-facial division splits into three sets of branches, viz.: temporal, crossing the zygoma; malar, crossing the malar bone; and infra-orbital, crossing the Masseter and joining the infra-orbital plexus. The cervico-facial division splits into three sets of branches, viz.: buccal, to the angle of the mouth; supra-mandibular, a single branch running along the lower jaw; and infra-mandibular, a single branch running below the lower jaw to the Platysma and communicating with the superficial cervical. These branches supply the muscles of the face.

[687]

The infra-orbital plexus is formed, below the lower eyelid, by the union of the infra-orbital branches of both the facial and superior maxillary.

[688]

Glosso-pharyngeal.-Emerging from the jugular foramen and developing two ganglia, this descends between the internal jugular and internal carotid, and then between the carotids, to the pharynx. Then crossing the Stylo-pharyngeus and stylohyoid ligament, it runs under the Hyo-glossus to the tongue and divides into lingual branches, which supply the mucosa on the dorsal third and lateral half of the tongue, extending to the glosso-epiglottidean folds and front of the epiglottis. While crossing the Stylo-pharyngus it gives off a branch which supplies that muscle and sends fibres through it to the pharyngeal mucosa. The pharyngeal branches arise in the neck and supply the pharyngeal mucosa directly after piercing the Superior constrictor, and indirectly through the pharyngeal plexus. A tonsillitic branch forms a plexus (circulus tonsillaris) which supplies the mucous membrane on the tonsil and adjacent parts of the soft palate and fauces.

[689]

The jugular ganglion, the smaller, lies in the jugular foramen above the petrous ganglion and involves only part of the nerve. It has no branches and may be absent or fused with the petrous ganglion.

[689]

The petrous ganglion lies in the lower part of the jugular fora- 


\section{AN'TERIOR ASPEC'T OF HEAD AND NECK.}

men; it communicates with the superior cervical ganglion of the sympathetic, and the auricular branch and, sometimes, ganglion of the root of the vagus. Its tympanic branch (Jacobson's nerve) runs, in a canal between the carotid canal and jugular foramen, to the tympanum and forms a plexus (tympanic) there with the small deep petrosal; the plexus supplies the tympanic mucosa; the fibres then reunite and join a branch of the geniculate ganglion, forming the small superficial petrosal which runs to the otic ganglion.

[689]

Vagus.--Emerging from the jugular foramen, and developing two ganglia, this descends in the carotid sheath, lying between and behind the vessels, to the thorax. Branches in the Neck: The superior and inferior cardiac descend to the thorax. The right inferior laryngeal arises over the subclavian artery, winds around this, then ascends behind the common carotid and inferior thyroid arteries, enters the larynx under the Inferior constrictor and supplies all the laryngeal muscles except the Crico-thyroid. Its other branches are cardiac; communicating, to the inferior cervical ganglion of the sympathetic; and muscular, to the trachea, œsophagus, and Inferior constrictor. On the left side the nerve arises in the thorax, ascends between the trachea and osophagus to the neck, and then follows the same course.

[690]

The ganglion of the root lies in the jugular foramen and is small and spherical. It communicates with the spinal accessory, superior cervical ganglion of the sympathetic and, sometimes, petrous ganglion of the glosso-pharyngeal. Branches: The meningeal supplies the dura of the posterior fossa. The auricular (Arnold's nerve) ascends in a fissure, between the jugular and stylo-mastoid foramina, to supply the external auditory meatus and back of the pinna. It communicates with the tympanic branch of the glosso-pharyngeal near its origin, with the facial in the aqueduct, and with the postcrior auricular (facial).

[692]

The ganglion of the trunk lies just below the preceding and 


\section{DISSECTING MANUAL.}

is large and fusiform. It communicates with the superior cervical ganglion, hypoglossal, loop between the first and second cervical, and spinal accessory (accessory part). Branches: The pharyngeal descends between carotids to the side of the pharynx, and there joins pharyngeal branches of the glossopharyngeal and superior cervical ganglion of the sympathetic in a plexus (pharyngeal plexus); this supplies the muscles of the pharynx and soft palate, except the Stylo-pharyngeus and Tensor palati, and sends a (lingual) branch to the hypoglossal. The superior laryngeal descends behind the carotids and divides into two branches, viz.: external laryngeal, descending upon the Inferior constrictor and supplying it and the Crico-thyroid; and internal laryngeal, running between the Middle and Inferior constrictor, and through the thyrohyoid membrane to supply the laryngeal mucosa and communicate with the inferior laryngeal.

[692]

Spinal Accessory.-This consists of two essentially separate parts, spinal and accessory, of different origin and different distribution; they unite at the foramen magnum and traverse the jugular foramen in the same dural compartment as the vagus. In the foramen the accessory portion sends a small branch to the root ganglion of the vagus, and then partially joins the trunk ganglion of the vagus, and partially the vagus itself beyond the ganglion. The spinal portion emerges from the jugular foramen and descends between the internal carotid and internal jugular; then passing over the vein and under the Sterno-mastoid, it pierces and supplies the latter and runs across the posterior triangle to enter the under surface of the Trapezius. It communicates with the Sterno-mastoid branch of the second cervical in or under that muscle; with the third and fourth cervical in the posterior triangle; and with the branches of the third and fourth cervical to the Trapezius under that muscle.

[695]

Hypoglossal.-Emerging from the anterior condyloid foramen, this descends on the outer side of the internal carotid, 
then runs over both carotids, under the Digastric and Stylohyoid, and around the occipital artery to the hyoid bone, and then between the Mylo-hyoid and Hyo-glossus to end in the tongue. It communicates near the skull with the superior cervical ganglion, trunk ganglion of the vagus and loop between the first and second cervical; over the external carotid with the pharyngeal plexus (lingual branch of the vagus); and at the anterior border of the Hyo-glossus with the lingual (inferior maxillary).

[696]

Branches: The recurrent (probably C. 1 and 2) arises near its origin and supplies the dura of the posterior fossa. The descendens hypoglossi (probably C. 1 and 2) descends in front of the carotid sheath to the middle of the neck and joins the descending cervical in a loop (ansa hypoglossi), which gives branches to the Sterno-hyoid, Sterno-thyroid, and Omo-hyoid. The nerve to the Thyro-hyoid (probably C. 1 and 2) descends behind the great cornu of the hyoid. The lingual branches (terminal) are distributed to the Hyo-glossus, Genio-hyo-glossus, intrinsic muscles of the tongue, and (probably C. 1 and 2) Genio-hyoid.

Sympathetic.-The cervical part of the gangliated cord lies on the prevertebral muscles, behind the carotids, and develops three ganglia; there are no white rami communicantes between it and the cervical spinal nerves. Its branches are central, to other nerves; and peripheral, which form plexuses accompanying and supplying the vessels and viscera.

[706]

The superior cervical ganglion is at least three-quarters of an inch long and lies near the base of the skull, between the internal carotid and internal jugular. It communicates with the anterior primary divisions of the first four cervical nerves, petrous ganglion of the glosso-pharyngeal, both ganglia of the vagus, and hypo-glossal. Branches: The pharyngeal descends behind the carotid sheath to the pharyngeal plexus. The superior cervical cardiac descends behind the large vessels to the thorax. The external carotid forms the external carotid plexus 


\section{DISSECTING MANUAL.}

on that artery. The internal carotid is an upward prolongation of the ganglion on the internal carotid; it divides into inner and outer parts which form two plexuses around the artery, respectively the cavernous plexus above and the carotid below. The carotid plexus communicates with the abducent and the Gasserian ganglion and gives off two large branches; one (great deep petrosal) joins the great superficial petrosal, of the facial, to form the Vidian; the other (small deep petrosal) enters the tympanic plexus of the glosso-pharyngeal. The cavernous plexus communicates with the oculo-motor, trochlear, and ophthalmic; it supplies the pituitary body and provides the sympathetic root of the ciliary ganglion.

[706]

The middle cervical ganglion lies over the inferior thyroid artery and is small and often absent, its branches arising from the cord. It communicates with the anterior primary divisions of the fifth and sixth cervical; and with the inferior cervical ganglion by a loop (subclavian) which passes over the subclavian artery. Branches: The middle cervical cardiac descends behind the great vessels to the thorax. Branches accompany the inferior thyroid artery inward to supply the thyroid body.

[708]

The inferior cervical ganglion lies behind the subclavian artery, between the last cervical transverse process and the neck of the first rib. It communicates with the anterior primary divisions of the seventh and eighth cervical nerves, middle cervical ganglion (by the subclavian loop), and often with the inferior laryngeal. Branches: The inferior cervical cardiac descends to the thorax. It also forms two plexuses, vertebral and subclavian, on those arteries; the branches forming the latter arise from the subclavian loop.

[708]

\section{Arteries.}

Common Carotid. - This runs in the carotid sheath, internal to the internal jugular, from the sterno-clavicular joint to the lower border of the third cervical vertebra, at the level of the 


\section{ANTERIOR ASPECT OF HEAD AND NECK.}

upper border of the thyroid cartilage, and divides into the internal and external carotid.

[801]

External Carotid.-Ascending under the posterior belly of the Digastric and the Stylo-hyoid, it finally becomes superficial to the internal carotid and divides, behind the neck of the mandible, into the temporal and internal maxillary. It has eight branches, as follows:

[803]

The superior thyroid arises anteriorly, just below the tip of the great cornu of the hyoid, and crosses the Inferior constrictor to the thyroid body. Its branches are: infra-hyoid, running below the great cornu; laryngeal, accompanying the internal laryngeal nerve; sterno-mastoid, to the under surface of the muscle; crico-thyroid, crossing the front of that membrane; anterior and posterior terminal, to the lateral lobe of the thyroid body.

[804]

The lingual arises anteriorly, opposite the tip of the great cornu of the hyoid and runs forward under the Hyo-glossus and, as the ranine artery, under the tongue to its tip. Its branches are: supra-hyoid, running above the great cornu; dorsalis linguæ, to the dorsum of the tongue; and sublingual, to that gland. [805]

The facial arises anteriorly, just above the lingual, and runs under the posterior belly of the Digastric and the Stylo-hyoid; then crossing the mandible at the anterior border of the Masseter it crosses the face superficially to the side of the nose and divides into the angular and lateral nasal. Its branches in the neck are: ascending palatine, ascending on the Superior constrictor and running over its upper edge to the soft palate; submental, running forward along the lower border of the mandible; submaxillary, to that gland; and tonsillar, running through the Superior constrictor to the tonsil. Its branches in the face are: inferior labial, running below the mouth; inferior and superior coronary, to the margins of the lips; masseteric, crossing the Masseter; buccal, crossing the Buccinator; lateral nasal, to the side of the nose; and angular, to the inner angle of the orbit.

[806] 


\section{DISSECTING MANUAL.}

The occipital arises posteriorly under the Digastric, under which and the Sterno-mastoid it runs upward and backward, then passes backward in a groove on the under surface of the mastoid, and then ascends to the scalp. Its branches are: muscular; sterno-mastoid, to that muscle; meningeal, traversing the anterior condyloid and posterior lacerated foramina; mastoid, traversing the mastoid foramen; princeps cervicis, dividing in two branches, superficial and deep, which run over and under the Complexus; auricular, to the back of the ear; external and internal terminal, to the back of the scalp.

[807]

The posterior auricular arises posteriorly, just above the Digastric, and ascends behind the ear. Its branches are: muscular; parotid, to that gland; stylo-mastoid, ascending in the aqueduct of Fallopius to the tympanum; auricular, to the pinna and region behind; and mastoid, running along the insertion of the Sterno-mastoid.

[808]

The ascending pharyngeal arises internally and ascends on the pharyngeal wall. Its branches are: pharyngeal, to the pharynx; prevertebral, to that region; meningeal, traversing the anterior condyloid, posterior lacerate, or middle lacerate foramen; tympanic, accompanying Jacobson's nerve to the tympanum; and palatine, running above the Superior constrictor to the soft palate.

[808]

The superficial temporal ascends over the zygoma to the front of the ear and divides into two terminal branches, anterior and posterior, which diverge to the top of the head. Its other branches are parotid, to that gland; articular, to the temporo-mandibular joint; auricular, to the ear; transverse facial, crossing the Masseter below the zygoma but above the duct (Stenson's) of the parotid; middle temporal, crossing the zygoma and piercing the Temporal; and orbital, running forward above the zygoma, between the layers of temporal fascia, to the orbit.

[809]

The internal maxillary begins behind the neck of the lower 


\section{ANTERIOR ASPECT OF HEAD AND NECK.}

jaw and runs (first part) forward in the zygomatic fossa, between the jaw bone and spheno-mandibular ligament, to the lower border of the External pterygoid; then (second part) upward and forward, over or under the lower head of the External pterygoid; and then (third part) between the heads of the External pterygoid and through the pterygo-maxillary fissure into the spheno-maxillary fossa.

Branches of first part of internal maxillary: deep auricular, to the external auditory meatus; tympanic, through the Glaserian fissure to the tympanum. Middle meningeal, running between the roots of the auriculo-temporal nerve, through the foramen spinosum, and upward in a groove on the great wing of the sphenoid; it gives off petrosal, Gasserian, tympanic, and orbital branches, and divides into anterior and posterior terminal branches. Small meningeal, running through the foramen ovale. Inferior dental, accompanying the inferior dental nerve in the inferior dental canal and giving off the following branches: lingual, accompanying the lingual nerve; mylohyoid, accompanying the mylo-hyoid nerve; molar, to the molars; bicuspid, to the bicuspids; incisive (terminal), to the canine and incisors; and mental (terminal), running through the mental foramen to the ehin.

Branches of second part: masseteric, running through the sigmoid notch to the Masseter; anterior and posterior deep temporal, ascending under the Temporal; pterygoid, to those muscles; and buceal, accompanying the long buccal nerve to the eheek. Branches of third part: posterior superior dental, descending to the back of the upper jaw; infra-orbital, accompanying that nerve to the face; posterior or descending palatine, running through the posterior palatine canal and forward on the roof of the mouth; Vidian, through the Vidian eanal to the pharynx; pterygo-palatine, through the pterygopalatine canal to the pharynx; spheno-palatine, running through the spheno-palatine foramen to the nose and giving off a naso-palatine branch which descends with 


\section{DISSECTING MANUAL.}

the naso-palatine nerve, grooving the vomer, to the incisive foramen.

[812]

Internal Carotid.-Ascending under the parotid gland and finally getting under the external carotid, it runs through the carotid canal to the cranial cavity. Its further course and branches are described with the arteries of the cranial cavity (page 47).

[813]

Vertebral.-Arising from the upper and back part of the subclavian this ascends (first part) between the Scalenus anticus and Longus colli; then (second part) traverses the foramina in the upper six cervical transverse processes; and then (third part) curves backward in a groove on the upper surface of the posterior arch of the atlas and runs under the oblique ligament of the atlas into the spinal canal. Then (fourth part) piercing the spinal dura it ascends to the cranium, inclining inward to the front of the medulla and joining its fellow at the lower border of the pons to form the basilar. Its branches are: muscular; spinal, running through the intervertebral foramina to the anterior and posterior spinal arteries; anastomotic, to the princeps cervicis and profuncla cervicis; meningeal, to the posterior fossa; posterior spinal, descending through the foramen magnum, at the side of the medulla and cord, in front of the posterior nerve roots; anterior spinal, descending in front of the medulla and uniting with its fellow in front of the anterior fissure of the cord; and posterior inferior cerebellar, to the vallecula cerebelli. [818]

Thyroid Axis.-Arising from the subclavian internal to the Scalenus anticus, this ascends and soon divides into three branches, as follows:

The inferior thyroid ascends behind the carotid sheath to the thyroid body. Its branches are: muscular; ascending cervical, ascending between the Scalenus anticus and Rectus capitis anticus major; œsophageal, to the œesophagus; tracheal, to the trachea; inferior laryngeal, accompanying the inferior laryngeal nerve; ascending terminal, to the posterior and 


\section{ANTERIOR ASPECT OF HEAD AND NECK.}

lower part of the thyroid; and inferior terminal, to the lower and inner part of the thyroid.

[823]

The transverse cervical crosses over the Scalenus anticus to the anterior border of the Trapezius, giving off muscular branches. It then divides into the superficial cervical, which ascends upon the Splenius; and the posterior scapular, which descends along the posterior border of the scapula.

[823]

The suprascapular crosses the Scalenus anticus, subclavian artery, brachial plexus, and suprascapular ligament, accompanying the suprascapular nerve. Its branches are: muscular; medullary, to the clavicle; acromial, to that region; articular, to the shoulder and acromio-clavicular joints; subscapular, to the subscapular fossa; supraspinous, to the supraspinous fossa; suprasternal, to the sterno-clavicular joint; and terminal, through the great scapular notch under the spinoglenoid ligament to the infraspinous fossa.

[825]

Superior Intercostal.- The profunda cervicis arises at the upper border of the neck of the first rib and ascends between the Complexus and Semispinalis colli.

[826]

\section{VEINS.}

The vence comites usually have the same course and branches as their arteries. But the vertebral veins correspond only to the extracranial part of the artery, receive the anterior and posterior deep cervical, and end in the innominate; while the inferior thyroid veins drain the thyroid body and descend in front of the trachea to the innominate.

[875]

The internal jugular is a continuation of the lateral sinus. Beginning in the jugular foramen it descends in the carotid sheath external to the artery, and joins the subclavian behind the first costal cartilage, forming the innominate. Its tributaries are the inferior petrosal sinus and the pharyngeal, common facial, lingual, ranine, superior and middle thyroid, and occipital veins.

[875]

The facial begins as the angular vein at the inner angle of 


\section{DISSEC'TING MANUAL.}

the eye, accompanies its artery across the face and the angle of the jaw, and then joins the anterior division of the temporomaxillary, to form the common facial.

[876]

The external jugular begins, behind the angle of the lower jaw, by the union of the posterior auricular and posterior division of the temporo-maxillary. It descends over the Sternomastoid and third part of the subclavian artery to join the subclavian vein. Its tributaries are: posterior external jugular, draining the posterior triangle; transverse cervical; suprascapular; anterior jugular, draining the anterior triangle, descending from the chin over the Sterno-mastoid, and communicating with the common facial and the opposite anterior jugular by anastomotic branches.

[877]

The internal maxillary begins in a plexus (pterygoid) which lies in the pterygoid and zygomatic fossx and has branches corresponding to those of the artery. It accompanies the first part of the artery and joins the superficial temporal in the parotid gland, forming the temporo-maxillary. The latter descends over the external carotid to the lower part of the parotid gland and there divides into two divisions, viz.: posterior, joining the posterior auricular to form the external jugular; and anterior, joining the facial to form the common facial.

[880]

\section{LyMPHATICS.}

Glands.-Those of the head are the following: occipital, lying over the insertion of the Trapezius; mastoid, lying over the mastoid bone and insertion of the Sterno-mastoid; internal maxillary, lying on the Buccinator and pharyngeal wall along the internal maxillary artery; parotid, lying both superficially and deeply in the gland.

[909]

The facial glands are the following: mandibular, lying along the facial artery as it crosses the mandible; buccal, lying on the fascia covering the front part of the Buccinator; lingual, lying between the Genio-hyo-glossi and on the outer sur- 


\section{ANTERIOR ASPEC'T OF HEAD AND NECK.}

face of the Hyo-glossus and Genio-hyo-glossus; and latcral nasal, an inconstant gland in the angle between the cheek and ala of the nose. An infraorbital and a malar gland are described.

[910]

Those of the neck are as follows: superficial cervical, lying over and at the posterior border of the Sterno-mastoid, along the external jugular; submaxillary, around that gland; suprahyoid, lying on the Mylo-hyoid below the chin; post-pharyngeal, lying behind the pharynx, on the two upper vertebræ; prelaryngeal, lying in front of the larynx, between the Cricothyroids; pre-tracheal, lying on the front of the trachea; and deep cervical, lying along the internal jugular and extending outward along the subclavian vein in two groups, upper and lower, respectively above and below the bifurcation of the carotid artery.

[911]

\section{The Mouth and Pharynx.}

Mouth.-The aperture is bounded by the lips. The vestibule is the-space between the lips and cheeks externally, and the teeth and gums internally. The cavity lies within the dental arches and has a roof and floor; it opens behind into the pharynx, through the isthmus of the fauces.

[995]

Teeth.-There are eight in each half of either jaw, arranged from before backward as follows: Two incisors, central and lateral, with chisel-shaped crowns and single roots. One $c a$ nine, with a conical crown and a long, single root. Two premolars (bicuspids), first and second, with two cusps in the crowns; the roots are either single or partly divided. Three molars, first, second, and third, with from three to five cusps on the crowns; the lower ones have doubled roots, and the upper ones tripled roots.

[1014]

Tongue.-The body consists of a cortical portion, chiefly longitudinal fibres, surrounding a central (medullary) portion; the latter is divided into lateral halves by a median fibrous septum and is mainly formed by vertical and transverse fibres. 
The dorsum is divided into anterior (oral) and posterior (pharyngeal) parts by a V-shaped groove (sulcus terminalis) whose apex, directed backward, lies in a blind depression (foramen cæcum), and whose sides end at the anterior pillars. The anterior part is almost horizontal, forms about two-thirds of the length, and usually has a median depression over the raphe; the posterior part is nearly vertical and covered by lymphoid follicles. The apex and part of the margin lying in front of the anterior pillar are free. The inferior surface is smooth and presents a mesial depression from which a fold (frenulum) of mucosa passes to the floor of the mouth; at either side are two indistinct folds (plicx fimbriatæ). The base is connected to the mandible and hyoid bone. Filiform (conical) papilla, the smallest, cover the oral part of the dorsum and occur on the upper part of the margin and tip; posteriorly they form rows running outward and forward from the raphe. Fungiform papilloe occur chiefly on the tip and margins, slightly on the dorsum. Circumvallate papilla, the largest and fewest, form a V-shaped row in front of and parallel to the sulcus terminalis; each presents a central cylindrical part surrounded by a trench (fossa) whose outer wall is the vallum. [1000]

Palate.-The roof of the mouth consists of an anterior bony part (hard palate), and a posterior part formed of soft tissues (soft palate).

[998]

The soft palate is a movable fold running downward and backward and ending in a conical projection (uvula), which contains a prolongation of the Azygos uvulæ. It consists of two layers of mucous membrane enclosing the palatine muscles, vessels, nerves, connective tissue, and glands. At each side. of the uvula it has a sharp concave edge which descends as a fold (posterior palatine arch) of mucous membrane covering the Palato-pharyngeus; another fold (anterior palatine arch) descends, from just in front of the base of the uvula, over the Palato-glossus. The isthmus of the fauces is the aperture between the anterior palatine arches.

[998] 


\section{AN'TERIOR ASPECT OF HEAD AND NECK.}

Pharynx. - This expanded upper part of the alimentary canal lies behind and communicates with the nose, mouth, and larynx. It extends from the base of the skull to the sixth cervical vertebra, where, at its narrowest part, it opens into the œsophagus; it is widest above (lateral recesses). The soft palate divides it into the naso-pharynx above and the pharynx proper below. The latter is divided into the oral pharynx, lying behind the mouth and tongue; and the laryngeal pharynx, lying behind the larynx. Loose areolar tissue (retropharyngeal space) separates it from the prevertebral muscles and fascia.

[1029]

Naso-pharynx.-The posterior wall inclines upward and forward (vault of the pharynx) to the anterior wall and presents on its upper part, especially in early life, a mass of lymphoid tissue (pharyngeal tonsil). On each lateral wall, one-third to one-half an inch behind the posterior end of the inferior turbinated bone, and just above the level of the hard palate, is the orifice of the Eustachian tube. This is bounded above and behind by a ridge (Eustachian cushion), caused by the projection of the cartilage. Just behind this is a vertical slit-like depression leading into a pouch (lateral recess, or fossa of Rosenmüller) which extends outward over the Superior constrictor.

[1032]

Oral Pharynx.-On each lateral wall the triangular interval between the palatine arches and tongue is filled by the tonsil, except at the upper (supratonsillar fossa) part. The orifice (pharyngeal isthmus) between the oral pharynx and nasopharynx is oblique and triangular. The tonsil is an oval mass of lymphoid tissue lying just above and in front of the angle of the lower jaw. Laryngeal pharynx. A deep depression (sinus pyriformis) lies on the anterior wall on each side of the laryngeal orifice, between the aryteno-epiglottic fold and ala of the thyroid cartilage.

$[1034,1036]$

Esophagus.-This muscular tube leads from the pharynx to the stomach. It descends on the Longus colli and spine, 
lying at first in the midline and then diverging slightly at the lower part of the neck.

[1038]

\section{The Salivary Glands.}

Parotid.-This is a three-sided mass, with anterior, posterior and superficial surfaces; it lies in the parotid recess, below and in front of the ear, and is encapsulated by the parotid fascia (deep cervical fascia). It extends from the zygoma to the angle of the jaw, or lower; and from the Sterno-mastoid to the ramus of the jaw. A variably developed facial process extends from it anteriorly over the Masseter; a part (socia parotidis) of this process, just above the duct, may be separate. The temporo-maxillary vein, facial nerve, and external carotid artery pass through it. The duct (Stenson's) runs from the most anterior part of the process across the Masseter and around its anterior border; then passing inward, through the Buccinator, it opens into the mouth at a papilla opposite the crown of the second upper molar.

[1009]

Submaxillary.-This is a three-sided mass, with external, internal, and superficial (inferior) surfaces. It lies on the Mylo-hyoid, Hyo-glossus, Digastric and Stylo-hyoid, just in front of the parotid, partly in the submaxillary triangle, and partly under cover of the mandible. A layer of deep cervical fascia encapsulates it. A narrow deep process extends, from its internal surface, under the Mylo-hyoid. The duct (Wharton's) runs, from the middle of the internal surface, forward under the Mylo-hyoid and along the upper and inner aspect of the deep process; then running under the floor of the mouth, on the inner side of the sublingual gland and across the Hyoglossus and Genio-glossus, it opens into the mouth at a papilla lying alongside of the frenulum linguæ and close to the papilla of the opposite duct.

[1011]

Sublingual.-This is a small almond-shaped mass lying under the floor of the mouth, on the Mylo-hyoid, between the mandible and Genio-glossus. Its ducts (Rivinus') leave its 


\section{ANTERIOR ASPECT OF HEAD AND NECK.}

upper border and open on a series of papillæ found along the summit of the plica sublingualis, a ridge produced in the mucous membrane by the upper border of the gland.

[1012]

\section{The LARYNX.}

This lies in the midline, in front of the pharynx and opposite the fourth, fifth, and sixth cervical vertebræ.

Cartilages.-There are three single ones and three pairs as follows:

The thyroid cartilage is single and formed by two diverging, quadrilateral plates. The anterior borders are separate above (thyroid notch) but fused below in an angle whose upper.part, in males, projects (pomum Adami). The posterior border of each plate is prolonged, above and below, in cylindrical processes (cornua); the superior cornu, the longer and thinner, bends slightly inward and backward; the inferior cornu curves slightly inward and has, on the inner side of its end, a facet for the cricoid. The superior border is slightly convex, joins the thyroid notch in front, and ends behind in a slight notch: A projection (inferior tubercle) divides the inferior border into a short and concave posterior part, and a longer and concave anterior part. The inner surface is smooth. On the external surface a ridge (oblique line) runs from the inferior tubercle to a prominence (superior tubercle) just below the superior border, in front of the root of the superior cornu.

[957]

The cricoid cartilage is a single ring formed behind by a thick plate (posterior lamina) and completed elsewhere by a curved band (anterior arch) which is thinnest in front; the aperture is circular below but elliptical above. The inner surface is smooth; the inferior border is nearly horizontal but may have a projection in front and at each side. The posterior lamina presents on its upper border a mesial notch between two facets, for the arytenoids, and on its posterior surface a median ridge between two depressed areas; at its junction with the arch a vertical ridge descends from the arytenoid 
facet, and presents below a facet for the inferior cornu of the thyroid.

[959]

The arytenoid cartilages are two pyramidal structures; one lies on each side, on the upper border of the posterior lamina of the cricoid. Each has an apex, base, and three surfaces separated by three borders (anterior, posterior, and external). The apex curves upward, backward, and inward; the base presents a facet for the cricoid. The internal surface is narrow, vertical, and covered by mucosa; the posterior surface is concave. The antero-external surface presents a deep depression centrally, and a small tubercle, for the superior thyro-arytenoid ligament, just above the base. At the base the external border is prolonged outward and backward (muscular process), and the anterior border forward (vocal process). [960]

The cartilages of Santorini (cornicula laryngis) are two conical nodules; one lies on the apex of each arytenoid, in the aryteno-epiglottidean fold. The cuneiform cartilages are two minute rods; one lies in each aryteno-epiglottidean fold in front of the preceding. The epiglottidean cartilage is a single thin and raquet-shaped lamina which supports the epiglottis and presents many pits and perforations. Its broad upper end is free; its margins lie mostly in the aryteno-epiglottidean folds; its lower end is pointed.

[961]

Joints, Ligaments, and Membranes.-The crico-thyroid and crico-arytenoid joints are diarthrodial, with synovial membranes, capsules, and posterior strengthening bands. The joint between the arytenoid and cartilage of Santorini is either diarthrodial or amphiarthrodial. A delicate Y-shaped ligament (jugale) usually runs from the tips of the cartilages of Santorini to the upper border of the posterior lamina of the cricoid. [961]

The thyro-hyoid membrane connects the hyoid bone with the thyroid cartilage. The central part (ligamentum thyrohyoideum medium) is thick and runs from the margins of the thyroid notch to the upper margin of the body of the hyoid, from which it is separated by a bursa. The lateral parts are 


\section{ANTERIOR ASPECT OF HEAD AND NECK.}

thin and run from the upper borders of the thyroid to the back of each great cornu of the hyoid. Each lateral margin is thick (ligamentum thyro-hyoideum laterale) and runs from the tip of the superior cornu of the thyroid to the tip of the great cornu of the hyoid, often enclosing a nodule (eartilago triticea).

[962]

The crico-thyroid membrane consists of a central and two lateral parts, which are continuous. The central part is triangular, its apex attached to the centre of the lower border of the thyroid, and its base to the upper border of the anterior arch of the cricoid. Each lateral part, sloping upward and inward, is continuous above with the inferior thyro-arytenoid ligament; it is attached below to the upper border of the cricoid, behind to the lower border of the vocal process of the arytenoid, and in front to the inner part of the ala of the thyroid, close to the angle.

[962]

Thyro-arytenoid Ligaments.-The inferior are the upper margins of the lateral parts of the crico-thyroid membrane; each runs from the tip and upper border of the arytenoid vocal process to the middle of the angle between the thyroid alx, close to its fellow. The superior run from the thyroid, just above the preceding, to the tubercle on the antero-external surface of each arytenoid.

[963]

Epiglottidean Ligaments.-The glosso-epiglottidean, middle and lateral, are three mucous folds running from the centre and each margin of the epiglottis to the base of the tongue, and to the sides of its base and the pharyngeal wall, respectively; between them are two fossæ (valleculæ). The hyoepiglottidean is a broad band running from the anterior surface of the epiglottis to the upper border of the hyoid. The thyro-epiglottidean runs from the lower end of the epiglottis to the angle between the thyroid alæ, below the notch. [963]

Interior of Larynx. - The true and false vocal cords divide it into three divisions. Its superior aperture is triangular with its apex between the arytenoids; the epiglottis forms its base; 
each side is a mucous fold (aryteno-epiglottidean) stretching from the epiglottis to the arytenoid and presenting posteriorly two elevations, the cuneiform tubercle and tubercle of Santorini, caused by those cartilages. The upper subdivision (vestibule) extends from the superior aperture to the false cords, narrowing rapidly. The thyro-epiglottidean ligament bulges (cushion, or tubercle of the epiglottis) into its anterior wall, low down. At each side, posteriorly, the cuneiform cartilage makes a vertical ridge which ends in the false cord; and behind this the anterior margin of the arytenoid and the cartilage of Santorini make another ridge which ends in the true cord.

[964]

The middle subdivision extends from the false to the true cords. The false vocal cords are two soft mucous folds which enclose the superior thyro-arytenoid ligaments and contain some muscle fibres; they run from the angle between the thyroid ala to the back of each lateral wall; the aperture between them is the false glottis. The true vocal cords are two prominent and whitish mucous folds enclosing the inferior thyro-arytenoid ligaments; they run from the angle between the thyroid alæ to the arytenoid vocal processes. The true glottis (rima glottidis) consists of the aperture between the true cords (glottis vocalis) together with that between the bases and vocal processes of the arytenoids (glottis respiratoria). Each side wall, between the true and false cord, is a recess (laryngeal sinus) which somewhat undermines the false cord; at its forepart a narrow aperture leads into a diverticulum (laryngeal saccule) which ascends under the false cord and onto the thyroid cartilage, usually to the upper border. The lower subdivision lies below the true cords; it widens out, becomes circular, and opens into the trachea.

[965]

\section{Intrinsic Laryngeal Muscles.}

Crico-thyroid.-Origin; lower border and outer surface of anterior arch of cricoid. Insertion; (anterior, or oblique part) 


\section{ANTERIOR ASPECT OF HEAD AND NECK.}

inner surface and lower margin of thyroid; (posterior, or horizontal part) anterior aspect of inferior cornu of thyroid cartilage.

[968]

Posterior Crico-arytenoid.-Origin; depression on posterior lamina of cricoid beside the mesial ridge. Insertion; posterior surface of muscular process of arytenoid.

[969]

Lateral Crico-arytenoid.-Origin; upper border of lateral part of anterior arch of cricoid, in front of the arytenoid facet; lateral part of crico-thyroid membrane. Insertion; anterior surface of muscular process of arytenoid.

[969]

Thyro-arytenoideus Externus.-Origin; lower half of inner surface of thyroid ala; lateral part of crico-thyroid membrane. Insertion; outer border and muscular process of arytenoid; Arytenoideus transversus. Some of the uppermost fibres curve upward (Thyro-epiglottideus) to the aryteno-epiglottidean fold and margin of the epiglottis.

[969]

Thyro-arytenoideus Internus.-This lies under and is more or less united with the preceding; it is prismatic and lies on the outer side of the true vocal cord. Origin; angle between thyroid alæ. Insertion; outer aspect of vocal process and depressed part of antero-external surface of arytenoid; outer side of true vocal cord (as the Ary-vocalis).

[970]

Arytenoideus Obliquus.-Origin; posterior aspect of muscular process of arytenoid. Course; across the opposite muscle. Insertion; summit of opposite arytenoid; aryteno-epiglottidean fold (as the Aryteno-epiglottideus).

[970]

Arytenoideus Transversus.-This unpaired muscle lies under the preceding. It consists of transverse fibres connecting the arytenoids behind, attached to the posterior aspect of the outer border of each and, in part, continuous with the Thyroarytenoideus externus.

[970]

Trachea.-This fibro-muscular tube is kept open by a series of cartilaginous rings, which are deficient posteriorly and are embedded in its walls. It begins opposite the lower border of the sixth cervical vertebra and descends in the median line to 


\section{DISSECTING MANUAL.}

the thorax. The cervical part is from two to two and a half inches long, lies on the œsophagus and is clasped by the thyroid body.

Thyroid Body.-This vascular structure consists of two lateral lobes connected by an isthmus; it clasps the upper part of the trachea anteriorly and extends upward on each side of the larynx, being firmly attached. Lateral lobe: Each is conical, with its base at the fifth or sixth tracheal ring, and its apex upon the thyroid ala. The superficial surface is flattened, the decp surface conforms to subjacent structures, and the posterior border overlaps the common carotid. Isthmus: This is a narrow band connecting the bases, crossing the second, third, and fourth tracheal rings. Middle (pyramidal) lobe : This is an inconstant narrow process from the upper borler of the isthmus, at one side, extending upward on the larynx and connected with the hyoid by a fibrous, or muscular, strand (Levator glandulæ thyroidex). Structure: It has a thin capsule from which septa project inward and branch, dividing it into numerous alveoli which are lined by epithelial cells and mostly filled with colloid matter.

[1216]

Parathyroid Glands.-These are two minute bodies on each side, separated by the inferior thyroid artery. One, the more constant, lies on the back of the œsophagus at the level of the lower border of the cricoid cartilage and close to the posterior border of the lateral lobe of the thyroid body. The second lies either close to the lower border of the lateral lobe of the thyroid body, or on the trachea below it. They consist of epithelial cells and closely resemble the anterior lobe of the pituitary body.

[1218]

\section{The Nasal Fosse.}

Each extends from the anterior to the postcrior nares. Just above the anterior nares is an expansion (vestibule) which is prolonged (ventricle) toward the tip: the vestibule is divided by a ridge, and is limited above and behind by another ridge 


\section{AN'TERIOR ASPECT OF HEAD AND NECK.}

(limen nasi). The inner wall (septum) is both bony and cartilaginous and often deflected. On it, just above and in front of a depression (recessus nasopalatinus) on the floor, over the incisive foramen, is an orifice whence a blind pouch (organ of Jacobson) runs upward and backward.

[719]

Outer Wall.-The sphenoidal sinus opens into a recess (spheno-ethmoidal) above the superior turbinated bone. The superior meatus is under cover of the superior turbinated bone; the posterior ethmoidal cells open into it in front. The middle meatus, lying under and external to the middle turbinated bone, presents an elevation (bulla ethmoidalis) into, or above, which the middle ethmoidal cells open; below and in front of the bulla is a deep groove (hiatus semilunaris) into which the anterior ethmoidal cells and antrum of Highmore open. The middle meatus is continuous antero-superiorly with the infundibulum, and anteriorly with a depressed area (atrium) lying just above the vestibule and limited above and in front by a ridge (agger nasi). The inferior meatus lies below the inferior turbinated bone and presents anteriorly the orifice of the nasal duct.

The olfactory nerves lie at first in grooves on the inner and outer walls of the olfactory area, the region of the superior turbinated bone and the corresponding part of the septum; they then pass in the mucosa to the olfactory cells.

[723]

The External Ear.

Pinna, or Auricle.-Outer surface: Near its centre is a depression (concha); a ridge (crus helicis) divides this into upper (cymba conchx) and lower (cavum conchæ) parts; the latter opens into the meatus. Anteriorly the crus helicis is continuous with the margin (helix) of the pinna, which is folded over, curves over the top of the pinna, and is lost just below its middle behind. Posteriorly a ridge (antihelix) ascends in front of the helix, a furrow (scapha) separating them, and bi- 
furcates (crura antihelicis) above to enclose a depression (fossa triangularis). A process (tragus) overlaps the cavum conchæ in front; another (antitragus) overlaps it behind; a notch (incisura intertragica) separates these processes; below the notch is the lobule. Inner surface: This presents elevations corresponding to the depressions on the outer surface, e.g., eminentia conchæ, etc.

Structure-A lamella of cartilage (cartilago auriculæ) supports the greater part, except the lobule which consists of adipose tissue; a narrow istlmmus connects the cartilage inferiorly with that of the meatus. The cartilage of the helix ends in front and below in processes, the spina helicis and cauda helicis respectively. Ligaments: The anterior runs from the zygoma to the tragus and spina helicis; the posterior runs from the mastoid process to the eminentia conchæ and upper wall of the meatus; the intrinsic ligaments are small bands connecting individual parts.

[745]

Intrinsic Muscles.—Outer surface: Helicis major, ascending along the helix from the spina helicis. Helicis minor, covering the crus helicis. Tragicus, ascending over the tragus. Antitragicus, ascending over the antitragus to the antihelix and cauda helicis. Cranial surface: Transversus auriculæ, running from the eminentia conchre to the convexity of the helix. Obliquus auriculæ, crossing the furrow which corresponds to the crus antihelicis inferior.

[746]

External Auditory Meatus. - This is a canal, about an inch long, which extends from the bottom of the concha to the ear drum; it is formed externally by fibro-cartilage and internally by bone. It is S-shaped, narrowest (isthmus) near the drum, and divided into the pars externa, which inclines inward, forward, and slightly upward; the pars media, the shortest, which inclines inward and backward; and the pars interna, the longest, which inclines inward, forward, and slightly downward. Its inner end is almost circular, and is closed by the ear drum.

[746] 


\section{The Middle Ear.}

Tympanic Cavity:- This is a small chamber in the temporal bone, between the external auditory meatus and the internal ear. It consists of the tympanum proper (atrium), lying next the ear drum; and of the recessus epitympanicus, lying above the ear drum. Its roof is a thin bony plate (tegmen tympani), which separates it from the cranial cavity and is prolonged over the mastoid antrum and canal for the Tensor tympani, as their roof. Its floor is a narrower and thin bony plate which separates it from the jugular fossa. The orifice for Jacobson's nerve lies near the junction of the floor and inner wall.

[748]

The posterior wall presents, from above downward, the following structures: The opening from the epitympanic recess into the mastoid antrum. A depression (fossa incudis), for the short process of the incus, at the lower and back part of the epitympanic recess. A conical process (pyramid), which is pierced at its summit by the canal for the Stapedius; this canal descends in front of the aqueductus Fallopii and opens in front of the stylo-mastoid foramen. The apertura tympanica canaliculi chordx, a small orifice just internal to the upper part of the posterior edge of the drum. The prominentia styloidea, an inconstant rounded eminence just below the latter, and produced by the styloid process.

The anterior wall is narrow and presents two canals, the upper for the Tensor tympani, and the lower forming the bony part of the Eustachian tube; a bony lamella (processus cochleariformis) separates them. The outer wall is chiefly formed by the membrana tympani, which is attached in a groove (sulcus tympanicus) contained in a bony ring; the ring is deficient above (notch of Rivinus). In front of this ring, superiorly, is the Glaserian fissure; near the inner end of this fissure is the canal of Huguier (iter chordæ anterius). The membrana tympani is elliptical, thickened at its edges, and formed of 


\section{DISSECTING MANUAL.}

fibrous tissue covered by skin and mucous membrane. It is concave externally, with the apex (umbo) of the concavity over the tip of the handle of the malleus. Two prolongations (anterior and posterior malleolar folds) of the membrane pass, at the extremities of the notch of Rivinus, to the short process of the malleus. The triangular part of the membrane above these folds is lax (pars flaccida), but the rest is tense (pars tensa).

[750]

The inner wall presents the following structures: An eminence (promontory) over the cochlea is grooved for the tympanic plexus. Above and behind this a funnel-shaped recess (fossula fenestræ vestibuli) leads into the vestibule through an oval opening (fenestra ovalis), which is occupied by the foot of the stapes. Above this is a prolongation of the processus cochleariformis, and also a ridge (prominentia canalis facialis) produced by the Fallopian aqueduct. Below and behind the promontory is a funnel-shaped recess (fossula fenestræ cochleæ), which leads into the cochlea through an opening (fenestra rotunda) closed by the membrana tympani secundaria. Between the fenestra ovalis and fossula rotunda is a small circular depression (sinus tympani) lying over the ampulla of the posterior semicircular canal.

[752]

Mastoid Antrum and Air Cells.-The antrum is a cavity in the temporal bone lying bchind the tympanum and roofed in by the tegmen tympani. The air cells vary in number and size; they open into the antrum and are found not only below and behind it, in the mastoid process, but also internal to and above it.

Eustachian Tube.-This canal runs downward and inward from the tympanum to the upper part of the naso-pharynx. It is formed by bone (pars ossea) externally and by fibro-cartilage (pars cartilaginea) antero-internally, being narrowest (isthmus) at their junction. The pars ossea is half an inch long and lies in the petro-squamous angle of the temporal. The pars cartilaginea is about an inch long and inclines a little more 


\section{ANTERIOR ASPECT OF HFAD AND NECK.}

downward; its inner wall presents a triangular plate of cartilage which is attached at the apex to the pars ossea, while the base projects into the naso-pharynx. The upper edge of the plate bends outward over the tube, which is completed externally and below by a fibrous layer (lamina membranacea) attached to the edges of the plate. The plate is attached to the skull in the groove between the petrous bone and great wing of the sphenoid.

[753]

Tympanic 0ssicles.-These form an articulated column between the outer and inner walls of the tympanum. Malleus: The head is elliptical, and convex above and in front; it presents posteriorly a facet, for the incus, which is divided by a ridge into upper and lower parts. Below the prominent lower edge (spur) of the facet, posteriorly, is an oblique crest (crista). The neck, just below the head, is flattened antero-posteriorly, and constricted. The handle runs downward, backward, and inward from the neck and is attached throughout to the membrana tympani. It is flattened antero-posteriorly above, but twisted below so that the surfaces look outward and inward. Near its upper end, internally, is a projection for the Tensor tympani tendon; the lower end is curved with the concavity in front. The short process is attached to the membrana tympani, and runs outward from the upper end of the handle. The long process runs forward from the neck toward the Glaserian fissure.

[754]

Incus.-This resembles a bicuspid tooth. The body has a saddle-shaped facet, directed forward, for the head of the malleus. The short process is thick and triangular; it projects horizontally backward, its conical tip articulating with the fossa incudis. The long process projects straight downward, behind and internal to the handle of the malleus. Its lower end bends inward and presents a short neck with a small knob (processus lenticularis) at the tip internally, for articulation with the head of the stapes.

[756]

Stapes.-The head has a concave facet externally for the 


\section{DISSECTING MANUAL.}

processus lenticularis. The neck, internal to the head, is constricted; it receives the Stapedius tendon posteriorly. The two crura spring from the neck, diverge, and are attached near the ends of the footplate. The footplate is oval, or reniform in shape.

[756]

Ligaments of the 0ssicles.-Malleus: The anterior is in two parts; one runs from the base of the long process, through the Glaserian fissure, to the spine of the sphenoid; the other runs from above the long process to the anterior end of the notch of Rivinus. The superior ascends from the head to the roof of the epitympanic recess. The external runs from the crista to the posterior half of the notch of Rivinus. Incus: The posterior fastens the tip of the short process in the fossa incuidis. Stapes: The annular runs from the edge of the footplate to the edge of the fenestra ovalis.

[757]

\section{Intrinsic Muscles of the Tympanum.}

Tensor Tympani.-Origin; roof of cartilaginous part of Eustachian tube; adjacent part of great wing of sphenoid; walls of its bony canal. Insertion; inner surface and anterior edge of handle of malleus, near its upper end, by a tendon which bends at right angles around the posterior extremity of the processus cochleariformis.

[757]

Stapedius.-Origin; inner surface of pyramid and canal prolonging it downward. Insertion; posterior surface of neck of stapes.

[757]

\section{The Internal Ear.}

Osseous Labyrinth.--This series of intercommunicating cavities in the petrous bone consists, from before backward, of the cochlea, vestibule, and semicircular canals.

[759]

The vestibule is an ovoid cavity behind the cochlea; its outer wall presents the fenestra ovalis. Its inner wall corresponds with the bottom of the internal auditory meatus and presents the following structures: A depression (recessus 


\section{ANTERIOR ASPECT OF HEAD AND NECK.}

sphæricus) for the saccule lies antero-inferiorly and contains many foramina (macula cribrosa media) for the auditory nerve. Above and behind this is an oblique ridge (crista vestibuli) which ends anteriorly in a prominence (pyramid), but divides behind to enclose a depression (recessus cochlearis). A depression (recessus ellipticus) for the utricle lies above and behind the crista, extending onto the roof and containing many foramina (macula cribrosa superior). Below and behind this is the orifice of a canal, the aqueductus vestibuli. Posteriorly it presents the five orifices of the semicircular canals; and anteriorly an elliptical opening into the scala vestibuli of the cochlea. Its floor presents anteriorly a narrow cleft (fissura vestibuli); this leads into the cochlea between a thin bony lamella (lamina spiralis ossea) arising just external to the recessus sphæricus, and another lamella (lamina spiralis secunclaria) projecting from the outer wall of the cochlea.

[759]

The semicircular canals are three in number; each forms two-thirds of a circle and has one end dilated (ampulla). The superior is vertical and transverse to the long axis of the petrous bone. Its ampulla opens into the vestibule high up; its other end joins that of the posterior eanal, forming the crus commune which opens into the upper and inner part of the vestibule. The posterior is vertical and at right angles to the superior. Its ampulla opens into the lower and back part of the vestibule; its upper end joins the crus commune. The external is almost horizontal; its ampulla opens into the vestibule just above the fenestra ovalis.

[760]

The cochlea is conical, with its base over the bottom (area (cochlex) of the internal auditory meatus, and its apex (cupola) directed forward and outward. It consists of a canal making about two and a half coils around a conical central pillar (modiolus) whose apex does not quite reach the cupola; in the modiolus are canals for nerves. A thin bony shelf (lamina spiralis ossea) winds around the modiolus and projects about half-way into the cochlear tube; it incompletely divides the 
tube into upper and lower passages, respectively the scala vestibuli and scala tympani. The division is completed by a membrane (membrana basilaris) which stretches from the edge of the lamina to the outer wall of the tube. This shelf begins in the vestibule near the foramen rotundum, and ends near the apex in a sickle-shaped process (hamulus) which helps form an aperture (helicotrema) connecting the scalæ. The scala vestibuli begins in the vestibule. The scala tympani begins at the fenestra rotunda, toward which a crest (crista semilunaris) stretches from the attached margin of the lamina spiralis; the aqueductus cochlex opens into the scala tympani near the crest.

[760]

Internal Auditory Meatus.-This canal runs in the petrous bone, from the cranial cavity, toward the internal ear; a transverse ridge (crista transversa) divides its bottom (fundus) into upper and lower parts, the fossulæ superior and inferior respectively. Fossula superior: the anterior part (area facialis) presents the orifice of the aqueductus Fallopii; the posterior part (area vestibularis superior) presents foramina for the nerves of the utricle and the ampullæ of the superior and external semicircular canals. Fossula inferior: the anterior part (area cochlex) presents the orifice of the canalis centralis, surrounded by foramina (tractus spiralis foraminosus) for the nerves of the cochlea; behind this, and separated by a ridge, is a group of foramina (area vestibularis inferior) for the nerves to the saccule; the posterior part presents the foramen singulare for the nerves to the ampulla of the posterior semicircular canal.

[761]

Membranous Labyrinth.-This structure has somewhat the shape of the bony labyrinth and lies in it, filled with endolymph and surrounded by perilymph. The semicircular and cochlear canals lie throughout on the inner aspect of the outer walls of their bony tubes. The bony vestibule contains two communicating sacs, the utricle and saccule. The utricle is the larger, lies postero-superiorly, and receives the semicircular 


\section{POSTERIOR ASPEC'T OF NECK.}

canals. From its inner part a small canal (ductus utriculosaccularis) leads to and joins a similar canal (ductus endolymphaticus) coming from the saccule and traversing the aqueductus vestibuli. The saccule is oval and lies anteroinferiorly. A small canal (ductus reunicns) from its lower part joins the cochlear canal (ductus cochlearis) near the end of the latter. The ductus cochlearis is triangular; it is formed by the basilar membrane and another membrane (of Reissner), which passes from the upper surface of the lamina spiralis to the outer wall of the cochlea, somewhat above the attachment of the basilar membrane. It contains the organ of Corti, which lies on the basilar membrane.

[762]

\section{POSTERIOR ASPECT OF NECK.}

Fascia.-The superficial fascia is usually thick and fatty. The deep fascia is attached to the ligamentum nuchæ and superior curved line of the occipital; it is continuous with the cervical fascia and invests the muscles.

[318]

\section{Superficial Muscles.}

Trapezius.-Origin; inner third of superior curved line of occipital; external occipital protuberance; ligamentum nuchx; spines of seventh cervical and all the thoracic vertebræ and corresponding supraspinous ligaments (by tendinous fibres from the occipital bone, lower part of the neck, and lower thoracic vertebræ; elsewhere by fleshy fibres). Insertion; outer third of posterior surface of clavicle; inner side of acromion process and whole upper border of spine of scapula; tubercle at base of spine of scapula, by a flat tendon with a bursa under it.

[318]

Levator Anguli Scapulæ.-Origin; posterior tubercles of transverse processes of upper three or four cervical vertebræ. Insertion; upper fourth of vertebral border of scapula, from superior angle to spine.

[319] 


\section{Deep Muscles.}

First Group.

Splenius.-Origin; ligamentum nuchæ below fourth cervical vertebra; spines of last cervical and upper four to six thoracic vertebrex. Course; separates in two parts. Splenius capitis (upper part): Insertion; mastoid process; cuter part of superior curved line of occipital. Splenius colli (lower part): Insertion; posterior tubercles of the upper three or four cervical transverse processes.

[392]

Second Group.

Cervicalis Ascendens (prolongs the Accessorius).-Origin; six upper ribs, by six slips. Insertion; posterior tubercles of transverse processes of fourth to sixth cervical vertebræ, behind the Scalenus posticus.

[393]

Transversalis Cervicis (prolongs the Longissinus dorsi).Origin; transverse processes of upper six thoracic vertebræ. Insertion; posterior tubercles of second to sixth cervical transverse processes.

[394]

Trachelo-mastoid (prolongs the Longissimus dorsi).-Origin; transverse processes of upper six thoracic vertebræ; articular processes of lower four cervical vertebræ. Insertion; mastoid process.

[395]

Complexus.-Origin; transverse processes of upper six thoracic and lower four cervical vertebræ; spine of last cervical vertebra. Insertion; occipital, between superior and inferior curved lines. The inner part is separate, as the Biventer cervicis, with two bellies and an intervening tendon.

[395]

\section{Third Group.}

Semispinalis Colli.-Origin; transverse processes of upper six thoracic vertebre; articular processes of lower four cervical vertebrx. Insertion; spines of second to fifth cervical vertebræ. 


\section{POS'TERIOR ASPECT OF NECK.}

Multifidus Spinæ (cervical part).-Origin; articular processes of lower four cervical vertebræ. Insertion; cervical spines, from the axis downward.

[395]

Fourth Group.

Obliquus Inferior.-Origin; spine of axis. Insertion; transverse process of atlas.

[397]

Obliquus Superior--Origin; transverse process of atlas. Insertion; occipital, above the inferior curved line and external to the Complexus.

[397]

Rectus Capitis Posticus Major.-Origin; spine of axis. Insertion; occipital, below the inferior curved line.

[397]

Rectus Capitis Posticus Minor-Origin; spine of atlas. Insertion; occipital, below the inferior curved line and the preceding.

[397]

The four preceding muscles enclose the suboccipital triangle.

Rectus Capitis Lateralis.-Origin; transverse processes of atlas. Insertion; jugular process of occipital:

[398]

Inter-spinales.-Bands connecting the spines.

Inter-transversales.-Slender double slips between the transverse processes.

[398]

\section{NeRves.}

First Cervical (Suboccipital).- The posterior primary division runs backward above the arch of the atlas to the suboccipital triangle; it there divides into muscular branches to the Complexus, Recti capitis postici, major and minor, and Obliqui, superior and inferior. It communicates with the second cervical.

[611]

Second Cervical.-The posterior primary division runs backward between the atlas and axis, below the Inferior oblique, and communicates with the third cervical; then piercing the Complexus and Trapezius it accompranies the occipital artery, as the great occipital nerve, to the scalp, piercing the deep fascia about an inch to the sicle of the occipital 


\section{DISSECTING MANUAI.}

protuberance, and supplying the skin of the scalp as far as the vertex. It supplies the Complexus, Inferior oblique, Semispinalis colli, and Multifidus spinæ; and communicates, on the scalp, with the great and the posterior auricular, and the small and the least occipital.

[612]

The posterior cervical plexus consists of communicating loops between the suboccipital and branches of the second, third, and (occasionally) fourth nerves. Branches of these loops supply the surrounding muscles.

[612]

Third Cervical.- The posterior primary division is smaller and communicates early with the second and, sometimes, the fourth cervical. It then divides into two branches: the external muscular branch supplies the contiguous muscles; the internal cutaneous branch runs backward and inward, becomes superficial near the midline as the third or least occipital nerve, and supplies the neck and scalp, communicating with the great occipital.

[612]

Fourth, Fifth, and Sixth Cervical.-The posterior primary divisions are still smaller. They divide under the Complexus into external muscular branches to neighboring muscles, and internal cutaneous branches to the back of the neck near the midline.

[613]

Seventh and Eighth Cervical.-Theposter ior primary divisions are the smallest and usually have only muscular branches, to the deep muscles of the neck.

[613]

\section{VEssels.}

The arteries are twigs of the vertebral, which enters the suboccipital triangle, and the other arteries of the front of the neck.

The veins are the venæ comites of the arteries. 


\section{THORAX.}

\section{BONES.}

Thoracic or Dorsal Vertebræ.-There are twelve, distinguished by having facets for the ribs. The body is heartshaped, slightly thicker behind than in front, and of nearly equal length and breadth; from the second to the ninth inclusive each has four costal demi-facets, an upper pair on the upper margin near the junction of the pedicle, and a lower pair on the lower margin just in front of the invertebral groove. The pedicles are short, thick, and directed backward and slightly upward; the superior notch is shallow and the inferior deep. The lamina are broad and flat with sharp margins; the upper overlap the lower. The spinal foramen is small and nearly circular. The spines incline downward, overlap, and end in tubercles; they are triangular at the base but compressed laterally elsewhere; the middle ones are the longest and most oblique. The transverse processes run backward, outward, and slightly upward; they end in an enlargement on whose front is a circular facet for the tubercle of the rib; they decrease in size from above downward. The superior articular processes are vertical with their facets directed backward and slightly upward and outward; the inferior have their facets directed forward and slightly downward and inward.

[80]

Peculiar Vertebrce.-The first has a whole facet on the side of its body, for the first rib; and a demi-facet on its lower edge, for the second rib; the supcrior articular surfaces look backward and upward; the body and spine resemble those of the seventh cervical. The ninth may have only the upper demifacets. The tenth may have either a single whole facet on its 


\section{DISSECTING MANUAL.}

body, or demi-facet on its upper edge, for the tenth rib; the facet on its transverse process is small, or absent. The eleventh has a single whole facet, for the eleventh rib, on the outer side of the pedicle; the transverse processes are short and without facets. The twelfth has a single costal facet on the pedicle; the transverse process has no facet and ends in three tubercles, external, superior, and inferior; the inferior articular processes look outward (those of the eleventh may do so).

[81]

Sternum.-The breastbone is flattened; it is broadest above, narrows opposite the second costal cartilage, then expands down to the fifth costal cartilage, and then tapers rapidly. It consists of three parts, viz.: Manubrium (upper part). This is triangular and usually separate. The anterior surface is saddle-shaped; the posterior is smoother and concave. The thick upper border presents a slight mesial notch (incisura jugularis) between lateral hollowings for the clavicular facets. Each lateral border presents, just below the clavicular facet, an excavation for the first costal cartilage; and below this a sharp border which slopes inward and has, at its lower end, a demi-facet for the second costal cartilage. The lower end is flat and joins the gladiolus.

[94]

Body or Gladiolus (mildle part).- The anterior surface is slightly convex vertically and concave transversely; it has three faint transverse ridges indicating the fusion of four primitive segments. The posterior surface is slightly concave vertically and has similar transverse lines. The upper border joins the manubrium (sternal angle) and has at each end an excavated demi-facet for the second costal cartilage. The lower border is curved, joins the xiphoid cartilage mesially, and on each side is pitted for the sixth and part of the seventh costal cartilages. The thick lateral borders have, at the ends of the transverse lines, U-shaped hollows, with projecting edges, for the third, fourth, and fifth costal cartilages. [95]

Ensiform or Xiphi-Sternum (lower part). - This is cartilaginous, has a bony core, and is pointerl, of varied shape, and 


\section{BONES.}

often piered in the centre; it partly supports the seventh costal cartilage.

[96]

Ribs.-There are twelve pairs. The costal cartilages of the upper seven (true ribs) join the sternum; those of the lower five (false ribs) do not. Of the latter, the eighth, ninth, and tenth costal cartilages join the cartilage of the seventh; the anterior ends of the lower two (floating ribs) are free. A typical rib has a head, neck, tubercle, and shaft, with its angle. The head is expanded; a horizontal ridge, for the interarticular ligament, divides its wedge-shaped inner end into two facets, upper and lower, for the bodies of the vertebræ. The neck is a constriction next the head, smooth in front and rough behind, with ridges on its upper border as a rule. The tubercle lies at the junction of the neck and shaft posteriorly and has two parts; the non-articular part lies externally and above, and is rough; the articular part is rounded, or oval, and directed downward, backward, and slightly inward.

[97]

The shaft is flattened and curved, the upper ribs curving most acutely; the seventh and eighth are the longest. Toward the back of each rib the curve is sharpest and here (the angle) a ridge crosses the outer surface obliquely. The distance between the angle and tubercle is greatest on the eighth rib; it diminishes rapidly above but only slightly below. The shaft also twists, so that the anterior end turns downward and the posterior upward. The outer surface is smooth and directed upward in the upper rib; upward and outward in the ribs next below; outward in the middle ribs; and outward and slightly downward in the lower ones. In the middle ribs an oblique ridge (anterior angle) may cross the outer surface anteriorly. The internal surface is conversely directed. The upper border is thick behind and thinner in front. The lower border is grooved behind, at the expense of the inner surface, and has a sharp and overhanging external margin; this (subcostal) groove fades anteriorly and its lips coalesce to a rounded edge. 


\section{DISSECTING MANUAL.}

Peculiar Ribs.-The first is small, flat, and not twisted; the head is small, with a single facet; the neck is flattened; the tubercle is prominent, curved, and coincides with the angle. On the thin inner border, about an inch from the anterior end, is a spine (scalene tubercle). A shallow oblique groove (subclavian vein) crosses the upper surface in front of the spine, and a deeper one (subclavian artery) behind it. The second has no twist, but its upper surface looks slightly outward; it is larger and less acutely curved. Near the middle of its outer surface and lower border is a rough oval area. The tenth has a single facet on its head. The eleventh is short, with a single facet on its head; the tubercle is poorly developed and has no facet; the angle is faint; the subcostal groove is faint; the anterior end is pointed. The twelfth resembles the eleventh but is shorter and has no subcostal groove.

Costal Cartilages.- There are twelve pairs, received in depressions at the ends of the ribs and held there by periosteum. They increase in length from the first to seventh, and then decrease below. The first inclines downward, the second is rather horizontal, and the third to the seventh become more and more curved, inclining at first downward and then bending upward; all these join the sternum. The eighth, ninth, and tenth each run downward and then turn upward to join the cartilage above. The eleventh and twelfth are pointed and free anteriorly.

[10]

\section{Articulations.}

Vertebral.-These are amphiarthrodial between (intercentral) the bodies, and true arthrodial diarthroses between (interneural) the articular processes.

[261]

Intervertebral Discs. - These adhere closely to the bodies and consist of a pulpy centre surrounded by fibres, mostly oblique and parallel; they are thickest behind; the third to the seventh are the thinnest.

[261]

Anterior Common Ligament.--This is a broad vertical band, 


\section{ARTICULATIONS.}

attached to the front of the dises and the margin of the bodies, the fibres varying in length.

[263]

Posterior Common Ligament.-This is a vertical band on the back of the bodies, attached to their margins and the discs; it is much wider over the dises than the centre of the bodies, forming dentations.

[263]

Capsular Ligament.-A thin but complete capsule, with a synovial membrane, connects the articular processes.

[263]

Ligamenta Subflava.-This is a layer of yellow elastic fibres running from the front of a lamina, just above its lower border, to the back of the lamina below; it extends from the capsule to the spine, where it joins its fellow.

[263]

Interspinous Ligaments.-These are obliquely interlacing fibres, running from the tips of two adjacent spines to their opposing margins, and extending from base to tip.

[263]

Supraspinous Ligaments. - These are longitudinal bands of fibres, in continuity with the preceding, connecting the tips of the spines.

[264]

Intertransverse Ligaments. - These are vertical fibres connecting the opposing margins of adjacent transverse processes.

[264]

Costo-central.-These are ginglymoid joints, between the heads of the ribs and the bodies of the vertebræ. Each has a complete capsule, and a synovial membrane in each compartment.

[269]

- Stellate or Anterior Costo-vertebral Ligaments.-These are three fasciculi on the front of each capsule, radiating from the head of the rib; the middle fasciculus is attached to the intervertebral disc, and the upper and lower ones to the adjacent margins of the vertebræ next the disc. The middle fasciculus is absent in joints where the rib does not touch an intervertebral disc.

[269]

Interarticular Ligaments.-These are short fibres, within each capsule, connecting the crest, on the head of the rib, with the disc, and dividing the joint into two compartments. It is 
absent in joints where the rib articulates with one vertebra only.

Costo-transverse.-There is an arthroclial diarthrosis between the tubercle of each rib and the facet on the transverse process of the lower of the two vertebra which its head joins. Each has a weak capsule with a synovial membrane. There is no such joint with the eleventh and twelfth ribs.

Anterior or Superior Costo-transverse Ligaments.- These are strong bands attached to the upper border of the neck of a rib, from the head to the non-articular part of the tubercle. The most internal run upward and outward to the transverse process next above, extending to the adjoining rib and its costo-transverse capsule. The middle ones ascend vertically; and those from the tubercle run upward and inward to the lower part and back of the adjoining transverse process. It is absent with the first rib; and absent or rudimentary with the twelfth.

[270]

Posterior Costo-transverse Ligament.-This is a transverse band on the capsule behind, connecting the external rough surface of the tubercle with the tip of the transverse process behind the facet.

[270]

Middle Costo-transverse Ligament.-This consists of short fibres arising from the back of the neck of the rib, and running backward and inward to the front of its transverse process and, partly, the back of the inferior articular process of the upper one of the vertebræ which the rib joins. It is rudimentary with the eleventh and twelfth ribs.

[270]

Ligamentum Lumbo-costale.-This is a band from the upper surface of the base of the first lumbar transverse process to the under surface of the neck of the twelfth rib and under surface of the twelfth dorsal transverse process.

Interchondral.- There are arthrodial diarthroses between the adjoining margins of the fifth to eighth, or ninth, costal cartilages; the cartilages here develop prolongations with flattened facets. Each joint has a capsule and synovial mem- 


\section{FASCIA.}

brane; the capsule is strengthened in front and behind by $e x$ ternal and internal interchondral ligaments.

[271]

Costo-sternal.-There are arthrodial diarthroses between the sternum and the second to seventh costal cartilages. Each has a capsule and one synovial membrane, or more if an interarticular ligament exists. The first costal cartilage joins the sternum directly without any joint.

[271]

Anterior Costo-sternal Ligament.-This consists of fibres radiating over the capsule, from the end of each costal cartilage to the front of the sternum.

[271]

Posterior Costo-sternal Ligament.-This consists of similar fibres on the capsule behind.

[272]

Ligamentum Costo-xiphoidea.-This consists of fibres ascending from the front of the xiphoid to the front of the seventh, and even the sixth, costal cartilage.

Interarticular Ligaments. - These consist of horizontal fibres between the sternum and the end of each costal cartilage, within the capsule. They always divide the second joint into two compartments, but are irregular elsewhere.

[272]

Sternal. - A species of amphiarthrosis usually persists between the manubrium and gladiolus; there is an intervening plate of hyaline cartilage but no joint cavity.

[272]

\section{FASCIA.}

Fasciæ.-Pectoral Region.-The superficial fascia is fatty. The deep fascia investing the Pectoralis major is attached above to the clavicle and internally to the sternum; it is continuous below with the abdominal fascia and externally with the deep fascia of the arm. It becomes thickened (axillary fascia) at the outer border of the Pectoralis major and forms the floor of the axilla. The costo-coracoid membrane is a deeper layer ascending from the upper border of the Pectoralis minor, which it invests. It splits at the lower border of the Subclavius into two layers, which enclose that muscle and are attached to the borders of the under surface of the clavicle. 


\section{DISSECTING MANUAL.}

It is attached internally to the first costal cartilage and externally to the coracoid process, a thickened portion (costo-coracoid ligament) connecting these points. Below the Pectoralis minor it passes under the Pectoralis major and outward to join the axillary fascia.

[321]

Back.-The superficial fascia is not peculiar. The deep fascia is attached mesially to the supraspinous ligament and vertebral spines, and laterally to the spine of the scapula and the clavicle; below the arm it is continuous, around the Latissimus dorsi, with the axillary and abdominal fasciæ. As the vertebral aponeurosis, concealing the Erector spinæ, it is attached to the angles of the ribs.

[318]

\section{Muscles.}

Pectoral Region.

Pectoralis Major.-Origin; (clavicular portion) inner half, or two-thirds, of front of clavicle; (costo-sternal portion) anterior surface of sternum, by tendinous fibre decussating with those of its fellow; first six costal cartilages; (abdominal portion) a separate slip from the Obliquus externus aponeurosis. Course; the muscle so twists on itself that the lower (costosternal) fibres get behind the upper (clavicular) fibres and are inserted higher on the humerus. Insertion; outer border of bicipital groove of humerus, extending up to the great tuberosity and blending externally with the Deltoid insertion, and internally with the Latissimus dorsi insertion. From the upper border of the insertion a band ascends to the shoulder-joint capsule, enveloping the Biceps tendon; from the lower border a fascial band descends to the fascia of the arm.

[322]

Pectoralis Minor.-Origin; third, fourth, and fifth ribs near their anterior ends; fascia over the third and fourth intercostal spaces. Insertion; front of tip of coracoid process; (usually) conjoint origin of Biceps and Coraco-brachialis.

[324]

Subclavius.-Origin; upper surface of first costal cartilage, 


\section{MUSCLES.}

in front of costo-clavicular ligament. Insertion; groove in middle third of under surface of clavicle.

[324]

Serratus Magnus.-Origin; external aspect of eight upper ribs, by fleshy slips, the first slip being double and coming from the two upper ribs and intervening fascia. Insertion; (from upper two ribs) ventral aspect of upper angle of scapula; (three slips from second, third, and fourth ribs) vertebral border of scapula; (four slips from fifth to eighth ribs) ventral aspect of lower angle of scapula.

[325]

\section{Muscles of Respiration.}

External Intercostals. - There are eleven pairs, each extending from the tubercle of the rib nearly to the costal cartilige, where it is continuous with the anterior intercostal fascia extending to the side of the sternum. Origin; sharp lower border of one rib. Insertion; outer edge of upper border of rib below.

Internal Intercostals. - There are eleven pairs, each extending from the side of the sternum to the angle of the rib, where it is continuous with the posterior intercostal fascia extending to the tubercle of the rib. Origin; costal cartilage and inner edge of subcostal groove of one rib. Insertion; upper border of rib and costal cartilage below.

Levatores Costarum.-Twelve slips, in series with the External intercostals. Origin; transverse processes (of seventh cervical and upper eleven thoracic vertebræ). Insertion; outer surface of each rib below, behind its angle.

Infra-costales.-Slips on the inner surface of the lower ribs, near their angles, passing over several ribs.

Triangularis Sterni.-Origin; back of ensiform cartilage and sternum, up to the third costal cartilage. Insertion; second to sixth costal cartilages.

Diaphragm.-Origin; (anteriorly) back of ensiform cartilage, by two fleshy slips; (laterally) deep surface of lower six ribs, by fleshy slips interdigitating with the Transversalis; (pos- 


\section{DISSECTING MANUAL.}

teriorly) lumbar vertebre, by the crura, and arcuate ligaments. Insertion; central tendon. The crura are two fibro-miscular bundles arising from the front of the upper three lumbar vertebræ on the right side, from the upper two on the left. After ascending they descussate (right crus in front of the left) in the miclline in front of the aorta, encircle the œesophagus, decussate again and join the central tendon. There are five arcuate ligaments; the middle one is a fibrous arch connecting the crura in front of the aorta and giving fibres to the lower decussation; the internal one is a thickened edge of psoas fascia connecting the body of the first lumbar vertebra with its transverse process, across the Psoas; the external is the thickened edge of the anterior layer of the lumbar fascia lying over the Quadratus lumborum, and connecting the last rib with the first lumbar transverse process. The central tendon has three lobes: right (the largest), left (the smallest), and anterior, or middle; it lies anteriorly.

Openings.-The aortic, under the middle arcuate ligament, transmits the aorta, vena azygos major, and thoracic duct. The osophageal transmits the cesophagus and both vagi. The foramen quadratum, in the right lobe of the central tendon, transmits the inferior vena cava and branches of the right phrenic nerve.

[424]

Superficial Muscles of Back.

Trapezius.-Origin; inner third of superior curved line of occipital; external occipital protuberance; ligamentum nuchæ; spines of seventh cervical and all dorsal vertebræ and corresponding supraspinous ligaments. Insertion; (upper part) outer third of posterior surface of clavicle; (middle part) inner side of acromion process and whole upper border of spine of scapula; (lower part) tuberosity at the base of scapular spine, by a flat tendon, with a bursa underneath.

[318]

Latissimus Dorsi.-Origin; vertebral aponeurosis (posterior layer of lumbar fascia), through which it is attached to the 


\section{MUSCLES.}

spines of the lower six thoracic and all the lumbar vertebræ and the Erector spinæ tendon; posterior part of iliac crest; lower three or four ribs, by fleshy interdigitations with the External oblique; (usually) lower angle of the scapula. Course; it ends in a narrow tendon which at first adheres to the Teres major. Insertion; floor of bicipital groove of humerus, behind the Coraco-brachialis and Biceps but in front of, and separated by a bursa from, the Teres major.

[319]

Rhomboideus Minor--Origin; ligamentum nuchæ; spines of last cervical and first thoracic vertebræ. Insertion; vertebral border of scapula, at base of its spine.

[320]

Rhomboideus Major.-Origin; spines and supraspinous ligaments of second to fifth thoracic vertebræ. Insertion; (upper part) vertebral border of scapula, through a membranous band which is attached by its ends to the base of the spine and the inferior angle, and is loosely connected with the border between by areolar tissue; (lower fibres) inferior angle of scapula.

[321]

\section{Deep Muscles of Back. First Group.}

Serratus Posticus Superior.-Origin; ligamentum nuchæ; spines of last cervical and upper three or four thoracic vertebra. Insertion; second to fifth ribs, by four slips.

[392]

Serratus Posticus Inferior--Origin; spines of lower two thoracic and upper two lumbar vertebræ, through the vertebral aponeurosis. Insertion; last four ribs, in four muscular bands.

[392]

\section{Second Group.}

Ilio-costalis (outer part of the Erector spinæ). Insertion; lower six ribs, by six slender slips; Accessorius (prolonging the preceding). Origin; lower six ribs, internal to preceding, by six slips. Insertion; upper six ribs, by similar slips. Cervicalis Ascendens (prolonging the preceding). Origin; upper six ribs, internal to the Accessorius. Insertion; pos- 


\section{DISSECTING MANUAL.}

terior tubercles of fourth, fifth, and sixth cervical transverse processes.

[393]

Longissimus Dorsi (inner part of the Erector spinæ). Insertion; nearly all the ribs; transverse processes of the thoracic, and accessory processes of the upper lumbar, vertebræ. Transversalis cervicis (prolonging the preceding). Origin; upper six thoracic transverse processes, internal to Longissimus dorsi. Insertion; posterior tubercles of second to sixth cervical transverse processes. Trachelo-mastoid (another prolongation). Origin; upper six thoracic transverse processes, with preceding. Insertion; mastoid process.

[393]

Spinalis Dorsi.-Origin; lower two thoracic and upper two lumbar spines; Longissimus dorsi tendon. Course; close beside spines. Insertion; upper thoracic spines.

[395]

Third Group.

Semispinalis Dorsi.-Origin; lower six thoracic transverse processes. Insertion; spines of last two cervical and upper four thoracic vertebræ.

Multifidus Spinæ (Thoracic part).-Origin; transverse processes of thoracic vertebræ. Course; in contact with laminæ. Insertion; vertebral spines.

[395]

Fourth Group.

Rotatores Dorsi.-There are eleven pairs of these muscles; each is a small slip. Origin; transverse process of vertebra. Insertion; lamina of vertebra next above.

Inter-spinales.-Bands connecting the spines. [398]

Inter-transversales. - Slender slips between the transverse processes.

[398]

\section{NeRVES.}

Pneumogastric.-From the neck both enter the thorax behind the large veins, the left nerve between the subclavian and common carotid arteries, the right after crossing over the sub- 


\section{NERVES.}

clavian artery. The right nerve then descends beside the innominate artery and trachea, behind the right innominate vein and superior vena cava, to the back of the root of the lung. The left nerve runs between the common carotid and subclavian arteries, behind the left innominate vein and phrenic nerve, and over the aortic arch, to the same place. Behind the root of each lung the nerve breaks up into a large plexus (posterior pulmonary), from whose lower end on each side two trunks descend to the œsophagus, crossing over the vena azygos major on the right side and the thoracic aorta on the left. On the œsophagus these split into a common plexus (asophageal), but then gather into two nerves just above the cesophageal opening of the diaphragm and pass through this, the left nerve lying in front of the osophagus and the right behind it.

[690]

Cervical Cardiac Branches.-The superior and inferior arise in the neck; both, on the right side, descend behind the subclavian artery and beside the trachea to the deep cardiac plexus. On the left side the superior descends beside the trachea to the deep cardiac plexus, while the inferior crosses over the aortic arch, with the vagus, to the superficial cardiac plexus. Cardiac branches of the right inferior laryngeal arise over the subclavian artery and descend beside the trachea to the deep cardiac plexus.

[692]

Thoracic Cardiac Branches.-On the right side they arise from the right vagus in the superior mediastinum and descend beside the trachea to the deep cardiac plexus. On the left side they arise from the left inferior laryngeal below the aortic arch and go to the deep cardiac plexus.

[693]

The left inferior laryngeal arises as the vagus crosses the aortic arch, hooks round this external to the ligamentum arteriosum, and ascends between the trachea and œsophagus to the neck, where it has the same course and branches as on the right side. Its cardiac branches arise below the aortic arch.

[693] 
Superficial Cardiac Plexus.-This lies in the hollow of the aortic arch, superficial to the pericardium, and contains a snall ganglion (of Wrisberg). It receives the left inferior cervical cardiac branch of the vagus, and left superior cervical cardiac branch of the sympathetic superior cervical ganglion. Branches pass between the aortic arch and pulmonary artery bifurcation to the deep cardiac plexus, along the left pulmonary artery to the left anterior pulmonary plexus, and along the pulmonary artery to the anterior coronary plexus.

[693].

Deep Cardiac Plexus.-This is much larger, lies on the sides of the trachea, just above its bifurcation, and consists of two connected lateral parts. The right half receives all the cardiac branches of the right vagus, right inferior laryngeal, and right superior, middle, and inferior cervical sympathetic ganglia. It forms chiefly the anterior or right coronary plexus, which proceeds on the right coronary artery to the heart and receives fibres from the superficial cardiac plexus. It sends branches to the posterior coronary plexus, and the right anterior pulmonary plexus. The left half receives the left superior cervical cardiac, cardiac branches of the left inferior laryngeal nerve and the left middle and inferior cervical sympathetic ganglia, and a branch of the superficial cardiac plexus. It forms the left or posterior coronary plexus, which proceeds on the left coronary artery, receiving branches from the right half. It also sends branches along the left pulmonary artery to the left anterior pulmonary plexus.

Pulmonary Plexuses. - The posterior, placed behind the root of the lung, is formed by most of the vagus, with branches of the second, third, and fourth thoracic sympathetic ganglia. Numerous fine branches run on the bronchi and vessels to the lung. The anterior lies on the front of the root of the lung on each side and is formed by a few fibres from the vagus, with others from the corresponding part of the deep cardiac plexus and (left side) the superficial cardiac plexus. It supplies the root of the lung in front.

[694] 


\section{NERVES.}

Esophageal Plexus.--This surrounds the œsophagus, in the posterior mediastinum, and is formed by both vagi, with branches of the great splanchnic nerve and ganglion. It supplies the œsophagus and pericardium. In the superior mediastinum the œsophagus gets branches from the right vagus and left recurrent laryngeal.

[695]

Supra-clavicular Nerves. - These descending branches of the cervical plexus are cutaneous and pierce the deep fascia above the clavicle. The sternal cross the inner end of the clavicle and descend to the lower end of the manubrium. The clavicular cross the middle third of the clavicle and descend to the nipple. The acromial cross the outer third of the clavicle and go to the shoulder.

[624]

Phrenic.-From the neck, both nerves enter the thorax between the subclavian vessels, after crossing the first (left side) or second (right side) part of the subclavian artery. Each descends, in front of the root of the lung and between the pericardium and pleura, to the diaphragm and divides into branches supplying it, most of them after piercing it. The left nerve, the longer, runs between the subclavian and carotid arteries and crosses the vagus and aortic arch. The right nerve accompanies the innominate vein and superior vena eava, but is separate from the vagus. The branches are muscular, to the diaphragm; pleural and pericardiac (arising in the mediastinum); inferior vena caval; capsular, to the suprarenal; and hepatic; (the latter three arise after the communication with the diaphragmatic plexus). The phrenic communicates with the solar plexus through the diaphragmatic plexus on the inferior phrenic artery.

Brachial Plexus.-This will be fully described with the upper extremity. The branches to the thorax are as follows: The nerve to the Subclavius crosses the subclavian artery to reach its muscle. A communicating branch joins the phrenic. The posterior scapular descends along the vertebral border of the scapula, under cover of and supplying the Levator anguli 


\section{DISSECTING MANUAL.}

scapulæ and the Rhomboidei, major and minor. The long thoracic descends on the outer surface of and supplies the Serratus magnus. The external anterior thoracic descends on the outer side, and the internal interior thoracic on the inner side, of the axillary artery, across which they communicate; they supply the Pectorales, major and minor. The long subscapular accompanies the subscapular artery and supplies the Latissimus dorsi.

[622]

Thoracic Nerves.-There are twelve on each side, each emerging below its corresponding vertebra and conforming, with certain exceptions, to the typical spinal nerve.

[635]

The typical spinal nerve has two roots, dorsal and ventral; the dorsal root, the larger, develops a spinal ganglion in the intervertebral foramen (within the canal, for the sacral and coccygeal ganglia). Both roots unite in the foramen, forming a spinal nerve which gives off a minute recurrent branch to the spinal canal; it then divides into two primary divisions, anterior and posterior, before leaving the foramen. The posterior division usually divides into two trunks, internal and external. The internal trunks are cutaneous, and the external muscular in the upper half of the body; the opposite is the case in the lower part. The cutaneous branches run inward and backward in the upper half of the body, downward and outward in the lower half. The anterior division receives, near its origin, a gray ramus communicans from the sympathetic gangliated cord and usually sends a white ramus communicans to it. A thoracic nerve (to be regarded as a type) then runs in an intercostal space, between the Intercostals, to the sternum, then pierces the pectoral muscles, and, as the anterior terminal cutaneous branch, supplies the skin. In its course the nerve supplies the Intercostals and, at the side of the chest, gives off a lateral cutaneous branch which pierces the External intercostal and divides into two trunks, anterior and posterior, running forward and backward.

$[608,610,615,635]$

Anterior Divisions of Thoracic Nerves.-Of the twelve, the [122] 


\section{NERVES.}

first to third, and seventh to twelfth are peculiar as follows: First thoracic (the largest): This divides at once into two parts; the upper and larger part ascends over the neck of the first rib to join the brachial plexus; the lower part runs in the first intercostal space, but rarely has either a lateral or an anterior cutaneous branch. Second thoracic: The lateral branch (intercosto-humeral nerve) does not divide into trunks but crosses the axilla, piercing the deep fascia just beyond its posterior fold, and extends down the arm. It ends between the internal condyle and olecranon, and supplies the skin of the armpit and back of the arm, internally, to the elbow. Third thoracic: The posterior trunk of the lateral branch communicates with the intercosto-humeral and supplies the skin on the posterior half of the inner side of the arm high up.

[635]

Seventh to eleventh thoracic: These are typical except that, at the anterior end of the intercostal space, each pierces the attachment of the Diaphragm and Transversalis and runs between the Transversalis and Internal oblique; then passing between the Rectus and the posterior layer of the sheath, it pierces the Rectus and anterior layer of the sheath as the anterior branch. As usual, muscular branches supply the adjacent muscles, and the lateral branches divide into trunks, but the lateral branch of the eleventh descends over the iliac crest. Tuelfth thoracic: This emerges below the last rib and runs outward under the Psoas, between the external arcuate ligament and Quadratus lumborum; then piercing the Transversalis it runs between this and the Internal oblique, and through the Rectus like the preceding. Its branches are typical, except that the lateral branch descends through the lateral abdominal muscles, becomes superficial over the iliac crest two inches behind the anterior superior spine, and supplies the skin of the buttock as far as in front of the great trochanter.

[638]

Posterior Divisions of Thoracic Nerves.-Each divides into an internal and an external branch. Of the upper six 


\section{DISSECTING MANUAI،}

the external branches are muscular; the internal are cutaneous, become superficial near the spines, and run directly outward. Of the lower six the internal are muscular; the external are cutaneous, pierce the Latissimus dorsi at some distance from the midline, and run downward and outward, even to the buttock.

[613]

Sympathetic.-The thoracic part consists of ten or eleven (or less) irregular ganglia which are connected by commissural cords, receive a white ramus communicans from each thoracic nerve, and send one to each. Pulmonary branches arise from the cord opposite the second, third, and fourth ganglia, and join the posterior pulmonary plexus. Aortic branches, from the upper five ganglia, supply the thoracic aorta above. The great splanchnic nerve arises between the fifth and ninth ganglia and descends through the posterior mediastinum and crus of the diaphragm, developing a ganglion (great splanchnic). It supplies the œsophagus and descending thoracic aorta, and joins the (solar plexus) semilunar ganglion. The small splanchnic nerve arises opposite the ninth and tenth ganglia, descends on the spine, pierces the crus and joins the solar plexus. The least splanchnic nerve arises from the preceding, or the last ganglion, pierces the diaphragm and joins the renal plexus.

[708]

\section{The Heart.}

The heart lies on the diaphragm, in the middle mediastinum, enclosed in the pericardium; its long axis is directed downward, forward, and to the left. It is hollow and divided by a septum into right and left halves, each consisting of an upper and lower chamber, the auricle and ventricle respectively. It is conical and irregularly flattened, with a base, apex, two surfaces and two borders. A transverse groove (auriculo-ventricular) indicates the separation between the auricles and ventricles, a longitudinal groove (interventricu- 


\section{THE HEART.}

lar) that between the ventricles, and an indistinct groove (interauricular) that between the auricles.

[783]

The base is quadrilateral, formed by the auricles (chiefly the left), and lies on the fifth to eighth vertebrx. The superior and inferior venæ cavæ enter it at the right upper and lower angles, the right pulmonary veins enter between them, and the left pulmonary veins near the left border. The apex is formed by the left ventricle and lies at the fifth intercostal space, three and a quarter inches from the midline. The inferior surface is entirely ventricular (chiefly the left) and lies on the central tendon and (left side) a small part of the muscle of the diaphragm. The antero-superior surface lies behind the sternum and third to sixth right costal cartilages; the upper part, entirely auricular, is concave; the lower part, entirely ventricular (chiefly the left), is convex; the pulmonary artery and, behind it, the aorta enter at the junction of the auricular and ventricular parts.

[784]

The left margin is thick and rounded, and formed chiefly by the left ventricle, slightly by the left auricle. Right margin: The sharp lower part is nearly horizontal and formed by the right ventricle. The upper part is nearly vertical, and formed by the right auricle; a shallow groove (sulcus terminalis) runs on it from in front of the superior vena cava to the left of the inferior vena cava.

[786]

Auricles.-These are cuboidal and lined with endocardium; the right one lies in front and to the right. A prolongation (auricular appendix) projects forward from the upper and anterior part of each auricle.

[786]

Interior of Right Auricle.-This is smooth, except in front and in the appendix where there are vertical muscle columns (musculi pectinati) which end above in a ridge (crista terminalis). On the posterior surface the superior vena cava enters above, and the inferior vena cava below; a small eminence (tubercle of Lower) lies between these orifices. On the septum is an oval depression (fossa ovalis), the remains of the 


\section{DISSECTING MANUAL.}

fœtal foramen ovale; this is bounded above and in front by a raised margin (annulus ovalis). A thin endocardial fold (Eustachian valve) stretches from the front of the annulus ovalis to the anterior and lower edge of the inferior vena cava orifice; just below this is another fold (Thebesian valve) over the coronary sinus. In the antero-inferior boundary is the opening (tricuspid orifice) into the right ventricle. Scattered over the walls are small fossæ (foramina Thebesii) into which the venæ minimi cordis often open.

[787]

Interior of Left Auricle.- This is smooth and only has musculi pectinati in the appendix. The pulmonary veins enter the upper part of the posterior surface; foramina Thebesii are scattered about. In the antero-inferior boundary is an oval aperture (mitral orifice) leading to the left ventricle. [788]

Ventricles.-This part is conical and flattened. A central fibro-cartilage lies in the triangle between the aortic and auriculo-ventricular orifices, and is continuous with the fibrous rings surrounding the latter. Endocardium lines the cavities. The interventricular septum is oblique, the right side looking somewhat forward; it is chiefly muscular, but the upper and posterior part (pars membranacea) is fibrous and thin opposite the aortic vestibule. The walls of the left ventricle, except the septum, are three times as thick as those of the right ventricle.

[78S]

Interior of Right Ventricle.-The cavity is triangular and divisible into anterior (infundibulum, or conus arteriosus) and posterior (body) parts, separated by a muscular fold; the infundibulum has smooth walls. The body has, on its walls, numerous muscular bundles (columnæ carneæ) of three sorts; the simplest are mere ridges; others are rounded bundles, free in the middle but attached at each end, one of them (moderator band) running from the septum to the base of the anterior papillary muscle. The third kind (musculi papillares) are conical bundles attached to the wall at their bases but ending at their apices in fine tendinous cords (chordx tendinex). Of 


\section{THE HEART.}

the musculi papillares there is a large anterior one whose cords go to the right and left cusps of the tricuspid valve; a smaller and posterior one whose cords go to the right and posterior cusps; and a varying group of bundles whose cords go to the left and posterior cusps.

[789]

The tricuspid orifice opens into the body and has a valve (tricuspid) with three cusps, right, left, and posterior. The cusps are doubled endocardial folds, with intermediate fibrous tissue, and thinnest at their free margin; they are usually continuous at the margins of the orifice, where they are attached to a fibrous ring. Their apices hang down; the chordæ tendinex are attached to the margins, apices, and ventricular surfaces. The pulmonary orifice lies in front of the tricuspid and opens from the infundibulum into the pulmonary artery. It has a valve (pulmonary) composed of three semilunar segments, posterior and two anterior, which are formed of fibrous tissue between an endocardial layer and one derived from the inner arterial coat. The outer border of each segment is attached to the arterial wall; the inner border is free and presents a small nodule (corpus Arantii) mesially, and on each side of this a thin and semilunar segment (lunule).

[789]

Interior of Left Ventricle.-The cavity is conical and separable into a body and a small aortic vestibule; the latter lies just below the aortic orifice. Many fine columnæ carneæ of the first two kinds are seen on the inferior wall and apex; there are two large musculi papillares, anterior and posterior, with chordx tendinex going to both cusps of the mitral valve. The mitral orifice opens into the body. It has a valve (mitral) with two triangular cusps; a smaller one (marginal) lying to the left and behind; and a larger one (aortic) lying to the right and in front, toward the aortic orifice. The bases of the cusps are either continuous at their attachment to the fibrous ring round the orifice, or separated by small intermediate cusps; the apices hang down. Their structure and the attachment of the chordæ tendinex is similar to that of the tricuspid 


\section{DISSECTING MANUAL.}

valve. The aortic orifice, opening from the vestibule into the aorta, is circular and lies in front and to the right of the mitral. It has a valve (aortic) with three semilunar segments, anterior and two posterior, like those of the pulmonary valve in structure and attachments.

[790]

Pericardium.-This sac lies in the posterior mediastinum, surrounding the heart, and consists of two parts, fibrous and serous. The fibrous pericardium is a conical sac attached at its base to the central tendon and muscle of the Diaphragm; the apex is lost on, and gives sheaths to, the great vessels of the base of the heart. The serous pericardium is a closed sac which is invaginated by the heart and therefore separable into two parts, viz.: parietal, which lines and adheres to the inner surface of the fibrous sac; visceral, which ensheathes the heart. These parts are continuous where the serous layer is reflected onto the great vessels as they pierce the fibrous layer. The superior vena cava is covered in front and laterally by pericardium; the pulmonary veins in front, above, and below; and the inferior vena cava in front and laterally, for a very short distance. A single complete sheath encloses the aorta and pulmonary artery; behind this there is a passage (great transverse sinus) from one side to the other. Between the vessels which are incompletely covered there are also pouches (sinuses); the largest (great oblique sinus) lies between the inferior vena cava and left inferior pulmonary vein. A small fold (vestigial fold of Marshall) runs from the left pulmonary artery to the left superior pulmonary vein, behind the left end of the transverse sinus.

[793]

\section{Arteries.}

Pulmonary.-Arising from the infundibulum of the right ventricle, this runs upward and backward toward the concavity of the aortic arch, curving round the left side of the ascending aorta. It divides, opposite the disc below the fifth vertebra, into right and left branches. It is just over two 


\section{ARTERIES.}

inches long and is enclosed in both pericardial layers. The right branch, the longer and larger, runs behind the ascending aorta, superior vena cava, and upper right pulmonary vein to the hilus of the right lung. At first it lies below the aortic arch and right bronchus, but above the lower right pulmonary vein; it then crosses in front of the right bronchus. Before entering the hilus it sends a branch along the eparterial bronchus to the upper lobe. The left branch is slightly higher and runs to the hilus of the left lung, passing behind the upper left pulmonary vein, in front of the left bronchus, above the lower left pulmonary vein, and below the aortic arch; the ligamentum arteriosum joins it to the aortic arch. Before entering the hilus it sends a branch to the upper lobe.

[795]

Thoracic Aorta.-Commencing at the base of the left ventricle, this arches upward and backward to the spine; then descending on the spine and passing through the diaphragm, it becomes the abdominal aorta. It is divided into the ascending portion, arch, and descending portion.

[797]

Ascending Aorta.-This begins at the left ventricle behind the left margin of the sternum, and opposite the lower border of the third left costal cartilage and the body of the fifth dorsal vertebra. Running upward, forward, and to the right, it becomes the arch behind the right margin of the sternum, opposite the second costal cartilage. At its origin it presents three small dilatations (sinuses of Valsalva) just above the cusps of the aortic valve; and also a diffuse bulging (great sinus) of the right wall. Its branches are the right and left coronary arteries.

[797]

Arch.-This is arched, with the convexity upward, and also curves with the convexity forward and to the left. It runs at first upward, backward, and to the left, in front of the trachea, then passes backward round the left side of the trachea to the left side of the body of the fourth dorsal vertebra, and then descends on this to the lower border of the body, where it becomes the descending aorta. A fibrous relic (ligamentum 


\section{DISSEC'TING MANUAL.}

arteriosum) runs from its under surface to the left pulmonary artery. Its branches are the innominate, left common carotid, and left subclavian arteries.

[797]

Descending Aorta.-Descending on the front of the spine this becomes the abdominal aorta, opposite the last dorsal vertebra, on passing through the aortic opening of the diaphragm. Its branches are the intercostal, subcostal, diaphragmatic, vas aberrans, bronchial, œesophageal, pericardial, and mediastinal arteries.

[798]

Right Coronary.-Arising from the ascending aorta at the anterior sinus of Valsalva, this runs forward between the pulmonary artery and right auricular appendix; it then passes to the right in the auriculo-ventricular sulcus as far as the inferior interventricular sulcus, dividing into two branches, transverse and interventricular. Branches: aortic and pulmonary, to those arteries; right auricular, to the right auricle in front; marginal, descending along the right margin of the heart; transverse, a continuation of the artery round the margin and to the left; interventricular, descending in the interventricular sulcus.

[800]

Left Coronary.-Arising from the ascending aorta at the left posterior sinus of Valsalva, this runs forward between the pulmonary artery and left auricular appendix to the auriculoventricular sulcus and divides in two branches, terminal and interventricular. Branches: aortic and pulmonary, to those arteries; left auricular, to the left auricle; terminal, running to the left in the auriculo-ventricular sulcus; and interventricular, descending in the anterior interventricular groove. [800]

Innominate.-Arising from near the right end of the convexity of the arch this runs upward, backward, and outward. It divides, opposite the right sterno-clavicular joint, into the right subclavian and right common carotid. Occasionally it sends a branch (thyroidea ima) to the trachea and thyroid body.

[801]

Left Common Carotid.-Arising from the convexity of the [130] 


\section{ARTERIES.}

arch, just behind and to the left of the preceding, and running upward and slightly outward, this enters the neck opposite the left sterno-clavicular joint.

[801]

Subclavian. - The origin differs on the right and left sides. It rises to a variable extent above the clavicle, sometimes to the level of the lower border of the thyroid body. The Scalenus anticus divides it in three parts. First part, left side: arising from the arch behind and to the left of the carotid, this ascends to the root of the neck and then arches upward and outward to the border of the Scalenus anticus. First part, right side: arising from the innominate, this runs to the border of the Scalenus anticus. Second part (both sides): this runs outward behind the Scalenus anticus. Third part (both sides): this runs from the outer border of the Scalenus anticus to the outer border of the first rib and there becomes the axillary. The branches are the vertebral, thyroid axis, internal mammary, and superior intercostal. The vertebral is the first branch, arises from the upper and back part of the first part, and ascends in the neck.

Thyroid Axis.-Arising from the upper and front part of the first part, close to the Scalenus anticus, this ascends and soon divides into three branches, viz.: Inferior thyroid, ascending into the neck on the Scalenus anticus. Transverse cervical, running backward in the neck to the Trapezius and giving off muscular branches, the superficial cervical and the posterior scapular. Suprascapular, running backward in the neck to the suprascapular notch.

Internal Mammary.-Arising from the under surface of the first part, just below the preceding, this descends behind the inner ends of the costal cartilages, lying on the pleura and Triangularis sterni. At the sixth interspace it divides into the musculo-phrenic and superior epigastric. Branches: Comes nervi phrenici, accompanying the phrenic nerve. Mediastinal, twigs to the anterior mediastinum. Pericardial, twigs to the pericardium. Anterior intercostal, two branches to each of 


\section{DISSECTING MANUAL.}

the upper six intercostal spaces, piercing the Internal intercostals. Anterior perforating, one branch to each of the upper six interspaces, piercing the Intercostals and Pectoralis major, and accompanying the intercostal nerves; the third and fourth go to the mammary gland. Musculo-phrenic, a branch descending behind the costal cartilages to the Diaphragm and piercing this; besides muscular branches it sends anterior intercostal branches to the seventh, eighth, and ninth interspaces. Superior epigastric, piercing the Diaphragm and descending behind and through the Rectus, this gives off the following branches: muscular; anterior cutaneous, piercing the Rectus with the intercostal nerves; ensiform, to that process; and hepatic, to the falciform ligament.

[825]

Superior Intercostal. - This arises from the back of the first (left side) or second (right side) part, arches backward over the pleura and descends in front of the neck of the first rib to the first interspace; there it divides into two branches, one of which runs outward in each of the first two interspaces, between the Intercostals. A branch (profunda cervicis) arises above the first rib, runs backward below the last cervical transverse process, and ascends under the Complexus into the neck.

[826]

Axillary.-The thoracic branches are the superior thoracic, to the first interspace; long thoracic, running along the lower border of the Pectoralis major; and the pectoral branch of the acromio-thoracic, which descends between the two pectoral muscles.

[827]

Branches of Descending Thoracic Aorta.-Intercostal: These nine pairs of arteries go to the nine lower interspaces, running over the bodies of the vertebræ but under other structures. Each runs in a subcostal groove, with the vein above and nerve below, between the Intercostals. It sends a collateral branch along the lower border of the interspace, a lateral cutaneous branch with the corresponding nerve, and muscular branches to adjacent muscles. A dorsal branch of 


\section{VEINS.}

each, arising early, runs backward between the necks of the ribs, sending a spinal branch through the intervertebral foramen, and dividing in the vertebral groove into internal and external branches. Subcostal: This pair resembles the intereostals; one runs along the lower border of the twelf th rib on each side, between the Transversalis and Internal oblique. Diaphragmatic: to the upper surface of the Diaphragm. Vas aberrans: This ineonstant branch arises high up, from the front and right side, and ascends behind the osophagus. Bronchial: There are usually but two, upper and lower, both on the left side and going to the left lung. The right bronchial artery may arise from the upper of these, from the first right aortic intereostal, or from the aorta itself. Esophageal: four or five small branches to the œsophagus. Pericardial: small branches to the pericardium. Mediastinal: small branehes to the posterior mediastinum.

[837]

\section{VeIns.}

Pulmonary Veins.-There are two on each side, upper and lower. The upper right vein clrains the right upper and middle lobes; the others each drain one lobe. In the root of each lung, the upper vein lies below and in front of the artery; the lower vein is at the lowest part. The right upper vein runs behind the superior vena cava, and the lower vein behind the right auricle. Both left veins run in front of the aorta. All enter the upper and back part of the left auricle.

Cardiac Veins.-The coronary sinus lies in the auriculo-ventricular sulcus, on the left side, and ends in the right auricle. Its tributaries are: left coronary vein (great eardiac), running in the anterior interventricular and auriculo-ventricular sulci to the left end of the sinus and receiving a vein (left marginal) from the left margin; right coronary vein (small eardiac) running in the auriculo-ventricular suleus, entering the right end of the sinus and receiving a vein (right marginal) from the right margin; oblique vein of Marshall, descending on the back 


\section{DISSECTING MANUAL.}

of the left auricle; inferior interventricular vein (inferior or middle cardiac), running in the inferior interventricular sulcus to the right end of the sinus. The anterior cardiac veins ascend on the right ventricle, in front, and join the right coronary, or end in the right auricle. The vena minima cordis drain the heart walls and end in its cavities.

[871]

Superior Vena Cava.-This is formed by both innominates behind the first right costal cartilage. It descends behind the aorta as far as the third right costal cartilage, and enters the upper and back part of the right auricle. It receives the vena azygos major, also pericardial and mediastinal veins.

[871]

Azygos Veins. - The vena azygos major arises either from the back of the inferior vena cava, opposite the right renal vein, or as a continuation of the right ascending lumbar vein. Ascending on the spine behind the right crus, it runs through the aortic opening of the diaphragm; then passing behind and then arching forward over the root of the right lung, it ends in the superior vena cava. It receives the right posterior (except the first) and superior intercostal, right subcostal, right bronchial, œsophageal, pericardial, mediastinal, and superior and inferior azygos minor veins. The vena azygos minor superior is formed by the fourth to seventh left posterior intercostals. Descending on the left of the spine, it crosses the seventh dorsal vertebra, under the œsophagus and thoracic duct, to join the azygos major. The vena azygos minor inferior is formed by the left ascending lumbar, lower four posterior intercostal, left subcostal, and mediastinal veins. Ascending on the left of the spine, it pierces the left crus, crosses the eighth dorsal vertebra under the thoracic duct and osophagus, and joins the vena azygos major.

[872]

Intercostal Veins.-The anterior join the internal mammary or musculo-phrenic. The posterior accompany the arteries; the first joins the vertebral or innominate. On the right side the second to fourth form a trunk (right superior intercostal) which joins the azygos major; the rest join it separately. On 


\section{VEINS.}

the left side the second to fourth form a trunk (left superior intercostal), which runs forward on the left side of the aortic arch to the left innominate. The fifth to eighth join the superior azygos minor, and the ninth to eleventh the inferior. [873]

Innominate Veins.-Both are formed by the union of the subclavian and internal jugular behind the sternal end of the clavicle; descending to the lower border of the first right costal cartilage, both unite, forming the superior vena cava. The right innominate receives the right lymphatic duct and the vertebral, internal mammary, inferior thyroid, and first posterior intercostal veins. The left innominate receives the thoracic duct and the vertebral, internal mammary, inferior thyroid, superior and first posterior intercostal, thymic, bronchial, mediastinal and pericardial veins.

[873]

The internal mammary veins have the same course and branches as the artery; they join the innominate. The vertebral veins correspond to and accompany only the extracranial parts of the arteries. They drain the intraspinal plexuses and adjacent structures of the neck, and receive the anterior and posterior vertebral (deep cervical) veins from plexuses on the front and back of the spine. The inferior thyroid drains the isthmus and corresponding lateral lobe of the gland; descending in front of the tracher, the left vein joins the left innominate, and the right vein the junction of the innominates; both veins may unite in one trunk. [874]

Subclavian Veins.-Continuing the axillary at the outer border of the first rib, each runs below and in front of its artery, and in front of the Scalenus anticus; it joins the internal jugular behind the sternal end of the clavicle, forming the innominate. It receives the external jugular.

[877]

\section{LyMPHATICS.}

Glands.-The parietal glands consist of the following groups: intercostal, lying in the posterior ends of the intercostal spaces; internal mammary (sternal), lying at the anterior ends of the 


\section{DISSECTING MANUAL.}

intercostal spaces; and diaphragmatic, lying on the diaphragm. The visceral glands consist of the following groups: anterior mediastinal, lying in the anterior mediastinum; superior mediastinal, surrounding the innominate veins along the upper part of the aortic arch and in front of the trachea; posterior mediastinal, surrounding the aorta and œsophagus; and bronchial, surrounding the bronchi.

[923]

Thoracic Duct.-Beginning in a dilatation .(receptaculum chyli) opposite the first two lumbar vertebræ, this ascends through the aortic opening of the diaphragm and on the front of the spine to the root of the neck, lying to the right of the midline below the fifth dorsal vertebra, and to the left above this. Then running outward between the vertebral and carotid arteries it joins the commencement of the left innominate vein. It is about eighteen inches long, thin-walled, of varying but small diameter; it lies in front of the small azygos veins, behind the œsophagus.

[906]

Right Lymphatic Duct.-This is a short trunk draining the right upper half of the body; it descends along the inner border of the Scalenus anticus and ends in the right innominate vein.

[909]

\section{The Respiratory System.}

Trachea.-Beginning at the lower border of the cricoid, this descends in the midline in front of the osophagus and spine; it finally deviates slightly to the right, and at the upper border of the fifth dorsal vertebra divides into the two bronchi; it is slightly dilated near its middle. It consists of a fibro-elastic tube containing from fifteen to twenty cartilaginous rings which are deficient behind; the lowest ring inclines downward anteriorly in a median peak, from which a strip runs backward between the bronchi. Within it posteriorly a layer of transverse involuntary muscle bundles (Musculus trachealis), on the posterior aspect of the inner surface of the trachea, connects the ends of the rings.

[972] 


\section{RESPIRATORY SYSTEM.}

Bronchi.-Both run obliquely downward and outward, and divide into branches for the lobes. - Their structure is that of the trachea. The right bronchus is the wider and more vertical; the pulmonary artery erosses its continuation below its branch to the upper lobe, which is thus eparterial. The left bronchus is twice as long; the pulmonary artery crosses it above all the branches, which are thus hyparterial.

[975]

Pleura.-A central vertical partition (mediastinum thoracis), extending from the spine to the anterior thoracic wall, divides the thoracic cavity into two lateral, or pleural, cavities. A serous membrane (pleura) lines each cavity and is prolonged onto the lung at its root, investing it completely. The part (visceral pleura) investing the lung is very thin and firmly adherent. The part (parietal pleura) lining the chest wall is arbitrarily divided according to its location (though all parts are continuous) as follows: The cervical pleura is the domeshaped roof of the eavity, rising one-half to one and a half inches above the clavicle and grooved on top by the subclavian artery; an expansion holds it to the first rib. The costal pleura lines the chest walls, from the sternum to the bodies of the vertebræ. The diaphragmatic pleura lines the diaphragm external to the pericardium. The mediastinal pleura extends on the side of the mediastinum from front to back, except where it passes on to the intervening root of the lung; a doubled fold (ligamentum latum pulmonaris) is prolonged downward from the root of the lung, stretehing between the lung and pericardium, and ends below in a free border.

Lines of Pleural Reflection.-The costal and mediastinal pleurx are continuous behind (posterior or vertebral line) along the front of the spine; the lines on the two sides are well apart above, and equidistant from the mesial plane, but gradually approach below, and also deviate to the left. These two pleurx are continuous in front (anterior line) along the back of the sternum; the lines of the two sides begin at the sternoclavicular joints, come together just above the gladiolus, and 


\section{DISSECTING MANUAL.}

descend in the mesial plane. The right line continues in this plane to the ensiform cartilage, while the left line deviates slightly outward, opposite the fourth costal cartilage, and then descends. The costal and diaphragmatic pleuræ are continuous (diaphragmatic line) along a curved line running a short distance above (except near the spine) the lower border of the thoracic wall, its lowest point being in the midlateral line. The diaphragmatic line, at its ends, joins the anterior and posterior lines; below it there is no pleura between the Diaphragm and chest wall.

Mediastinal Space.-This lies between the pleural sacs and is arbitrarily divided by the pericardium into four portions, viz.: The superior mediastinum lies above the pericardium and is bounded below by a plane drawn from the lower border of the manubrium to that of the fourth dorsal vertebra. The middle mediastinum is the part containing the pericardium. The anterior mediastinum is the part in front of the pericardium, and the posterior mediastinum the part behind. [982]

Lungs. - The lungs are soft, spongy, elastic, and of the shape of their cavities; the right one is the shorter, wider, and slightly the larger. Each has an apex, base, two surfaces, and two borders. The apex is rounded and rises half an inch to an inch and a half above the clavicle; it is grooved by the great vessels. The base is semilunar, concave, and has a thin margin, at the sides and behind, which descends to the level of the eighth rib in the midlateral line; below the margin is found a narrow pleural recess (phrenico-costal sinus). The outer surface is convex and grooved by the ribs. The inner surface presents a concavity for the pericardium, and above and behind this a wedge-shaped depression (hilus) where the structures of the root enter. The posterior border is long, thick, and rounded; it descends as far as the tenth dorsal spine. The anterior border is short, very sharp, and prolonged into the narrow pleural recess (costo-mediastinal sinus) behind the sternum. On the right side it fills the recess; on the left side, over the apex of 


\section{GLANDULAR STRUCTURES.}

the heart, it presents a marked notch, so that the recess is not filled and the pericardium is uncovered.

[983]

Fissures and Lobes.-The left lung is divided into two lobes, upper and lower, by a deep fissure which penetrates nearly to the hilus. This fissure begins at the posterior border, two and a half inches below the apex, and runs, on the outer sufface, to just bchind the anterior end of the base. The right lung is divided into three lobes, upper, middle, and lower, by a similar fissure which ends inferiorly somewhat farther outward; and by a second cleft which begins in the main fissure at the posterior border, and runs horizontally over the outer surface to the anterior border opposite the fourth costal cartilage.

[988]

Root.-This consists of the structures entering the hilus and is enclosed by pleura; it lies behind the superior vena cava on the right side, and in front of the descending aorta on the left. The chief structures of each root are the pulmonary vessels, nerves, and lymphatics, bronchus, and the bronchial vessels and glands. The bronchus lies behind the pulmonary vessels. The pulmonary artery runs below the undivided part of the bronchus on the right side, but crosses it to a higher level on the left. The pulmonary veins lie at a lower level than the artery and bronchus, but the upper vein is in front of the artery. The right bronchus gives off two branches (of which the upper is eparterial) to the upper and middle lobes, while the main stem enters the lower lobe. The left bronchus sends a large branch to the upper lobe, and then enters the lower lobe. The right upper branch is eparterial, all the other branches are hyparterial.

[989]

\section{The Glandular Structures.}

Mammary Glands.-One lies on each side of the front of the thorax in the superficial fascia, over the Pectoralis major and (slightly) Serratus magnus, and usually extending from the second to sixth rib. At the summit is a projection (nipple) 


\section{DISSECTING MINUAL.}

which is covered by wrinkled skin and surrounded by a colored circular area (areola); on the areola are seen many small projections due to cutaneous glands. Each consists of glandular tissue covered by fat. The glandular tissue (corpus mammæ) consists of fifteen to twenty distinct lobes which are connected by fibrous tissue (stroma); each lobe has its own duct which opens separately on the summit of the nipple. Each duct has a small dilatation (ampulla, or sinus lactiferi).

[1207]

Thymus Gland.--This is pinkish and consists of two lobes of unequal size which are separated by a fissure. It ends above in blunt prolongations which ascend into the neck, rarely as far as the thyroid body. The thoracic portion lies in the superior and anterior mediastina, close behind the sternum and costal cartilages; it extends down to the fourth costal cartilage and is in contact with the pericardium, great vessels behind, and pleural sacs. After the second year the gland slowly diminishes in size, or it may remain stationary till puberty when a rapid degeneration sets in but never becomes entirely complete.

[1218]

Structure.-It consists of lobules which are separated by septa derived from its sheath. Each lobule consists of lymphoid follicles. A follicle consists of an outer cortical part, and a central medullary part whose cells are less closely packed.

[1219] 


\section{UPPER EXTREMITY.}

\section{BONES.}

Clavicle.-This has a shaft and two extremities, inner (sternal) and outer (acromial). The sternal end is enlarged and presents a facet, for the mallubrium, which is convex antero-posteriorly and slightly concave vertically; the edge around the facet is rounded below but sharp elsewhere. The shaft is curved with the convexity in front in its inner twothirds, and behind in its outer third. The anterior border is rough internally; externally it is sharper and often has a spur (deltoid tubercle). The posterior border is broad internally but more rounded externally, where a marked projection (conoid tubercle) marks its union with the acromial end. The superior surface is smooth and looks upward and forward. The inferior surface looks downward and backward; near its sternal end is an impression for the rhomboid ligament; external to this is a groove, for the Subclavius, running almost to the conoid tubercle. The acromial end is flattened vertically and expanded transversely. The anterior edge is sharp, the posterior is rougher, and the outer edge has an oval facet for the acromion process. The upper surface is smooth. The under surface has a ridge (trapezoid, or oblique) running obliquely from behind forward and outward to join the posterior border at the conoid tubercle.

Scapula.-This is triangular and flattened; it has two surfaces, dorsal and ventral. The body has three borders and three angles. The superior border, the shortest, runs from the superior angle almost to the root of the coracoid process and there presents a notch (suprascapular). The internal (verte- 


\section{DISSECTING MANUAL.}

bral) border, the longest, connects the superior and inferior angles and is curved; it presents a narrow surface for muscular attachments. The external (axillary) border, connecting the external and inferior angles, is the stoutest; its upper inch is rough and usually limited below by a groove for the dorsalis scapulæ artery. The superior angle is sharp and rather rectangular; the inferior is blunter and more acute. The external angle (head) has a pyriform and slightly concave facet (glenoid surface) with a slightly raised edge, for the humerus; this edge is confluent below with an impression (infraglenoid), and blends above with a tubercle (supraglenoid). A constricted portion (neck), corresponding to a line between the suprascapular notch and infraglenoid tubercle, supports the head. The coracoid process springs from the whole upper part of the head in line with the superior border; it runs upward, then bends nearly at right angles, and ends in a process running outward and slightly forward over the glenoid fossa.

[186]

The spine is a triangular process on the dorsal surface; it divides this surface into the supraspinous and infraspinous fossæ. One border is attached in a line ruming, from near the lower limit of the upper fourth of the vertebral border, toward the centre of the posterior glenoid edge; it is separated from this edge by a notch (great scapular). The surfaces of the spine are concave, look upward and downward, and enter into the fossæ. Its external border is free and concave. Its free posterior border has two strongly lipped edges, upper and lower, and an intervening space which is triangular at the inner end but narrow elsewhere. This posterior border is prolonged as a flattened plate (acromion process), which bends-sharply (acromial angle) and curves forward, upward, and outward over the glenoid fossa. The under surface of the acromion process is smooth but the upper is rough; on the internal border, near the tip, is a facet for the clavicle.

[187]

The supraspinous fossa, the smaller and upper, communicates with the infraspinous fossa at the great scapular notch; 


\section{BONES.}

the suprascapular notch opens into it. The infraspinous fossa is triangular. The ventral surface of the body is concave and has a rounded ridge which runs from the head and neck to the inferior angle; it also presents several rough ridges converging toward the neck.

[188]

Humerus.-The superior extremity comprises the head and tuberosities. The head forms one-third of a spheroid, articulates with the glenoid fossa, and looks upward, inward, and slightly backward; a shallow groove (anatomical neck) separates it from the tuberosities externally and is usually notched opposite the small tuberosity. The great tuberosity abuts on the outer side of the head and is continuous with the shaft; its upper surface is quadrangular and divided into three facets, upper, middle, and lower; its outer surface is rough; a groove (bicipital) separates it anteriorly from the small tuberosity. The small tuberosity lies in front of the outer half of the head, has a facet (for muscular attachment) above and in front, and helps form the bicipital groove. Below the tuberosities is seen a constriction (surgical neck) of the shaft.

The shaft in its upper half is cylindrical. Anteriorly the bicipital groove.runs downward and slightly inward, its edges being prolonged from the tuberosities, as their crests, and fading out below. The outer edge of the groove ends in the anterior limb of a rough $\mathrm{V}$-shaped elevation (deltoid eminence) on the outer side of the shaft, near the middle; the posterior limb of the $\mathrm{V}$ winds round the outer side and is continuous with a ridge behind, which leads to the great tuberosity. At the middle of the shaft the inner surface forms a rounded border with a rough linear impression for the Coraco-brachialis. The lower half of the shaft is compressed, and expanded laterally, presenting two surfaces, and two lateral borders (epicondylic ridges) which end inferiorly in prominences (epicondyles). The internal ridge (margo medialis), the more curved and less prominent, begins in the Coraco-brachialis impression. The external ridge (margo lateralis) begins behind the deltoid emi- 


\section{DISSECTING MANUAL.}

nence, being separated from it by a shallow groove (musculo-spiral) which winds round the outer edge. The anterior surface is triangular and has a mesial ridge. The posterior surface is smooth and rounded above, but flattened below. The interial epicondyle is the more prominent; the external is stunted.

The lower extremity has two articular surfaces of which the outer (capitellum), for the radius, is rounded and lies on the anterior surface and lower border; above this, anteriorly, is a depression (fossa radialis) for the radius. A shallow groove separates the capitellum from the inner articular surface (trochlea), for the ulna. The trochlea is grooved, has prominent edges which wind spirally round the lower extremity, curving from behind forward and inward, and its axis slightly oblique to the long axis of the shaft. The inner edge of the trochlea is the sharper and more prominent; the outer edge is rounded in front, but forms a crest behind the capitellum. Just above the trochlea anteriorly is a depression (coronoid fossa) for the coronoid process of the ulna, and posteriorly there is another (olecranon fossa) for the olecranon; only a thin layer of bone separates these fossæ.

Ulna.-The superior extremity is enlarged and supports the olecranon and coronoid processes. The olecranon process is in line with the shaft; its triangular posterior surface is smooth; its superior surface forms, with the posterior, a rectangular projection; the anterior surface helps form the great sigmoid cavity; the anterior border is crescentic. The coronoid process juts forward from the fore and upper part of the shaft, its upper surface entering into the great sigmoid cavity; the anterior surface is triangular, slopes downward and backward, and ends below in a tubercle; the inner surface is smooth; of the lateral margins the inner is the best defined and presents a tubercle where is joins the superior border. The great sigmoid cavity is a semicircular notch, with sharp margins, formed by the olecranon process above and the coronoid below; 


\section{BONES.}

notches in its lateral borders constrict its deepest part; a longitudinal ridge, extending from the prominence of the olecranon border above to the apex of the coronoid process below, divides it into inner and outer parts, which respectively are slightly concave and convex transversely. The small sigmoid cavity, for the radius, is oblong and lies on the outer side of the coronoid process, separated from the great sigmoid cavity by a curved edge; it is plane vertically, concave antero-posteriorly, and pointed in front where it joins the anterior border of the coronoid process; the posterior border prolongs the interosseous margin of the shaft.

The shaft is nearly straight, thick above but tapered below, and divided into two surfaces by two borders. The outer (interosseous) border is sharp in its upper three-fourths but faint below. The posterior border curves outward above and inward below, being continuous above with the borders of the triangular posterior surface of the olecranon; it is sharp above but faint below where it ends on the back of the styloid process. The flexor surface, the front and inner side, presents a ridge running from the tubercle to the styloid process. Just below the small sigmoid cavity is a hollow triangular area, for the bicipital tubercle of the radius, which is limited behind by the interosseous crest, and in front by a line running obliquely downward and backward from the outer edge of the coronoid process. The lower fourth is limited above by a ridge which runs downward and backward toward the front of the root of the styloid process. The extensor surface is the back; superiorly it extends on the outer side of the olecranon, behind the sigmoid cavities; its upper third is marked off by an oblique ridge running from the outer border; a faint longitudinal ridge divides the part below this oblique ridge.

The inferior extremity has a rounded head from whose back and inner side a pointed process (styloid) projects downward; a groove on the back and outer surface of this process extends upward on the shaft. The antero-external half of the circum- 


\section{DISSEC'TING MANUAL.}

ference of the head has a narrow convex facet for the radius. The inferior surface of the head is flat, semilunar, and separated from the styloid process by a groove.

Radius.-The upper extremity has a disc-shaped head with a concavity superiorly, for the capitellum; and a smooth circumference, broadest internally, for the small sigmoid eavity and orbicular ligament. Below the head is a constriction (neck); and below this, internally, an oval prominence (bicipital tuberosity) which is rough posteriorly but smooth anteriorly.

The shaft is narrow above but broad below, triangular on section with the base outward, and curved outward; it has two surfaces separated by two borders. The internal (interosseous) border descends from the posterior border of the bicipital tuberosity, becoming sharper, and splits at the middle third into two lines; these run to the ends of the sigmoid cavity, enclosing a triangular area. The external border is thick and rounded above, has a rough impression at its centre, becomes sharper below, and ends in the styloid process. The anterior (flexor) surface has a ridge (anterior oblique line) running, from the bicipital tubercle, downward and outward to the middle of the outer borler. The posterior (extensor) surface has a similar but less distinct ridge (posterior oblique line) which also ends at the centre of the outer border. [200]

The lower extremity is triangular and turned slightly forward. Its lower surface is concave; a slight antero-posterior ridge divides this into two facets, a triangular external one for the scaphoid, and a quadrilateral inner one for the semilunar bone. The anterior border is prominent and rough; the posterior is rough and has many grooves for tendons. A pointed process (styloid) descends from the outer side; its outer surface has a shallow groove. On the inner side of this extremity is a narrow facet (sigmoid cavity) for the ulna; this is plane vertically, concave transversely, and separated from the carpal facets by a rectangular edge.

[201] 


\section{BONES.}

Carpal Bones.-From without inward the first (proxinal) row consists of the scaphoid, semilunar, cuneiform, and pisiform; and the second row of the trapezium, trapezoid, os magnum, and unciform. Each bone is irregularly six-sided, with non-articular palmar and dorsal surfaces.

[203]

Scaphoid.-The inferior external angle of the palmar surface projects (tuberosity). The superior surface is a convex facet for the radius; the inferior surface is convex and consists of two facets, for the trapezium externally, and the trapezoid internally. The outer surface is narrow and non-articular; the inner surface is hollow in front, for the os magnum, and presents above this a narrow semilunar facet for the semilunar bone. The dorsal surface is non-articular.

[203]

Semilunar.-The palmar surface is larger than the dorsal. The superior surface is convex, for the radius; the inferior is deeply concave and consists of two facets, for the head of the os magnum externally, and the unciform internally. The external surface is crescentic, for the scaphoid; the internal surface is quadrilateral, for the cuneiform.

[204]

Cuneiform (pyramidal).-The palmar surface has, inferiorly, a small oval facet for the pisiform; the dorsal surface is ridged and grooved internally. The superior surface has a convex facet for the triangular fibro-cartilage; the inferior surface is concavo-convex, for the unciform. The external surface joins the semilunar; the inner is non-articular.

[205]

Pisiform.-This is the shape and size of a large pea; dorsally it has an oval facet for the cuneiform; the rest of the bone is rounded and non-articular.

[205]

Trapezium.-The palmar surface has a prominent ridge, with a groove beside it; the dorsal surface is irregular. The superior surface is mainly rough but presents a half oval facet for the scaphoid; the inferior surface has an oval and saddleshaped facet for the first metacarpal. The external surface is non-articular. The inner surface has two facets: the upper, a 


\section{DISSECIING MANUAL.}

half oval, for the trapezoid; and the lower, circular, for the second metacarpal.

[205]

Trapezoid.-The palmar surface is much smaller than the dorsal. The superior surface has a small facet for the scaphoid, and the inferior a saddle-shaped one for the second metacarpal. The outer surface has a facet for the trapezium; and the inner a deeply curved facet for the os magnum.

[206]

Os Magnum.-The palmar and dorsal surfaces are rough. The superior part forms a rounded head which has eonvex facets, separated by a ridge, for the scaphoid and semilunar. The inferior surface is widest behind and divided by two antero-posterior ridges into three facets, for the second, third, and fourth metaearpals. The outer surface has a facet for the trapezoid; and the inner a facet, which may be subdivided, for the unciform.

[207]

Unciform.-The palmar surface is triangular and, at its lower and inner part, presents a hook-like process; the dorsal surface is triangular. The superior and internal surfaces form a long facet for the euneiform. The outer surface has a facet, sometimes two, for the os magnum; the inferior has two facets, separated by a ridge, for the fourth and fifth metacarpals. At the junction of the superior and external surfaces is a narrow facet for the semilunar.

[207]

Metacarpal Bones.-There are five, lying side by side; each has a shaft and two extremities. The shafts are slightly eurved ventrally; on the dorsal surface two divergent lines run from the base to tubercles placed on each side of the head; on the palmar surface is a sharp longitudinal ridge; the sides are grooved. The bases (earpal extremities) are wedge-shaped. The heads (phalangeal ends) are rounded and have a pit on each sicle; behind each pit is a tubercle. Each head has a pha- . langeal articular surface which is convex, widest anteriorly, and extends farthest on the palmar aspect, where it is notehed, its edges forming tubereles.

The first (thumb) is the shortest and stoutest; the head is 


\section{ARTICULATIONS.}

large. The base has a saddle-shaped facet for the trapezium but no lateral facets; externally it has a slight tubercle. The second is the longest. The base has a deep facet for the trapezoid; on its radial side a half oval facet for the trapezium; and on its ulnar side a narrow facet for the os magnum, and in front of this two half-oval facets for the third metacarpal. The third has a pointed process (styloid), at the back of the base, which is directed radialward. The base has a facet superiorly for the os magnum, with two half-oval facets on the radial side for the second metacarpal, and two facets, oval or circular, on the ulnar side for the fourth metacarpal. 'The fourth has a quadrilateral facet at its base for the unciform, with two facets on the radial side for the third metacarpal, and a narrow facet on the ulnar side for the fifth. The fifth has a saddle-shaped base, for the unciform, with a tubercle on the ulnar side; on its radial side is a facet for the fourth metacarpal.

Phalanges.-There are three for each finger and two for the thumb. The first (proximal) on each finger is the longest and stoutest, and curves slightly forward; the palmar surface is flat, with sharp lateral borders; the dorsal surface is convex transversely. The proximal end is enlarged and has an oval facet for the metacarpal; the distal end is smaller and its facet is convex and divided into two condyles by a groove. The second resembles the first, except that it is smaller and its proximal facet is divided by an antero-posterior ridge. The third (terminal, or ungual) is the smallest and has a spatula-shaped surface on its distal end, for the nail; its proximal facets resemble those of the second.

[212]

\section{ARTICULATIONS.}

Sterno-clavicular Joint.-This arthrodial diarthrosis involves the sternal end of the clavicle, and the manubrium and (slightly) superior surface of the first costal cartilage, close to the sternum. A nearly circular interarticular fibro-cartilage, 


\section{DISSECTING MANUAL.}

which is thinnest at the centre and sometimes perforated, divides the joint into two cavities. The cartilage adheres to the capsule; it is fixed to the first costal cartilage by its lower margin, and to the apex of the clavicular facet by its upper margin. There are two synovial membranes for the two cavities.

[273]

The capsule is thin below but thick elsewhere. It presents the following thickenings, or proper ligaments, viz.: Anterior sterno-clavicular; short fibres running from the front of the sternal end of the clavicle, downward and inward to the front of the sternum and anterior border of the first costal cartilage. Posterior sterno-clavicular; similar but weaker fibres on the posterior surface.

[273]

Accessory Ligaments. - The interclavicular is a broad band running from the apex of the sternal end and the adjacent margins of the facet on one clavicle to those on the other. While crossing the supra-sternal notch it dips down and is partly attached to the sternum. The rhomboid consists of short fibres running from the top of the first costal cartilage, upward and outward to the rough impression on the under surface of the sternal end of the clavicle.

[274]

Acromio-clavicular Joint.-This is an arthrodial diarthrosis between the acromion process and acromial end of the clavicle. It has a complete capsule whose upper and lower parts (superior and inferior acromio-clavicular ligaments) are especially strong. A meniscus usually lies obliquely within, and attached by its edges to, the capsule; it is usually incomplete. A synovial membrane lines the capsule.

[274]

Coraco-clavicular Ligament.-This is accessory to the joint and is divisible into two parts, conoid and trapezoid. The conoid ligament is a triangular band attached by its apex to the top of the coracoid process close to the supra-scapular notch, and by its base to the conoid tubercle of the clavicle. The trapezoid ligament is a band attached below to the top of the posterior half of the coracoid process, antero-external to the 


\section{ARTICULATIONS.}

preceding; and above to the trapezoid ridge on the under surface of the clavicle. A bursa usually lies in the re-entrant angle of junction of these two parts.

[274]

Ligaments of the Scapula. - The coraco-acromial is a triangular band attached by its base to the postero-external border of the coracoid process, and by its apex to the tip of the acromion process just external to the acromio-clavicular joint. The suprascapular is a short, flat band bridging the suprascapular notch; a small duplicate may bridge the foramen ventrally. The spino-glenoid consists of fibres running from the external border of the spine to the back of the head.

[275]

Shoulder Joint.-This is an enarthrodial diarthrosis between the head of the humerus and the glenoid fossa of the scapula. The glenoid ligament, lying within the capsule, is a strong ring of dense fibrous tissue, which is attached to the free margin of the glenoid fossa along its broad outer edge, or base; its inner edge is free and thin; the long tendon of the Biceps partly fuses with it at the apex of the fossa.

[276]

The capsule is attached above to the circumference of the fossa, external to the glenoid ligament, and also to the ligament; and below to the neck of the humerus. It is strongest above; the fibres are partly circular but mainly longitudinal. A prolongation (transverse humeral ligament) bridges the part of the bicipital groove between the tuberosities of the humerus; it leaves an opening for the long tendon of the Biceps, which runs within the capsule, above the head and neck of the humerus. There is usually another opening in its upper and front part under the Subscapularis tendon, where a protrusion of the synovial membrane forms a bursa; there may be an opening under the Infraspinous tendon; through these openings the joint communicates with the bursæ under these tendons. The tendons of the Subscapularis, Supraspinatus, and Infraspinatus fuse with the upper part of the capsule. On the inner aspect of the anterior part of the capsule are seen three thick bands (gleno-humeral ligaments), which are 


\section{DISSECTING MANUAL.}

formed by its longitudinal fibres and run from the anterior border of the glenoid fossa to the neck of the humerus; of these, one (superior) lies above the opening under the Subscapularis tendon, and the others (middle and inferior) lie below it.

[276]

Accessory Ligaments.-The coraco-humeral is a flat band running from the outer border of the root of the coracoid process to the neck of the humerus close to the great tuberosity; its posterior border fuses with the capsule. The coraco-glenoid (inconstant) is a band arising from the coracoid process with the preceding, and running to the upper and posterior margin of the head of the scapula.

[277]

The synovial membrane lines the capsule, extending from the margin of the glenoid fossa to the humeral attachments of the capsule, whence it is reflected on the humeral neck, chiefly inferiorly, as far as the articular surface. It forms a sheath for the Biceps tendon, being prolonged into the bicipital groove, and communicates with the bursæ.

[278]

Elbow Joint.-This is a ginglymus diarthrosis between the trochlea and capitellum of the humerus and, respectively, the great sigmoid cavity of the ulna, and the cup on the head of the radius. It has a complete capsule formed by the union of the four following proper ligaments, viz.: The anterior is a layer of oblique, vertical, and transverse fibres, attached above to the upper margins of the coronoid and supracapitellar fossæ; and below to the margin of the coronoid process and to the orbicular ligament, some fibres reaching the neck of the radius; the lateral portions are relatively thin. The posterior is a thin layer attached above to. the margin of the olecranon fossa; and below to the summit and sides of the olecranon process; externally some fibres run from the back of the capitellum to the posterior border of the lesser sigmoid cavity.

[279]

The internal lateral is a fan-shaped layer, strongest at its margins; it is attached above to the anterior, inferior, and pos- 


\section{ARTICULATIONS.}

terior aspects of the internal condyle, and below to the inner margin of the great sigmoid cavity. The anterior band goes to the inner margin of the coronoid process, the posterior band to that of the olecranon, and the weak intermediate fibres to a transverse band which connects the immer margins of the coronoid and olecranon processes. The external lateral is a flat band attached above to the back and lower part of the external condyle, and blending below with the orbicular ligament of the superior radio-uluar joint.

[280]

Pads of fat lie within the capsule in front of the coronoid and supracapitellar fossa, and projecting toward the olecranon fossa. The synovial membrane lines the capsule, fat pads, and the enclosed bone which is not covered by cartilage, especially the radial neck; the elbow and superior radio-ulnar joints have a common cavity.

[281]

Superior Radio-ulnar Jcint.-This is a lateral ginglymus between the lesser sigmoid cavity of the ulna and the side of the head of the radius. Its synovial membrane is continuous with that of the elbow joint. The special feature is the orbicular ligament, a broad band which forms four-fifths of a circle and is attached by its ends to the anterior and posterior margins of the lesser sigmoid cavity; it encircles the head of the radius and is widest above.

[281]

Inferior Radio-ulnar Joint.-This is a lateral ginglymus between the side of the head of the ulna and the sigmoid cavity of the radius; it includes the lower end of the head of the ulna, which articulates with the fibro-cartilage. The triangular interarticular fibro-cartilage is attached by its apex to the depression on the outer side of the root of the ulnar styloid process, and by its base to the edge between the sigmoid cavity and carpal surface of the radius, binding them together; it helps form two joints. The capsule is imperfect and consists of transverse fibres (anterior and posterior radio-ulnar ligaments) connecting the bones in front and behind. A synovial membrane completes the cavity, covers the fibro-cartilage, and sends a diver- 


\section{DISSECTING MANUAL.}

ticulum (recessus sacriformis) upward between the radius and ulna.

[282]

Accessory Ligaments.-The interosseous membrane is a strong layer connecting the interosseous borders of the radius and ulna; its fibres run chiefly downward and outward. It begins about an inch below the bicipital tuberosity, leaving a gap (hiatus interosseous) above its upper border, and extends downward to the inferior radio-ulnar joint. The oblique ligament is a slender band running from the outer part of the coronoid process, downward and outward to the radius just below the bicipital tuberosity.

[283]

Radio-carpal Joint.--This is a bi-axial diarthrosis, or condyloid joint, between the radius and triangular fibro-cartilage, and the scaphoid, semilunar, and cuneiform bones. It has a complete capsule, lined by a synovial membrane, and divisible into the four following proper ligaments, viz.: The external lateral is a band running from the tip of the radial styloid process to a rough area at the base of the tubercle of the scaphoid. The internal lateral is a rounded band running from the tip of the ulnar styloid process to the rough non-articular border of the cuneiform, some fibres being prolonged to the pisiform. The anterior is a layer attached to the anterior border of the lower end of the radius and (slightly) base of the ulnar styloid process, adhering to the triangular fibro-cartilage. Some fibres are transverse; most run obliquely downward and inward to the palmar surfaces of the scaphoid, semilunar, cuneiform, and (sometimes) os magnum; fibres from the ulna run obliquely outward. The posterior is a layer running from the posterior border of the lower end of the radius, obliquely downward to the dorsal surfaces of the proximal carpal row, especially the cuneiform.

[283]

Carpal Joints.-These are gliding (arthrodial) diarthroses. Joints of proximal row: The scaphoid, semilunar, and cuneiform are united by short and strong transverse ligaments, viz.: two (anterior, or palmar) between their palmar surfaces; two 


\section{ARTICULATIONS.}

(posterior, or dorsal) between their dorsal surfaces; and two (interosseous) between their lateral surfaces, at the level of their superior surfaces, separating the radio-carpal from the inter-carpal joints. Joints of distal row: The trapezium, trapezoid, os magnum, and unciform are united by similar ligaments, three palmar, three dorsal, and three interosseous, though one of the latter, between the trapezium and trapezoid, is often absent. Pisi-cuneiform joint: This has a complete capsule with two strengthening bands (pisi-unciform and pisi-metacarpal) running from the lower and inner aspect of the pisiform to, respectively, the hook of the unciform and the base of the fifth metacarpal.

Transverse Carpal Joint.-This is between the two rows; it has a strong and complete capsule with certain special, though not readily defined bands as follows: Palmar ligaments radiating from the os magnum to the scaphoid, cuneiform, and pisiform; oblique fibres filling the interval between the os magnum and semilunar, some passing from the scaphoid to the cuneiform and others descending from the anterior radio-carpal ligament. Dorsal ligaments of feebler structure, the chief being a band between the scaphoid and os magnum, and another between the cuneiform and unciform. Lateral ligaments continuous with those of the radio-carpal joint, one (external) running between the radial surfaces of the scaphoid and trapezium, and the other (internal) between the ulnar surfaces of the cuneiform and unciform. An interosseous ligament may join the os magnum to the scaphoid. The synovial membrane extends between the two rows and has prolongations between the bones of each row; through absence of interosseous ligaments it may communicate with the adjacent joints. [285]

Intermetacarpal Joints.-These are arthrodial diarthroses between the opposing surfaces of the bases of the four inner metacarpals; their cavities are continuous with that of the carpo-metacarpal joint. Three strong transverse ligaments bind the adjacent palmar, dorsal, and interosseous areas of the 


\section{DISSECTING MANUAL.}

inetaearpal bones, viz.: the ligamenta basium volaria, dorsalia, et interossea.

[287]

Carpo-metacarpal Joints.-Articulatio carpo-metacarpea pollicis: The joint between the trapezium and first metacarpal is one of mutual coaptation of saddle-shaped surfaces. It has a complete capsule with palmar, dorsal, external lateral, and internal lateral bands; and a separate synovial membrane. Articulationes carpo-metacarpca digitorum: These are arthrodial diarthroses between the distal carpal row and the four inner metacarpals. There is a common capsule with special oblique bands, viz.: Oblique palmar ligaments; one or two slips running to each metacarpal from the carpal bones, but the third may get three. Oblique dorsal ligaments; similar stronger bands joining the second metacarpal to the trapezium and trapezoid; the middle metacarpal to the os magnum and (often) trapezoid; the fourth metacarpal to the os magnum and uneiform; and the fifth metacarpal to the unciform. One or two interosseous ligaments lie within the capsule, usually in relation to the eontiguous margins of the bases of the third and fourth metacarpals, and extending thence to the adjacent margins of the os magnum and unciform. A synovial membrane lines the capsule and has prolongations into the intermetacarpal and interearpal joints.

[287]

Metacarpo-phalangeal Joints.-The thumb is a ginglymus diarthrosis; the others are slightly modified enarthrodial diarthroses. Each joint has a capsule (which cannot be demonstrated (lorsally) with its separate synovial membrane. Strong cord-like external lateral and internal lateral ligaments run, from the tubereles and adjacent depressions on the sides of the heads of the metacarpals, to the contiguous non-articular areas on the bases of the proximal phalanges. The palmar ligaments are plates of fibro-cartilage placed between and eonnected with the lateral ligaments, and grooved ventrally for tendons.

[288]

Transverse Metacarpal Ligament.-This structure unites [156] 


\section{SHOULDER AND ARM.}

the distal extremities of the four inner metacarpals; it is composed of three sets of transverse fibres placed in front of the three inner interosseous spaces.

[288]

Interphalangeal Joints.-These are ginglymus diarthroses. They resemble the metacarpo-phalangeal joints, each having a capsule with palmar and lateral cord-like ligaments, and a synovial membrane. The extensor tendons are their chief support dorsally, as in the metacarpo-phalangeal joints.

[288]

\section{SHOULDER AND ARM.}

\section{Fascia.}

Fascia.-Axillary Region.-The pectoral deep fascia invests the Pectoralis major and, at its outer border, becomes thickened and forms the floor of the axilla (axillary fascia); thence it is continued posteriorly onto the posterior fold of the axilla, and externally to join the deep fascia of the arm. A deeper stratum (costo-coracoid membrane) descends from the under surface of the clavicle in two layers which enclose the Subclavius and then unite in one layer; this splits again to enclose the Pectoralis minor, then unites and passes under the axillary floor to join the fascia over the Biceps and Coraco-brachialis. The part extending from the first costal cartilage to the coracoid process is thickened (costo-coracoid ligament).

Shoulder.-The deep fascia is attached to the clavicle and the acromion process and spine of the scapula.

Arm. - The deep fascia is attached to the condyles and olecranon process. Two processes run inward from it to the supracondyloid ridges; the stronger (internal intermuscular septum) lies between the Triceps and Brachialis anticus and extends upward to the insertion of the Coraco-brachialis; the weaker (external intermuscular septum) lies between the Triceps and the Brachialis anticus and Brachio-radialis, and extends upward to the insertion of the Deltoid.

[332] 


\section{Moscles.}

Pectoral Group.

Pectoralis Major.-Origin; (clavicular portion) inner half, or two-thirds, of front of clavicle; (costo-sternal portion) anterior surface of sternum, first six costal cartilages; (abdominal portion) a separate slip from the aponeurosis of the Obliquus externus. Course; it so twists on itself that the lower fibres get behind the upper and are inserted higher on the humerus. Insertion; outer border of bicipital groove of humerus, extending to the great tuberosity and blending with the insertion of the Deltoid and Latissimus dorsi; a band ascends from this to the shoulder-joint capsule, enveloping the Biceps tendon, and another descends to the fascia of the arm.

Pectoralis Minor.-Origin; third, fourth, and fifth ribs anteriorly; fascia on third and fourth intercostal spaces. Insertion; front of tip of coracoid process; (usually) conjoint origin of Biceps and Coraco-brachialis.

Subclavius.-Origin; upper surface of first costal cartilage in front of costo-clavicular ligament. Insertion; groove in middle third of under surface of clavicle.

[324]

Serratus Magnus.-Origin; external aspect of upper eight ribs, by fleshy slips; the first slip is double and attached to the upper two ribs and intervening fascia. Insertion; (from upper two ribs) ventral aspect of upper angle of scapula; (three slips from second to fourth ribs) vertebral border of scapula; (four slips from fifth to eighth ribs) ventral aspect of lower angle of scapula.

[325]

\section{Shoulder Group.}

Deltoid.-Origin; front of outer third of clavicle; outer border of acromion process; lower border of spine of scapula. Course; the most anterior fibres are parallel; the intermediate 


\section{SHOULDER AND ARM.}

ones are multipennate and attached above and below to three or four septal tendons. Insertion; outer side of shaft of humerus at the V-shaped impression lying above the spiral groove. A bursa separates the muscle from the shoulder-joint capsule.

Supraspinatus.-Origin; supraspinous fossa and fascia covering it. Course; under the acromion process and coracoacromial ligament. Insertion; (by a broad, thick tendon) uppermost facet on great tuberosity of humerus; capsule of shoulder joint.

[329]

Infraspinatus.-Origin; infraspinous fossa (except a flat surface along the axillary border) and fascia covering it. Course; a bursa separates it from the neck of the humerus. Insertion; middle facet of great tuberosity of humerus; capsule of shoulder joint.

Teres Minor.-Origin; upper two-thirds of flat surface on back of axillary border of scapula. Insertion; lowest facet on great tuberosity of humerus; shoulder-joint capsule. [329]

Teres Major-Origin; lower third of flat surface on back of axillary border of. scapula, except a small area at lower angle. Course; the upper border is separated from the Subscapularis and Teres minor by a triangular interval which the long head of the Triceps divides into two openings, one quadrilateral and the other triangular. Insertion; inner border of bicipital groove of humerus.

Subscapularis.-Origin; whole subscapular fossa, except at the angles; septa attached to the ridges in the fossa. Insertion; lesser tuberosity of humerus; capsule of shoulder joint. A bursa separates it from the neck of the scapula.

[330]

\section{Dorsal Group.}

Latissimus Dorsi.-Origin; vertebral aponeurosis (connecting it with the spine); posterior part of iliac crest; lower three or four ribs, by fleshy interdigitations with External oblique; (usually) lower angle of scapula. Insertion; floor of bicipital 
groove of humerus. A bursa separates its tendon from that of the Teres major just before they fuse.

[319]

\section{Arm Group.}

Coraco-brachialis.-Origin; tip of coracoid process, conjointly with short hearl of Biceps. Insertion; impression at middle of inner border of humerus.

[332]

Biceps.-Origin; (short head) tip of coracoid process, with precelling; (long head) supra-glenoid impression at root of coracoid process, and glenoid ligament, by a long rounded tendon. Course; the two bellies become united by fascia and join a flat tendon. Insertion; rough posterior portion of bicipital tubercle of radius; deep fascia of forearm internally, by a membranous band (semilunar, or bicipital fascia) derived from the lower muscle fibres and the inner and anterior part of the tendon.

[332]

Brachialis Anticus.-Origin; lower two-thirds of front of humerus, below Deltoid insertion; both intermuscular septa. Insertion; inferior surface of ulnar coronoid process. [334]

Triceps.—Origin; (middle, long, or scapular head) axillary border of scapula just below glenoid fossa; (outer head) outer border of humerus from insertion of Teres minor to musculospiral groove, external intermuscular septum; (inner head) triangular area on back of humerus from insertion of Teres major to olecranon fossa, both intermuscular septa. Course; the heads join a broad, common tendon. Insertion; upper end of olecranon process and deep fascia of forearm on either side of it.

[334]

\section{NERTES.}

Brachial Plexus.-This is formed by the anterior primary divisions of the lower four cervical nerves and most of the first thoracic; it often receives a branch from the fourth cervical, and sometimes one from the second thoracic which enters the intercosto-humeral. It appears in the posterior triangle be- 


\section{SHOULDER AND ARM.}

tween the Scaleni, anticus and medius, and quickly unites in primary cords, the first being formed by the fifth and sixth cervical, the second by the seventh cervical, and the third by the eighth cervical and first dorsal; at the same time each cervical nerve divides into two trunks, ventral and dorsal. Then passing under the clavicle these trunks unite in secondary cords, named from their relation to the axillary artery. The outer cord, on the outer side of the artery, is formed by the ventral trunks of the fifth, sixth, and seventh cervical; the inner cord, on its inner side, by the ventral trunk of the eighth cervical and the whole first thoracic; and the posterior cord, placed behind it, by the dorsal trunks of the lower four cervical nerves.

[622]

Above the clavicle (supraclavicular nerves) the branches are as follows: Twigs from the lower four cervicals, near the foramina, to the Longus colli and all the Scaleni. A branch from the fifth cervical to the phrenic. A branch from the first primary cord to the Subclavius, descending over the subclavian artery and often communicating with the phrenic. Posterior scapular: Arising from the fifth cervical, near the foramen, this pierces the Scalenus medius, appears in the posterior triangle and descends along the vertebral border of the scapula, under and supplying the Levator anguli scapulie and Rhomboids. Long thoracic: This arises from the fifth, sixth, and seventh cervicals, at the foramina, by three roots; it pierces the Scalenus medius in one or two trunks and descends behind the plexus, then between the axillary artery and upper edge of the Serratus magnus, and then over the outer surface of the Serratus magnus, which it supplies. Suprascapular: Arising from the back of the first primary cord, this runs downward and outward above the plexus, and through the suprascapular foramen, where it supplies the Supraspinatus; it then runs in the great scapular notch to supply the Infraspinatus; branches supply the shoulder joint.

[624]

Below the clavicle (infraclavicular nerves) the outer cord 


\section{DISSECTING MANUAL.}

gives off the external anterior thoracic, musculo-cutaneous, and median (outer head); the inner gives off the ulnar, median (inner head), internal cutaneous, lesser internal cutaneous, and internal anterior thoracic; the posterior cord gives off the circumflex, three subscapular, and the musculo-spiral. These are divided into two sets, an anterior derived from the inner and outer cords, and a posterior derived from the posterior cord.

Anterior Thoracic Nerves.-The external arises from the outer cord by three roots, from the fifth, sixth, and seventh cervical; and the internal from the inner cord, from the last cervical and first thoracic. Each descends on either side of the axillary artery; a communicating loop crosses the artery and connects them. Branches of the external pierce the costocoracoid membrane to reach the sternal and clavicular portions of the Pectoralis major. Branches of the internal and of the communicating loop pierce the Pectoralis minor, supplying it and the sternal part of the Pectoralis major.

[626]

Musculo-cutaneous.-Arising from the outer cord this descends between the axillary artery and the Coraco-brachialis, and then through the latter and between the Biceps and Brachialis anticus to the bend of the elbow; here it pierces the deep fascia and divides into cutaneous branches, anterior and posterior, for the outer side of the forearm. Muscular branches supply both heads of the Biceps, and the Brachialis anticus; the nerve to the Coraco-brachialis, from the seventh cervical, usually arises with it but soon separates.

[627]

Median.-The outer head arises from the outer cord and descends on the outer side of the axillary artery; the inner head, arising from the inner cord, crosses the artery to join the outer head in the upper arm. The united nerve descends on the outer side of the brachial artery, then crosses this to the inner side and enters the forearm between the heads of the Pronator radii teres. It has no branches in the arm.

[627]

Ulnar.-Arising from the inner cord, this descends between 


\section{SHOULDER AND ARM.}

the axillary vessels, and on the inner side of the brachial artery to the midarm; then passing behind the internal intermuscular septum it descends, with the inferior profunda artery, to the interval between the olecranon and internal condyle; thence it runs between the heads of the Flexor carpi ulnaris to the forearm. It has no branches in the arm.

Internal Cutaneous.-Arising from the inner eord, this descends superficial to the main vessels, pierces the deep fascia at the midarm, and supplies the lower half of the arm anterointernally. Then accompanying the basilic vein to the elbow it divides into two branches, anterior and internal, for the forearm.

[631]

Lesser Internal Cutaneous.-Arising from the inner cord this descends between the axillary vessels, pierces the deep fascia internally, and supplies the skin on the upper half, or more, of the upper arm internally. It varies inversely in size with the intercosto-humeral, and may be absent.

[632]

Circumflex.-Arising from the posterior cord, this runs downward and outward behind the axillary artery, and then, with the posterior circumflex vessels, through the quadrilateral space bounded by the humerus, Subscapularis, Teres major and Triceps (long head). Then winding round the surgical neek of the humerus it supplies the Teres minor and Deltoid, ending in the latter; branches supply the shoulder joint. A cutaneous branch descends under the Deltoid and then runs through it, or around its lower border, to the skin over its insertion, and the upper half of the arm on the outer side.

[632]

Musculo-spiral.-Arising from the posterior eord, this descends behind the axillary artery, and then on the inner side of the humerus, lying upon the Trieeps (long head) behind the brachial artery. Then running in the spiral groove behind the middle third of the humerus, with the superior profunda artery, it pierces the external internuscular septum, descends to the bend of the elbow, lying in front of the external eondyle 


\section{DISSECTING MANUAL.}

and between the Brachialis anticus and Brachio-radialis, and divides into the radial and posterior interosseous. In the arm its branches arise in three sets, viz.: on the inner side, behind. and on the outer side of the humerus.

[632]

Internal Branches.-The internal cutaneous pierces the fascia high up, internally, and supplies the skin of the arm internally in its upper third, above and behind the area of the lesser internal cutaneous. Muscular branches, in two sets, supply the long head and the inner head of the Triceps; one of the latter (ulnar collateral) accompanies the ulnar nerve to the lower part of the muscle. Posterior branches: Muscular branches, arising in the groove, supply all the heads of the Triceps; the branch to the inner head runs through it and behind the external condyle to the Anconeus. External branches: Two cutaneous branches arise before it pierces the external intermuscular septum and pierce the deep fascia below; the superior descends behind the external condyle, supplying the skin on the lower third of the arm, externally and behind, and the upper half of the back of the forearm; the inferior branch goes to the forearm. Muscular branches, arising between the Brachialis anticus and Brachio-radialis, supply then and the Extensor carpi radialis longior, and sometimes the brevior. [633]

Subscapular.-All three arise from the postcrior cord. The first (short) descends behind the axillary artery to the Subscapularis. The second (lower) runs downward and outward behind the axillary artery and below the circumflex nerve to the Teres major; it also sends branches to the Subscapularis. The third (long) runs downward and outward between the two preceding, and over the posterior axillary wall with the subscapular artery, to enter the Latissimus dorsi on its anterior (inner) surface.

Intercosto-humeral.-This is the lateral cutaneous branch of the second thoracic. It pierces the Intercostals and Serratus magnus, crosses the axilla, piercing the deep fascia just beyond the posterior axillary fold, and then descends on the arm to 


\section{SHOULDER AND ARM.}

the interval between the olecranon and internal condyle. It supplies the skin of the armpit and back of the arm internally as far as the elbow. It joins the lesser internal cutaneous and communicates with the posterior part of the lateral branch of the third intercostal.

[636]

\section{Arthries.}

Axillary.-Beginning at the outer border of the first rib as a continutation of the subclavian, this runs downward and slightly outward along the outer wall of the axilla, internal to the humerus; it becomes the brachial at the lower border of the Teres major. It is arbitrarily divided into three parts, the first above. the second behind, and the third below the Pectoralis minor. It lies external to the axillary vein; the cords and branches of the brachial plexus lie closely behind it, at its sides, and (third part) in front of it. Its branches are as follows:

[827]

Superior Thoracic.--A small branch from the first part, running downward and inward on the first intercostal space. Acromio-thoracic: A short branch from the second part which runs forward over the upper border of the Peetoralis minor and divides into four branches, viz.: clavicular, to the sternoclavicular joint; pectoral, descending between the two pectoral muscles; humeral, descending in the groove between the Deltoid and Pectoralis major; and acromial, crossing the coracoid process to the acromion. Long thoracic: A branch from the second part which descends along the lower border of the Pectoralis major and often (external mammary artery) supplies the mammary gland. Alar thoracic: A branch, or branches, of irregular origin, to the axillary glands. Subscapular: A large branch from the third part which descends along the lower border of the Subscapularis with the long subscapular nerve; a branch (dorsalis scapulæ) runs through the triangularspace between the Supscapularis, Teres major, and Triceps 


\section{DISSECTING MANUAL.}

(long head) to the infraspinous fossa, often grooving the border of the scapula and always sending a branch (infrascapular) to the subscapular fossa.

[828]

Posterior Circumflex.-A branch from the third part which runs backward with the circumflex nerve through the quadrilateral interval between the Triceps (long head), Teres major and minor, and humerus, and then around the latter to end under the Deltoid. Its branches are muscular; acromial, to that process; descending, along the Triceps (outer head); articular, to the shoulder joint; nutrient, to the head of the humerus; and terminal, to the Deltoid. Anterior circumflex: A small branch from the third part, close to the preceding, which runs outward around the front of the neck of the humerus and sends a branch (ascending bicipital) upward in the bicipital groove.

[829]

Brachial.-Beginning at the lower border of the Teres major this descends at the inner side of the Biceps, lying successively on the Triceps (long and inner heads), Coraco-brachialis (insertion), and Brachialis anticus. Entering the ante-cubital fossa it divides opposite the neck of the radius into the radial and ulnar. Its branches are as follows. Superior profunda: A large branch arising high up, accompanying the musculo-spiral nerve in the musculo-spiral groove. It divides into two branches; one (posterior terminal) descends behind the external intermuscular septum to the back of the external condyle; the other (anterior terminal) accompanies the nerve through the septum and descends on it to the front of the external condyle. Behind the humerus it also gives off a slender twig which descends in the Triceps (internal head) to the back of the elbow, a nutrient branch to the humerus posteriorly, and an ascending branch. Muscular, to the muscles. Nutrient, to the humerus anteriorly.

[830]

Inferior Profunda.-A branch which descends with the ulnar nerve, through the internal intermuscular septum, to the back of the internal condyle. Anastomotic: A branch aris- 


\section{SHOULDER AND ARM.}

ing low down and running inward on the Brachialis anticus, through the internal intermuscular septum, and then outward under the Triceps to the back of the external condyle. All the branches reaching the condyles anastomose with each other and the branches of the radial and ulnar, viz.: External condyle; (anteriorly) anterior branch of superior profunda, radial recurrent; (posteriorly) posterior branch of supcrior profunda, anastomotic, posterior interosseous recurrent. Internal condyle: (anteriorly) anastomotic, anterior ulrar recurrent; (posteriorly) inferior profunda, anastomotic, posterior ulnar recurrent.

[831]

\section{VEINS.}

The veins are in two sets, superficial and deep. The deep veins, except the axillary, which is single, accompany (venæ comites) the arteries in pairs. The superficial veins do not accompany arteries.

[888]

Axillary. - Beginning at the lower border of the Teres major, as a continuation of the basilic, this ascends internal to the artery and becomes the subclavian at the outer border of the first rib. Besides tributaries corresponding to the arterial branches it receives the brachial venxi comites at the lower border of the Subscapularis, and the cephalic at the upper border of the Pectoralis minor.

[888]

Superficial Veins. - The basilic is formed at the inner side of the bencl of the clbow by the union of the median basilic and posterior ulnar. Ascending along the inner borler of the Biceps to the niddle of the arm, it runs through an opening (hiatus semilunaris) in the deep fascia, continues deeply along the inner side of the brachial artery, and becomes the axillary at the lower border of the Teres major. The cephalic is formed at the outer side of the bend of the elbow by the union of the radial and median cephalic. It ascends along the outer border of the Biceps and then, piercing the deep fascia, between 
the Deltoid and Pectoralis major. Just below the clavicle it pierces the costo-coracoid membrane and joins the upper part of the axillary.

[891]

\section{LYMPHATICS.}

Superficial Glands.-These lie in the subcutaneous tissue in two groups, upper and lower. The upper (supra-trochlear) group lies just above the internal condyle, beside the basilic vein, and usually contains but two glands. The lower (antecubital) group (inconstant) consists of two or three glands in front of the elbow.

[913]

Deep Glands.-Besides one or two glands found with the arteries of the forearm, and a few with the brachial artery, there are two main divisions, viz.: The infra-clavicular glands lie just below the clavicle, deep in the groove between the Pectoralis major and Deltoid. The axillary glands lie along the vessels in the axilla in three groups, viz.: one (external group) consists of a chain of six or more glands along the antero-internal aspect of the axillary vessels, extending from the lower border of the Pectoralis major to the outer borler of the first rib); one (posterior, or subscapular set) consists of four or five glands on the posterior axillary wall, along the subscapular artery: the third (anterior axillary, or pectoral glands) of four or five glands at the front part of the axilla, in the angle between the Serratus magnus and Pectural muscles; and the fourth (central group) of from three to five glands at the base of the axilla, upon the axillary fascia and between the other groups.

[914]

\section{FOREARM, WRIST, AND HAND.}

Fascia.

Deep Fascia.-In the forearm it is attached to the whole posterior border of the ulna.

[337]

At the urists it is strengthened by transverse fibres and [168] 


\section{FOREARM, WRIST, AND HAND.}

forns the annular ligaments. The anterior annular ligament is a wide band attached externally to the scaphoid and trapezium; and internally to the pisiform and unciform. Arching over the carpus it forms a small compartment externally for the tendon of the Flexor carpi radialis, with its synovial sheath; and a large compartment internally which transnits the median nerve, the tendon of the Flexor longus pollicis in one synovial sheath, and the flexor tendons of the fingers in another sheath. The posterior annular ligament is a wide and oblique band lying somewhat higher and running from the outer side of the radius to the lower end of the ulna, the carpus, and the carpal internal lateral ligament. Septal bands running from it to the radius and ulna divide it into six compartments, each with its synovial sheath. The compartments are occupied, from without inward, by the tendons of the Extensores (1) ossis metacarpi pollicis, and brevis pollicis; (2) carpi radialis, longior and brevior; (3) longus pollicis; (4) communis digitorum, and indicis; (5) minimi digiti; (6) carpi ulnaris.

The palmar fascia is a thick and triangular portion attached by its apex to the lower edge of the anterior annular ligament, and continuous laterally with the deep fascia. Its base separates into four slips, for the fingers, which are connected by transverse fibres (superficial transverse metacurpal ligament); each slip divides in two parts, which are attached to the sides of the metacarpo-phalangeal joints and proximal phalanges of the fingers.

[338]

The digital sheaths are tubular envelopes which enclose the flexor tendons, are continuous with the palmar fascia, and are attached to the sides of the phalanges and interphalangeal joints. They are loose and thin over the interphalangeal joints but thickened (ligamentum vaginale) over the first two phalanges of each finger and the first phalanx of the thumb. Synovial sheaths line the digital sheaths, enveloping the flexor tendons, and extend into the palm; those of the little 


\section{DISSECTING MANUAL.}

finger and thumb, and sometimes all of them, join the sheaths lying under the anterior annular ligament.

[339]

Palmaris Brevis.-This is a quadrilateral subcutaneous muscle on the inner side of the hand, under the superficial fascia. Origin; inner border of palmar fascia. Insertion; skin of inner border of hand.

[336]

\section{Muscles.}

Front and Inner Side of Forearm, Superficial Layer.

Pronator Radii Teres.-Origin; (superficial head) common tendon from internal condyle of humerus; fascia over it; intermuscular septum; (deep head) inner side of coronoid process of ulna. Insertion; oval impression on middle of outer surface of radius.

[339]

Flexor Carpi Radialis.-Origin; common tendon from internal condyle; fascia over it; internuscular septa. Course; its rounded tendon runs in a groove in the trapeziun. Insertion; anterior surfaces of upper ends of second and third metacarpals.

[339]

Palmaris Longus.-Origin; common tendon from internal condyle; fascia over it; intermuscular septa. Insertion; surface of anterior annular ligament; apex of triangular palnar fascia.

[340]

Flexor Carpi Ulnaris.--Origin; (humeral) common tendon from internal condyle; fascia over it; intermuscular septum; (ulnar) olecranon process and upper three-fifths of posterior border of ulna, through the deep fascia. Insertion; pisiform bone.

[340]

Flexor Sublimis Digitorum.-Origin; (humeral) common tendon from internal condyle; internal lateral ligament of elbow joint; intermuscular septa; (ulnar) inner border of coronoid process, above origin of Pronator radii teres; (radial) oblique line and middle third of outer border of radius, by an aponeurosis. Course; it separates in the lower third of the 


\section{FOREARM, WRIST, AND HAND.}

forearm into four parts; each part has a tendon. In the digital sheath each tendon splits in two parts which surround the tendon of the deep flexor, then partly reunite, and then partly decussate. Insertion; sides of second phalanx of each finger, in two portions. The vincula accessoria are additional insertions. They consist of triangular bands (ligamenta brevia), which pass from each tendon, near its insertion, to the front of the inter-phalangeal joint and head of the first phalanx; and of narrow bands (ligamenta longa), which run from the back of each tendon to the upper part of the front of the first pha$\operatorname{lan} \mathbf{x}$.

[341]

\section{Deep Layer.}

Flexor Profundus Digitorum.-Origin; anterior and inner surfaces of ulna, including inner side of olecranon process and embracing insertion of Brachialis anticus; middle third of inner half of interosseous membrane; deep fascia. Course; its broad tendon divides in the palm into four tendons; the index finger tendon is usually separate from the rest throughout; each tendon pierces that of the Flexor sublimis opposite the first phalanx. Insertion; base of terminal phalanx of each finger. The tendons, like those of the Flexor sublimis digitorum, have vincula accessoria; ligamenta brevia attached to the capsules of the second interphalangeal joints, and ligamenta longa attached to the subjacent Flexor sublimis tendons.

Lumbricales.-These are four small muscles arising from the Flexor profundus tendons. Origin; (two outermost) radial side of first and second tendons; (two innermost) adjacent sides of second and third, and third and fourth tendons, each by two heads. Insertion; radial side of each metacarpophalangeal joint capsule, outer border of first phalanx, and outer side of extensor tendon of each finger.

Flexor Longus Pollicis.-Origin; middle two-fourths of front of radius, from oblique line to insertion of Pronator 
quadratus; corresponding part of interosseous membrane. Insertion; terminal phalanx of thumb.

Pronator Quadratus. - Origin; lower fourth of anterior border and surface of ulna. Insertion; lower fourth of anterior surface of radius.

[344]

Short Muscles of Hand.

-Abductor Pollicis.-Origin; anterior annular ligament; ridge on trapezium. Insertion; outer side of first phalanx of thumb; capsule of metacarpo-phalangeal joint.

Opponens Pollicis.-Origin; (under preceding) anterior annular ligament; ridge on trapezium. Insertion; whole anterior surface of first metacarpal.

[345]

Flexor Brevis Pollicis.-Superficial part: Origin; anterior annular ligament: Insertion; outer side of base of first phalanx of thumb, developing a sesamoid bone. Deep part: Origin; ulnar side of base of first metacarpal: Insertion; inner side of base of first phalanx of thumb.

Adductor Obliquus Pollicis.-Origin; anterior surfaces of trapezium, trapezoid, and os magnum; tendon of Flexor carpi radialis; bases of second and third metacarpals. Insertion; inner side of base of first phalanx of thumb, developing a sesamoid bone; outer side of base of first phalanx of thumb, by a slip from the outer border of the muscle.

Adductor Transversus Pollicis.-Origin; lower two-thirds of front of first metacarpal. Insertion; inner side of base of first phalanx of thumb.

[346]

Abductor Minimi Digiti.-Origin; pisiform bone; tendon of Flexor carpi ulnaris. Insertion ; inner side of base of first phalanx of little finger.

[347]

Opponens Minimi Digiti.-Origin; anterior annular ligament; hook of unciform. Insertion; whole inner margin of fifth metacarpal.

[347]

Flexor Brevis Minimi Digiti.-Origin; anterior annular liga- 


\section{FOREARM, WRIST, AND HAND.}

ment; hook of unciform. Insertion; inner side of first phalanx of little finger.

[347]

Palmar Interossei.-These are three muscles which occupy the three inner interosseous spaces; each arises by a single head and is inserted into the dorsal expansion of the extensor tendon, the capsule of the metacarpo-phalangeal joint, and the side of the first phalanx of its finger. Origin; (first) ulnar side of shaft of second metacarpal; (second and third) radial sides of shafts of fourth and fifth metacarpals, respectively. Insertion; (first) ulnar side of second finger; (second and third) radial sides of fourth and fifth fingers respectively.

Dorsal Interossei.-These are four muscles which occupy the interosseous spaces and are inserted like the Palmar interossei. Origin; sides of metacarpal bones bounding each interosseous space, by two heads. Insertion; (first and second) radial sides of index and third fingers and (third and fourth) ulnar sides of third and fourth fingers respectively.

[347]

Back of Forearm. Superficial Layer.

Brachio-radialis.-Origin; upper two-thirds of external supracondyloid ridge of humerus; external intermuscular septum. Insertion; ridge on front of base of styloid process of radius.

[349]

Extensor Carpi Radialis Longior.-Origin; lower third of external supracondyloid ridge of humerus; external intermuscular septum; external condyle, by the commion tendon. Insertion; back of base of second metacarpal.

[349]

Extensor Carpi Radialis Brevior.-Origin; external condyle of humerus, by the common tendon; external ligament of elbow; fascia over it; intermuscular septa. Insertion; back of base of third metacarpal.

[349]

Extensor Communis Digitorum.-Origin; external condyle, by the common tendon; intermuscular septa. Course; it ends in four tendons; on the back of the hand the inner three are 


\section{DISSECTING MANUAL.}

joined together by two oblique bands. Insertion; each tendon spreads out over the metacarpo-phalangeal joint of its finger, forming its posterior ligament, and over the first phalanx. At the lower end of this phalanx it splits into median and lateral slips, which pass over the back of the first inter-phalangeal joint and form the posterior ligament. The median slip is inserted in the back of the base of the second phalanx; the lateral slips then unite, pass over the next joint, and are attached to the base of the terminal phalanx.

[349]

Extensor Minimi Digiti.-Origin; external condyle, by the common tendon; fascia over it; intermuscular septa. Insertion; expansion of Extensor communis tendon on back of first phalanx of little finger.

[350]

Extensor Carpi Ulnaris._Origin; (humeral head) external condyle, by the common tendon; fascia over it; intermuscular septa; (ulnar head) middle two-fourths of posterior border of ulna, through the deep fascia. Insertion; back of base of fifth metacarpal.

[350]

Anconeus.-Origin; external condyle, by a separate tendon. Insertion; triangular surface on outer side of olecranon process and back of ulna, down to oblique line.

[350]

Deep Layer.

Supinator Radii Brevis.-Origin; external condyle; orbicular and external lateral ligaments of elbow; triangular surface on ulna below lesser sigmoid cavity; fascia over it. Course; envelops the upper part of the radius. Insertion; anterior and outer surfaces of radius, extending forward to the bicipital tuberosity, upward to the neck, and downward to the oblique line and insertion of the Pronator radii teres.

Extensor Ossis Metacarpi Pollicis.-Origin; posterior surfaces of radius and ulna, below the preceding; intervening portion of interosseous membrane. Insertion; outer side of base of first metacarpal.

[351] 


\section{FOREARM, WRIST, AND HAND.}

\section{Nerves.}

Musculo-cutaneous. - This divides in front of the elbow into two cutaneous branches. The anterior descends on the front of the outer side of the forearm to the wrist, supplying the outer half of the forearm in front, and the ball of the thumb and communicating with the radial. The posterior runs downward and backward, supplying the upper three-fourths of the outer side of the forearm posteriorly and communicating with the musculo-spiral.

Median.-Passing between the heads of the Pronator radii teres this descends in the midline under the superficial muscles, and then under the anterior annular ligament, external to the digital flexor tendons, where it divides into six terminal branches.

[627]

Branches in Forearm.-Articular : to the elbow-joint. Muscular: arising near the elbow, to the Pronator radii teres, Flexor carpi radialis, Palmaris longus, Flexor sublimis digitorum, and often the Flexor longus pollicis and Flexor profundus digitorum. Anterior interosseous: This descends with the anterior interosseous artery in front of the interosseous membrane and under the Pronator quadratus; it supplies these structures and also the Flexor longus pollicis, Flexor profundus digitorum (outer half), radius, ulna, and (terminal branches) radiocarpal joint. Palmar cutaneous (inconstant): arising low down this pierces the deep fascia and crosses the anterior annular ligament to the palm, supplying this and communicating with the ulna.

Branches in Hand.-M uscular: a branch running onto the ball of the thumb, to the Abductor, Flexor brevis (superficial head), and Opponens pollicis. Cutaneous: There are five branches, running between the flexor tendons and superficial palmar arch; the outer three supply the sides of the thumb and the radial side of the index finger; the inner two 


\section{DISSECTING MANUAL.}

divide at the finger clefts into branches supplying the adjacent sides of the second, third, and fourth fingers. All lie superficial to the digital arteries and supply the sides and front of each finger, with the back of the last phalanx of the thumb and last two phalanges of the index finger. The middle branch and the next internal supply the two outer Lumbricales. [629]

Ulnar.-Passing between the heads of the Flexor carpi ulnaris, and then descending under that muscle, and then on the inner side of the ulnar artery, it pierces the deep fascia external to the pisiform bone, crosses the annular ligament to the palm and divides under the Palmaris brevis into two branches, superficial and deep. It may communicate with the median in the forearm.

[629]

Branches in Forearm.-Articular: to the elbow-joint. Muscular: arising near the elbow, to the Flexor carpi ulnaris and Flexor profundus digitorum (inner half). Palmar cutaneous: a branch piercing the deep fascia low down and supplying the hypothenar eminence and palm. Dorsal cutaneous: This arises in the middle third and runs downward and backward under the Flexor carpi ulnaris; then becoming cutaneous low down on the inner side of the forearm it passes to the back of the hand. After supplying the wrist and back of the hand it divides. One branch supplies the back of the inner side of the little finger; the other divides at the finger cleft to supply the contiguous sides of the little and ring fingers, communicating with the radial.

[629]

Branches in Palm.-Muscular: to the Palmaris brevis. Superficial: a cutaneous branch which subdivides; the inner branch supplies the inner border of the little finger in front; the outer branch divides at the finger cleft to supply the adjacent sides of the little and ring fingers, in front, and communicate with the median. Deep: a muscular branch running between the Flexor brevis and Abductor minimi digiti; it supplies them and the Opponens minimi digiti, and then passes with the deep palmar arch, under the deep flexor tendons, to 


\section{FOREARM, WRIST, AND HAND.}

the Interossei, two inner Lumbricales, and the Flexor brevis (deep part) and Adductores, obliquus and transversus, pollicis.

[630]

Internal Cutaneous.--This divides in front of the elbow into two branches. The anterior descends to the wrist, supplying the inner half of the forearm in front; the internal runs downward and backward, supplying the upper two-thirds, or three-fourths, of the back of the forearm internally.

[631]

Musculo-spiral.-Before dividing in front of the elbow into the radial and posterior interosseous, this gives off two cutaneous branches which descend behind the external condyle. The superior branch supplies the upper half of the back of the forearm, and the inferior branch the upper two-thirds of the back of the forearm, internal to the area supplied by the musculo-cutaneous.

[633]

Radial.-This cutaneous nerve descends under the Brachioradialis and, lower down, on the outer side of the radial artery, passes backward under the Brachio-radialis tendon and pierces the deep fascia on the outer side of the forearm. It supplies the back of the wrist and hand, and divides into five digital branches; two supply the back of the thumb as far as the inter-phalangeal joint, one supplies the radial side of the index finger as far as the second phalanx; the others subdivide at the finger clefts to supply the adjacent sides of the second, third, and fourth fingers, as far as the second phalanges. It communicates with the musculo-cutaneous on the ball of the thumb, and the ulnar (dorsal branch) on the back of the hand.

[634]

Posterior Interosseous. - This runs downward and backward through the Supinator brevis and round the outer side of the radius. Then descending on the back of the forearm under the superficial extensors and with the posterior interosseous artery, it passes under the Extensor longus pollicis and upon the interosseous membrane. Then running under the extensor tendons to the back of the carpus it ends in a gangliform en- 


\section{DISSECTING MANUAL.}

largement giving articular branches to the carpal joints. Muscular branches supply the Extensor carpi radialis brevior, Supinator brevis, Extensor communis digitorum, Extensor minimi digiti, Extensor carpi ulnaris, Extensor ossis metacarpi pollicis, Extensor longus pollicis, Extensor brevis pollicis, and Extensor indicis.

\section{Arteries.}

The brachial divides in front of the elbow into the radial and ulnar.

[830]

Radial.-The first part descends under the Supinator longus and then runs superficially to the styloid process of the radius; thence the second part curves, under the tendons, around the outer side of the carpus and across the trapezium to the upper end of the first interosseous space; and thence the third part runs forward between the heads of the first Dorsal interosseous and then inward to join the deep branch of the ulnar and complete the deep palmar arcls.

[831]

Branches.-First part: radial recurrent, to front of external condyle; muscular; superficialis volæ, to front of ball of thumb, often completing the superficial palmar arch; anterior radial carpal, to front of carpus. Second part: dorsales pollicis, two branches to sides of thumb on dorsal aspect; dorsalis indicis, to radial border of dorsum of index finger; metacarpal (first dorsal interosseous) to second interdigital cleft, dividing to supply adjacent sides of second and third fingers; and posterior radial carpal, to back of carpus. Third part: princeps pollicis, to thumb, dividing to supply both sides of its dorsum; radialis indicis, to radial side of index finger.

[832]

Ulnar.-Running downward and inward under the superficial museles to the junction of the upper and middle thirds of the forearm, it then descends vertically, crosses the annular ligament external to the pisiform bone and enters the palm to form the superficial palmar arch.

[834]

Branches : anterior ulnar recurrent, to front of internal con- 


\section{FOREARM, WRIS'T, AND HAND.}

dyle, arising high up; posterior ulnar recurrent, to back of internal condyle, arising high up; common interosseous, arising high up, running backward toward upper border of interosseous membrane, and dividing into the anterior and the posterior interosseous; anterior ulnar carpal, to front of carpus, arising low down; posterior ulnar carpal, to back of wrist, arising low down; profunda, arising at lower end, descending between Abductor and Flexor brevis minimi digiti, and then turning outward under the latter to form the deep palmar arch.

[834]

The anterior interosseous descends on the front of the interosseous membrane, pierees this at the upper border of the Pronator quadratus and descends on the back of the membrane and then on the radius to the earpus. Branches: nutrient, to radius and ulna; muscular; anterior communicating, deseending under Pronator quadratus to anterior earpal areh; anastomotic, to posterior interosseous; comes nervi mediani, accompanying the median nerve. The posterior interosseous runs backward between the interosseous membrane and the oblique ligament, and descends between the superficial and deep muscles. Branches: posterior interosseous recurrent, ascending to back of external condyle; muscular; cutaneous, to back of forearm and wrist.

Arches.-The anterior carpal is formed by the anterior carpal branches of the radial and ulnar, on the front of the carpus, behind the flexor tendons. The posterior or dorsal carpal is formed by the posterior earpal branches of the radial and ulnar, on the back of the carpus, behind the extensor tendons. Branches: articular, to adjacent joints; dorsal interosseous, two branches descending to elefts between third, fourth, and fifth fingers and dividing into branches for adjacent sides of fingers forming each cleft. Each dorsal interosseous artery receives a branch (superior perforating) from the deep palmar arch through the upper part of the interosseous space, and sends a branch (inferior perforating) through the lower part 


\section{DISSECTING MANUAL.}

of the space to unite with a digital branch of the superficial palmar arch.

[835]

The superficial palmar is formed by the terminal part of ulnar which runs from the ball of the little finger across the palm, in the line of the lower border of the fully abducted thumb, just under the palmar fascia, and is usually completed by joining the superficialis volæ. Four digital branches descend from its convexity; the innermost runs along the ulnar border of the little finger, receiving a branch from the deep palmar arch or inner palmar interosseous; the outer three each receive a branch (inferior communicating, or perforating) from the dorsal interosseous, and one (palmar interosseous) from the deep palmar arch, and then divide at the clefts between the outer four fingers into two branches (collateral digital) for the adjacent sides of the fingers forming each of the clefts.

[836]

The deep palmar is formed by the terminal part of the radial joining the profunda branch of the ulna, half or three-quarters of an inch below the level of the superficial arch. It extends under the flexor tendons from the base of the fifth metacarpal to the upper end of the first interosseous space, crossing the bases of the metacarpals. Branches: superior perforating, three branches running through upper ends of three inner interosseous spaces to join dorsal interosseous arteries; recurrent, to anterior carpal arch; articular, to adjacent joints; palmar interosseous, three branches descending to join the three outer palmar digital arteries; communicating, to innermost palmar digital artery.

[836]

\section{VEINS.}

Deep Veins (venæ comites).-These accompany their arteries in pairs.

Superficial Veins.-These arise in the superficial fascia of the hand and form the following trunks: Median: commencing on the back of the thumb this winds round the outer bor- 


\section{FOREARM, WRIST, AND HAND.}

der of the forearm, ascends to the middle of the bend of the elbow, receives a branch (deep median) from the deep veins, and divides into the median cephalic and median basilic. $\mathrm{Me-}$ dian cephalic: running outward in the groove between the Biceps and Supinator longus, this joins the radial just above the external condyle, forming the cephalic. Median basilic: running inward in the groove between the Biceps and Pronator radii teres, this joins both ulnar veins, forming the basilic. Radial: commencing on the back of the hand, this ascends on the radial side of the forearm and joins the median cephalic. Anterior ulnar: commencing at the little finger, this ascends on the front of the ulnar side of the forearm and joins the median basilic. Posterior ulnar: commencing at the little finger this ascends on the back of the ulnar side of the forearm and joins the median basilic.

[890] 


\section{ABDOMEN AND PELVIS.}

\section{BONES.}

Lumbar Vertebræ.-There are five, distinguished by the absence of costal facets, and of foramina in the transverse processes. The body is large and kidney-shaped, widest transversely and thickest in front. The pedicles are short, stout, and directed backward; the superior notches are shallow, and the inferior deep. The lamince are broad and almost vertical. The spinal foramen is large and triangular. The spine is spatulous, thick posteriorly, and inclined slightly downward. The transverse processes run outward and slightly backward from the junction of pedicle and lamina in the upper ones, slightly more anteriorly in the lower ones. Each presents posteriorly, just external to and below the superior articular process, a small accessory tubercle. The superior articular processes spring from the pedicles and laminæ, and have concave, vertical, and in-turned facets; on the posterior edge of each is an elongated oval mammillary process. The inferior articular processes spring from the lower edges of the laminæ, at the root of the spine, and have convex, vertical, and out-turned facets.

Fifth Vertebra.-The body is the largest and its under surface is cut away behind. The transverse process is pyramidal and comparatively thick, and springs from the pedicle and body by a broad base; it is directed outward and slightly upward and backward, and its upper surface is slightly grooved by the superior notch; a deep notch separates it from the superior articular process, which looks backward and inward. The inferior articular processes are in line with the superior and 


\section{BONES.}

comparatively far apart. The spine is comparatively short and narrow.

Sacrum.-This is triangular and has an apex, base, two surfaces, and two sides. The anterior surface is concave vertically and (slightly) transversely. Its central part corresponds to the bodies of the five original vertebræ and has four transverse ridges at their lines of fusion. On either side these ridges end in four foramina (anterior sacral); these lie between five bony bars which unite externally in a solid mass (lateral mass). A groove leads outward from each foramen.

[83]

The posterior surface is convex; mesially it presents a ridge (crest) with four tubercles (rudimentary spines), and on each side of this a groove (sacral). On each side, in line with the intervals between the spines, and widest apart above, is a row of tubercles (articular processes). The most inferior of these tubercles project downward (sacral cornua) and the laminæ are absent (hiatus sacralis) between them. Just external to the articular processes are four foramina (posterior sacral); external to them, on the lateral mass, are four tubercles (transverse processes).

[84]

Base.-The body lies centrally and in front; the upper surface of the body articulates with the last lumbar vertebra and its anterior margin (promontory) projects. Behind the body is the triangular spinal canal, and behind this the spine. From the side and back of the body, on each side, springs a fan-shaped mass (ala), the upper edge of the lateral mass. Superiorly the ala is concave transversely and convex anteroposteriorly. From the back of the lateral mass on each side, and separated from it by a notch, springs a process (superior articular) with a vertieal facet which is concave transversely and looks backward and slightly inward.

[85]

The borders superiorly are thick and present articular surfaces (iliac articular surfaces) for the ilium, and behind this, on each side, three depressions. Inferiorly they are thin and each ends in an angle (inferior lateral). The apex is the small 


\section{DISSECTING MANUAL.}

oval body of the fifth sacral vertebra. The sacral canal is triangular above but flattened below, where it is deficient posteriorly.

Coccyx.--This consists of four (sometimes five, or three) rudimentary vertebræ, more or less fused. The first piece, the largest, has superiorly an oval facet, for the sacrum, and posteriorly two processes (cornua coccygea) which project upward to join the sacral cornua. A rudimentary transverse process projects on each side and may join the sacral inferior angle. The second vertebra has only rudimentary transverse processes and pedicles. The lower segments are mere nodules of bone.

Os Innominatum.-Each consists of three, originally separate, parts (ilium, ischium, and pubis) which have fused in and around the acetabulum. It belongs properly to the lower extremity.

Ilium.-This, the upper part, is a quadrilateral plate. The superior border (crest) curves with a double bend; externally it is convex in front and concave behind. It is thick and presents an outer lip, an inner lip, and an intermediate space; it ends in a pointed process (anterior superior spine) in front, and another (posterior superior spine) behind. The anterior border, descending from the spine to the margin of the acetabulum, is thin above but forms a thick process (anterior inferior spine) below. The posterior border, descending from the spine, is sharp and ends below in a prominent angle (posterior inferior spine); in front of this the edge of the bone becomes rounded and curves forward and downward to the acetabulum, forming a wide notch (ilio-sciatic, or great sciatic notch).

[214]

The external surface is divided into upper (gluteal) and lower (acetabular) parts, the latter forming nearly two-fifths of the acetabulum. The gluteal portion is concavo-convex antero-posteriorly and traversed by three curved ridges (curved lines). The inferior curved line begins just above the anterior inferior spine and runs toward the great sciatic notch. 


\section{BONES.}

The middle curved line begins at the crest, an inch and a half. behind the anterior superior spine, and runs toward the upper and back part of the great sciatic notch. The superior (posterior) curved line begins at the crest, two and a half inches in front of the posterior superior spine, and descends just in front of the posterior inferior spine.

The internal surface has two parts. The posterior (sacral) part presents anteriorly a smooth, articular surface for the sacrum; and above and behind this an elevated, irregular area (tuberosity). The anterior part is smooth and subdivided by an oblique ridge (ileo-pectineal line) which runs from the most prominent part of the articular surface toward the inner side of an (ileo-pectineal) eminence. The part above the ridge forms the iliac fossa, and the part below helps form the true pelvis.

Ischium.-This is the lower and hinder part and consists of a body and two rami. The body forms a little more than the inferior two-fifths of the acetabulum. The superior ramus, which runs downward and backward from the body, is a threesided bar from whose lower end the inferior ramus, a flattened bar, runs forward at an angle. On the outer aspect of the ischium, superiorly, the acetabular surface is marked off by a prominent margin which is deficient in front, forming the floor of the cotyloid notch. Below the acetabular margin there is a well-marked groove. The postero-external surface of the ischium forms the convex surface on the back of the acetabulum; a pointed process (spine) springs from its sharp inner border, opposite the lower edge of the acetabulum; lower down the surface narrows and its inner border is hollowed (small sciatic notch) out. A rough pyriform mass (tuberosity), with prominent inner and outer lips, caps the lower part of this surface and the angle between the rami; an oblique ridge divides it into two areas, supero-external and infero-external. The inner surface of the body and superior ramus helps form the wall of the true pelvis and is widest opposite the spine; 


\section{DISSECTING MANUAL.}

below this the posterior edge presents a marked groove. The inner surface of the inferior ramus is smooth and its lower edge tends to be everted.

Pubis.-This is the lower and front part and consists of a body and two rami. The body has two surfaces, inner (posterior) and outer (anterior), and two borders. The inner border presents an oval facet (symphysis). The thick upper border (crest) ends externally in a process (spine), and joins the inner border internally, forming the angle. The superior (ascending or horizontal) ramus runs upward and outward from the body and forms one-fifth of the acetabulum. It has three surfaces, viz.: internal (posterior), which is smooth and concave, with a sharp inferior border; antero-inferior, which roofs over a groove (obturator) running downward and forward between the lower borders of the antero-superior and internal surfaces; and antero-superior. The latter surface is triangular with its apex at the spine, while its base lies at the ileo-pectineal eminence above and the edge of the cotyloid notch below; the anterior border is a ridge (obturator crest) running from the spine to the cotyloid notch, while the posterosuperior border prolongs the ileo-pectineal line to the spine. The inferior (descending) ramus is flattened and runs downward and outward from the body to join the ischial ascending ramus. It has two surfaces, external and internal, and two borders, upper and lower; the latter is everted.

[218]

Acetabulum (cotyloid cavity).-This nearly circular hollow for the head of the femur looks downward, outward, and forward. A prominent margin surrounds it except opposite the obturator foramen, where it is deficient (cotyloid notch). The floor has a horseshoe-shaped articular surface, which encloses a rather circular rough area (fossa acetabuli) continuous with the floor of the cotyloid notch. Thyroid (obturator) foramen: This lies between the pubis and ischium; it varies in shape from oval to triangular. Its margins are sharp except where the obturator groove channels the pubic superior ramus. 


\section{ARTICULATIONS.}

Below, and on either side of this groove, are two tubercles: one (anterior obturator tubercle) lies on the lower border of the inner surface of the pubic superior ramus; the other (posterior obturator tubercle) lies just in front of the cotyloid notch, on the edge of the ischium.

[212]

\section{Articulations.}

Vertebral.-These are amphiarthrodial between the bodies, and arthrodial between the articular processes.

Intervertebral Discs.-These adhere to the contiguous surfaces of the bodies and consist of a pulpy centre surrounded by fibres, chiefly oblique and parallel; they are thickest on their anterior aspects.

[261]

Anterior Common Ligament.-This is a broad vertical band on the front of the bodies, attached to their margins and to the discs; the fibres vary in length.

Posterior Common Ligament.-This is a vertical band on the back of the bodies, attached to their margins and to the discs; being wider over the discs than the centres of the bodies, it forms dentations.

[263]

Capsular.-A thin but complete capsule, with a synovial membrane, encloses the articular facets.

[263]

Ligamenta Subflava.-This is a layer of yellow elastic fibres running from the front of each lamina, just above its lower border, to the back of the lamina below; it extends from the capsule to the spine, where it joins its fellow.

[263]

Interspinous Ligaments.-These are obliquely interlacing fibres, running from the tips of two adjacent spines to their opposing margins, and extending from tip to base.

[263]

Supraspinous Ligaments.-These are longitudinal bands, in continuity with the preceding, connecting the tips of the spines.

Intertransverse Ligaments. - These are vertical fibres between the transverse processes. 
Lumbo-sacral.-This joint between the last lumbar vertebra and the sacrum follows exactly the above vertebral type. It has also an accessory lateral lumbo-sacral ligament which runs from the front of the inferior border of the last lumbar transverse process, downward and outward to the front of the lateral aspect of the ala of the sacrum. Another (inconstant) band may run from the lower part of the side of the body of the last lumbar vertebra to the anterior surface of the ala of the sacrum.

[289]

Sacro-coccygeal.-There is an intervertebral disc between the sacrum and coccyx, and also the following ligaments: anterior, a continuation of the anterior common ligament; posterior, descending from the edge of the lower opening of the sacral canal; lateral, on each side; and interarticular, strong bands connecting the cornua.

Inter-coccygeal.-When separate, the coccygeal segments are united by intervertebral discs, and anterior and posterior ligaments.

[264]

Sacro-iliac.-There is a diarthrosis between the articular surfaces of the sacrum and ilium on each side. Fibrous bands may cross the capillary joint interval. There is a capsule (with a rudimentary synovial cavity) formed by the following ligaments : Anterior sacro-iliac: short fibres connecting adjoining surfaces of the sacral ala and the iliac fossa. Short posterior sacro-iliac: strong fasciculi running from the rough area on the ilium, above and behind its articular surface, downward and inward to the transverse tubercles and the depressions behind the first two sacral segments. Long (oblique) posterior sacro-iliac: a special superficial band of the preceding, running from the postero-superior iliac spine to the transverse tubercles of the third and fourth sacral segments.

[290]

The accessory ligaments are the following: Nio-lumbar: this is the thickened anterior lamina of lumbar fascia which runs, from the tip of the last lumbar transverse process, outward to the inner lip of the iliac crest, just behind its highest level, and 


\section{AR'TICULATIONS.}

also (lig. ilio-lumbale inferius) to the inner rough surface of the ilium between its crest and articular surface. Great (posterior) sacro-sciatic: This is a triangular layer attached by its base to the posterior inferior iliac spine, back of the transverse tubercles and lateral margins of the third to fifth sacral segments, and side of the first coccygeal segment; its apex, expanding somewhat, is attached to the inner side of the ischial tuberosity just below the groove for the Obturator internus tendon. A prolongation (processus falciformis) of its inner border runs upward and forward on the inner side of the ischial ramus. Small (anterior) sacro-sciatic. This is a triangular layer in front of the preceding, attached by its base to the lower two sacral segments and first coccygeal segment, and by its apex to the tip and upper aspect of the ischial spine.

Symphysis Pubis.-There is an amphiarthrosis between the bodies of the pubic bones. Between the hyaline cartilage plates covering them is seen an interposed fibro-cartilage in whose interior is a vertical cleft; this has no synovial membrane. The ligaments are anterior pubic, transverse and (superficially) oblique fibres connecting the bones; posterior pubic, weak transverse fibres connecting the bones behind; superior pubic, weak transverse fibres connecting the pubic crests; and inferior or subpubic, a strong band connecting the bones below, in the pubic arch, and extending laterally to the descending rami, while its lower border is free.

[292]

Triangular Ligament of Perineum.-This is a membranous layer which fills the pubic arch below, and is distinct from the subpubic ligament. Laterally it is attached to the sides of the arch; its base fuses with Colles' fascia; its apex (transverse perineal ligament) is free and well-defined. It has two surfaces, perineal and pelvic.

[292]

Obturator Membrane.-This is a membrane which fills the thyroid foramen and is attachcd to the pelvic aspect of the circumference. At its highest point it is incomplete and forms a U-shaped border, for the obturator canal.

[293] 


\title{
DISSECTING MANUAL.
}

\author{
Fasciæ and Musclis.
}

\section{Fascice and Muscles of Abdominal Wall.}

Fascia.-The superficial fascia is fatty and separated at the groin into two layers; a superficial fatty layer which is continuous over Poupart's ligament with the fascia of the thigh; and a deeper membranous layer which is attached to the inner half of Poupart's ligament and, more externally, to the fascia lata of the thigh below Poupart's ligament. The deep fascia is like the deep fascia elsewhere.

The fascia lining the abdomen (fascia transversalis) is a continuous membrane, named according to its location. It lines the Transversalis and is continuous with the diaphragmatic and iliac fasciæ and, through the lumbar facia, the fasciæ of the Quadratus lumborum and Psoas. It forms the infundibuliform fascia, helps form the femoral sheath, and is separated from the peritoneum by a thick and usually fatty layer of extra-peritoneal tissue.

[427]

Obliquus Externus Abdominis (the most superficial anteriorly).-Origin; outer surfaces of eight lower ribs, by slips interdigitating with the Serratus magnus and Latissimus dorsi. Course; radiates downward and forward. Insertion; anterior half or two-thirds of outer lip of iliac crest; ensiform cartilage, symphysis pubis, and linea alba through its triangular aponeurosis. This aponeurosis gives rise below to the following structures:

[427]

Poupart's Ligament.-This arched band is the lower limit of the aponeurosis and extends from the anterior superior iliac spine to the pubic spine. At its inner end a triangular band (Gimbernat's ligament) of fibres is reflected horizontally backward to the ilco-pectineal line. External abdominal ring: This is an extensive split in the aponeurosis, just above the pubic spine; its edges (pillars) are connected by a thin fascia strengthened superficially by arched and horizontal fibres [190] 


\section{FASCIA AND MUSCLES.}

(intercolumnar fibres) arising from Poupart's ligament. The outer edge (external pillar) joins the pubic spine and is continuous with Poupart's ligament; the inner edge (internal pillar) joins the pubic crest and symphysis. The pillars and intercolumnar fibres are continuous with a thin sheath (intercolumnar or external spermatic fascia) enveloping the cord, or round ligament, below the ring. Triangular fascia: This is a triangular band of fibres from the aponeurosis, which passes through the linea alba to the opposite side and there runs behind the internal pillar to join the pubic crest and spine. [429]

Obliquus Internus Abdominis (under the preceding).-Origin; lumbar fascia; anterior half of iliac crest; outer half of Poupart's ligament. Course; mostly upward and forward. Insertion; last three ribs (highest fibres); seventh to ninth costal cartilages, and linea alba from the ensiform cartilage to the pubic symphysis, through its broad aponeurosis. Its fibres, and those of the Transversalis, from Poupart's ligament unite in a band (conjoint tendon), which passes in front of the Rectus to the crest and spine of the os pubis, and the ileopectineal line.

[430]

Cremaster.-This consists of the lowest fibres of the preceding. Origin; lower border of Internal oblique; middle of Poupart's ligament. Course; arching, as a thin sheet of loops, over the cord and enveloping this and the testicle. Insertion; fascia; (uppermost fibres) pubic spine. In the female it is chiefly fascial (cremasteric fascia).

Transversalis (under the Internal oblique).-OOrigin; under surface of lower six costal cartilages, interdigitating with Diaphragm; lumbar fascia; anterior half of inner lip of iliac crest; outer third of Poupart's ligament. Course; mostly horizontal. Insertion; pubic crest and spine, and ileo-pectineal line, through the conjoint tendon (lower fibres); linea alba and ensiform cartilage through its aponeurosis.

Pyramidalis Abdominis (inconstant).-Origin; pubic crest in front of Rectus. Insertion; linea alba. 


\section{DISSECTING MANUAL.}

Rectus Abdominis.-Origin; pubic symphysis and crest, by two heads, inner and outer. Insertion; front of ensiform cartilage; fifth to seventh costal cartilages. On its anterior surface there are three or more transverse tendinous intersections (linece transversa) which adhere to its sheath; the lowest lies opposite the umbilicus and the highest about the level of the costal arch. The convex outer border of the muscle forms the linea semilunaris.

[432]

Sheath of Rectus.-This is derived from the aponeuroses of the lateral abdominal muscles. In the upper three-fourths of the abdominal wall the aponeurosis of the Internal oblique splits at the linea semilunaris; the anterior layer, joined by the External oblique aponeurosis, passes in front of the Rectus as the anterior lamina of the sheath; the posterior layer, joined by the Transversalis aponeurosis, passes behind the Rectus as the posterior lamina. In the lower fourth the aponeuroses pass in front of the Rectus, so that the sheath is deficient behind and the posterior lamina ends inferiorly in a crescentic border (fold of Douglas). Intcrnally all the aponcuroses interlace with those of the opposite side in a broad band (linea alba) attached to the ensiform cartilage and pubic symphysis.

[432]

Inguinal Canal.-This begins at the internal abdominal ring, an orifice lying in the transversalis fascia half an inch above Poupart's ligament and midway between the pubic symphysis and anterior superior iliac spine. It runs obliquely through the abdominal wall and ends at the external ring, which lies above the pubic spine and crest. Front wall; aponeurosis of External oblique; (outer part) Internal oblique. Back wall; transversalis fascia; (inner part) conjoint tendon. Floor; Poupart's ligament; (inner part) Gimbernat's ligament. The spermatic cord, in traversing it, receives three investments; the first (infundibuliform fascia) of transversalis fascia from the margin of the internal ring; the second (cremasteric fascia) from the lower border of the Internal oblique; and the third, 


\section{FASCIN AND MUSCLES.}

or external (intercolumnar fascia), from the edges of the external ring.

Hesselbach's triangle is bounded below by Poupart's ligament, internally by the Rectus, and externally by the deep epigastric artery on the mesial side of the internal ring; the fascia transversalis and conjoint tendon form its floor. The spermatic cord, covered by the External oblique aponeurosis, crosses its base.

Psoas Magnus.-Origin; intervertebral discs above each lumbar vertebra, and adjacent margins of vertebre from lower border of last thoracic to upper border of last lumbar; four aponeurotic arches passing over sides of bodies of upper four lumbar vertebræ; transverse processes of all lumbar vertebræ. Course; under Poupart's ligament. Insertion; apex of lesser trochanter of femur.

Psoas Parvus (inconstant).-Origin; intervertebral disc between last thoracic and first lumbar vertebræ, and their contiguous margins. Insertion; ileo-pectineal eminence and centre of ilio-pectineal line, by a narrow tendon.

[363]

Iliacus.-Origin; around margin of iliac fossa; (partially) anterior sacro-iliac and ilio-lumbar ligaments. Insertion; outer side of Psoas tendon; anterior surface of small trochanter of femur; (most external fibres) capsule of hip joint. The latter are often separate (Jliacus minor or Ilio-capsularis).

The iliac fascia covers the Iliacus and Psoas.

Quadratus Lumborum (lying cxternal to the Psoas and between the anterior and middle layers of lumbar aponeurosis).Origin; posterior part of iliac crest; ilio-lumbar ligament; lower lumbar transverse processes. Insertion; lower border of last rib; upper lumbar transverse processes.

[434]

Fascioe and Muscles of Back.

Fascia.-The superficial fascia is as elsewhere. The deep fascia forms the vertebral aponeurosis, a stronger layer which extends outward from the vertebral spines and over the pos- 


\section{DISSECTING MANUAL.}

terior surface of the Erector spinæ, being attached to the iliac crest and angle of the last rib. The lumbar fascia is a narrow band extending from the last rib to the iliac crest, between the muscles of the back and abdominal wall. It is formed, at the outer borders of the Quadratus lumborum and Erector spinæ, by the fusion of three fascial strata, as follows: The posterior layer is the vertebral aponeurosis; the middle layer extends outward from the tips of the transverse processes, between the Erector spinæ and Quadratus lumborum; the anterior layer begins at the junction of the transverse processes and bodies of the lumbar vertebræ and runs outward in front of the Quadratus lumborum.

[391]

Erector Spinæ.-Origin; iliac crest and posterior sacro-iliac ligament by fleshy fibres; iliac crest, back of sacrum, and spines of upper sacral and all lumbar vertebræ, by tendinous fibres continuous with preceding. Course; it ascends and divides into two columns, viz.: Ilio-costalis (the outer column and derived from the fleshy origin). Insertion; lower six ribs, by six slips. Longissimus dorsi (the inner and larger column). Insertion; nearly all the ribs, by an outer series of slips; transverse processes of thoracic, and accessory processes of upper lumbar vertebræ, by an inner series of slips. These columns are prolonged in the back and neck.

[393]

Spinalis Dorsi.-Origin; lower two thoracic and upper two lumbar spines; tendon of Longissimus dorsi. Insertion; upper (four to eight) thoracic spines.

[395]

Multifidus Spinæ.-Origin; sacrum; sacro-iliac ligament; lumbar mammillary processes; thoracic transverse processes; and lower four cervical articular processes. Course; upward upon the laminæ. Insertion; vertebral spines, except that of atlas.

[395]

Interspinales.-These are slips connecting together the spinous processes.

[398]

Intertransversales.-These are slips connecting the transverse processes.

[398] 


\section{FASCI 2 AND MUSCLES.}

Fascice and Muscles of Perineum.

Superficial Fascia.-This is continuous with adjacent superficial fasciæ and is prolonged onto the penis and scrotum; on the penis it is not fatty; on the scrotum it is intermingled with involuntary muscle fibres (Dartos muscle) and also forms an incomplete septum between the testicles. In the female it is fatty and helps form the mons veneris and labia majora. Over the posterior part of the perineum it fills the ischio-rectal fossæ, forming adipose pads.

Over the anterior part of the perineum it is divisible into a superficial fatty layer continuous with the same layer in the thigh, and the ischio-rectal fatty pads; and into a deeper membranous layer (Colles') which is attached to the pubic arch, the base of the triangular ligament, and, by a median raphe continuous with that of the scrotum, the root of the penis. Anteriorly it is continued over the spermatic cords to the anterior abdominal wall. The central tendinous point of the perineum lies over the base of the triangular ligament.

[435]

The deep fascia is practically non-existent.

Sphincter Ani Externus.-This is a flattened muscle surrounding the anus and divisible into three layers, viz.: Most superficial lamina; subcutaneous fibres decussating in front of and behind anus, without bony attachment. Sphincter ani superficialis (the main part); attached behind to coccyx, and in front to central point of perineum. Deep fibres; a complete sphincter for the canal, continuous with the Levator ani and blending with the Transversus perinei and central point of perineum.

Corrugator Cutis Ani.-Fibres radiating from anus, superficial to preceding.

Transversus Perinei Superficialis (inconstant). -Origin; ascending ramus of ischium and fascia over it; base of triangular ligament. Insertion; central point of perineum.

[436]

Bulbo-cavernosus.-Origin; central point of perineum, [195] 


\section{DISSECTING MANUAL.}

median raphe under bulb and corpus spongiosum. Course; outward and forward, surrounding bulb, corpus spongiosum, and root of penis. Insertion; under surface of triangular ligament; membrane over corpus spongiosum; fascia on dorsum of penis.

Ischio-bulbosus (inconstant).-Origin; ischium. Course; over Bulbo-cavernosus. Insertion; a raphe, superficial to Bulbo-cavernosus.

[436]

Compressor Hemispherium Bulbi.-This surrounds the end of the bulb, under the Bulbo-cavernosus.

Sphincter Vaginæ.-This consists of two layers covering the bulbs, separated by the vaginal and urethral orifices. Origin; central point of perineum. Insertion; root of clitoris, partly embraicing corpora cavernosa.

[436]

Ischio-cavernosus (Erector penis.)-Origin; ischial tuberosity; great sacro-sciatic ligament. Course; forward. Insertion; under surface of crus penis, and outer side and dorsum of corpus cavernosum. In the female (Erector clitoridis) it is smaller.

[436]

Pubo-cavernosus (inconstant).-Origin; pubic ramus. Insertion; dorsum of penis.

[437]

Compressor Urethræ (on pelvic aspect of triangular ligament).-Origin; lower part of pubic ramus. Course; radiating inward and enclosing urethra. Insertion; median raphe in front of and behind urethra. Certain fibres, without bony attachment, form a sheath for the urethra. In the female it is smaller; the anterior fibres are continuous with those of the opposite side, in front of the urethra; the middle fibres pass between the urethra and vagina; the posterior fibres join the side of the vagina with the Transversus perinei profundus (transversus vaginæ).

[437]

Transversus Perinei Profundus (a bundle lying below and behind the preceding).-Origin; ascending ramus of ischium. Insertion; median raphe.

Ischio-pubicus (inconstant).-A bundle lying above and in 


\section{FASCIE AND MUSCLES.}

front of the Compressor urethræ. Origin; pubic ramus. Insertion; median raphe in front of urethra.

[437]

Fascia and Muscles of Pelvis.

Fascia.-The parietal pelvic fascia is a cylindrical membrane which lines the pelvic wall, and acts as an aponeurosis for the muscles. It is attached above to the sacral promontory, ilio-pectineal line, and back of the pubis; below to the coccyx, great sacro-sciatic ligament, tuber ischii, and base of the triangular ligament; and on each side to the ischial spine. It is divided into the pyriformis fascia behind, obturator fascia laterally, and posterior layer of the triangular ligament in front. It is deficient at the obturator groove. A thickened band (white line) of it extends from the back of the pubis to the ischial spine.

[438]

The visceral pelvic fascia is a secondary sheet which springs from the white line and arches downward and inward to the viscera. Posteriorly this is thin as it passes from the lower sacral vertebræ to the rectum. Anteriorly it runs from the pubis to the neck of the bladder and prostate, forming two folds (pubo-prostatic ligaments) with a hollow (cavum Retzii) between them. Laterally (recto-vesical layer) it is divisible into three parts-vesical, rectal, and between these the rectovesical layer which passes between the rectum and bladder and encloses the seminal vesicles and vas deferens. It is separated from the peritoneum by the extra-peritoneal tissue, and is continuous mesially with the fibrous coats of the rectum and bladder, enclosing the prostate.

In the female it envelops the neck of the bladder, vagina, and uterus.

[439]

Levator Ani.-Origin; back of body of pubis; parietal pelvic fascia along or above white line; ischial spine. Course; downward and inward under visceral pelvic fascia and pelvic viscera. Insertion; central point of perineum; External sphincter around anus and ano-coccygeal raphe; sides of 


\section{DISSECTING MANUAL.}

coccyx and lower sacrum. It is divisible into four parts according to its termination, viz.: pubo-rectalis, inserted at central point of perineum; pubo-coccygeus, inserted at anus and ano-coccygeal raphe; ilio-coccygeus and ilio-sacralis, inserted at sacrum and coccyx.

[440]

Ischio-coccygeus.-This overlaps the posterior border of the preceding. Origin; ischial spine; small sacro-sciatic ligament. Insertion; sides of lower two sacral and upper two coccygeal vertebræ. The visceral pelvic fascia separates it from the rectum.

[441]

\section{NeRves.}

Posterior Spinal Nerves.-Lower Thoracic.-The external cutaneous branches supply the skin of the loin and (two lowest) buttock.

[613]

First, Second, and Third Lumbar.-These divide into internal and external branches. The internal branches supply the deep muscles of the back. The external (cutaneous) branches descend, pierce the vertebral aponeurosis posteriorly above the iliac crest, and supply the skin from the midline above the iliac crest to below and behind the great trochanter.

[613]

Fourth and Fifth Lumbar.- These (usually) supply only the longitudinal muscles of the back. A branch of the fifth may join the first sacral.

[613]

First, Second, and Third Sacral.--Loops between them, often joined by branehes of the fifth lumbar and fourth sacral, form the Posterior sacral plexus on the back of the sacrum. From the loops spring internal (muscular) branches to the Multifidus spinæ; and external cutaneous branches, piercing the sacro-sciatic ligament and Gluteus maximus, to the skin on the back of the sacrum and buttock near by.

Fourth and Fifth Sacral, and Coccygeal.-These unite as the Posterior sacro-coccygeal nerve, which pierces the sacro-sciatic ligament to supply the skin over the coccyx.

[614]

Anterior Spinal Nerves. - Seventh to Eleventh Thoracic.-At [ 198] 


\section{NERVES.}

the ends of the intercostal spaces they pierce the Diaphragm and Transversalis, and run forward between the latter and Obliquus internus; then passing between the Rectus and its sheath (posterior layer), and then through the Rectus and its sheath (anterior layer), they supply (anterior cutaneous branches) the midline from the ensiform cartilage to just below the umbilicus. Muscular branches supply the Transversalis, Obliqui, and Rectus. Lateral cutaneous branches descend through the interdigitations of the External oblique, supplying the loin down to the buttock; this branch of the eleventh extends over the iliac crest.

[638]

Twelfth Thoracic.- This runs forward below the last rib, under the Psoas, between the Quadratus lumborum and external arcuate ligament, then through the Transversalis and between this and the Internal oblique, and then through the Rectus and its sheath to (anterior cutaneous branch) the skin midway between umbilicus and pubis. Muscular branches supply the Transversalis, Obliqui, Rectus, and Pyramidalis. The lateral cutaneous (iliac) branch descends anteriorly over the iliac crest, to the buttock as far as in front of and below the great trochanter.

[638]

Lumbar, Sacral, and Coccygeal.-These form the Lumbo-sacral plexus which, for convenience, is divided into the lumbar, sacral (sciatic), and pudendal plexuses. From the abdominal and pelvic sympathetic cord each nerve receives gray rami communicantes, which cross the vertebræ under the Psoas. White rami communicantes run from the first two (sometimes first four) lumbar nerves to the upper part of the lumbar gangliated cord; and from the third (sometimes second, third, and fourth) sacral nerves, across the cord to the sympathetic pelvic plexus.

[639]

\section{IUMBAR PLEXUS.}

This lies deeply in the Psoas muscle, just in front of the transverse processes, and is formed by the first three and 


\section{DISSECTING MANUAL.}

part of the fourth lumbar nerves. The first and second each divide into upper and lower branches. The upper branch of the first (often getting a branch from the twelfth thoracic) divides into the ilio-hypogastric and ilio-inguinal. The lower branch of the first and upper branch of the second join, forming the genito-crural. The lower branch of the second, the third, and the portion of the fourth each divide into an anterior and a larger posterior part; the anterior parts (except sometimes that of the second) unite, forming the obturator; the posterior parts also unite, forming the anterior crural. The external cutaneous arises from the back of the posterior parts of the second and third. Muscular branches to the Quadratus lumborum arise from the first three or four lumbar (sometimes the last thoracic), and to the Psoas from the second and third (sometimes also the first or fourth) lumbar nerves near their origins.

[641]

Ilio-hypogastric.-This runs through the Psoas, across the Quadratus lumborum, and between the Transversalis and Internal oblique above the iliac crest. Then piercing the Internal oblique just in front of the anterior superior spine it runs between this and the External oblique aponeurosis, pierces the latter an inch and a half above the external abdominal ring and (as the hypogastric branch) supplies the adjacent skin. Muscular branches supply the abdominal wall. Iliac branch (inconstant); this descends through the abdominal wall and over the iliac crest behind the iliac branch of the last thoracic, to the skin on the upper and outer part of the buttock.

[642]

Ilio-inguinal.-This is often fused at first with the preceding; it runs a similar course, at a lower level, but pierces the Internal oblique further forward. It then runs through the external abdominal ring and supplies (cutaneous branches) the abdominal wall over the symphysis, the thigh over Scarpa's triangle supero-internally, and the top of the scrotum and root and dorsum of the penis (mons Veneris and labium majus). Muscular branches supply the abdominal wall.

[642] 


\section{NERVES.}

Genito-crural.-Arising by two roots which unite in the Psoas, the nerve then pierces and descends on the front of the Psoas, runs through the psoas fascia, along the outer side of the iliac vessels, and divides above Poupart's ligament into two branches, viz.: The genital branch runs across the external iliac vessels and through the inguinal canal to the skin of the scrotum (or labium majus) and adjacent thigh; branches go to the external iliac artery, Cremaster, and (sympathetic) spermatic plexus. The crural branch descends on the outer side of the femoral artery to the thigh.

[643]

External Cutaneous.-This runs under the Psoas, then across the Iliacus (under the iliac fascia) to the anterior superior spine and then under the end of Poupart's ligament to the thigh.

Obturator.-This arises by three roots which, in front of the anterior crural, unite in the Psoas and emerge at its inner border. The nerve then descends behind the common iliac and along the outer side of the internal iliac vessels, runs forward below the pelvic brim with the obturator artery, and entering the obturator canal divides into two branches, superficial and deep; these pass to the thigh.

Anterior Crural.-This arises by three roots which unite in the Psoas and emerge at its outer border. The nerve descends between the Psoas and Iliacus, sending a branch to the latter, and runs under Poupart's ligament, external to the femoral sheath, to the thigh.

\section{SACRAL (SCIATIC) PLEXUS.}

This lies at the back of the pelvis, between the Pyriformis and parietal fascia; it is formed by part of the fourth lumbar, the fifth lumbar, and the first three sacral nerves. The nerves converge into a triangular band whose apex runs through the great sacro-sciatic foramen below the Pyriformis, and then into the buttock as the great sciatic nerve. The lumbar and first two sacral nerves each divide into anterior and posterior 


\section{DISSECTING MANUAL.}

parts; the third sacral divides into upper and lower parts. The anterior parts of the lumbar nerves unite in one trunk, and the posterior parts in another, which together form the lumbosacral cord. The posterior parts of the lumbar and first two sacral nerves form the peroneal nerve; the anterior parts of the same nerves, together with the upper part of the third sacral, form the tibial nerve.

[647]

\section{PUDENDAL PLEXUS.}

This lies on the back wall of the pelvis and is formed by fibres from the first three sacral nerves, and all the fourth and fifth sacral and the coccygeal. A visceral branch (white ramus communicans) runs from the third (and second or fourth) sacral to the pelvic plexus and viscera. The perforating cutaneous nerve arises from the back of the second and third sacral and runs through the great sacro-sciatic ligament to the buttock. Muscular branches, from the loop between the third and fourth sacral, supply the Levator ani, Coccygeus, and External sphincter; offsets from the branch to the latter supply the skin on the ischio-rectal fossa and fold of the nates behind the anus. The anterior sacro-coccygeal nerves are the descending branches of the fourth and fifth sacral and the coccygeal; they form a plexus (coccygeal) beside the coccyx, and twigs from this run through the great sacro-sciatic ligament to the skin near the coccyx. The other branches of the pudendal plexus are the small sciatic and the pudic.

[655-658]

Small Sciatic.-Springing from the back part of the first three sacral nerves at the junction of the sacral and pudendal plexuses, this runs through the great sciatic notch, below the Pyriformis, to the thigh. Its perineal branch (inferior pudendal) arises at the lower border of the Gluteus maximus, runs inward over the hamstrings and below the ischial tuberosity, becomes subcutaneous over the pubic arch, and supplies the skin on the scrotum and root of the penis (labium majus and 


\section{NERVES.}

clitoris), eommunicating with branches of the ilio-inguinal and pudic.

[655]

Pudic.-Arising usually from the second, third, and fourth sacral, this runs through the great sacro-sciatic foramen below the great sciatic nerve; then crossing the ischial spine (or lesser sacro-sciatic ligament) it runs through the small sacrosciatic foramen with the pudic artery, and then along the outer wall of the ischio-rectal fossa in a sheath of parietal pelvic fascia, and divides at the base of the triangular ligament into the perineal nerve and the dorsal nerve of the penis. The inferior hemorrhoidal nerve, its other branch, arises usually at the back of the ischio-rectal fossa, but may arise separately from the plexus (third and fourth sacral) and accompany the pudic. It crosses the ischio-rectal fossa with the inferior hemorrhoidal vessels and divides into muscular branches, to the External sphincter; cutaneous, to the anus; and communicating, to the small sciatic, pudic, and fourth sacral.

[658]

The perineal nerve divides at once into two parts, superficial and deep. The superficial part consists of two nerves; one (posterior, or external superficial perineal) runs over the Transversus perinei and base of the triangular ligament, while the other (anterior, or internal superficial perineal) runs through them; both run forward to the skin of the scrotum (labium majus) and communicate with the small sciatic and inferior hemorrhoidal. The deep part runs forward between the layers of the triangular ligament, then pierces the anterior layer and the bulb of the urethra, to supply the erectile tissue and mucous membrane of the bulb and corpus spongiosum. Muscular branches supply the Levator ani, External sphincter, Transversus perinei, Erector penis (clitoridis), Bulbo-cavernosus (Sphincter vaginæ), and Compressor urethræ.

[659]

The dorsal nerve of the penis runs forward, with the internal pudic artery, under the superficial layer of the triangular ligament, and along the pubic arch, under the crus and Erector penis (vel clitoridis). Then piercing the triangular ligament it 


\section{DISSECTING MANUAL.}

runs on the dorsum of the penis (or clitoris) to supply the skin of the distal two-thirds. A branch (nerve to the corpus cavernosum) runs through the triangular ligament to the erectile tissue of the crus and corpus cavernosum.

[660]

\section{SYMPATHETIC SYSTEM.}

Lumbar Part of Cord.-This lies on the bodies of the vertebra, interual to the Psoas, and presents from four to eight ganglia; it is continuous with the thoracic and sacral portions. White rami communicantes pass to it from the first two or three lumbar nerves; gray rami communicantes pass from it to the anterior divisions of the lumbar nerves; all these rami pass under the Psoas. Numerous small branches go to the abdominal aorta and aortic plexus.

[710]

Sacral Part of Cord. - This lies on the sacrum, internal to the foramina; it is continuous with the lumbar cord above and ends below, over the coccyx, in a plexiform (parietal branches) union with the opposite cord, the two parts being often connected by the coccygeal ganglion (ganglion impar). It usually presents four ganglia. It receives no white rami communicantes, but gray rami communicantes pass from it to the anterior divisions of the sacral and coccygeal nerves. Visceral branches from its upper part join the pelvic plexus.

[711]

Plexuses.-Taken together there are three, the solar, hypogastric, and pelvic. They are formed by peripheral branches of the lower thoracic, lumbar, and upper sacral parts of the gangliated cord, and supply the abdominal and pelvic viscera and vessels. They are connected with the central nervous system through its visceral branches (white rami communicantes). The visceral branches of the middle sacral nerves pass directly to the plexuses, but those of the lower thoracic and upper lumbar nerves pass indirectly, first joining the gangliated cord and then running in (chiefly) the splanchnic nerves and (partly) the lumbar part of the cord.

[712]

Solar Plexus.-This lies on the posterior abdominal wall, [204] 


\section{NERVES.}

behind the stomach, and consists of the cœliac plexus and two semilunar ganglia. Its branches form subordinate plexuses on the aorta and its branches; one of these (the aortic) is continuous with the hypogastric plexus through the hypogastric nerves.

[712]

Semilunar Ganglia.-One lies on each crus of the Diaphragm, under the suprarenal capsule and (right sicle) inferior vena cava. They are irregular, often subdivided, and the lower end (aortico-renal ganglion) is detached; the great splanchnic nerve joins the upper end, and the smaller splanchnic the lower end. Branches radiate to the subordinate plexuses. Other small cell masses (ganglia coeliaca) are present in the cœliac plexus.

[712]

Coliac Plexus.-This is a dense meshwork surrounding the origin of the coeliac axis, joined by branches of the semilunar ganglia and right vagus, and continuous below with the superior mesenteric and aortic plexuses. It forms subsidiary plexuses on the branches of the coliac axis: coronary, hepatic, and splenic.

[713]

Subordinate Plexuses. - These are formed on, and named from their location on, the aorta and its branches viz.: The diaphragmatic accompanies the inferior phrenic artery, is formed by branches of the semilunar ganglion, and communicates with the phrenic nerve. A ganglion (diaphragmatic) develops at its junction with the right phrenic nerve. The suprarenal is mainly derived from the semilunar ganglion and receives branches from the diaphragmatic and renal plexuses. The renal is derived from the semilunar ganglion and aortic plexus, receives the least splanchnic nerve, and is connected with the suprarenal plexus. The superior mesenteric is continuous with the coliac and artic plexuses, receives branches from the semilunar ganglion, and contains a ganglion (superior mesenteric). Its branches form plexuses on the arterial branches. The aortic lies on the abdominal aorta, continuous with the solar and superior mesenteric plexuses, and receives branches from 


\section{DISSECTING MANUAL.}

the lumbar gangliated cord. It is connected with subordinate plexuses and gives off the hypogastric nerves. The spermatic is derived from the aortic plexus and gets branches from the renal. The ovarian has the same origin as the preceding and is connected with the uterine plexus. The inferior mesenteric is derived from the aortic plexus and forms plexuses on the branches of the inferior mesenteric artery.

[713]

Hypogastric Plexus.-This is formed from the hypogastric nerves, which descend from the aortic plexus on the aorta and become plexiform over its bifurcation and the sacral promontory. It continues downward on the sacrum on either side of the rectum, bifurcating, and ends in the pelvic plexuses. [714]

Pelvic Plexuses. - These are prolongations of the halves of the hypogastric plexus, one on each side of the rectum. Each accompanies the internal iliac artery and its branches and gives off subordinate plexuses. Each gets fibres from the upper sacral part of the gangliated cord, and visceral branches from the sacral nerves.

[714]

Subordinate Plexuses.-The hemorrhoidal is connected with the inferior mesenteric. The vesical lies on the vesical arteries. The prostatic lies on either side of the gland, and is prolonged forward on each side as the cavernous plexus of the penis. The uterine accompanies the artery between the folds of the broad ligament and communicates with the ovarian plexus. The vaginal is formed mainly by visceral branches of sacral nerves entering the pelvic plexus, and forms a cavernous plexus for the clitoris.

\section{Arteries.}

Abdominal Aorta.-Beginning at the aortic opening in the diaphragm, at the middle of the lower border of the last dorsal vertebra, this descends on the left side of the spine to the left side of the body of the fourth lumbar vertebra, and there divides into the common iliac arteries. 


\section{ARTERIES.}

\section{Paired Branches.}

The inferior phrenic runs behind (right side) the inferior vena cava or (left side) œsophagus and across the crus to the inferior surface of the diaphragm, dividing into two branches, internal and external; a branch (superior capsular) of ten supplies the suprarenal body. The lumbar are four (or five) branches on each side which cross the spine under the Psoas and pass forward between the Transversalis and Internal oblique; their branches are dorsal and muscular. The middle suprarenal (capsular) runs above the renal artery to the suprarenal gland. The superior and inferior suprarenal arise from the inferior phrenic and renal respectively.

[839]

The renal arises high up and runs almost transversely behind the pancreas, and (right side) inferior vena cava and duodenum, to the hilus of the kidney, which it enters, dividing into three branches; of these one passes behind the pelvis of the ureter and two in front. Branches; inferior suprarenal, to the suprarenal body; ureteral, to the ureter; peri-renal, to the kidney capsule; glandular, to renal and lumbar glands. [842]

The spermatic arises just below the renal and descends over the external iliac artery and the ureter to the internal abdominal ring, then traverses the inguinal canal and descends to the scrotum. Branches; ureteral to the ureter; cremasteric, to the Cremaster; ependymal, to the epididymis; and testicular to the testicle. The ovarian has the same origin and earlier course as the spermatic, but turns inward near the internal abdominal ring, descends into the pelvis, and runs in the broad ligament. Branches; ureteral to the ureter; tubal, to the Fallopian tube; ligamentous, to the round ligament; ovarian, to the ovary; and uterine, to the uterus.

[842]

\section{Unpaired Branches.}

The middle sacral arises just above the bifurcation of the aorta and descends in the midline, upon the sacrum and coccyx, to the tip of the latter. 
The coliac axis arises high up, from the front of the aorta, runs forward for about half an inch, and then divides into three branches, coronary, hepatic, and splenic.

The coronary (cœliac axis) runs to the left and then bending sharply, along the lesser curvature of the stomach, in the lesser omentum, to join the pyloric branch of the hepatic. Branches; œsophageal, to the œsophagus; gastric, to the stomach. [844]

The splenic (cœliac axis) runs along the upper border of the pancreas, across the suprarenal body and kidney, and in the lieno-renal ligament, dividing into branches which enter the hilus of the spleen. Branches. Pancreatic, small branches (pancreatica parvæ) to the gland and a large one (pancreatica magna) running in it from left to right, just above the duct. Vasa brevia, small branches to the left end of the stomach. Left gastro-epiploic, running along the greater curvature of the stomach from left to right, in the great omentum, to join the right gastro-epiploic.

[844]

The hepatic (cœliac axis) runs along the head of the pancreas, then forward in the right pancreatico-gastric fold to the duodenum, and then upward in the small omentum in front of the portal vein; it divides at the transverse fissure of the liver into the right and left hepatic. Branches. Pyloric, to the pylorus and lesser curvature of the stomach, joining the coronary. Gastro-duodenal; descending behind the duodenum this divides into two branches; one (right gastro-epiploic) runs along the greater curvature of the stomach; the other (superior pancreatico-duodenal) runs between the duodenum and head of the pancreas, supplying both. Left hepatic; after supplying the Spigelian lobe, this enters the left end of the transverse fissure. Right hepatic; after running behind the cystic duct and sending a branch (cystic) along it to the gall bladder, this enters the right end of the transverse fissure.

The superior mesenteric arises from the front of the aorta just below the cœliac axis, descends between the pancreas and duodenum, enters the mesentery, and then curves downward 


\section{AR'TERIES.}

and to the right in this to the right iliac fossa. Branches. Rami intestini tenuis; intestinal branches running in the mesentery; each divides and the branches unite to form arches from which other branches arise; this process is kept up till there are four or five tiers of arches. Inferior pancreaticoduodenal; running between the duodenum and pancreas this divides into branches which ascend in front of and behind the pancreas. Middle colic; running in the transverse mesocolon this divides into two branches, right and left, which join, respectively, the right and left colic. Right colic; running behind the peritoneum toward the ascending colon this divides into two branches, ascending and descending, which join the middle colic and ileo-colic respectively. Ileo-colic; running behind the peritoneum toward the lower end of the ascending colon, this divides into two branches, ascending and descending, which join the right colic and ileo-cæcal respectively. Terminal; ileal, to the lower end of the small intestine; appendicular, running in the meso-appendix to the appendix; anterior and posterior ileo-creal, to the front and back of the ileocxcal junction; and colic, to the ascending colon.

[845]

The inferior mesenteric arises from the aorta below the preceding, descends to the left common iliac, and there becomes the superior hemorrhoidal. Branches. Left colic; running toward the splenic flexure this divides into ascending and descending branches, which join the middle colic and sigmoid respectively. Sigmoid; running toward the sigmoid flexure this divides into ascending and descending branches, which join the left colic and superior hemorrhoidal respectively. Superior hemorrhoidal; crossing over the left common iliac, this descends in the pelvis to the third sacral vertebra and divides into two branches, which descend on either side of the rectum.

[847]

Common Iliac.-Beginning at the middle of the body of the fourth lumbar vertebra, just to the left of the midline, each muns downward and outward on the spine and becomes the 


\section{DISSECTING MANUAL.}

internal iliac in front of the lumbo-sacral joint, at the same time giving off the external iliac. The right common iliac crosses the inferior vena cava and common iliac veins.

Internal Iliac (hypogastric).-Beginning at the lumbo-sacral joint this descends into the pelvis and divides, usually at the upper border of the great sciatic notch, into two divisions, anterior and posterior. Branches of posterior division. The iliolumbar ascends over the pelvic brim to the iliac fossa, sending a branch (lumbar) upward under the Psoas, and another (spinal) to the spine. The lateral sacral are two branches (superior and inferior) which descend on the front of the sacrum and coccyx. The gluteal is a continuation of the posterior division; it runs through the great sciatic foramen, just above the Pyriformis, to the buttock where it divides into two branches, superficial and deep. In the pelvis its branches are muscular; neural, to the sacral plexus; and nutrient, to the hip-bone.

[848]

Branches of Anterior Division.

The vesical are the superior, middle, and inferior; they supply the upper part, back, and base of the bladder respectively, The obliterated hypogastric is a fibrous cord which crosses the pelvic wall under the vas deferens, or round ligament, and ascends on the abdominal wall, external to the urachus, toward the umbilicus. The artery to the vas accompanies the vas deferens. The middle hemorrhoidal supplies the rectum. The vaginal supplies the walls of the vagina and corresponds to the inferior vesical in the male. The uterine runs in the broad ligament, crossing the ureter, to the neck of the uterus, then ascends on the side of the body almost to the fundus, and then runs outward under the Fallopian tube to join the ovarian artery.

[851]

The obturator runs along the pelvic wall, just below the brim, and through the obturator foramen, dividing into external and internal branches which skirt round the margin of the fora- 


\section{ARTERIES.}

men. Its branches in the pelvis are muscular; nutrient, to the ilium; vesical, to the bladder; and pubic, to the back of the pubis.

The internal pudic descends on the sacral plexus and then runs through the great sciatic foramen below the Pyriformis; then crossing the ischial spine, it runs through the small sciatic foramen and along the wall of the ischio-rectal fossa in Alcock's canal; then continuing between the layers of the triangular ligament close to the pubic ramus, almost to the subpubic ligament, it pierces the anterior layer of the triangular ligament. Branches. (Buttock): muscular and anastomotic. (Ischio-rectal fossa): inferior hemorrhoidal, to lower end of rectum; superficial perineal, running forward on perineum under superficial fascia; transverse perineal, running inward at base of perineum. (Urethral triangle): artery to the bulb, to bulb of corpus spongiosum (or vestibule); artery of corpus cavernosum, to crus penis (vel clitoriclis); dorsal artery of penis (or clitoris), running along dorsum of the penis (or clitoris) to the glans.

The sciatic descends through the sacral plexus, runs through the great sciatic foramen below the Pyriformis, and descends in the buttock with the great sciatic nerve. Small visceral, muscular, and neural branches arise in the pelvis.

[854]

External Iliac.-Beginning at the lumbo-sacral joint this runs along the pelvic brim, upon the iliac fascia, to a point under Poupart's ligament midway between the symphysis pubis and iliac anterior superior spine, and there becomes the femoral artery. Its vein lies internal to it and both are enclosed in a thin fascial sheath. Branches. Twigs to the Psoas and the lymphatic glands; deep epigastric; deep circumflex iliac.

[856]

The deep epigastric arises just above Poupart's ligament and turns round the lower border of the peritoneal sac; then ascending along the inner side of the internal abdominal ring and outer border of Hesselbach's triangle, it pierces the sheath 
and runs upward behind and then in the Rectus. At the internal ring the vas deferens (or round ligament) and genital nerve hook rounds its front and outer side. Its branches are muscular; cutaneous, to the anterior abdominal wall; cremasteric, descending in the inguinal canal to the cord (or round ligament); and pubic, descending beside the crural ring to the pubis.

[856]

The deep circumflex iliac runs just above the lower border of Poupart's ligament to the anterior superior iliac spine, then through the Transversalis, and then backward between this muscle and the Internal oblique. Its branches are muscular and cutaneous.

[857]

\section{Veins.}

Inferior Vena Cava.-Commencing on the right side of the body of the fifth lumbar vertebra, by the union of the common iliacs, this ascends on the right side of the spine, to the right of the aorta, and pierces the diaphragm opposite the eighth dorsal vertebra. Tributaries. The hepatic veins open into its upper end, just under the diaphragm, in two groups: the upper group consists of $\mathbf{a}^{*}$ right, a left, and (usually) a Spigelian trunk, from those lobes; the lower group consists of from six to twenty small veins from the right and Spigelian lobes. The renal veins are single and lie in front of their arteries: the left one crosses over the aorta. The inferior phrenic are the vense comites; the left ones usually end in the left suprarenal vein. The suprarenal veins are single; the left one usually joins the left renal vein. There are usually four lumbar veins on each side, one with each artery; they may all end in a common trunk which joins the inferior vena cava; on each side they are all united by the ascending lumbar vein. The spermatic veins form a plexus (pampiniform) about the cord, from which two veins ascend through the internal ring and unite later in a single trunk, which joins the (right side) vena cava or (left side) left renal vein. The ovarian veins form a plexus (pam- 


\section{VEINS.}

piniform) in the broad ligament from which two veins ascend and, uniting later, end like the spermatic veins.

[892]

Common Iliac.-Each commences at the pelvic brim, by the union of the internal and external iliacs, ascends to the fifth lumbar vertebra and unites with its fellow to form the inferior vena cava. The right vein lies at first behind and then to the outer side of its artery; the left vein lies internal to its artery and then under the right common iliac artery. They receive the ilio-lumbar veins; the left common iliac receives the middle sacral vein.

[895]

Internal Iliac.-This is single and accompanies its artery. Its tributaries are the obturator, internal pudic, sciatic, gluteal and lateral sacral venx comites, with vessels from the plexuses, and the middle hemorrhoidal, uterine, vaginal, and vesical veins. Plexuses; the uterine lie along the lateral borders of the uterus and give rise to (usually) two uterine veins on each side; the vaginal lie at the sides of the vagina and give rise to a single vaginal vein on each side; the superior vesical occupies the sides and top of the bladder and empties into the prostatico-vesical (inferior vesical, in the female) plexus; the prostatico-vesical lies round the prostate and neck of the bladder and sends efferent branches on each side to the internal iliac; the inferior vesical, representing the preceding in the female, lies around the neck of the bladder and upper part of the urethra. The deep dorsal vein of the penis runs in the nidline under the deep fascia and joins the prostatico-vesical plexus; the dorsal vein of the clitoris has a similar course and ends in the inferior vesical plexus. The superficial dorsal vein of the penis divides to join the superficial external pudic vein of each side.

[895]

External Iliac.-Beginning under Poupart's ligament as a continuation of the femoral this ascends to the pelvic brim, at first internal to and then behind its artery, and joins the internal iliac. Its branches correspond to those of the artery and it also reeeives the pubie branch of the obturator.

[899] 


\section{DISSECTING MANUAL.}

Portal System.-The veins involved are single; the tributaries of origin agree closely with the terminal arterial branches and have similar names. The terminal veins, however, leave their arteries finally; the inferior mesenteric vein joins the splenic and the latter unites with the superior mesenteric to form the portal vein.

[901]

Portal Vein.- Commencing by the union of the splenic and superior mesenteric, behind and to the left of the neck of the pancreas, this ascends behind the duodenum to the foramen of Winslow and runs forward in the right pancreatico-gastric fold to the gastro-hepatic omentum; then ascending in front of the foramen of Winslow, behind the bile duct and hepatic artery, to the transverse fissure of the liver, it divides into two branches, right and left, for those lobes. The left branch also supplies branches to the quadrate and Spigelian lobes; the round ligament joins it in front, while from its back a fibrous cord (ductus arteriosus) runs to the inferior vena cava. The coronary and pyloric veins join the portal vein; the cystic vein joins its right branch.

[902]

The superior mesenteric begins in the right iliac fossa and ascends on the right of its artery, receiving corresponding branches. The splenic begins at the hilus of the spleen and runs just below its artery and then across the aorta; besides branches corresponding to those of the artery it receives the inferior mesenteric. The inferior mesenteric begins as the superior hemorrhoidal, which drains the hemorrhoidal plexus surrounding the rectum. It ascends with its artery, receiving the sigmoid and left colic; then crossing over the left renal vein it runs behind the pancreas and joins the splenic. [903]

\section{LYMPHATICS.}

The thoracic duct begins as an elongated ovoid dilatation, (receptaculum chyli) which is two or three inches long and lies in front of the two upper lumbar vertebræ, between the aorta 


\section{LYMPHATICS.}

and vena azygos major, under the right crus of the diaphragm. It ascends through the aortic opening of the diaphragm and then along the spine to empty into the left innominate vein. It drains the lower half of the body.

[906]

The deep glands are in two groups, visceral and parietal.

The visceral glands are the following: gastric, in three groups, one (coronary) lying along the lesser curvature of the stomach and behind the cardiac orifice, one (sub-pyloric) along the greater curvature near the pylorus, and the third (retro-pyloric) behind the pylorus and first part of the duodenum; splenic, lying at the hilus of the spleen; hepatic, lying below the transverse fissure of the liver in the small omentum; pancreatic, lying along the upper border of the pancreas; superior mesenteric, lying in the mesentery, especially the jejunal; ileo-cocal, lying in the lowest part of the mesentery, between the ileum and ascending colon; rectal, lying in the meso-rectum; inferior mesenteric, lying along that artery and its branches; colic, lying in the meso-colon; and caliac, lying around the cœliac axis and adjacent part of the aorta.

[918]

The parietal glands are the following: External iliac, lying on either side and in front of that artery in three groups, outer, middle, and inner, of which the latter extends into the pelvic cavity as far as the obturator nerve; obturator (inconstant), lying at the back of the obturator canal; circumflex iliac and epigastric (inconstant), lying along the deep circumflex iliac and deep epigastric arteries; supra- and infra-umbilical (inconstant), lying on the posterior surface of the Rectus sheath, above and below the umbilicus; internal iliac, lying along that artery, on the pelvic wall below the obturator nerve; lateral sacral, lying on the front of the sacrum internal to the anterior sacral foramina; common iliac, lying along that artery; lumbar (inconstant), lying on the lumbar transverse processes behind the Psoas; and aortic, lying along all sides of the abdominal aorta and therefore known as the pre-aortic, lateral aortic, and retro-aortic glands.

[920] 


\section{DISSECIING MANUAL.}

\section{DIGESTIVE SYSTEM.}

Stomach.-This is pyriform, ten or eleven inches long, four to four and a half inches wide, and will hold about a quart; its long axis is almost horizontal when empty but runs obliquely forward, downward and to the right when distended. It has two ends, cardiac and pyloric; two margins, greater and lesser curvatures; two surfaces, superior and inferior; and two orifices, cardia and pylorus. It is firmly fixed at the cardia but movable elsewhere.

[1050]

The upper surface is the more convex and larger. It is in relation with the diaphragm, anterior abdominal wall, and left lobe of the liver when distended; when empty, the transverse colon intervenes. The lower surface is in relation with the diaphragm, spleen, left kidney and suprarenal, pancreas, and transverse colon and mesocolon. The cardiac end (fundus) is a large rounded cul-de-sac directed backward and to the left. The pyloric end is a narrow and cylindrical prolongation joining the duodenum; when distended this has a special dilatation (antrum pylori).

[1054]

The lesser curvature extends from pylorus to cardia and is directed toward the liver. The greater curvature is three times as long, extends from the cardia over the fundus to the pylorus, and is directed forward and to the left. The esophageal orifice (cardia) opens into the gullet and lies deeply, opposite the eleventh dorsal vertebra. The pyloric orifice (pylorus) opens into the duodenum; it presents an external constriction, marking an internal thickening (pyloric valve) of the wall produced by circular muscular fibres (Sphincter pylori).

[1055]

Structure.-There are four coats, as follows, from without inward: The peritoneal consists of greater sac anteriorly and lesser sac posteriorly, and covers it completely except over a small triangular area posteriorly, below and to the left of the cardia. The muscular consists of an external longitudinal 


\section{DIGESTIVE SYSTEM.}

layer throughout; of a middle circular layer on the body and pyloric end, where it forms the sphincter; and of an internal circular layer on the fundus. The submucous is loose connective tissue. The mucous is thickest at the pylorus.

[1058]

Structure of Intestines.-All have four coats, as follows, from without inward: Peritoneal, varying in extent. The muscular coat cousists of an inner circular layer, forming the pyloric and ilio-creal valves; and an outer longitudinal layer covering the small intestine completely but gathered in three bands (tæniæ coli) on the large intestine. The submucous is loose areolar tissue. The mucous consists, from within outward, of an epithelial layer, a basement membrane, a retiform layer, and a muscular layer (Muscularis mucosæ).

[1061]

The valvulc conniventes are permanent transverse and rather crescentic folds which rarely form a complete circle, and are composed of two layers of mucosa with submucosa. They occur only in the small intestine, beginning in the duodenum an inch or two below the pylorus, becoming prominent in its lower half and the upper half of the jejunum, and then disappearing at the middle of the ileum. The villi are minute projections on the mucosa.

[1062]

The solitary glands are minute lymphatic nodules found everywhere in the mucosa. Peyer's patches are aggregations of solitary glands which form slightly elevated areas, half an inch long, or less. There are thirty or forty, found only in the small intestine, chiefly in the lower part of the ileum and always along the free border.

[1063]

Small Intestine.-This is cylindrical, an inch or more in liameter, and over twenty feet long. It is divided into the duodenum, the upper eleven inches, which is fixed and has no mesentery; the jejunum, the upper two-fifths of the remainder, about eight feet long, lying above and to the left; and the ileum, the lower three-fifths, about twelve feet long, lying below and to the right.

[1064]

Duodenum.-From the pylorus this curves round the head 


\section{DISSECTING MANUAL.}

of the pancreas, and then bends forward to become the jejunum. It has three parts. The first portion runs from the pylorus to the right and backward, ending at the neck of the gall bladder where it turns downward; it is an inch and a half to two inches long. Peritoneum covers its first inch entirely, but only the front beyond this point. Above and in front of it is the quadrate lobe; below are the neck and head of the pancreas; and behind are the portal vein, bile duct, and (to the right) vena cava.

[1065]

The second (descending) portion is three and a half or four inches long and descends to the right side of the third or fourth lumbar vertebra; peritoneum covers it in front, except under the colon. In front of it are the gall bladder above, small intestine below, and the transverse colon crossing it mesially; behind it is the right kidney; externally is the liver and internally the vena cava and pancreas, with the common bile duct intervening.

[1068]

The third portion runs transversely (transverse part) for an inch or two across the vena cava, then ascends (ascending terminal part) in front of the aorta and Psoas to the lower edge of the pancreas, and then bends (duodeno-jejunal flexure) sharply forward to become the jejunum. Peritoneum covers it anteriorly, except under the mesentery and superior mesenteric vessels and also on the left side of the ascending terminal part. The mesentery and superior mesenteric vessels cross it anteriorly; behind it are the vena cava, aorta, left renal vessels, and left Psoas; above it is the pancreas. The duodenojejunal flexure is fixed by a band of unstriped muscle (suspensory muscle of duodenum, or muscle of Treitz) running from it: to the connective tissue around the cœliac axis.

[1068]

Duodenal Fosse.-On drawing the ascending terminal part to the right, two peritoneal folds are generally seen at its left, extending from it to the parietal peritoneum. The upper (superior duodenal fold) has its lower edge free and under it is the superior duodenal fossa, which opens downward; the lower [218]. 


\section{DIGESTIVE SYSTEM.}

(inferior fold) has its upper edge free and the inferior duodenal fossa under it opens upward. The paraduodenal fossa (infantile) is further to the left; its fold is vertical, with the right edge free, produced by and containing the inferior mesenteric vein. A duodeno-jejunal fossa, at the front of the flexure, and five others have been described.

[1068]

The bile papilla is prominent, contains the common orifice of the bile and pancreatic ducts, and lies on the inner aspect of the interior of the descending portion, three and a half to four inches below the pylorus.

[1070]

Jejunum and Ileum.-Both are connected to the parietes by the mesentery, a large and fan-shaped peritoneal fold about six inches long, containing their vessels and glands. The mesentery is attached (root of the mesentery) along an oblique line, six or seven inches long, extending approximately from the left side of the second lumbar vertebra to the right iliac fossa, crossing the terminal part of the duodenum, aorta, vena cava, ureter, and Psoas. The jejunum is the wider, redder, and more vascular, with thicker walls and prominent valvulx conniventes, but few Peyer's patches; the ileum has many and larger Peyer's patches but few valvulæ conniventes. Meckel's diverticulum (inconstant) is a wide protrusion, about two inches long, from the lower part of the ileum.

[1071]

Large Intestine.-This is about five feet long, or more, curves around the small intestine, and is divided into the cxcum, the ascending, transverse, descending, iliac, and pelvic colon, and the rectum. It is three inches wide in the crecum but diminishes beyond this, to an inch and a half in the iliac colon. The appendices epiploice are small fatty peritoneal pouches which project from it everywhere except on the rectum. The tonice coli are three bands, about a quarter of an inch wide and one-sixth shorter than the gut, into which the longitudinal muscular fibres are gathered. They produce sacculations of the gut, are nearly equidistant from each other, and run from the base of the appendix to the rectum, where 
they spread out in a continuous layer; one lies on the anterior surface of the gut, and two behind.

[1074]

Cæcum.-This is the wide cul-de-sac, about two and a half inches long, which lies below the ileo-cæcal valve with its lower end (fundus) directed downward and inward. It lies in the right iliac fossa, just above Poupart's ligament, upon the Psoas and is usually completely covered by peritoneum. The ileo-cacal valve lies on the back of the inner wall guarding the orifice of the ileun. It consists of two projecting folds (segments) which are formed by an infolding of all the coats of the gut except the peritoneum and longitudinal muscular fibres. The upper fold is horizontal, the lower slopes upward and inward; they unite at each end of the orifice and are prolonged around the wall as two prominent folds (frenula). [1076]

Vermiform Process.-This long, narrow, tubular outgrowth springs from the inner and back part of the cæcum, an inch to an inch and a half below the ileo-cxcal valve. It usually runs either upward, upward and inward, or downward and inward, but varies in length, size, and position. It is completely covered by peritoneum and has a mesentery (mesoappendix) extending to its tip and connected with the under surface of the mesentery proper.

[1079]

Cacal Fossa.-The most prominent are the following: The retro-colic fosse (inconstant) are shown by turning the cæcum upward; the external lies behind the outer part of the ascending colon, just above the cæcum; the internal is behind the inner part. The ileo-cacal fossa is shown by drawing the appendix down. It lies under the end of the ileum, and opens to the left, behind a fold (ileo-cæcal) running from the ileum to the front of the meso-appendix. The ileo-colic fossa lies above the end of the ilcum, and opens to the left, behind a fold (ileocolic) containing the anterior cæcal artery.

[1081]

Colon.--The ascending colon is about eight inches long, and ascends from the ileo-cxcal orifice to the liver. Then bending (hepatic flexure) forward and to the left it becomes the trans- 


\section{DIGESTIVE SYSTEM.}

verse colon in front of the duodenum. It lies on the Iliacus, Quadratus lumborum, and lower and outer part of the right kidney; peritoneum covers its front and sides.

[1082]

The transverse colon is nineteen or twenty inches long, runs transversely to the left to the lower end of the spleen, and there bends (splenic flexure) sharply downward to become the descending colon. A triangular fold (phrenico-colic, or costocolic ligament, or sustentaculum lienis) runs from the splenic flexure to the diaphragm opposite the eleventh rib. Peritoneum covers it completely, except the back of the first few inches. The meso-colon is short at its ends but long elsewhere and allows this colon to hang down; for this reason the left end runs upward, backward, and to the left. This colon lies below the liver, stomach, and pancreas (tail); behind the omentum and (left end) stomach; and in front of the duodenum and pancreas (head).

[1082]

The descending colon is from four to six inches long and descends to the iliac crest, where it becomes the iliac colon. It lies external to the left kidney and upon the Diaphragm and Quadratus lumborum. Peritoneum usually covers its front and sides only.

[1083]

The iliac colon is five or six inches long and runs downward and then inward upon the Ilio-psoas to the inner border of the Psoas, where it becomes the pelvic colon. Peritoneum usually covers its front and sides only.

[1085]

The pelvic colon is fifteen, or more, inches long and descends into the pelvis, where it forms loops, and becomes the rectum opposite the third sacral vertebra. It is completely covered by peritoneum, has an extensive meso-colon, and is freely movable.

[1086]

Rectum.-This is dilated, five or six inches long, and descends to the lower and back part of the prostate (one and a half inches in front of but lower than the tip of the coccyx). There, bending backward and downward around the anococcygeal body (muscular and connective tissue), it pierces 


\section{DISSECTING MANUAL.}

the pelvic floor and becomes the anal canal. It lies on the sacrum, coccyx, and pelvic floor, following their curves, and also curves laterally in (usually) three flexures, the upper and lower being concave to the left, and the middle one to the right. External creases mark these flexures, which produce, inside the gut, lateral crescentic shelves (rectal valves). At its lower end is a special enlargement (rectal ampulla). Peritoneum covers only the upper two-thirds, at first in front of and at the sides, later on in front only, and is then reflected at a point one inch above the prostate, or three inches above the anus. [1087]

Anal Canal.-This is an inch to an inch and a half long, quite narrow, and runs downward and backward to the external orifice (anus); it is surrounded by the Sphincters and (above) edges of the Levatores ani. It lies close behind the bulb of the urethra (or perineal body). Its circular fibres are greatly thickened in its upper inch, forming the Internal sphincter. On the upper half of its mucous membrane are from five to ten permanent vertical folds (columns of Morgagni); these are connected at their lower ends by semilunar folds (anal valves) which form pockets (sinuses).

[1091]

Liver.-This lies under the diaphragm, on the right side and extending to the left. Its position is sufficiently outlined by lines connecting the following points, viz.: half an inch below the right nipple; half an inch below the tip of the tenth right rib; an inch below the left nipple. It has two surfaces, parietal and visceral, separated by the inferior margin; and consists of two main lobes, right and left, with three secondary ones, quadrate, caudate, and Spigelian. Peritoneum covers it entirely except the "uncovered area" on the right lobe (a small triangular area on the posterior parietal surface), under the falciform ligament, and (usually) the fossa of the gall bladder; the lesser sac covers the caudate and Spigelian lobes only, the rest being covered by the greater sac.

[1108]

The parietal surface is convex, adapted to the shape of the diaphragm, and divided, according to position, into four areas. 


\section{DIGESTIVE SYSTEM.}

The superior area has two lateral convexities separated by a mesial hollow. The right and anterior areas are smooth. The posterior area is devoid ("uncovered area ") of peritoneum over a space, on the back of the right lobe, about two inches wide and three or four long. This space presents an impression (suprarenal) for the suprarenal body, to the right of the vena cava; and also at its left end a vertical fossa for the vena cava, which may be converted into a foramen by liver tissue (pons hepatis). On the posterior area (right lobe), to the left of the fossa for the vena cava, is a vertical oblong mass (Spigelian lobe) bounded by the fissure of the ductus venosus; to the left of the latter, on the left lobe, is the (œsophageal) groove for the œsophagus.

[1110]

The visceral (inferior) surface looks downward, backward, and to the left. On the left lobe is a deep impression (gastric), and to the right of this a prominence (omental tubercle) projecting over the lesser curvature. The right lobe is divided by the gall bladder. On its left side anteriorly is the quadrate lobe, bounded by the gall bladder and the umbilical and portal fissures; behind this is the portal fissure; and behind this the caudate lobe, a narrow ridge connecting the right and Spigelian lobes. On the right side of the right lobe, anteriorly, is an impression (colic) for the hepatic flexure; behind this is a large impression (renal) for the kidney; and internal to the latter is a small impression (duodenal) for the duodenum. [1113]

The inferior margin is indistinct behind; stout but distinct on the right side; and thin and sharp in front where it presents a notch (umbilical) at the end of the umbilical fissure, and another (notch of the gall bladder) at the fundus of the bladder.

[1.114]

Fissures.-There are five, arranged like the letter A, on the back and under surface. The umbilical fissure, the left lower limb of the A, separates the left and quadrate lobes, leads from the umbilical notch to the portal fissure, and contains the round ligament. The fissure of the ductus venosus, the left 


\section{DISSECTING MANUAL.}

upper limb, separates the left and Spigelian lobes, contains the remains of the ductus venosus, and runs from the portal fissure to join the fissure of the vena cava. The two preceding fissures constitute the longitudinal fissure, which separates the right and left lobes. The portal or transverse fissure, the cross piece, is a transverse cleft between the quadrate and the caudate and Spigelian lobes; through this the portal vein and the hepatic artery, ducts, lymphatics, and nerves pass. The fossa of the gall bladder, the right lower limb, is a slight fissure running from the notch of the gall bladder to the portal fissure, between the quadrate and rest of the right lobe. The fossa of the vena cava, the right upper limb, is a deep groove, between the Spigelian and rest of the right lobe, which meets the fissure of the ductus venosus above.

Ligaments.-The coronary consists of the peritoneal folds (greater sac) which are reflected from the edges of the "uncovered area" to the diaphragm; its right pointed end is the right lateral. The left lateral is a triangular peritoneal fold, not connected with the coronary, which runs from the parietal surface of the left lobe, near its posterior border, to the diaphragm. The falciform is a crescentic peritoneal fold which is attached, by its convex border to the diaphragm and abdominal wall (to the right of the midline) to within an inch or two of the umbilicus, and by its concave border to the parietal surface of the liver; its free edge extends from the umbilical notch to near the umbilicus, surrounding the round ligament. The round is a fibrous cord, the remains of the umbilical vein, which runs from the portal vein throughout the umbilical fissure and thence to the umbilicus. The remains of the ductus venosus is a slender fibrous cord, a fotal relic, which runs in its fissure from the portal vein to the vena cava.

[1116]

Structure.-It has an outer serous (peritoneal) coat, and under this an areolar coat. The latter becomes thickened (Glisson's capsule) near the portal fissure, enters through this, and surrounds the vessels. The liver substance consists of 


\section{DIGESTIVE SYSTEM.}

minute lobules which surround the branches of the hepatic veins and are connected by areolar tissiue.

[1121]

Gall Bladder and Bile Passages.-The hepatic duct is about an inch long and begins in the portal fissure, by the union of the right and left chief ducts from the liver; it descends to join the cystic duct just outside the fissure, forming the common bile duct. The cystic duct is smaller but slightly longer and runs from the neck of the gall bladder. The common bile duct descends in the lesser omentum, in front of the foramen of Winslow, with the portal vein behind and hepatic artery to the left; it then continues behind the first part of the duodenum to meet the pancreatic duct between the pancreas and duodenum. The two ducts run together, pierce the inner wall of the descending duodenum obliquely, and open by a common orifice on the bile papilla, three or four inches below the pylorus.

[1118]

The gall bladder is a pyriform reservoir lying in its fossa, under the liver. Its wide end (fundus) usually reaches the edge of the liver and is in contact with the abdominal wall at the outer border of the right Rectus. Its body ends in a constricted neck which curves inward toward the portal fissure and ends in the cystic duct. Peritoneum covers it in front and laterally, forming its outer coat; it has a middle coat of fibrous and muscular tissue, and an inner mucous coat.

Pancreas.-This is a soft glandular mass which stretches transversely on the posterior abdominal wall between the duodenum and spleen. The head, or right end, is hook-like, large and flattened, and lies in the curve of the duodenum upon the vena cava and aorta; the lower part (uncinate process) descends to the left and is separated from the neck by a deep notch (incisura pancreatis) for the superior mesenteric vessels; peritoneum covers it anteriorly except above and to the right, under the transverse colon. The neck is comparatively narrow, lies on the portal vein, and joins the head to the body; 
it runs upward to the left from the upper and right part of the head; peritoneum covers it partly in front.

[1124]

The body is prismatic and tapers to a rather pointed end (tail); it has three surfaces and three borders. Surfaces; the upper (or anterior) looks upward and forward, is covered by lesser sac, and has a prominence (omental tuberosity) at its right end; the inferior is covered by the descending layer of the transverse mesocolon; the posterior crosses, from right to left, the aorta, superior mesenteric artery, left renal vessels, left suprarenal body, and left kidney. Borders; the anterior gives attachment to the transverse mesocolon; the upper and posterior borders have no special interest. The anterior surface is covered by peritoneum of the lesser sac, and the inferior by that of the greater sac.

[1126]

The pancreatic duct (Wirsung) begins at the tail, runs transversely through the axis of the body, and bends downward through the head; thence it runs with the common bile duct through the wall of the descending duodenum, to empty by a common orifice in the bile papilla. The accessory pancreatic duct drains the head and opens into the duodenum nearly an inch above and in front of the preceding.

[1127]

\section{The Peritoneum.}

The peritoneum is a serous sac lining (parietal peritoneum) the walls of the abdomen and investing (visceral peritoneum) the viscera. It is closed in the male, but communicates, in the female, with the Fallopian tubes. The peritoneal sac is subdivided into a greater and a lesser sac; the latter is practically a diverticulum running behind the stomach and adjacent organs, and communicating with the great sac at the foramen of Winslow. The peritoneal folds between the viscera and parietes are divided into omenta, between the stomach and other viscera; mesenteries, between intestine and posterior abdominal wall; and ligaments, between the abdominal wall and viscera other than the digestive tube.

$[1048,1097]$ 


\section{DIGESTIVE SYSTEM.}

Great Sac.-The anterior layer lines the anterior abdominal wall. Superiorly it forms a crescentic fold (falciform ligament), just to the right of the midline, running to the parietal surface of the liver and enclosing the round ligament. Inferiorly it forms folds over five structures descending from the umbilicus, viz.: the urachus mesially and the deep epigastric and obliterated hypogastric arteries on each side. Three inguinal fossce are formed on each side by these folds, viz.: one (external) outside the deep epigastric artery, over the internal abdominal ring; one (middle) between the arteries; and one (internal) between the obliterated hypogastric artery and the urachus. Under the inner end of Poupart's ligament, over the crural ring, is another (femoral, or crural fossa).

[1097]

The posterior layer, when traced vertically in the midline, runs from the diaphragm to (upper layer of coronary ligament) the liver and over the parietal and then the visceral surface to the portal fissure. Thence it descends (anterior layer of lesser omentum) to the lesser curvature of the stomach, and runs over the upper surface to the greater curvature. It descends thence as the anterior layer of the great omentum; then, bending on itself, it ascends as the posterior layer to the transverse colon, covers the posterior surface of this and passes (posterior layer of transverse mesocolon) to the anterior border of the pancreas. Thence it covers the inferior surface of the pancreas and descends along the posterior abdominal wall, running forward around the small intestine and back again to form the mesentery, to the pelvis.

Then descending into the pelvis (pelvic peritoneum) it covers the pelvic colon completely, forming the pelvic mesocolon, and then partly covers the upper two-thirds of the rectum. From the front of the rectum it passes, on each side, to the posterior pelvic wall, forming the bottom of a large fossa (pararectal) seen at the sides of the rectum when empty. It also passes forward from the rectum in two folds (in the male), between which is the recto-vesical pouch, to the back of the blad- 


\section{DISSEC'TING MANUAL.}

der and onto the upper surface; thence it passes laterally to the pelvic walls, and from the apex (surrounding the urachus) to the abdominal wall, forming the false ligaments of the bladder. In the female these folds (of Douglas) pass from the rectum to the uterus, enclosing the utero-sacral ligaments and forming the pouch of Douglas between them; thence the peritoneum runs over the back and fundus of the uterus, passes in two folds, between which is the utero-vesical pouch, to the bladder, and continues as in the male; from each side of the uterus it runs to the pelvic wall in a wide fold (broad ligament).

[1100]

Traced transversely, just above the iliac crest, after leaving the anterior abdominal wall it runs on each side to the back, and thence inward over the colon and across the Psoas, ureters, and great vessels; thence it runs forward around the small intestine and back again (mesentery). Higher up, to the left, it runs on the posterior wall behind the stomach and spleen to the left kidney, covers the upper and outer part of this, and runs forward (posterior layer of lieno-renal ligament) to the spleen. Thence it runs around the spleen to the hilus and then passes (anterior layer of gastro-splenic omentum) to the stomach.

[1101]

Small Sac.-This diverticulum begins in a narrow passage (foramen of Winslow) just behind and below the portal fissure. In front of the foramen is the free right border of the lesser omentum, containing the portal vein, hepatic artery, and bile duct; behind it is the vena cava; below it are the hepatic artery and duodenum; and above it is the caudate lobe.

[1102]

The posterior layer runs, from the foramen, over the vena cava and upward to form a cul-de-sac behind the Spigelian lobe. To the left it runs over the pancreas, left kidney, and suprarenal, passes thence (anterior layer of lieno-renal ligament) to the spleen, where it covers the inner part of the gastric surface, and then runs (posterior layer of gastro-splenic omentum) to the stomach. From the anterior border of the 


\section{DIGESTIVE SYSTEM.}

pancreas it descends (upper layer of transverse mesocolon) to the transverse colon, covers the upper surface of this gut, and descends as the anterior layer of the pesterior fold of the great omentum.

[1103]

The anterior layer, traced vertically, covers the Spigelian lobe and then descends (posterior layer of lesser omentum) from the portal fissure and fissure of the ductus venosus to the lesser curvature of the stomach, and runs over the visceral surface to the greater curvature. Thence it descends as the posterior layer of the anterior fold of the great omentum to meet the posterior layer.

[1102]

Omenta.- Of the two layers composing them, one is from each sac. The lesser omentum is attached above to the margins of the portal fissure and fissure of the ductus venosus, and below to the lesser curvature of the stomach and the upper border of the duodenum for an inch beyond the pylorus. It is sometimes divided, according to its lower attachments, into the hepato-gastric and hepato-duodenal ligaments. The right border is free and bounds the foramen of Winslow; the left end is narrow and attached to the diaphragm. The great omentum is a large apron-like fold which is very fatty and hangs down in front of the intestine. It consists of two folds, each formed of two layers. The anterior (descending) fold begins at the great curvature of the stomach, descends a variable distance, then bends sharply backwarl and upward on itself and ascends (posterior, or ascending fold) to the transverse colon. In adult life the four layers become more or less adherent. The gastro-splenic omentum is attached by one edge to the wide end of the stomach, and by the other to the gastric surface of the spleen just in front of the hilus. Its layers are continuous with the great omentum below; superiorly they separate at the "uncovered area" of the stomach.

[1104]

Ligaments.-The phrenico-colic (sustentaculum lienis) runs from the splenic flexure to the diaphragm opposite the eleventh rib. The gastro-phrenic runs from the stomach, upward on the 


\section{DISSECTING MANUAL.}

left of the œsophagus to the diaphragm. The lieno-renal runs from the left kidney to the spleen, the anterior layer being lesser sac and the posterior layer greater sac. The hepato-renal runs from the lower edge of the uncovered area of the liver to the right kidney.

[1104] 


\section{UROGENITAL SYSTEM.}

Kidneys. - These are bean-shaped and each is about four and a half inches long, two inches wide, and one and a quarter thick, and weighs about four and a half ounces. Each has two ends, upper and lower, the latter being the more pointed; two surfaces, anterior and posterior; and two borders, of which the outer is convex while the inner is concave and presents an opening (hilus) into the cavity (sinus). A thin capsule covers the kidney and lines the sinus. They lie in a mass of fat on the muscles of the posterior wall, behind the peritoneum, close to the spine and in front of the last rib and upper three lumbar transverse processes on each side. Their long axes are somewhat oblique, the upper ends being approximated; their lower ends are an inch or two above the highest part of the iliac crest, but the left kidney is usually higher than the right. The outer border of each kidney lies in a plane posterior to the inner border.

[1130]

Anterior Surface.-Right kidney. On the upper part a small area is in relation with the suprarenal body and is not covered by peritoneum; below this, it is in contact with the liver and covered by greater sac. The lower end is in relation externally with the hepatic flexure, and internally with the descending duodenum, being bound to them by the greater sac. This surface presents three impressions; one (hepatic) over the whole upper end; another (colic) stretching from the most prominent point to the lower end; and a third (duodenal) on the inner margin, below the hilus. Left kidney. The extreme upper and inner part lies under the suprarenal and has no peritoneum. Below this is a small triangular area, lying under the stomach and covered by lesser sac. Below this, around the 
hilus, it lies under the pancreas and has no peritoneum. The upper and outer part lies under the spleen and is covered by greater sac except along the origin of the lieno-renal ligament. The lower end is related internally to the jejunum, and externally to the splenic flexure. There are three impressions; one (splenic) on the upper and outer part; another (for the colon and jejunum) descending to the lower end; and a third (gastric) above and near the hilus.

[1135]

Structure.-The floor of the sinus presents twelve to fifteen small conical elevations (renal papillæ), the summit of each being pierced by the minute orifices (foramina papillaria) of the secreting tubercles. On section pyramidal masses (medullary pyramids) are seen with their bases toward, but not reaching, the surface, while their apices form the renal papillæ; these pyramids form the medulla, which appears striated; the outer part of each pyramid (intermediate zone) appears formed of light and dark streaks while the inner (papillary) part is lighter and more uniform. A granular layer (cortex) separates the bases of the pyramids from the outer surface of the kidney, and sends prolongations (columns of Bertin) between them toward the sinus. The secreting tubules arise in the cortex and traverse the pyramids to the foramina.

[1137]

Ureter.-This begins as a thin funnel-shaped dilatation (pelvis) lying both within and outside of the kidney sinus, behind the renal vessels. In the sinus it divides into two or three tubes, each with several branches (calyces, or infundibula) surrounding the papillæ; there are usually twelve calyces and one may surround two or more papillæ. Near the lower end of the kidney it narrows rapidly to become the ureter. The ureter is a thick-walled tube, about ten inches long, which runs behind the peritoneum to the bladder. At first it runs downward and slightly inward on the Psoas to the pelvic brim, passing over the genito-crural nerve and common or external iliac artery, but under the spermatic or ovarian vessels and (left side) root of the pelvic mesocolon or (right side) duodenum and 


\section{UROGENITAL SYSTEM.}

root of the mesentery. It then descends on the pelvic wall in front of the internal iliac artery to the level of the ischial spine, crossing the obturator vessels and nerve and the obliterated hypogastric artery. Then bending inward under the vas deferens, it passes in front of the upper end of the seminal vesicles, reaching the bladder in front of the vas, two inches from the other ureter, and piercing the wall obliquely. In the female it accompanies the uterine artery along the outer side of the cer ${ }^{\circ} \mathrm{x}$ and upper part of the vagina.

Bladder.-This lies in front of the pelvis, its size and shape depending on its distention. The lower portion rests on the pelvic floor and is but slightly movable. At its lowest part, in an apparently constricted neck or cervix, is the internal urethral orifice, which lies about two inches behind and slightly below the upper border of the symphysis in the male, somewhat lower in the female. The base, or postero-interior surface, is a triangular area looking downward and backward, and lying behind the urethral orifice. The rest of the under aspect of the lower portion consists of two more triangular areas (infero-lateral), which are directed downward and outward but meet in the midline in front of the urethral orifice. These three areas are separated by three rounded borders, one extending from the urethral orifice to the bladder apex, and two to the points where the ureters reach the bladder. The apex, or summit, is the part of the empty, or slightly filled, bladder lying nearest the upper border of the symphysis; a fibrous cord (urachus) runs from it to the umbilicus. The part between the apex and base is the body of the bladder.

[1144]

When empty the bladder has the shape of an inverted tetrahedron, its apex lying at the urethral orifice, and its base being formed by the superior surface, which is triangular and looks upward. The basal angles correspond to the apex of the bladder and the lateral angles, or points where the ureters join it; the posterior border connects the lateral angles; the lateral borders extend from the bladder apex to the lateral angles. 
When distended the angles and borders become rounded and obliterated, the lateral borders forming the "lateral surfaces." The outline becomes oval or circular, and the highest part, a point behind the apex, rises into the abdominal cavity. In normal distention it will hold about a pint.

[1147]

Relations.- The base rests, in the male, on the rectum below the recto-vesical pouch, separated by the seminal vesicles, vasa deferentia, and recto-vesical layer of pelvic fascia; in the female it lies on the vagina and lower part of the uterus below the utero-vesical pouch. When empty, the vas deferens lies above and parallel to the lateral border, only coming in relation with the base after crossing the ureter; the obliterated hypogastric artery lies often an inch above the lateral border. When distended, both the vas and (often) the obliterated hypogastric cross its side wall; the apex lies an inch and a half or more above the symphysis.

[1147]

Interior.-The mucous membrane is generally loosely connected and forms folds in the empty bladder. It is firmly connected, and does not form folds, on a triangular smooth area (trigonum vesicae) which lies over the base and is bounded by lines connecting the internal orifices of the urethra and ureters. The middle lobe of the prostate causes a bulging (uvula vesic(e) just behind the urethral orifice, often well marked in old people. A smooth curved ridge, caused by a transverse bundle of muscle fibres, stretches between the ureteral orifices; its lateral portions (plica uretericce) are produced by the ureters. Minute folds radiate from the urethral orifice. The ureteral orifices are elliptical, an inch apart when the bladder is empty, half an inch more at least when full.

[1151]

Peritoneal Relations.-Peritoneum covers the superior surface only. From each lateral border it passes (lateral false ligaments) to the pelvic wall at the white line, lining a groove (paravesical fossa) which is present on each side when the bladder is empty. Anteriorly it passes (anterior false ligament) over the urachus to the anterior abdominal wall, at the 


\section{UROGENITAL SYSTEM.}

upper border of the symphysis when the bladder is full, two inches higher, or more, when this is empty. Along the posterior border it passes to the rectum, or uterus, forming a fold (posterior false ligament) at each side of the recto-vesical, or utero-vesical, pouch.

Fixation.-The basal part is chiefly fixed by the true ligaments, processes of the pelvic fascia reaching it in front (puboprostatic, or anterior ligaments) from the pubis, and laterally (lateral ligaments) from the sides of the pelvis. It is also fixed by fibrous and muscular tissue to the ureters, seminal vesicles, and vasa deferentia (or vaginal wall).

[1156]

Structure.-It consists of four coats, from without inward the serous (peritoneal), muscular, submucous, and mucous. The muscular coat consists of three strata; externally longitudinal fibres, attached (I'ubo-vesicalis) to the lower part of the symphysis; mesially circular and oblique fibres, which form the Sphincter vesicæ around the urethral orifice; and internally longitudinal fibres.

[1156]

Urethra.- The male urethra is described with the reproductive organs.

The female urethra is an inch or an inch and a half long, slightly curved, and runs from the bladder downward and forward under the symphysis and close to the vagina. Between the layers of the triangular ligament, which it pierces, it is surrounded by the Compressor urethræ. The external orifice is slit-like, with lateral lips, and lies between the labia minora just above the vaginal orifice. The mucosa forms longitudinal folds; the most prominent one (crista urethralis) is on the posterior wall.

[1157]

The Male Rrproductive Organs.

Testes.-Each testicle is oval and slightly flattened, an inch and a half long, an inch from before backward, and somewhat less in thickness. It has two flattened surfaces, outer and inner; and two rounded borders, anterior and posterior, 
of which the anterior is the more convex and free; the borders end in the upper and lower extremities. It lies in the scrotum with its long axis directed upward, slightly forward, and outward.

[1159]

The epididymis is a crescentic structure curving round and attached to the posterior border of the testis and overlapping the outer surface behind. Its enlarged upper end (globus major) overhangs the upper end of the testis and is attached there by emerging ducts, connective tissue, and the serous covering; its small lower end is attached to the lower end of the testis by arcolar tissue and the serous covering; its intermediate part (body) is separated from the back of the outer surface of the testis by an involution of the serious covering, which forms a pocket (digital fossa) under it. One or two minute pedunculated bodies (hydatids) are usually attached to the upper end of the epididymis or testis.

[1160]

The tunica vaginalis is a serous membrane lining (parietal portion) the scrotal cavity and reflected from its posterior wall onto (visceral portion) the epididymis and testicle. It covers them completely, except the back of the epididymis and where the testicle and epididymis are united. A small crescentic fold descends from the lower part of the testicle or epididymis.

Structure.-The testicle has an external coat (tunica albuginea) of dense white fibrous tissue; from this septa (septula testis) run inward, dividing the gland into lobules, and ending behind in a fibrous mass (mediastinum testis, or corpus Highmori) which projects forward along the posterior border of the tunica albuginea. Numerous convoluted tubules (seminiferous) occupy the lobules and unite to form a smaller number of straight tubules (tubuli recti), which open into a canal network (rete testis) in the mediastinum. From this fifteen to twenty minute tubules (vasa efferentia) run through the tunica albuginea and into the globus major, where each twists into a conical mass (conus vasculosus); they then open into a single 


\section{UROGENITAL SYSTEM.}

convoluted tube (canal of the epididymis), about twenty feet long, which forms the chicf bulk of the epididymis and ends at the globus minor, by becoming the vas deferens.

[1161]

Vas Deferens.-This is a rounded and thick-walled cord, about eighteen inches long, which continues the canal of the epididymis, and begins at the globus minor. It has three coats-an outer fibrous, an intermediate muscular, and an inner mucous coat; the lumen is small; it is very tortuous at first, but less so later on. It ascends at first on the inner side of the epididymis, behind the testis, to enter the spermatic cord in which it becomes the most posterior structure. Then running upward in this to the pubic spine and through the external abdominal ring, it traverses the inguinal canal, lying in the upper grooved surface of Poupart's ligament. At the internal abdominal ring it leaves the cord, turns round the deep epigastric artery on its outer and posterior aspect, and runs backward, upward, and inward under the peritoneum to cross the ileo-pectineal line nearly two inches from the pubic spine and enter the pelvis.

[1162]

It then runs backward and slightly downward, under the peritoneum, on the pelvic wall toward the ischial spine, crossing over the obliterated hypogastric artery, obturator nerve and vessels, vesical vessels, and ureter. Beyond the latter it bends, runs downward and inward, just in front of the posterior false ligament of the bladder, to the interval between the rectum and base of the bladder, and approaching the other ureter becomes tortuous and dilated (ampulla) between the seminal vesicles. The ampulla, which is thin-walled, soon contracts to a narrow canal, which joins the duct of its seminal vesicle, forming the common ejaculatory duct; this runs through the prostate, behind the middle lobe and very close to the opposite duct, and opens into the first part of the urethra by a slit-like aperture lying beside the sinus pocularis.

[1163]

Seminal Vesicles.-These lie between the bladder and the recto-vesical pouch and rectum, with their upper and posterior 


\section{DISSECTING MANUAL.}

ends just behind the ureters and some distance apart, and their lower ends just behind the prostate and close together. Each vesicle is about two inches long and formed by a twisted tube, which is four or five inches long and has many lateral diverticula; it has thin walls like those of the ampulla; the lower end tapers to a short duct which joins the vas deferens, forming the common ejaculatory duct.

Spermatic Cord.-This begins at the internal abdominal ring, runs through the inguinal canal, and then descends to the posterior border of the testes. It consists of the vas deferens, spermatic vessels, and nerves and lymphatics of the testis; all these are loosely connected and covered, like an inguinal hernia, by three fascial layers. These are, from without inward; intercolumnar fascia, derived from the External oblique aponeurosis at the external ring; cremasteric fascia, derived from the Internal oblique in the canal, and consisting partly of muscle fibres which form loops on the testis and tunica vaginalis; and infundibuliform fascia, derived from the transversalis fascia at the internal ring, with some areolar tissue from the subperitoneal tissue.

[1168]

Scrotum.-This pendulous bag presents externally a median raphe which is prolonged backward to the anus, and forward onto the penis; an incomplete septum, partly continuous with the dartos tissue, divides its interior into two cavities, for the testes. The wall of each cavity consists, from within outward, of tunica vaginalis and of infundibuliform, cremasteric, and intercolumnar fascia. Both cavities are enclosed by skin and superficial fascia; in the latter is a layer of muscle fibre (Dartos muscle).

[1169]

Penis.-This consists chiefly of erectile tissue which is found mostly in three rounded longitudinal columns, the corpus spongiosum and corpora cavernosa. In the body of the penis the corpora cavernosa lie side by side, one on each side of the midline; they are separated on the upper (dorsal) aspect by a shallow groove, and on the under (urethral) aspect by a wider 


\section{UROGENITAL SYSTEM.}

and deeper one in which lies the corpus spongiosum; each ends distally in a blunt point whose apex is received in a hollow in the glans. The corpus spongiosum expands, at its distal end, into a conical cap (glans penis) which covers the ends of the corpora cavernosa, its prominent margin (corona) projecting past them; the urethra traverses it and ends at its apex in a slit-like opening (meatus urinarius). The skin on the body is thin, freely movable, and destitute, except near the root, of hairs; on its urethral aspect is a median raphe continuous with that of the scrotum. Distally the skin forms a free fold (prepuce) which overlaps the glans, is then reflected onto the penis just above the corona, and is then continued, over the glans (firmly attached to it) to the meatus urinarius. [1170]

At the root of the penis the corpora cavernosa diverge laterally (crura penis), enlarging at first and then tapering, to be attached to the inner part of the pubic arch; each is covered by the Ischio-cavernosus. The corpus spongiosum enlarges in a spherical mass (bulb of the urethra), which rests on and is attached to the triangular ligament; on the back and under surface of the bulb there is usually a median groove indicating the fusion of two original halves (hemispheria). A strong and triangular fibrous band (suspensory ligament) runs from the front of the symphysis to the capsule of the penis.

[1171]

Structure.-Each corpus cavernosum is enclosed in a fibrous coat (tunica albuginea), which fuses with its fellow and forms an incomplete septum (septum pectiniforme) with nearly parallel, slit-like openings between the corpora. Fibrous strands (trabeculæ) from the deep surface of the tunica albuginea form a sponge-like framework. The corpus spongiosum has a similar, but thinner, fibrous coat and finer trabeculæ.

[1172]

Prostate.-This is chestnut-shaped, an inch and a quarter or a half wide, three-fourths of an inch long, and an inch and a quarter vertically. The upper surface (base) lies against the under aspect of the bladder (near the urethral orifice), and is continuous with it mesially but separated from it laterally and 
posteriorly by deep grooves. The lateral surfaces are convex and meet anteriorly in a rounded border (anterior surface). The posterior surface is triangular and flattened and lies on the rectum, separated from it by pelvic fascia. The apex lies on the triangular ligament.

[1173]

The urethra, entering near the middle of the upper surface, runs through the prostate, in a curve which is concave forward and nearer the posterior surface than the anterior border; it emerges at a point on the anterior border just above and in front of the apex. The common ejaculatory ducts enter the edge between the base and posterior surface, and descend to the prostatic part of the urethra. The part between these ducts and the urethra is the middle lobe, which projects against the bladder just behind the urethral orifice; the rest of the body forms two lateral lobes.

[1174]

Structure.-Unstriped muscle fibres constitute the greater bulk, forming the outer layers and sending processes inward through the glandular tissue; posteriorly some fibres are continuous with the bladder. The glandular tissue is practically confined to the region behind the urethra; its ducts (about twenty) chiefly open in a groove on each side of the crista urethralis, on the posterior wall of the urethra.

[1175]

Cowper's Glands.-These are two small glands, the size of a pea; they lie under the membranous urethra between the layers of the triangular ligament, between the apex of the prostate and the bulb of the corpus spongiosum. Their ducts pierce the bulb and open into the spongy urethra.

[1176]

Male Urethra.-This is about eight inches long and runs from the bladder to the meatus urinarius; it is divided into three portions, prostatic, membranous, and spongy. The prostatic portion is about an inch long and descends through the prostate in a slight curve, concave forward, from base to apex. Its posterior wall (floor) presents a mesial ridge (crista urethræ, or verumontanum) which projects forward and extends downward to the membranous urethra and upward to (some- 


\section{UROGENITAL SYSTEM.}

times) the uvula vesicx. The prostatic ducts open mainly into grooves on each side of the ridge, slightly at its ends. On the summit of the ridge is a slit-like orifice (prostatic utricle, or sinus pocularis), leading backward and upward into the prostate for a quarter of an inch. On each side of the mouth of the utricle is the smaller opening of the common ejaculatory duct.

[1177]

The membranous portion, the shortest and narrowest, is less than half an inch long; it extends from the apex of the prostate, downward and forward through the triangular ligament to the bulb of the corpus spongiosum. It lies about an inch behind and below the subpubic ligament; the Compressor urethræ surrounds it and Cowper's glands lie on each side, behind it. Its upper wall is longer than its posterior wall. The spongy portion is about six inches long and begins half an inch in front of the posterior end of the bulb; it runs through the centre of the corpus spongiosum to the meatus urinarius. It runs at first forward through the bulb, and then downward and forward to a point in front of the lower part of the symphysis pubis, beyond which the penis is movable. Its calibre is enlarged in the bulb and also (fossa navicularis) in the glans; the external urethral orifice (meatus urinarius) is a vertical slit, the narrowest and least dilatable part of the canal. The ducts of Cowper's glands open on the floor of the proximal part. Numerous pit-like recesses (lacunæ) open into it and have their openings directed obliquely forward.

[1179]

\section{The Female Reproductive Organs.}

Ovary.-This is about the size and shape of an almond; it lies, with its long axis vertical and its outer surface against the pelvic wall, in a little peritoneal fossa (fossa ovarica) which extends from the obliterated hypogastric artery to the ureter and uterine vessels. The upper end (tubal pole) is the larger and more rounded and lies below the external iliac vessels; the lower end (uterine pole) lies just above the pelvic floor. 


\section{DISSECTING MANUAL.}

Its surfaces, internal and external, are flattened; the Fallopian tube almost covers the inner. Its posterior border is convex and free; the vessels and nerves enter its straighter and narrower anterior border (hilus).

[1182]

Connections.-A triangular peritoneal fold (suspensory ligament), part of the broad ligament, ascends from its upper pole over the external iliac vessels and Psoas. A mesentery (mesovarium) derived from the broad ligament, and containing the vessels and nerves, joins the whole anterior border. A rounded cord (ligament of the ovary) runs in a fold of the posterior layer of the broad ligament, from the lower pole to the lateral angle of the uterus behind and below the end of the Fallopian tube. A large fimbria (ovarian) of the Fallopian tube often joins its upper pole.

[1183]

Structure.-It is solid, consisting chiefly of connective tissue, and is covered by a layer of epithelium. Near the surface are numerous vesicles (Graafian follicles) of various sizes, containing the ova. The cavity of a ruptured follicle is at first (corpus luteum) filled with yellowish cellular tissue and blood; later on this degenerates, atrophies, and becomes whitish (corpus albicans).

[1184]

Fallopian Tubes.-Each tube is about four and a quarter inches long and enclosed in a fold (mesosalpinx) of the broad ligament. In the free end (fimbriated extremity) the small pelvic orifice (ostium abdominale) lies at the bottom of a funnel-shaped expansion (infundibulum) whose margins have many irregular processes (fimbrix). The fimbrix are covered internally with mucous membrane and one (ovarian fimbria), usually the largest, is connected with the upper pole of the ovary. At the ostium abdominale begins the (ampulla) widest and longest part of the tube; this ends in a thickerwalled part (isthmus) which is attached to the lateral angle of the uterus. The last part (pars uterina) runs through the uterine wall and ends in a narrow orifice. The calibre of the tube diminishes from without inward.

[1185] 


\section{UROGENITAL SYSTEM.}

From the uterus the tube runs at first horizontally outward toward the lower pole of the ovary, then ascends on the inner side of the anterior border to the upper pole, then arches backward and descends on the inner surface along the posterior border. The fimbriated end lies against the lower part of the inner surface of the ovary.

[1186]

Structure.-There are four coats, from without inward as follows: serous; muscular, longitudinal fibres superficially and circular ones deeper; submucous; and mucous. [1186]

The epoophoron (parovarium, organ of Rosenmüller) consists of small blind tubules lying in the mesosalpinx between the Fallopian tube and ovary; one (duct of Gartner) lies close and parallel to the Fallopian tube and is joined by the others at right angles. The hydatids of Morgagni are small pedunculated cystic structures lying near the infundibulum. The paroophoron consists of tubules in the mesosalpinx, but nearer the uterus; it is only easily found in the newborn.

[1128]

Uterus.--This is pear-shaped, three inches long and nearly two wide. The upper portion is flattened and divided into the fundus and the body by a line joining the points of junction (lateral angles) of the Fallopian tubes. The fundus is the convex upper part. The body is the triangular lower part, with its base upward; its margins (lateral borders) separate two rounded surfaces, anterior and posterior. The lower portion of the uterus, the neck or cervix, is cylindrical, about an inch long and separated from the body by a constriction. It pierces the upper part of the anterior vaginal wall, being thus divided into supra- and infra-vaginal portions, and tapers somewhat. At its lower end is the opening (external os) of the cervical canal, which is directed toward the upper part of the posterior vaginal wall; this is circular at first but, after childbirth, becomes a transverse slit.

[1187]

The cavity of the body is a triangular chink; its base is directed upward and extends between the orifices of the Fallo- 


\section{DISSECTING MANUAL.}

pian tubes, its sides are convex inward, and its apex is directed downward; its walls are smooth. The cavity of the cervix (cervical canal) is spindle-shaped, and communicates with the cavity of the body by a circular orifice (internal os), and with the vagina by another (external os). On its walls the mucous membrane forms all anterior and a posterior fold, with secondary folds branching obliquely from them (arbor vitx, or plicæ palmatr).

[1188]

The peritoneum which covers the fundus descends anteriorly on the body to the junction with the cervix, and then passes (utero-vesical fold, or "anterior ligament") to the bladder, forming the utero-vesical pouch. Posteriorly it descends over the body, supra-vaginal cervix, and upper part of the posterior vaginal wall before passing (recto-vaginal fold) to the rectum, forming the pouch of Douglas. On each side a fold (recto-uterine, or fold of Douglas) runs from the back of the cervix to the pelvic wall beside the rectum; fibrous and muscular tissue pass in each fold to the rectum (Recto-uterine muscle) and front of the sacrum (utero-sacral ligament). The broad ligament is formed by the peritoneum of the surfaces passing from the lateral border, on each side, in a rather vertical fold to the lateral pelvic wall. Its free upper edge contains the Fallopian tube, forning a triangular mesentery (mesosalpinx) whose apex is at the lateral angle; this overhangs the ovary, forming a pocket for it (bursa ovarii). From its posterior layer a short mesentery (mesovarium) runs to the hilus of the ovary. The part below the mesosalpinx, separated by the ligament of the ovary, is the mesometrium.

[1189]

The round ligament is a narrow fibrous band attached to the uterus just in front of and below the Fallopian tube. It runs in the front of the broad ligament to the pelvic wall, then forward and slightly upward over the obliterated hypogastric artery and pelvic brim, to follow the course of the vas deferens through the inguinal canal and end in the labium majus. Near 


\section{UROGENITAL SYSTEM.}

the uterus it contains muscle fibre; its lower end is connective tissue only.

[1190]

Position.-The uterus lies with its large end upward and usually bent to one side, between the rectum and bladder, separated from the rectum by peritoneum and from the bladder by peritoneum above and connective tissue below. The cervix is comparatively fixed and the body bends on this with the movements of the bladder, on which its anterior surface rests. The ureters run downward, inward, and slightly forward on each side of, but three-fourths of an inch from, the cervix. On either side of the cervix and upper vagina are large vessels lying in loose fatty tissue (parametrium).

[1190]

Structure.-There are three coats, from without inward as follows: serous (perimetrium); muscular, forming the chief bulk and containing connective and elastic tissue in its deeper layers; and mucous.

Vagina. - This passage runs downward and forward from the uterus, curving slightly with the convexity backward; it opens into the urogenital cleft between the labia minora, behind the urethral orifice and clitoris; the angle between its axis and that of the uterus is somewhat more than a right angle. Its anterior wall is three inches long, and its posterior three and a half; it is widest at its middle part. Normally the anterior and posterior walls are in contact; on transverse section, the lower part is an $\mathrm{H}$-shaped cleft and the middle part a transverse slit, while the lumen of the upper part is more open. Between the infra-vaginal part of the cervix and its upper end is a recess which is deeper behind (posterior fornix) than laterally (lateral fornix) or (anterior fornix) in front. Its lower orifice is partly closed in the virgin by a thin fold (hymen), which persists after rupture as torn fragments (carunculæ hymenales) round the orifice.

[1192]

Relations.-The anterior wall is connected with the base of the bladder above, by connective tissue, and with the urethra below. The posterior wall is covered by peritoneum (pouch 
of Douglas) in its upper fourth of an inch, mesially; lower down it lies on the rectum, separated by pelvic fascia except near its lower end where a mass of fibrous and fatty tissue (perineum or perineal body) intervenes. At the sides are the Levatores ani and, near the upper part, ureters. The terminal part pierces the triangular ligament, lying between the bulbs of the vestibule, the glands of Bartholin, and the Sphincter vaginæ muscle.

[1193]

Structure.-It has a muscular coat of longitudinal fibres, with circular fibres in the deeper part at the lower end. The mucous coat is corrugated, with transverse ridges (rugæ) and also a slight median longitudinal ridge (columnæ rugarum) on both the anterior and posterior walls; the lower end (carina urethralis) of the anterior column is near the urethra.

[1195]

Vulva or Pudendum.-This term comprises the external genital organs, i.e., the labia majora and structures lying between them.

[1195]

Labia Majora. - These are two prominent rounded folds of skin, enclosing fatty and areolar tissue. They bound the urogenital cleft and are narrow behind, toward the anus, and sometimes joined by a transverse fold (posterior commissure). They increase in size while passing forward and upward to end in a median elevation (mons pubis, mons Veneris, anterior commissure) of similar structure. The outer surfaces of the labia and mons are hairy; the inner surfaces are smooth and (in virgins) in contact.

Labia Minora (nymphæ).--These are two smaller and narrower vertical folds lying between the labia majora; their posterior ends are lost on the labia majora, being joined (in virgins) by a transverse fold (frenulum, fourchette). Each divides anteriorly into two portions, outer and inner; the outer portions of both unite over the glans clitoridis as a fold (preputium clitoridis); the inner portions unite at an acute angle and join the under surface of the glans (frenulum clitoridis). 


\section{UROGENITAL SYSTEM.}

The skin covering them resembles that on the inner surface of the labia majora.

[1195]

The vestibule is the cleft between the labia minora and behind the glans clitoridis; on its floor are the openings of the urethra, vagina, and ducts of Bartholin's glands; its posterior part, between the fourchette and vaginal orifice, is the fossa navicularis. The external urethral orifice lies just in front of the vaginal orifice.

[1196]

Clitoris.-This represents the penis and has a body, two crura, and a glans, but is not traversed by the urethra. The body consists chiefly of erectile tissue, is an inch to an inch and a half long, bent with the convexity upward, and tapers distally. It is enclosed in a fibrous coat and divided by an incomplete septum into two symmetrical and cylindrical corpora cavernosa; a suspensory ligament runs from the fibrous coat to the symphysis. The glans is a small mass of erectile tissue on the pointed end of the body; a fold (prepuce) covers it and another (frenulum) is attached inferiorly, both being continuous with the labia minora. The crura are the corpora cavernosa, which diverge posteriorly to be attached to the sides of the pubic arch; each is covered by the Erector clitoridis and has a fibrous sheath.

[1197]

Bulbus Vestibuli.-This is a mass of erectile tissue which corresponds to the corpus spongiosum. It consists of two lateral halves which lie on either side of the vaginal wall, upon the triangular ligament; these taper in front where they are joined, above the urethra, by a narrow median part (pars intermedia) continuous with the glans. The Bulbo-cavernosus covers each lateral part.

[1198]

Glands of Bartholin.-These are the size and shape of a small bean and represent Cowper's glands. One lies on each side of the lower part of the vagina, covered by the Bulbocavernosus and often overlapped by the bulb: a long duct opens on the vestibule between the vaginal orifice and the labium minus. 


\section{The Ductless Glands.}

Spleen.-This is an irregular tetrahedron, somewhat purple, five inches long and three wide at the widest; it lies to the left of and behind the stomach, its long axis almost corresponding to that of the back part of the tenth rib. Its upper end (apex) is somewhat curved and points inward and backward. The most extensive surface (diaphragmatic), looking backward and outward, rests on the diaphragm over the ninth, tenth, and eleventh ribs. The visceral aspect presents three surfaces (gastric, renal, and basal), which are separated by three ridges radiating from a blunt prominence (internal basal angle) respectively upward (margo intermedius) to the apex, backward to the posterior basal angle, and forward to the prominent anterior basal angle.

[1210]

The gastric surface is large and concave and lies along the anterior border; it presents, an inch or so in front of the margo intermedius, a slit (hilus) for the entrance of vessels and nerves; between the hilus and internal basal angle is a depression for the tail of the pancreas. The renal surface is flat and even, lies along the posterior border, and is applied to the front of the kidney antero-superiorly. The basal surface is the smallest and triangular; it looks downward and inward and touches the splenic flexure and costo-colic ligament. [1211]

The anterior border is sharp, prominent, and notched. The posterior border practically lies along the last intercostal space. The other border is the inferior. Peritoneum almost completely covers the spleen and passes from it, near the hilus, in two folds; one fold (lieno-renal ligament) passes to the front of the left kidney and the other (gastro-splenic omentum) to the fundus of the stomach.

[1212]

Structure.-It is very vascular and, besides an outer serous coat, has a strong fibrous capsule (tunica propria) from whose deep surface processes (trabeculæ) run inward to form a supporting network. This network is filled with the spleen pulp, 


\section{DUCTLESS GLANDS.}

containing blood-vessels, leucocytes, and large special (splenic) cells.

Suprarenal Capsules.-These are small and flattened. The right capsule is triangular and rests on the antero-internal aspect of the upper end of the right kidney. Its anterior surface looks forward and outward and presents two impressions; one (for the vena cava) is a narrow strip along the anterior border, which presents a short fissure (hilus) near its upper end; the other, the rest of the surface, is for the back of the right lobe of the liver. Its posterior surface is divided by a curved ridge into an upper flat part which rests on the diaphragm over the spine, and a concave lower part which rests on the kidney. Peritoneum covers only a small and variable part of the lower part of the anterior surface.

[1213]

The left capsule is semilunar, usually slightly larger, and rests on the inner border of the kidney just above the hilus. Its anterior surface lies behind the stomach and (lower portion) pancreas and splenic vessels; near its lower end is a slit (hilus); peritoneum covers only the gastric area. Its posterior surface is divided by a curved ridge into an upper flat area resting on the left crus of the diaphragm; and a lower concave area resting on the kidney.

[1214]

Structure.-It has a thin connective-tissue capsule from whose inner surface processes run inward to form a framework. The outer cortical portion of the gland forms the chief bulk and is firm and yellowish, the inner medullary part is soft and dark brown.

[1215]

Coccygeal Body.-This is a small body lying in front of the tip of the coccyx. It is composed of nodular masses of epithelial-like cells, separated from each other by connectivetissue strands.

[1221] 


\section{LOWER EXTREMITY.}

\section{BONES.}

The os innominatum is described with the abdomen and pelvis (see page 184).

[214]

Femur.-The upper extremity comprises the head, neck, and trochanters. The head is hemispherical, and directed upward, inward, and slightly forward; its circumference is an irregular lip, most prominent above and behind; just below its summit is an oval pit for the ligamentum teres. The neck is compressed, thickest vertically, and directed upward, inward, and slightly forward; it expands internally to support the head, and externally, in its vertical diameter, to join the upper end of the shaft at an angle of $125^{\circ}$. Anteriorly a ridge (anterior intertrochanteric line), running downward and inward from a prominence (tubercle of the femur), separates it from the shaft. Posteriorly another ridge (posterior intertrochanteric line) connecting the trochanters, separates it from the shaft; above the middle of this ridge is a fulness (quadrate tubercle). On its upper part, under the trochanter major, is a fossa (digital) from which a groove runs across the back of the neck.

The trochanter major is quadrilateral and caps the upper and outer part of the shaft; an oblique line connecting the posterosuperior and anterior inferior angles bisects its outer surface; a horizontal ridge bounds it below. Its anterior surface is oblong and bounded in front by an oblique line ascending to the tubercle. Its superior border is curved and joins the thick posterior border (upper part of posterior intertrochanteric line) in a prominent angle. The trochanter minor is a pyram- 


\section{BONES.}

idal process at the junction of the lower and back part of the neck with the shaft.

[225]

Shaft.-This is cylindrical, curved with the convexity forward, and widest below. A rough longitudinal ridge (linea aspera) runs in the midline posteriorly and consists of two lips and an intervening space; it begins about two inches below the trochanter minor by the convergence of three lines. The outer line (gluteal ridge) is continuous with the outer lip, begins external to the trochanter minor, and may develop a process (trochanter tertius); the inner (spiral line) winds upward and forward from the inner lip, in front of the trochanter minor, and joins the anterior intertrochanteric line; the middle line (pectineal) descends from the trochanter minor and fades away. The lips of the linea aspera diverge at the beginning of the lower third of the shaft and pass (inner and outer epicondylic lines) to the condyles, enclosing a triangular area (popliteal surface); the inner line ends in a spur (adductor tubercle) on the upper and inner surface of the internal condyle.

[226]

Lower Extremity.-This comprises the condyles, two recurved processes which are united in front but separated behind by a notch. This notch (intercondylic) extends as far forward as the centre of the external condyle; its floor slopes upward and backward toward the popliteal surface, but is separated from this by a ridge (intercondylic). Within the notch an oval surface, for the posterior crucial ligament, lies on the lower and anterior part of the inner condyle, and another, for the anterior crucial ligament, on the upper and posterior part of the outer condyle. The external condyle is the broader and longer, and extends higher in front; the lower surfaces of both are level in the normal position. The cutaneous aspect of each condyle has an elevation (tuberosity); the inner tuberosity is the more prominent and is capped by the adductor tubercle; below the outer tuberosity is a groove which ends anteriorly in a pit.

Two grooves, which run from before backward toward the 


\section{DISSECTING MANUAL.}

intercondylic notch, divide the articular surface into three areas. The anterior area (trochlea) lies on the inferior surface of the coalescence of the condyles; it is convex vertically and presents a shallow groove between two convex surfaces, of which the outer is the wider, more prominent, and higher in front. The posterior areas (condyloid, or tibial surfaces) are convex and curve spirally round the under surfaces and posterior extremities of the condyles. From below, the inner condyloid surface is the narrower and is curved round a vertical axis while the outer surface runs backward and slightly outward.

Patella. - This sesamoid bone lies in the Quadriceps extensor tendon in front of the knee. It is somewhat triangular and presents a projecting lower angle (apex) and a broad upper edge (base), which is divided by a transverse line into two areas, anterior and posterior; the latter is triangular. The borders, inner and outer, are curved; the anterior surface is convex. A vertical ridge divides the posterior (femoral articular) surface into two parts; the outer is the larger and slightly concave; the inner is slightly concave vertically but plane, or convex, transversely; on the inner edge of the inner area there may be a third vertical area. The deep surface of the apex is rough and irregular.

[230]

Tibia.- The upper extremity is expanded and comprises the tuberosities, spine, and tubercle. On the top of each tuberosity is an articular condyle; the inner is slightly concave, has a well-defined edge, and is oval, with its long axis anteroposterior; the outer is the smaller and rounder, slightly concave transversely and convex antero-posteriorly, and has a sharp edge which becomes rounded off behind. Between the condyles is a prominence (spine) whose summit is grooved and capped on either side by a prolongation (tubercle) of the condyle; the inner tubercle is higher, longer, and less pointed than the outer. Between the condyles, in front of and behind the spine, are two V-shaped surfaces (intercondylic fossæ); the 


\section{BONES.}

anterior fossa is the larger and wider; the posterior is concave transversely and slopes downward and backward. The external tuberosity is the smaller but overhangs the shaft more; the facet for the fibula lies on the under surface of its most projecting part postero-externally; the impression for the iliotibial band is antero-external. The Semimembranosus tendon grooves the circumference of the internal tuberosity posterointernally. An oval elevation (tubercle of the tibia, or anterior tuberosity) lies in front of the tuberosities, an inch below the condyles; its upper half is smooth but the lower half is rough, for the ligamentum patellæ.

Shaft.-This has three surfaces and three borders. The anterior border (crest, or shin) is curved and prominent; from the tubercle it runs downward in front to the lower third and then, fading away, toward the anterior border of the internal malleolus. The internal border descends, from the internal tuberosity, to the posterior border of the internal malleolus; it is sharp at its midpart only. The external border (crista interossea) is a vertical ridge which descends, from the external tuberosity, to within two inches of the lower extremity and then divides into two lines enclosing, a triangular articular area. The internal (subcutaneous) surface extends to the internal tuberosity above, and becomes continuous with the inner surface of the inner malleolus below. The external surface turns forward, inferiorly, onto the front of the shaft. The posterior surface is crossed above by a ridge (oblique, or popliteal line) which runs downward and inward, from the fibular facet, to the internal border at the junction of the upper and middle thirds; a vertical ridge descends from about the middle of the popliteal line and divides this surface into inner and outer parts.

[233]

Inferior Extremity.-This is expanded and quadrangular. On its under surface is a saddle-shaped facet, concave anteroposteriorly and slightly convex transversely, with sharp anterior and posterior borders; the anterior border is often 


\section{DISSECTING MANUAL.}

grooved. The external border of the facet is the base of the triangular facet enclosed by the splitting of the interosseous ridge; at its ends are tubercles. Internally a process (internal malleolus) projects downward and is pointed inferiorly in front but notched behind; its inner surface is convex and subcutaneous; its outer surface has a pyriform facet continuous with the saddle-shaped facet. A broad groove descends obliquely along the posterior border of the malleolus, with a smaller one just external to it.

[234]

Fibula.-The upper extremity (head) is expanded, and bevelled on its inner surface. A pointed eminence (styloid process) projects upward from the summit of its upper edge, and just internal to this, at the top of the internal surface, is a triangular facet for the tibia. There are usually tubercles in front of and behind the head. Below the head is a constricted portion (neck).

[235]

Shaft.-The anterior border descends from the front of the head and splits, enclosing a triangular subcutaneous area just above the malleolus. The interosseous border, or ridge, lies just internal to the preceding, being separated from it by a considerable interval below but often fused with it above. The posterior border descends from the base of the styloid process and ends just above the pit on the inner surface of the lower extremity. The flexor surface lies between the interosseous and anterior borders. The outer (peroneal) surface lies between the anterior and posterior borders; it looks forward above, but twists backward below where it is continuous with the groove on the back of the malleolus. The extensor surface, looking backward above and inward below, lies between the posterior and interosseous borders; it is crossed by a curved ridge (so called "internal border") which begins below at the junction of the middle and lower thirds of the interosseous ridge and ascends, inclining at first backward and then forward, to join the interosseous ridge on the neck (marking off the "internal surface").

[236] 


\section{BONES.}

Lower Extremity (external malleolus).-This is pyramidal. The inner surface has a triangular facet which is plane anteroposteriorly and slightly convex vertically; behind this is a pit for the posterior fasciculus of the external lateral ligament; above the facet is a triangular area from whose summit the interosseous ridge arises. The external surface is rounded and continuous with the surface enclosed by the splitting of the anterior border; it ends below in a pointed process which is lower than that of the internal malleolus. The posterior surface is broad above but narrow below, and is grooved.

[238]

Astragalus. - This consists of a body, neck, and head; it lies above the os calcis, wedged between the malleoli. Body. A saddle-shaped facet (trochlea), broadest in front, lies on the upper surface. This is continuous, on the outer surface, with a quadrant-shaped facet, concave vertically, whose inferior angle (external process) is everted; and on the inner surface with a comma-shaped facet, below whose tail is a circular impression for the internal lateral ligament. The preceding facets articulate with the tibia and fibula. At the back of the inferior surface is an oval concave facet (posterior calcanean) which is placed obliquely; in front of this a deep furrow runs forward and outward; in front of this is a small oval and convex facet (middle calcanean). On the posterior surface a groove, running downward and inward, separates two tubercles. The head is oval and directed forward and inward. On its anterior surface is a convex facet, for the scaphoid, which is usually confluent with the middle calcanean facet, though a small facet (anterior calcanean) may intervene. On the inner and under surface is a facet for the inferior calcaneo-navicular ligament. The neck, best seen above, runs forward and slightly inward from the body to the head; it forms a wide groove externally which joins the interosseous groove below.

Os Calcis.-This lies posteriorly, under the astragalus. The upper surface is rounded transversely behind; in front of this is a convex facet; in front of this a groove runs forward and 
outward and forms, with the groove under the astragalus, the tarsal canal; to the front and inner side of this groove is an elongated facet, often subdivided; all these facets are for the astragalus. The inferior surface is concave antero-posteriorly and convex transversely; posteriorly it presents two tubercles, inner and outer, of which the inner is the larger; anteriorly an elongated tubercle ends abruptly at the anterior border, often forming a notch. The internal surface presents a broad groove running downward and forward; a bracket-like process (sustentaculum tali, or lesser process) overhangs the groove in front, and is also grooved on its lower surface. The external surface is flattened and broadest behind; a process (peroneal spine) springs from it just below the outer end of the tarsal canal. The anterior extremity (greater process) has, on its anterior surface, a saddle-shaped facet, for the cuboid, which is convex transversely and concave vertically. The posterior extremity (tuberosity) is oval, rounded, and divisible into three areas; the highest area is smooth and crescentic; the intermediate one is smooth and separated from the rough lowest area by an irregular line.

Navicular (scaphoid). - This lies on the inner side, between the astragalus and cuneiforms. The posterior surface has a large oval, concave facet for the astragalus. The anterior surface has a semilunar facet which is subdivided by faint ridges into three wedge-shaped facets for the cuneiforms. The superior surface is convex transversely and rough; the inferior is concave and rough; the external is usually rough but may have a facet for the cuboid. The inner surface is a rounded projection (tubercle).

[245]

Cuneiform Bones.-The three are wedge-shaped and lie between the navicular and the three outer metatarsals.

Internal Cuneiform (the largest).-The upper, lower, and internal surfaces are rough and convex; at the front of the inner surface is an oval impression for the Tibialis anticus tendon. 


\section{BONES.}

The external surface has, along its posterior and upper edges, an L-shaped facet for the middle cuneiform and second metatarsal. The posterior surface has a pyriform facet for the navicular; the anterior surface is the longest and has a semilunar facet for the first metatarsal.

[246]

Middle Cuneiform (the smallest and shortest).-The superior surface is broad and convex; the inferior is narrow. The inner surface has, along its posterior and superior borders, an Lshaped facet for the internal cuneiform; the outer surface has posteriorly a facet, often constricted mesially, for the external cuneiform. The posterior surface has a triangular facet for the navicular; the anterior surface has a wedge-shaped facet for the second metatarsal.

[246]

External Cuneiform.-The superior surface is broad and convex; the inferior is narrow. The inner surface has two narrow facets, often constricted mesially, along its anterior and posterior borders, for the second metatarsal and middle cuneiform respectively. The outer surface presents posteriorly a large facet for the cuboid, and a small one, for the fourth metatarsal, along the upper part of the anterior border. The posterior end has a triangular facet for the navicular; the anterior has another for the third metatarsal.

Cuboid.-This lies on the outer side, between the os calcis and two outer metatarsals. The upper surface is almost plane; the rounded outer surface is notched inferiorly by the peroneal groove. The under surface presents a thick ridge running forward and inward; in front of the ridge is a groove (peroneal); at the outer end of the ridge is a prominence (tubercle) with a facet antero-externally for the sesamoid bone in the Peroneus longus tendon. The internal surface has a facet, near the centre of its upper border, for the external cuneiform, and sometimes another behind this, for the navicular. The anterior surface has a facet, subdivided by a vertical ridge, for the two outer metatarsals. The posterior surface is semilunar, with a pointed process (calcanean) at its inferior internal angle; it 


\section{DISSECTING MANUAL.}

has a saddle-shaped facet, concave vertically and convex transversely, for the os calcis.

Metatarsal Bones.-These resemble the metacarpals but are longer, while the bases are larger and the shafts and heads smaller. They are numbered from within outward. First (the shortest and stoutest). The base is widest vertically; at its end is a reniform facet for the internal cuneiform; the inferior angle projects (tubercle) backward and outward. The shaft tapers rapidly. The head has on its end a convex facet, for the phalanx, and this is confluent with a facet on its under side which is divided by a median ridge into two grooves for sesamoid bones. Second (the longest). The base is wedge-shaped; at its end is a facet for the middle cuneiform; on its inner side, high up, is a facet for the internal cuneiform; on its outer side are two facets, each divided into anterior and posterior parts, for the third metatarsal and external cuneiform respectively. The shafts of this and the remaining metatarsals are thin, and the ends of the heads are convex.

Third. The base is wedge-shaped; at its end is a facet for the external cuneiform, and on its inner side one or two facets for the second metatarsal; on its outer side is a facet for the fourth metatarsal, and below this is a groove. Fourth. The base is cubical; at its end is a facet for the cuboid; on its inner side is an elongated oval facet, divided by a vertical ridge, for the third metatarsal in front and internal cuneiform behind; on its outer side is a demi-oval facet, slightly saddle-shaped, for the fifth metatarsal. Fifth. The base has, at its end, a semicircular facet for the cuboid, and on its inner side a demioval, concave facet for the fourth metatarsal; a tubercle projects backward and outward from the outer side.

[251].

Phalanges.-These resemble those of the fingers but are much smaller, and the shafts, especially in the first row, are much compressed longitudinally. In the first row the proximal end is large and has a simple hollow; the distal ends have condyloid surfaces. In the second row the proximal ends each 


\section{ARTICUI.ATIONS.}

have two concavities, separated by a ridge. The surfaces between the second and third rows are similar. The distal ends of the terminal phalanges are spatulous. The two phalanges of the great toe differ only in being larger.

[244]

\section{ARTICULATIONS.}

Hip Joint.-In this enarthrodial diarthrosis the head of the femur, which is covered with hyaline cartilage except over the pit, is received in the acetabulum; this is lined at the sides with hyaline cartilage, and is completed by the transverse ligament and deepened by the cotyloid ligament. The transverse ligament consists of transverse fibres which bridge the acetabular notch and are attached to the sides, especially the posteroinferior; under its lower edge is an opening for vessels and nerves. The cotyloid ligament is a fibro-cartilaginous ring attached by its broader edge to the rim of the acetabulum and transverse ligament; its contracted free edge grasps the head of the femur.

[293]

The capsule is attached superiorly, around the acetabulum, to the innominate bone above and behind, and the cotyloid and transverse ligaments below and in front. Inferiorly it is attached to the femur, viz.: to the anterior intertrochanteric line in front; the inner aspect of the root of the great trochanter above; the lower part of the neck, near the small trochanter, below; and the line of junction of the outer and middle thirds of the neck behind. It consists of circular fibres (zona orbicularis) which are best marked behind; and of longitudinal fibres which are best marked in front, where they form special ligaments. Many fibres are reflected upward on the neck of the femur in ridges (retinacula).

The special ligaments of the longitudinal fibres are the following: The ilio-femoral is a strong triangular portion attached above (by its apex) to the lower part of the anterior inferior iliac spine and adjacent rim of the acetabulum, and below to 


\section{DISSECTING MANUAL.}

the anterior intertrochanteric line; the lower part is thinned at its centre, so that the ligament may seem Y-shaped (Bigelow). Its outer part may be extended by an additional band (ileo-trochanteric) which runs from the anterior part of the dorsum of the acetabulum to the femoral neck, close to the anterior end of the inner surface of the great trochanter. The pubo-femoral (pubo-capsular) consist of bands arising from the outer end of the pubic horizontal ramus, ilio-pectineal eminence, and obturator crest and membrane. They are mostly lost on the capsule but some pass to the lower part of the neck of the femur and adjoin the lower attachment of the iliofemoral. The ischio-capsular is a broad short band attached above to the ischium, between the small sciatic notch and obturator foramen, and merged below with the zona orbicularis of the capsule.

[295]

The interarticular ligament (ligamentum teres) lies within the capsule; it is a somewhat flattened fibrous band running from the upper half of the pit on the head of the femur to the lower edge of the articular surface of the transverse ligament, with extensions to the opposite borders of the acetabulum notch, especially the posterior. The Haversian gland is a mass of fat at the bottom of the acetabulum, which is covered by synovial membrane and continuous with extra-capsular fat under the transverse ligament.

[295]

The synovial membrane lines the capsule and passes, at its acetabular end, onto the outer and then the inner surfaces of the cotyloid and transverse ligaments, and over the Haversian gland and ligamentum teres. Inferiorly it is reflected over the femoral neck almost to the articular margin of the head, forming loose folds over the retinacula near its line of reflection. The bursa under the Ilio-psoas tendon may communicate with the joint through an opening on the anterior wall of the capsule, between the pubo-femoral and ilio-femoral ligaments. [295]

Knee Joint.-This ginglymus diarthrosis is formed between the condyloid surfaces on the femur.and the condylar 


\section{ARTICULATIONS.}

facets on the tibia; and also between the femoral trochlear surface and the patellar. Besides hinge motion, the tibia rotates slightly in extreme flexion. The capsule consists of strong special bands with intervals between them, which are filled by a capsular membrane consisting largely of fascial and tendinous expansions; it is absent above under the Quadriceps extensor tendon. The expansions are derived anteriorly (lateral patellar ligaments) from the fascia lata and Vasti tendons, on either side of the patella and ligamentum patell ; internally from the Sartorius and Semi-membranosus tendons; externally from the ilio-tibial band; and posteriorly from the Semi-membranosus tendon.

The anterior ligament, or ligamentum patelloe, is a strong flat band running from the tubercle of the tibia to the apex and adjoining margins of the patella. It acts as the Quadriceps extensor tendon and some fibres cover the front of the patella. A bursa separates it from the tibial tubercle; above this it rests on the infra-patellar fat pad. The posterior ligament is attached above to the popliteal surface of the femur, and the condyles just above their articular areas; and below to the posterior border of the tibial head, presenting an opening externally for the Popliteus tendon. It is thin laterally but thickened mesially by an expansion (ligamentum posticum Winslowii) of the Semi-membranous tendon; this runs obliquely upward and outward to lose itself in the capsule, but may present upper and lower arcuate borders between the femoral condyles.

[299]

The internal lateral ligament is a strong flat band consisting of two parts, which arise close together from the internal condyle just below the adductor tubercle. The short (posterior) portion descends slightly backward to the postero-internal aspect of the tibia, just above the groove for the Semi-membranosus tendon. The long (anterior) portion descends slightly forward, over the Semi-membranosus tendon, to the tibia just below the level of its tubercle. The ligament adheres 


\section{DISSECTING MANUAL.}

to the semilunar cartilage; a bursa separates it from overlying tendons. The (long) external lateral ligament is a rounded band running from the tubercle on the femoral external condyle to the outer side of the fibular head, in front of its styloid process; it descends under the capsule and splits the Biceps tendon. The short or posterior external lateral ligament (inconstant) arises just behind the preceding, under the Gastrocnemius, and descends over the Popliteus to the styloid process. [300]

The crucial ligaments are two strong rounded bands, within the capsule, which cross each other; they are distinct and each has its own partial synovial covering. The anterior begins at the inner part of the depressed area in front of and close to the tibial spine, and runs upward, outward, and backward to the external femoral condyle, at the back part of the intercondyloid notch; it is tense in extension. The posterior begins at the back of the depressed area behind the tibial spine, close to the popliteal notch, and runs upward, forward, and inward to the internal femoral condyle, near the front part of the intercondyloid notch; it is tense in flexion.

[300]

The semilunar interarticular fibro-cartilages lie between the femur and tibia. Each has a thick convex outer border, and a thin concave and free inner border; each ends in two horns (cornua), anterior and posterior. The internal fibro-cartilage forms nearly a semicircle; its horns are attached to the tibia just in front of the anterior and posterior crucial ligaments respectively; the deep part of the internal lateral ligament is attached to its periphery. The external fibro-cartilage forms nearly a circle and its horns are embraced by those of the internal. It is attached to the tibia by its anterior horn in front of the spine, external to and partly under the anterior crucial ligament; and by its posterior horn to the interval between the tubercles on the spine. It is also attached to the posterior ligament behind, while a large bundle of fibres runs from its posterior border to the back of the posterior crucial ligament. Short bands (ligamenta coronaria) join the outer margins of the fibro-car- 


\section{ARTICULATIONS.}

tilages to the circumference of the tibial head, while a round band (transverse ligament) passes between their anterior convex margins.

[301]

The synovial membrane, beside lining the capsule, covers the deep surface of the common extensor tendon and extends above the patella. Over the fatty pad (infra-patellar) in the interval between the femur, tibia, and patella, it extends in a band (ligamentum mucosum) from the front of the intercondyloid notch to below the level of the patellar facet, its lower part expanding on each side in fatty fringes (alar ligaments). It covers the surfaces of the fibro-cartilages and the parts of their outer margins not attached to the capsule. It invests the intracapsular part of the Popliteus tendon and separates this from the tibia. A prolongation from behind partly covers the crucial ligaments.

[302]

The joint eavity may communicate with the superior tibiofibular joint, with bursæ under the inner head of the Gastrocnemius and the Semi-membranosus tendon, and with a bursa (supra-patellar) above its extension upward under the Quadriceps extensor.

[303]

Tibio-fibular Joints.-These are arthrodial, with but little motion.

[304]

The superior joint is between the facets on the head of the fibula and tuberosity of the tibia, and may communicate with the knee joint. It has a capsule which is lined by a synovial membrane, and presents the following special bands: anterior superior tibio-fibular ligament, running from the front of the fibular head, upward and inward to the adjoining part of the tuberosity; and posterior superior tibio-fibular ligament, running from the back of the fibular head, upward and inward to the back of the tuberosity, just below the orifice for the Popliteus tendon in the knee-joint eapsule.

[304]

The interosseous membrane acts as an accessory ligament for both joints and connects the interosseous borders of the tibia and fibula. Its fibres run chiefly downward and outward. It 
may extend upward to the superior joint; above its upper margin is an oval aperture, about an inch long, for vessels and nerves; in its lower part is a small opening for vessels. Inferiorly, it runs into the interosseous ligament.

[304]

The inferior joint is between the lower ends of the tibia and fibula and does not always have articular cartilage; when present the cartilage is only a narrow strip at the lower end of each bone, continuous with that of the ankle joint. Most of the opposing surfaces are rough and non-articular. The supporting ligaments are the following: anterior inferior tibio-fibular, fibres running downward and outward from the front of the lower end of the tibia to the front. of the external malleolus; posterior inferior tibio-fibular, similar fibres posteriorly; transverse inferior tibio-fibular, running from the posterior inferior border of the tibia to the upper end of the pit on the posterointerior aspect of the external malleolus; interosseous, fibres connecting the rough opposing surfaces and in contact with the others. The synovial membrane lining it is prolonged from the ankle joint.

[304]

Ankle Joint.-This is a ginglymus diarthrosis. The lower ends of the tibia and fibula, with the transverse inferior tibiofibular ligament, form a three-sided socket, which is widest in front at its highest part, for the upper surface and sides of the astragalus. Its synovial membrane lines the capsule, communicates with the inferior tibio-fibular joint, and covers the fatty pads at the front and back and also above, in the angle between the three bones. Its capsule is formed by the following ligaments: The anterior ligament is very thin and extends from the lower border of the tibia to the upper border of the head of the astragalus. The posterior ligament connects the contiguous borders of the tibia and astragalus; many fibres radiate inward from the external malleolus.

[306]

The external lateral ligament is strong and divisible into three fasciculi. The anterior, the shortest, runs from the anterior border of the malleolus to the astragalus just in front of its 


\section{ARTICULATIONS.}

external facet. The middle fasciculus is a rounded cord running from the front of the tip of the malleolus to the outer side of the os calcis just above the peroneal groove. The posterior, the strongest, runs from the lower part of the fibular fossa on the malleolus to the external tubercle and adjoining rough surface on the posterior surface of the astragalus. The internal lateral ligament (deltoid) runs from the impression on the lower part of the malleolus to the scaphoid, astragalus, and os calcis, spreading out in a continuous layer. It presents the following special bands: (ligamentum talo-tibiale anticum) from the front of the malleolus to the neck of the astragalus; (ligamentum talo-tibiale posticum) from the back of the malleolus to the postero-internal rough surface of the astragalus; (ligamentum tibio-naviculare) from the tip of the malleolus to the inner side of the scaphoid; (ligamentum calcaneo-tibiale) from the tip of the malleolus to the inner side of the sustentaculum tali; and (ligamentum talo-tibiale profundum) deeper fibres from the tip of the malleolus to the inner side of the astragalus.

[307]

Intertarsal Joints. - These are arthrodial diarthroses, as follows: The talo-calcanean is between the posterior calcanean facet on the astragalus and the corresponding facet on the os calcis. Its capsule consists of the following talo-calcaneal ligaments, viz.: Anterior, a band at the anterior end of the tarsal canal, which descends from the antero-external aspect of the neck of the astragalus to the adjacent upper surface of the os calcis: External, short fibres connecting the adjacent outer margins of the bones, in continuity with the posterior borders of the preceding, and parallel to, but deeper than, the middle fasciculus of the external lateral ligament: Posterior, fibres radiating from the back of the cxternal tubercle of the astragalus to the upper surface of the os calcis, just behind the facet: Internal, fibres passing from the inner posterior tubercle of the astragalus to the posterior border of the sustentaculum tali: Interosseous, strong fibres connecting the bottoms of the 


\section{DISSECTING MANUAL.}

grooves forming the tarsal canal. A distinct synovial membrane lines the capsule.

[308]

The talo-calcaneo-navicular is between the head of the astragalus and the socket formed by the sustentaculum tali, scaphoid, and inferior calcaneo-scaphoid ligament. Its capsule is formed by the following ligaments, viz.: Inferior (internal) calcaneo-scaphoid, a strong fibro-cartilaginous band running from the anterior margin of the sustentaculum tali to the inferior surface of the scaphoid, some of the upper fibres radiating upward to join the tibio-navicular ligament: Superior (external) calcaneo-scaphoid, short fibres running from the dorsum of the os calcis, at the outer side of the sustentacular facet, to the outer side of the scaphoid (it may articulate with an extra facet on the postero-external part of the head of the astragalus): Astragalo-scaphoid, a thin membrane running from the upper non-articular area on the head of the astragalus to the dorsum of the scaphoid and divisible into dorsal, lateral, and medial parts or ligaments. The interosseous talo-calcaneal ligament completes the capsule posteriorly. A distinct synovial membrane lines the capsule.

[309]

The calcaneo-cuboid is between the facets on the front of the os calcis and back of the cuboid. Its capsule is formed by the following calcaneo-cuboid ligaments, viz.: Internal (interosseous), short fibres in the tarsal canal, arising from the os calcis with the superior calcaneo-scaphoid ligament, with which it forms a V-shaped structure, and passing to the inner side of the cuboid: Dorsal, a broad band connecting the dorsal surfaces of the bones: External, a narrower band running from the outer side of the os calcis to the outer side of the cuboid, just behind the sesamoid facet on its tubercle: Inferior, two in number, superficial and deep, which are separated by a layer of areolar tissue. Of the latter the superficial set of fibres (long plantar ligament) runs from the under surface of the os calcis, in front of its tuberosities, to the under surface of the cuboid ridge; many fibres continue under (superficial to) the Peroneus 


\section{ARTICULATIONS.}

longus tendon to the bases of the three outer metatarsals. The deep set (short plantar ligament) is a broad and strong band running from the under surface of the front end of the os calcis to the under surface of the cuboid just behind its ridge. A synovial membrane lines the capsule.

The transverse tarsal is a term sometimes applied to the astragalo-scaphoid and calcaneo-cuboid joints, though they do not communicate. The scaphoid and cuboid sometimes articulate directly (scapho-cuboid joint) through a prolongation from the scapho-cuneiform and cubo-cuneiform series of joints. They are always connected by the following accessory scaphocuboid ligaments, viz.: dorsal, short oblique fibres between the dorsal surfaces of the cuboid and scaphoid; plantar, transverse fibres between their adjacent plantar surfaces; and interosseous, fibres connecting their contiguous surfaces.

The scapho-cuneiform is between the scaphoid and the cuneiform bones. The capsule is visible on all sides except toward the cuboid, and consists of short bands. On the dorsal and plantar aspects these form the dorsal and plantar scapho-cuneiform ligaments; the former extend to the inner aspect. A synovial membrane lines the capsule and sends prolongations forward on each side of the middle cuneiform; it communicates often with the cubo-cuneiform joint, and always with the scapho-cuboid joint when present.

[312]

The intercuneiform are two joints between the adjacent contiguous surfaces of the cuneiforms. The intercuneiform ligaments are dorsal, transverse bands between the bones; and interosseous, strong bands between their contiguous surfaces which close the joint cavities below, and the outer one in front. A synovial membrane, which is prolonged from the scaphocuneiform joint, lines them and is prolonged from the outer one to the tarso-metatarsal joints.

[312]

The cubo-cuneiform is between the facets on the opposing surfaces of the cuboid and external cuneiform. The cubo-cuneiform ligaments are the dorsal, a flat band connecting the dorsal 


\section{DISSECTING MANUAL.}

surfaces; plantar (theoretical), a band between the plantar surfaces, subjacent to the long plantar ligament; and interosseous, strong fibres anteriorly between the contiguous surfaces of the bones. The synovial membrane may be distinct, but of ten communicates with those of the scapho-cuneiform and scaphocuboid joints.

Tarso-metatarsal Joints. - There are three, the inner, middle, and outer, as follows.

[313]

The inner joint is between the distal end of the internal cuneiform and proximal end of the base of the first metatarsal. Its capsule is complete but the dorsal and plantar tarso-metatarsal bands are its strongest parts; a separate synovial membrane lines it.

The middle joint is between the three cuneiforms and the bases of the second, third, and part of the fourth metatarsal. Its parts are interlocked as the second metatarsal projects backward between the internal and external cuneiforms, while the external cuneiform projects forward between the second and fourth metatarsals. It has a complete capsule with a separate synovial membrane, which is prolonged forward on both sides of the second and third metatarsals, and backward between the inner and middle cuneiforms to open into the scapho-cuneiform joint. Of the tarso-metatarsal ligaments, the dorsal are antero-posterior flat bands, one running from the external cuneiform to the third metatarsal, and one from each cuneiform to the second metatarsal; the palmar are weaker bands similarly disposed, with oblique bands between the internal cuneiform and second and third metatarsals. Of the three interosseous cuneo-metatarsal ligaments, the inner connects the outer side of the internal cuneiform with the inner side of the second metatarsal; the middle connects the inner side of the external cuneiform with the outer side of the second metatarsal; and the outer connects the adjacent outer sides of the external cuneiform and third metatarsal.

The external joint is between the cuboid and the proximal 


\section{ARTICULATIONS.}

ends of the fourth and fifth metatarsals. Its capsule is complete and presents the following tarso-metatarsal ligaments, viz.: dorsal, antero-posterior flat bands, the fifth metatarsal receiving one from the cuboid, and the fourth metatarsal one each from the cuboid and external cuneiform; and plantar, similar weak bands connecting the cuboid with both metatarsals, and including transverse fibres between the external cuneiform and fifth metatarsal, and other fibres from the long plantar ligament to both metatarsals. The synovial membrane lining it is distinct, and sends a prolongation between the two outer metatarsals.

Intermetatarsal Joints. - These are formed between the contiguous sides of the bases of the four outer metatarsals. Each joint has an incomplete capsule, which communicates with the tarso-metatarsal joint behind it and is lined by synovial membrane prolonged therefrom. The ligaments are transverse bands connecting the bases, viz.: dorsal, plantar, and interosseous.

The transverse metatarsal ligament lies upon and connects the plantar aspects of the heads of all the metatarsals: it sends prolongations (ligamenta accessoria plantaria) to the plantar fibrous plates of the metatarso-phalangeal joints.

[314]

Metatarso-phalangeal Joints.- These modified enarthrodial diarthroses are formed betwcen the heads of the metatarsals and proximal ends of the first phalanges. Each has a modified capsule which is lined by synovial membrane and presents the ligamenta collateralia, strong cord-like bands connecting the contiguous rough surfaces on the inner and outer sides. Expansions of the extensor tendons practically form the capsule dorsally. The plantar aspect of the capsule consists of a fibrous plate which is grooved for the long flexor tendons; on the great toe it develops two large sesamoid bones within itself. [314]

Interphalangeal Joints.- These ginglymus diarthroses are formed between the contiguous ends of the phalanges. Each has a capsule whose dorsal aspect is either very thin or limited 


\section{DISSECTING MANUAL.}

to synovial membrane; its plantar aspect presents a fibrous plate. The lateral ligaments (ligamenta collateralia) are welldefined bands like those of the metatarso-phalangeal joints. A synovial membrane lines each capsule.

[314]

\section{THIGH AND BUTTOCK.}

\section{FASCIA.}

Superficial Fascia.-This is continuous with that of the abdomen, back, perineum, and leg; it is thick and fatty in the buttock. In the groin it separates into two layers, superficial and deep, between which are the femoral and inguinal glands, small arteries, and internal saphenous vein and tributaries. The superficial fatty layer is continuous with a similar layer on the perineum and front of the abdomen. The deep membranous layer is attached above to the inner half of Poupart's ligament and the fascia lata below the outer half of the ligament, and internally to the pubic arch, while below Scarpa's triangle it blends with the superficial layer.

[355]

Deep Fascia or Fascia Lata.-This is attached above to the iliac crest, great sacro-sciatic ligament, ischium, pubic arch, pubic symphysis and crest, and Poupart's ligament; and below to the patella, tuberosities of the tibia, and head of the fibula, joining the deep fascia of the leg. On the buttock it is thick in front but thinner behind, and splits at the upper border of the Gluteus maximus to enclose this muscle. On the front of the thigh it is thick, pierced by vessels and nerves, and presents the saphenous opening. Internally it is thinner. At the knee, with the Vasti tendons, it forms the lateral patellar ligaments, which are attached to the borders of the patella and the tibial tuberosities. Externally it forms a broad layer (ilio-tibial band) running from the iliac crest to the knee-joint capsule and outer tibial tuberosity; a prolongation of this layer, which runs upward under the Tensor fasciæ femoris, sends a 


\section{THIGH AND BUTTOCK.}

band to join the hip-joint capsule and both origins of the Rectus femoris.

[356]

On each side of the thigh, above the knee, it forms an intermuscular septum. The external septum runs from the iliotibial band to the external supra-condyloid ridge of the femur. The internal septum encloses the Gracilis and Sartorius separately, and the Adductors in the upper two-thirds of the thigh. It roofs over the femoral artery in Hunter's canal, is strengthened mesially by fibres from the Vastus internus and Adductors, and is mostly replaced in the lower third of the thigh by the Adductor magnus tendon. On the back of the thigh and over the popliteal space it is strengthened by fibres from the hamstrings; the external saphenous vein usually pierces it over the popliteal space.

[357]

The saphenous opening is an oval opening in the fascia lata just below the inner half of Poupart's ligament and in front of the femoral vessels; it transmits the internal saphenous vein. It is covered by the superficial fascia, and by a special, thin, and perforated layer (cribriform fascia) attached to its margin. Its outer edge is the margin of the iliac portion of the fascia lata, which is attached to the iliac crest and Poupart's ligament; its superior cornu is a triangular prolongation (falciform ligament) of the iliac portion, which runs inward in front of the femoral sheath to join the inner half of Poupart's ligament. Its inner edge is the margin of the pubic portion of the fascia lata, which passes upward under the femoral sheath, but over the Pectineus and Adductor longus, to the ileo-pectineal line and hip-joint capsule. Both layers of the fascia lata are continuous at its lower concave margin, forming its inferior cornu.

[356]

The femoral sheath is conical and formed by transversalis fascia in front and iliac fascia behind; it is prolonged under Poupart's ligament into Scarpa's triangle. It is divided into three compartments, of which the outer and intermediate ones contain the femoral artery and vein respectively. The inner 


\section{DISSECTING MANUAL.}

compartment (crural canal) contains lymphatics, usually some fat, and is the channel for femoral hernia; its wall is the crural sheath. The upper limit (crural ring) of the canal lies in front of the Pectineus, external to Gimbernat's ligament, internal to the femoral vein, and behind part (superficial crural arch) of Poupart's ligament; the fascia transversalis forming the sheath is thickened (deep crural arch) in front of it. The ring is filled (crural septum) by a plug of fat or a lymphatic gland, and is separated from the internal abdominal ring by the deep epigastric artery. The canal is covered above by the falciform ligament, and ends at the saphenous opening.

[358]

A femoral hernia descending through the canal, and pushing the septum in front of it, is retarded in front by the falciform ligament, but its posterior part continues onward and hooks round this ligament; the hernia thus passes forward through the saphenous opening and upward over Poupart's ligament. Its coverings from without inward are skin, superficial fascia, cribriform fascia, crural sheath, crural septum, extra-peritoneal tissue, and peritoneum.

[359]

\section{Muscles.}

Front of Thigh.

Sartorius.-Origin; anterior superior spine of ilium, and half of notch below it. Insertion; inner surface of shaft of tibia, just below inner tuberosity, by aponeurotic fibres; capsule of kneejoint and fascia lata of leg by fascial expansions from its borders. Course; diagonally downward and inward on the thigh, its upper third forming the boundary of Scarpa's triangle, and its middle third the roof of Hunter's canal; a bursa lies under its tendon of insertion.

[359]

Quadriceps Extensor.-This is composed of four muscles, as follows; all are finally inserted in the tibia, through the ligamentum patellæ and lateral patellar ligaments.

Rectus Femoris.-Origin; (straight head) anterior inferior [272 ] 


\section{THIGH AND BUTTOCK.}

spine of ilium; (reflected head) rough groove on dorsum of ilium just above highest part of acetabulum. A bursa lies under the latter. Course; the heads, bound together and to the hip-joint capsule by a process from the ilio-tibial band, give origin to a single anterior tendon. From this and a medial septum the fibres arise in a bipenniform manner, and end in a broad posterior tendon which narrows below; under this is a bursa which communicates with the knee-joint. Insertion; upper border of patella.

[359]

Vastus Externus.-Origin; shaft of femur (anterior tubercle, lower border of great trochanter, gluteal ridge, and upper half of linea aspera); fascia lata and external intermuscular septum. Insertion; outer border of tendon of Rectus femoris; upper and outer border of patella; capsule of knee-joint and external lateral ligament of patella.

[361]

Vastus Internus.-Origin; shaft of femur (anterior tubercle, spiral line, linea aspera, and upper two-thirds of internal epicondylic line); fascial roof of Hunter's canal; internal intermuscular septum and tendon of Adductor magnus. Insertion; inner border of Rectus tendon; upper and inner border of patella; capsule of knee-joint and internal lateral ligament of patella.

[361]

Crureus.-Origin; upper two-thirds of anterior and external surfaces of shaft of femur; lower half of linea aspera, and upper part of external epicondylic line; corresponding portion of external intermuscular septum. Insertion; deep surface of Rectus and Vasti tendons through fibres which join a membranous expansion on its surface. This muscle is inseparable from the Vastus internus below the lower third.

[361]

Subcrureus (several separate muscle bundles).-Origin; lower fourth of front of femur. Insertion; synovial membrane of knee-joint, under Rectus tendon.

[362]

Ilio-psoas.-This is composed of the Iliacus and Psoas magnus.

[362]

Psoas Magnus.-Origin; intervertebral discs above each 18 


\section{DISSECTING MANUAL.}

lumbar vertebra, and adjacent margins of the vertebræ they lie between; four aponeurotic arches over sides of bodies of first four lumbar vertebra; all the lumbar transverse processes. Course; it descends over the pelvic brim and under Poupart's ligament; a bursa, which may communicate with the hip-joint, separates its tendon from the pubis and hipjoint capsule. Insertion; apex of lesser trochanter.

[362]

Psoas Parvus (inconstant).-Origin; intervertebral disc between last thoracic and first lumbar vertebra; contiguous margins of these vertebræ. Insertion; middle of ileo-pectineal line and ileo-pectineal eminence.

[363]

Iliacus.-Origin; around margin of iliac fossa; anterior sacro-iliac and ilio-lumbar ligaments. Course; under Poupart's ligament and over hip-joint. Insertion; outer side of Psoas magnus tendon; concave anterior surface of small trochanter; capsule of hip-joint (the latter are the most external fibres and are often separate, forming the Iliacus minor, or Ilio-capsularis).

[363]

Pectineus.-Origin; sharp anterior portion of pubic iliopectineal line, and (sometimes) triangular surface of pubis in front of this. Insertion; upper half of line leading from small trochanter to linea aspera.

[364]

Scarpa's triangle corresponds to the depression just below the groin and is triangular, apex downward. It is bounded above by Poupart's ligament, externally by the Sartorius, and internally by the Adductor longus. Its floor is formed, from without inward, by the Ilio-psoas, Pectineus, and Adductor longus.

Hunter's canal is a channel in the middle third of the thigh, which extends from the apex of Scarpa's triangle to the opening, for the femoral artery, in the Adductor magnus. Its floor is formed by the Adductor longus above and Adductor magnus below; its roof by the Sartorius and the fascial expansion under this; and its outer wall by the Vastus internus. 


\section{THIGH AND BUTTOCK.}

Inner Side of Thigh.

Gracilis.-Origin; lower half of edge of symphysis pubis, and similar distance on adjoining part of pubic arch, by a linear origin. Course; downward on inner side of thigh and knee. Insertion; inner side of shaft of tibia, just below inner tuberosity, behind the Sartorius and above the Semi-tendinosus and separated from their tendons by two bursæ.

[365]

Adductor Longus (may be double, or partly fused with Pectineus).-Origin; angle between pubic symphysis ard crest, by a rounded tendon. Course; connected with origin of Vastus internus by aponeurotic roof of Hunter's canal. Insertion; middle two-fourths of linea aspera.

[365]

Adductor Brevis.-Origin; oval surface on body of pubis, surrounded by muscles of this group. Insertion; lower twothirds of line leading from small trochanter to linea aspera; upper fourth of linea aspera.

[366]

Adductor Magnus.-Origin; lower part of outer border of ischial tuberosity and edge of pubic arch. Course; radiating, the upper fibres horizontally and the lower vertically; it separates the adductors and hamstrings. Insertion; space below insertion of Quadratus femoris but above linea aspera; whole length of linea aspera; internal supra-condyloid ridge; femoral internal condyle, by a tendon which receives the ischial fibres and is closely connected with the internal lateral ligament of the knee. The fibres attached above the linea aspera may form a separate muscle (Adductor minimus).

[366]

Obturator Externus. - Origin; inferior half of margin of thyroid foramen and corresponding outer surface of obturator membrane. Course ; inward, converging toward great trochanter and ending in a tendon which passes below and behind the hip-joint. Insertion; digital fossa of great trochanter. [367]

Buttock.

Gluteus Maximus.-Origin; dorsum ilii above superior curved line; tendon of Erector spinæ; back of sacrum and 
coccyx; back of great sacro-sciatic ligament. Insertion; (superficial fibres and upper half of deep fibres) fascia lata over great trochanter, joining ilio-tibial band; (most of lower half of deep fibres) gluteal ridge of femur; (lowest deep fibres) fascia lata, being thus connected with external intermuscular septum and origin of short head of Biceps. Under it are three bursæ; one (inconstant) over the ischial tuberosity; one over the outer side of the great trochanter; and one over the Vastus externus.

[368]

Tensor Fasciæ Femoris.-Origin; dorsum ilii external to anterior superior spine, and upper part of notch below it. Course; downward superficially in a separate investment of fascia lata. Insertion; fascia lata, about level of great trochanter (iliotibial band).

[369]

Gluteus Medius.-Origin; dorsum ilii, between the iliac crest and superior curved line above and middle curved line below; fascia lata covering its anterior surface. Course; under Gluteus maximus in front. Insertion; diagonal line on outer surface of great trochanter, a bursa lying under its tendon on the trochanter.

[370]

Gluteus Minimus.-Origin; dorsum ilii, between middle and inferior curved lines. Course; under two preceding muscles. Insertion; outer border of anterior surface of great trochanter, and (sometimes) front of upper border. A bursa lies under its tendon on the great trochanter.

[370]

Pyriformis.-Origin; pedicles of second, third, and fourth sacral vertebræ; upper margin of great sacro-sciatic notch. Course; through great sacro-sciatic notch. Insertion; facet on upper border of great trochanter.

Obturator Internus (occupying pelvic aspect of os innominatum).-Origin; whole margin of thyroid foramen, except obturator notch; obturator membrane; smooth surface of hip bone behind thyroid foramen; (slightly) parietal pelvic fascia covering it. Course; converging and ending in several tendons which pass through the lesser sacro-sciatic foramen, hook round 


\section{THIGH AND BUTTOCK.}

its margin (a bursa intervening), and unite later in a single tendon. Insertion; facet on inner surface of great trochanter above digital fossa.

[371]

Gemelli (accessory portions of the preceding).-Gemellus superior. Origin; gluteal surface of ischial spine; upper part of margin of lesser sciatic notch. Insertion; upper margin and superficial surface of Obturator internus tendon. Gemellus inferior. Origin; upper part of gluteal surface of ischial tuberosity; lower part of margin of lesser sciatic notch. Insertion; lower margin and superficial aspect of Obturator internus tendon.

Quadratus Femoris (often fused with Adductor magnus).Origin; outer margin of ischial tuberosity. Insertion; quadrate line of femur. A bursa separates it from the small trochanter.

[372]

Back of Thigh (Hamstrings).

Biceps Flexor Cruris.-Origin; (long head) great sacrosciatic ligament and lower and inner facet on ischial tuberosity, in common with Semitendinosus; (short head) whole of linea aspera and upper two-thirds of external supra-condyloid ridge; corresponding extent of external intermuscular septum. Course; the long head soon leaves the Semitendinosus, descends to the lower third of the thigh, and ends in a tendon which is joined by the short head. Insertion; head of fibula, by a tendon which is bisected by the external lateral ligament of the knee; popliteal fascia along its posterior border, by transverse aponeurotic fibres from the tendon.

[372]

Semitendinosus.-Origin; lower and inner facet on ischial tuberosity, in common with long head of Biceps. Course; in the mid-thigh it develops in a tendon which descends on the inner side of the knee, spreads out, and becomes membranous. Insertion; inner side of shaft of tibia, just below the internal tuberosity, below the Gracilis and behind the Sartorius. A bursa 


\section{DISSECTING MANUAL.}

lies under its insertion, and another between it and the Sartorius.

[373]

Semimembranosus.-Origin; upper and outer facet on ischial tuberosity, by a tendon which soon develops a fleshy belly. Insertion; horizontal groove on back of inner tuberosity of tibia (mainly); posterior border of internal lateral ligament, by a fascial band which runs downward and inward; oblique line of tibia, by a fascial band which runs downward and outward and covers the Popliteus; back of external condyle, by a fascial band which runs upward and outward, forming the posterior ligament of the knee.

[374]

The popliteal space is lozenge-shaped, lies in the hollow behind the knee, and is widest opposite the joint. It is bounded externally by the Biceps above the joint, and the Plantaris and outer head of Gastrocnemius below; and internally by the Semimembranosus and Semitendinosus above, and the inner head of the Gastrocnemius below. Its floor is formed by the femur, knee-joint capsule, tibia, and fascia over the Popliteus.

\section{NeRVES.}

Posterior Spinal Nerves.-Lower thoracic; the external cutaneous branches of the two lowest supply the buttock. First, second, and third lumbar; the external cutaneous branches supply the buttock to below and behind the great trochanter. First, second, and third sacral; loops between them, often joined by branches of the fifth lumbar and fourth sacral, form a plexus (posterior sacral) on the back of the sacrum; the external cutaneous branches of the plexus pierce the sacro-sciatic ligament and Gluteus maximus to supply the buttock. Fourth and fifth sacral and coccygeal; these unite (posterior sacrococcygeal nerve), pierce the sacro-sciatic ligament, and supply the skin over the coceyx.

[613]

Anterior Spinal Nerves.-Eleventh thoracic; the lateral cutaneous branch extends over the iliac crest. Tuelfth thoracic; the lateral cutaneous (iliac) branch descends over the front of 


\section{THIGH AND BUTTOCK.}

the iliac crest to the buttock as far as in front of and below the great trochanter.

[638]

Lumbar, Sacral, and Coccygeal.-These form the lumbo-sacral plexus, which is arbitrarily divided into the lumbar, sacral (sciatic), and pudendal plexuses. Gray rami communicantes, from the abdominal and pelvic sympathetic cords, cross the vertebræ, under the Psoas, to each nerve. White rami communicantes from the first two (or four) lumbar nerves run to the upper part of the lumbar sympathetic cord; and from the third (or second to fourth) sacral nerves, across the cord, to the pelvic sympathetic plexus.

\section{LUMBAR PLEXUS.}

[639]

This is formed by the first three, and part of the fourth lumbar nerves, and lies in the Psoas, in front of the transverse processes. The first and second lumbar nerves each divide into upper and lower branches. The upper branch of the first (often getting a branch from the last dorsal) divides into the ilio-hypogastric and ilio-inguinal, which run forward in the abdominal wall. The lower branch of the first joins the upper branch of the second to form the genito-crural. The lower branch of the second, the third, and the part of the fourth each divide into two parts, anterior and posterior; the anterior parts (except sometimes the second) unite to form the obturator; the posterior (larger) parts unite to form the anterior crural. The external cutaneous spring from the backs of the posterior parts of the second and third. Muscular branches to the Quadratus lumborum spring from the upper three or four lumbar (and sometimes last dorsal), and to the Psoas from the second and third (or first to fourth) lumbar nerves near their origins.

[641]

Mio-hypogastric.-The iliac branch (inconstant) descends over the iliac crest, behind the iliac branch of the last thoracic, to the skin on the upper and outer part of the buttock. [642]

Ilio-inguinal.-After passing through the external abdominal ring it supplies (cutaneous branches) the abdominal wall 


\section{DISSECTING MANUAL.}

over the symphysis, skin over Scarpa's triangle above and internally, top of scrotum, and root and dorsum of penis (mons Veneris and labium majus).

[642]

Genito-crural.-Arising by two roots which unite in the Psoas, the nerve then pierces and descends in front of the Psoas and runs through the psoas fascia and along the outer side of the iliac vessels under the ureter; it divides above Poupart's ligament into two branches, genital and crural. The minute genital branch runs across the iliac vessels and through the inguinal canal to the skin of the scrotum (or labium majus) and adjacent part of the thigh; branches go to the external iliac artery, Cremaster, and sympathetic spermatic plexus. The crural branch runs on the outer side of the femoral artery and through the saphenous opening, or iliac part of fascia lata, to the skin over Scarpa's triangle external to the ilio-inguinal; it supplies the femoral artery and communicates with the middle cutaneous.

[643]

External Cutaneous. - This runs under the Psoas and across the Iliacus, under the iliac fascia, to the anterior superior iliac spine, and then under the outer end of Poupart's ligament, either over, under, or through the Sartorius origin. Then, after giving off small branches, it pierces the fascia lata four inches below the spine and divides into two branches. The anterior branch, the larger, supplies the outer side of the front of the thigh, almost to the knee. The posterior branch supplies the outer side of the buttock below the great trochanter, and the upper two-thirds of the outer side of the thigh.

[643]

Obturator.-Arising by three roots which unite in the Psoas and emerge at its outer border, the nerve descends behind the common iliac and along the outer side of the internal iliac vessels. It then runs below the pelvic brim with the obturator artery, and through the obturator groove of the thyroid foramen, where it divides into two branches, superficial and deep. The deep branch pierces the Obturator externus, descends between the Adductor brevis and magnus, pierces the latter, and 


\section{THIGH AND BUTTOCK.}

appears in the popliteal space on the vessels. It supplies (muscular branches) the Obturator externus and the Adductor magnus and (occasionally) brevis; the terminal (articular) branch runs through the posterior ligament to the knee-joint. [643]

The superficial branch runs in front of the Obturator externus and Adductor brevis, under the Pectineus and Adductor longus, and then descends along the inner border of the latter. It divides into two terminal branches; one runs in Hunter's canal to the femoral artery; the other (cutaneous branch) joins branches of the internal cutaneous and internal saphenous under the Sartorius, forming a plexus (obturator, or subsartorial plexus), and may supply the lower two-thirds of the thigh internally. The other branches are: articular, to the hip-joint; muscular, to the Adductor longus, Gracilis, Adductor brevis (usually), and Pectineus (occasionally); and communicating (inconstant), to the anterior crural.

[644]

Accessory Obturator (very inconstant).-This arises from the third, or third and fourth lumbar nerves, between the roots of the obturator and anterior crural. Emerging from the inner side of the Psoas and coursing over the pelvic brim behind the external iliac vessels, it leaves the obturator nerve and runs over the pubis to the thigh. It divides behind the femoral vessels into three branches; one goes to the hip-joint, one replaces the branch of the obturator to the Pectineus, and one communicates with the superficial branch of the obturator. More rarely it may be more or less extensive.

[647]

Anterior Crural.-Arising by three roots which unite in the Psoas and emerge at its outer border, the nerve descends between the Psoas and Iliacus, and under Poupart's ligament external to the femoral sheath; it splits up in Scarpa's triangle into terminal branches. Muscular branches supply the Iliacus, arising in the abdomen; Pectineus, running under the femoral vessels; Sartorius, in two sets, to the upper and the middle part; Vastus externus and Rectus femoris, to their deep surfaces; Crureus, superficially, the nerve running through it to 


\section{DISSECTING MANUAL.}

the Subcrureus; and Vastus internus, one trunk to its upper part (and the Crureus also), and another to its inner side below, descending on the outer side of the femoral artery and crossing Hunter's canal. Articular branches. One goes to the hip, arising from the branch to the Rectus. Four supply the knee; three arise from the branches to the Vasti and Crureus and descend in front of the femur; one arises (sometimes) from the internal saphenous. The cutaneous branches are the middle and internal cutaneous and the internal saphenous.

[645]

The middle cutaneous arises in the upper part of Scarpa's triangle in two parts (an external and an internal branch), which pierce the fascia lata over the upper third of the Sartorius, supplying it, and descend to the patella. They supply the lower three-fourths of the front of the thigh, between the external and internal cutaneous, and also join the patellar plexus; the external branch communicates with the genital branch of the genito-crural, and may pierce the Sartorius.

[646]

The internal cutaneous varies with the size of the internal saphenous and the cutaneous branch of the obturator. It supplies the lower two-thirds of the inner side of the thigh through three branches (upper, middle, and lower), which descend to the apex of Scarpa's triangle on the outer side of the femoral vessels and then cross over them. The upper branch arises high up, pierces the fascia lata at the apex of Scarpa's triangle, and supplies the upper part of the thigh, along the saphenous vein; it may be represented by several twigs. The middle (or anterior) branch arises at the apex of Scarpa's triangle, runs over the Sartorius, becomes cutaneous at the middle third of the thigh, and supplies the lower half internally down to the knee; it joins the patellar plexus. The lower (or internal) branch, the termination, descends over or through the Sartorius, forms a plexus (obturator) with the internal saphenous and obturator in the middle third of the thigh, pierces the fascia lata in the lower third, and supplies the inner side of the knee, joining the patellar plexus.

[646] 


\section{THIGH AND BUTTOCK.}

The long (or internal) saphenous (terminal branch of anterior crural) descends from Scarpa's triangle throughout Hunter's canal, crossing over the femoral sheath from without inward; then crossing over the Adductor magnus tendon and running between the Sartorius and Gracilis it becomes cutaneous at the inner side of the knee, descends on the leg with the internal saphenous vein, runs in front of the inner ankle, and ends at the middle of the inner border of the foot. Its branches are: communicating, to the obturator plexus, arising in Hunter's canal and running inward; patellar, arising at the lower end of Hunter's canal, piercing the Sartorius, and descending below the patella and over the inner tibial tuberosity to the front of the knee and upper part of the leg, as well as the patellar plexus; articular (inconstant) to the knee, arising at its inner side; terminal, to the front and inner side of the leg, and posterior half of the dorsum and inner side of the foot.

[646]

Patellar Plexus.-This consists of fine subcutaneous communications, in front of the knee, between branches of the internal (patellar branch) saphenous, internal and middle cutaneous, and (sometimes) external cutaneous.

\section{SACRAL or SCIATIC PLEXUS.}

This lies at the back of the pelvis upon the Pyriformis, under the parietal fascia, and is formed by the descending part of the fourth lumbar, the fifth lumbar, the upper two sacral, and the upper part of the third sacral nerves. These converge and unite in a triangular band whose apex runs through the great sacrosciatic foramen, below the Pyriformis, to become the great sciatic nerve. The lumbar and first two sacral nerves each divide into anterior and posterior (ventral and dorsal) parts; the third sacral divides into upper and lower parts. The anterior parts of the lumbar nerves unite in a trunk, and the posterior parts in another; together these trunks form the lumbo-sacral cord. The anterior parts of the lumbar and upper two sacral nerves unite with the upper part of the third sacral to form the tibial nerve and anterior collateral branches; the posterior 
parts of the lumbar and upper two sacral nerves unite to form the peroneal nerve and posterior collateral branches. The branches of the plexus are collateral and terminal, the latter being the tibial and peroneal; all are divisible, according to their origin, into anterior and posterior branches.

[647]

The great sciatic nerve consists of the tibial and peroneal nerves, with the collateral branches to the hamstrings and short head of the Biceps, all bound together in a sheath. It descends with the sciatic artery uncler the Gluteus maximus, between the ischial tuberosity and great trochanter, and then upon the Adductor magnus, under the hamstrings; it divides at a variable point in the thigh into the tibial and peroneal nerves. The latter may be distinct from their origin, and even separated by part of the Pyriformis; in all cases they may be artificially separated by removing the sheath.

Collateral Branches. Anterior series.

[648]

The nerve to the Quadratus femoris arises from the front of the fourth and fifth lumbar and first sacral nerves; it descends on the back of the hip-joint capsule, under the sacral plexus, Gemelli, and Obturator internus, to enter the deep surface of the muscle. It also supplies the Inferior gemellus. The nerve to the Obturator internus arises from the front of the fifth lumbar and first two sacral nerves and descends on the outer side of the pudic vessels, below the great sciatic nerve; then crossing the ischial spine it runs through the lesser sciatic foramen to enter the pelvic surface of the muscle. It supplies the Superior gemellus also.

The nerve to the hamstrings arises from the roots of all the nerves of the plexus, descends with the tibial nerve, and separates into two sets of branches. The upper set passes inward just below the ischial spine, to the upper part of the Semitendinosus and the ischial head of the Biceps; the lower set leaves the great sciatic (tibial) lower down and supplies the Semimembranosus, lower part of the Semitendinosus, and the Adductor magnus. Articular branches, to the hip, arise from the 


\section{THIGH AND BUTTTOCK.}

nerve to the Quadratus femoris, and often from the front of the great sciatic (tibial) near its origin; they enter the back of the capsule.

\section{Posterior Series.}

The nerve to the Pyriformis arises from the back of the second, or first and second sacral nerves and enters the front of the muscle. The superior gluteal arises from the back of the fourth and fifth lumbar and first sacral nerves, and runs outward above the Pyriformis and then across the Gluteus minimus, under the Gluteus maximus and medius, to end in the under surface of the Tensor vaginx femoris; it supplies the Gluteus medius and minimus. The inferior gluteal arises from the back of the fifth lumbar and first two sacral nerves, runs under the Pyriformis, and at once divides into branches to the Gluteus maximus.

[649]

The nerve to the short head of the Biceps arises from the fifth lumbar and first two sacral nerves, and it usually descends in the sheath of the great sciatic nerve to the mid-thigh. An articular branch, to the outer side of the knee-joint, generally arises from the great sciatic (peroneal) with the preceding, descends under the Biceps, and divides into upper and lower branches.

[649]

Peroneal or External Popliteal.-After leaving the great sciatic this descends through the upper and outer part of the popliteal space, under the Biceps, and then over the outer head of the Gastrocnemius, ending about an inch below the head of the fibula. Collateral branches; to the knee-joint and short head of the Biceps as described just above; sural and peroneal communicating (cutaneous), arising in the popliteal space and descending to the leg. Terminal branches; anterior tibial, recurrent tibial, and musculo-cutaneous.

[650]

Tibial or Internal Popliteal.--After leaving the great sciatic, this descends through the popliteal space under the hamstrings, Gastrocnemius, and Plantaris, crossing over the popliteal vessels from without inward and then over the Popliteus; 
at the lower border of the Popliteus it becomes the posterior tibial when the upper part is called the internal popliteal. Its branches to the hip-joint and muscles of the thigh arise apparently from the great sciatic and have just been described. Its branches below the knee-joint will be described with the leg. Branches arising in popliteal space. Articular; an azygos branch pierces the posterior ligament of the knee-joint; an internal branch (inconstant) crosses the popliteal vessels and descends with the lower internal articular artery to the inner side of the knee-joint. Muscular; one each to the Plantaris and both heads of the Gastrocnemius, entering them at the borders of the popliteal space; one to the Soleus, entering it superficially; one to the Popliteus, descending over it and around its lower border to its anterior surface. The latter branch also supplies the Tibialis posticus, interosseous membrane, tibia, and upper tibio-fibular joint. Cutaneous (tibial communicating) ; descending between the heads of the Gastrocnemii to the back of the leg.

[652]

\section{PUDENDAL PLEXUS.}

This lies on the back wall of the pelvis and is formed by fibres from the first three sacral nerves and all the fourth and fifth sacral and the coccygeal. A visceral branch (white ramus communicans) runs from the third (and second or fourth) sacral to the pelvic plexus and viscera. The other branches are the small sciatic, perforating cutaneous, pudic, muscular, and sacro-coccygeal. The perforating cutaneous arises from the back of the second and third sacral nerves and runs through the great sacro-sciatic ligament to the buttock. The muscular branches arise from a loop between the third and fourth sacral and supply the Levator ani, Coccygeus, and External sphincter; offsets from the latter branch supply the skin on the ischiorectal fossa and fold of the nates behind the anus. The anterior sacro-coccygeal consist of descending branches from the fourth and fifth sacral and the coccygeal which form a plexus (coccygeal) besides the coccyx; twigs from this run 


\section{THIGH AND BUTTOCK.}

through the sacro-sciatic ligament to the skin near the coccyx.

[655-658]

Small Sciatic.-Springing from the backs of the first three sacral nerves at the junction of the sacral and pudendal plexuses, this runs through the great sciatic notch below the Pyriformis, descends behind the great sciatic, and then continues over the hamstrings to end as the sural branches. It is purely cutaneous, and has the following branches: Perineal (inferior pudendal); arising at the lower border of the Gluteus maximus and running inward over the hamstrings below the isçhial tuberosity, this becomes subcutaneous over the pubic arch and supplies the scrotum and root of the penis (labium majus and clitoris) communicating with the pudic and ilio-inguinal; collateral branches supply the upper and inner part of the thigh. Gluteal; many large branches arising under the Gluteus maximus and piercing the fascia lata along its lower border to supply the lower half of the buttock, from the great trochanter almost to the coccyx. Femoral; two sets, internal and external, pierce the fascia lata at intervals and supply the back of the thigh on its inner and outer sides respectively. Sural; two or more branches which pierce the popliteal fascia and supply the calf.

Pudic.-Arising usually from the second, third, and fourth sacral this runs through the great sacro-sciatic foramen below the great sciatic nerve, and across the ischial spine (or lesser sacro-sciatic ligament); then running through the small sacrosciatic foramen with the pudic artery, and along the outer wall of the ischio-rectal fossa in a special sheath of parietal pelvic fascia, it divides at the base of the triangular ligament into the perineal nerve and the dorsal nerve of the penis. The inferior hemorrhoidal, its other branch, arises in the back of the ischiorectal fossa usually, but may arise separately from the plexus (third and fourth sacral) and accompany the pudic. All these branches of the pudic go to the perineum and adjacent genitals (see page 203).

[658] 


\section{DISSEC'TING MANUAL.}

\section{SYMPATHETIC SYSTEM.}

The sacral part of the cord lies on the sacrum, internal to the foramina; it is continuous with the lumbar cord above and ends below, over the coccyx, in a plexiform (parietal branches) union with the opposite cord, the two parts often being connected by a ganglion (ganglion impar); it usually presents four ganglia. It receives no white rami communicantes, but gray ones pass from it to the sacral and coccygeal nerves. Visceral branches from its upper part join the pelvic plexus.

The hypogastric plexus is formed by the hypogastric nerves (from the aortic plexus), and lies on the bifurcation of the aorta and the sacral promontory; it descends on either side of the rectum and ends in the pelvic plexuses. The pelvic plexuses lie on each side of the rectum and accompany the internal iliac arteries, giving off subordinate plexuses along the branches; each gets fibres from the upper sacral part of the cord, and visceral branches from the sacral nerves.

[714]

\section{Arteries.}

Internal Iliac.-Beginning at the lumbo-sacral joint, this descends on the pelvic wall and divides, usually at the upper border of the great sciatic notch, into two divisions, anterior and posterior.

[848]

Branches of Posterior Division.-Ilio-lumbar, to the iliac fossa, sending a branch (lumbar) upward under the Psoas, and another (spinal) to the spine. Lateral sacral ; superior and inferior, descending on the front of the sacrum and coccyx. Gluteal; a continuation of the division, which gives off muscular, neural (to the sacral plexus), and nutrient (to the hip-bone) branches in the pelvis. It then runs through the great sacrosciatic foramen above the Pyriformis and divides under the Gluteus maximus into two branches, superficial and deep; the former at once breaks up. The deep branch divides into two branches, upper and lower, which run forward between the 


\section{THIGH AND BUTTOCK.}

Gluteus medius and minimus, the upper one along the origin of the Gluteus minimus and the other lower down.

[850]

Visceral Branches of Anterior Division.-Superior, middle, and inferior vesical, to the bladder; obliterated hypogastric, to the bladder and abdominal wall; artery to the vas; middle hemorrhoidal, to the rectum; uterine and vaginal, to the uterus and vagina.

[851]

Parietal Branches of Anterior Division.-The obturator runs along the pelvic wall just below the brim and through the obturator foramen, and then divides into two branches, external and internal; these skirt round the margins of the foramen upon the obturator membrane, under the Obturator externus. Its pelvic branches are muscular; nutrient, to the ilium ; vesical, to the bladder; and pubic, ascending on the back of the pubis and sometimes passing on the inner side of the crural ring. The internal pudic runs through the great sacro-sciatic foramen below the Pyriformis, across the ischial spine, and with the pudic nerve through the small sciatic foramen to the perineum; there it runs along the wall of the ischio-rectal fossa in Alcock's canal, and then along the pubic ramus between the layers of the triangular ligament. Its branches in the buttock are muscular and anastomotic; those in the perineum have been described (page 211). The sciatic runs through the great sacrosciatic foramen below the Pyriformis and descends with the great sciatic nerve to the lower border of the Gluteus maximus, and then with the small sciatic nerve. Its branches in the buttock are muscular; coccygeal, to the back of the coccyx; anastomotic, to the crucial anastomosis; cutaneous; and comes nervi ischiatici, to the great sciatic nerve.

External Iliac.-Beginning at the lumbo-sacral joint, this runs along the pelvic brim upon the iliac fascia and becomes the femoral artery undcr Poupart's ligament, midway between the pubic symphysis and anterior superior iliac spine. It lies external to the vein and both are enclosed in a thin sheath. Its branches are: twigs to the Psoas and glands; deep epigastric, 


\section{DISSECTING MANUAL.}

arising just above Poupart's ligament and ascending in the abdominal wall; and deep circumflex iliac, running outward above Poupart's ligament and the iliac crest, in the abdominal wall.

[856]

Femoral.-Beginning at the lower border of Poupart's ligament, midway between the pubic symphysis and anterior superior iliac spine, this descends to the opening in the Adductor magnus and there becomes the popliteal artery. Its course is a line from its origin to the adductor tubercle, when the thigh is flexed and rotated outward. Entering the base of Scarpa's triangle in the outer compartment of the femoral sheath, it descends to the apex, gradually getting in front of its vein, and then descends throughout Hunter's canal, also in front of its vein though somewhat internal below.

[858]

The superficial circumflex iliac arises near Poupart's ligament, pierces the femoral sheath and fascia lata, and runs to the anterior superior iliac spine. The superficial epigastric, arising near the preceding, pierces the femoral sheath and cribriform fascia and ascends on the abdominal wall between the layers of superficial fascia. The superficial external pudic pierces the femoral sheath and cribriform fascia and runs over the pubic spine to the external genitals. The deep external pudic runs inward on the Pectineus to the external genitals. Muscular branches supply the thigh muscles.

[859]

The profunda arises from the outer side of the femoral, about an inch and a half below Poupart's ligament; it descends behind the femoral (separated by the Adductor longus), close to the femur, to the lower third of the thigh where it pierces the Adductor magnus as the fourth perforating artery. Its branches are as follows: External circumflex; running outward under the Sartorius and Rectus and dividing into three terminal branches, ascending, transverse, and descending. Internal circumflex; running straight backward to the upper border of the Adductor magnus and dividing into two branches; ascending, to the digital fossa of the femur; and transverse, 


\section{THIGH AND BUTTOCK.}

continuing backward above the Adductor magnus. It also gives off muscular branches, and an articular branch to the hip. Perforating; piercing the Adductors close to the femur, the first two running through the Adductor brevis, and the third below it. Muscular; to the thigh.

[860]

The anastomotic arises from the femoral near its end and divides at once into two branches, superficial and deep, to the inner side of the knee.

[862]

Crucial Anastomosis: This is formed under the Gluteus maximus by branches of the sciatic, the first perforating, and the transverse branches of the external and internal circumflex.

[862]

Popliteal. - Beginning as a continuation of the femoral at the upper and inner part of the popliteal space, under the Semimembranosus, this descends, at first slightly outward and then vertically, to the lower border of the Popliteus and there divides into the anterior and the posterior tibial. Its branches are muscular, upper and lower sets; superior articular, internal and external, one running on each side transversely above the femoral condyle; inferior articular, internal and external, one running on each side transversely below the femoral condyle; azygos articular, running forward through the centre of the knee-joint capsule; and cutaneous, one (superficial sural) descending on the calf in the midline.

[863]

\section{Veriss.}

There are two sets, superficial and deep; the former do not accompany arteries but end in the deep veins. The deep veins (venæ comites) accompany their arteries in pairs (except the popliteal, femoral, and iliacs, which are single) and have the same names and branches. The popliteal ascends behind its artery, gradually crossing it from within outward. The femoral in Hunter's canal lies behind, and at first to the outer side of, its artery ; in Scarpa's triangle it lies at first behind and 


\section{DISSECTING MANUAL.}

to the inner side of the artery, but gets to the inner side above and runs in the middle compartment of the femoral sheath. The external iliac lies at first to the inner side of its artery, but gets behind this higher up. The internal iliac lies behind and to the inner side of its artery.

[895-899]

The superficial veins end in two trunks, the saphenous veins. The internal or long saphenous ascends from the foot and over the leg to the knee, where it runs just behind the internal femoral condyle and then upward and slightly forward to the saphenous opening; here it pierees the cribriform fascia and femoral sheath to end in the femoral vein. The external or short saphenous ascends on the back of the leg to the lower part of the popliteal space, where it pierces the popliteal fascia and joins the popliteal vein.

[900]

\section{LYMPHATICS.}

Glands of Pelvis.-The pelvic parietal glands include the following groups, viz.: external iliac, lying on that artery in three groups, outer, middle, and inner, placed respectively to the outer side, in front of, and to the inner side of it; obturator (inconstant), lying at the back of the obturator canal; lateral sacral, lying in the hollow of the sacrum, behind the rectum; internal iliac, lying beside that artery on the pelvic wall; and common iliac, lying beside that artery.

[920]

Glands of Lower Extremity.-The superficial glands lie about the groin in three groups, viz.: superior or inguinal, lying parallel with and just below Poupart's ligament; inferior or superficial femoral, lying along the upper part of the internal saphenous vein; and internal or pubic, lying internal to the saphenous opening and close to the pubic spine.

[916]

The deep glands include the following groups, viz.: popliteal, lying in the popliteal space, generally around the artery; and deep femoral, lying on the inner side of the femoral vein in Scarpa's triangle and (the largest gland) the crural canal.

[916] 


\section{LEG AND FOO'T.}

\section{LEG AND FOOT.}

FASCIA.

The superficial fascia is very fatty in the sole of the foot, especially under the tuberosity of the os calcis and balls of the toes, and adheres firmly to the plantar fascia.

[376]

Deep Fascia.-About the knee it forms the popliteal fascia behind; it is attached in front to the patella, ligamentum patellæ, and tibial tubercle, and laterally to the tibial tuberosities and head of the fibula, forming the lateral patellar ligaments. In the leg it blends with the periosteum on the inner surface of the tibia and is attached to the lower part of the shaft of the fibula. It sends a septum from the anterior border of the fibula between the peronei and extensors; and another from the posterior border of the fibula between the peronei and flexors; from the latter another septum runs between the superficial and deep flexors.

[376]

At the ankle it is attached to the malleoli and os calcis and strengthened by transverse fibres, forming the annular ligaments. Of these the internal extends from the inner malleolus to the tuberosity of the os calcis while the external, a smaller thickened band, stretches from the outer malleolus to the os ealcis. The anterior is in two parts, viz.: a broad upper band, undefined at its borders, stretching between the malleoli; and a well-defined lower band which runs inward from the greater process of the os calcis, and divides on the dorsum of the foot into an upper part going to the upper band and internal malleolus, and a lower part going to the inner border of the fascia on the sole.

On the sole of the foot it forms the plantar fascia, which consists of a central portion and two thin lateral portions. The central portion is a thick triangular band attached to the tuberosity of the os calcis; this splits in front into five slips which extend to the bases of the toes, joining the digital 


\section{DISSECTING MANUAI.}

sheaths and tissues of the web; a band runs forward on each side of the toe to the side of the metatarso-phalangeal joint and base of the first phalanx; bands (superficial transverse metatarsal ligament) of transverse fibres connect these slips as they separate; an intermuscular septum ascends from the central portion on each side of the Flexor brevis digitorum. On the toes the digital sheaths are arranged as on the fingers; vaginal ligaments occur over the first and second phalanges.

[378]

\section{Muscles.}

Front of Leg and Dorsum of Foot.

Tibialis Anticus.-Origin; upper two-thirds of outer surface of tibia; interosseous membrane; fascia over it; intermuscular septum externally. Course of tendon; through special compartments under both parts of anterior annular ligament, in a separate synovial sheath. Insertion; internal cuneiform; base of first metatarsal.

[378]

Extensor Longus Digitorum.-Origin, outer side of external tuberosity of tibia; upper two-thirds, or more, of anterior surface of fibula; fascia over it; intermuscular septa on either side. Course of tendon; under anterior annular ligament, running under the lower part in a separate compartment with the Peroneus tertius and with a special synovial sheath; dividing in front of ankle into four tendons. Insertion; into four outer toes in same way as corresponding tendons in hand (see page 174). It forms membranous expansions on the dorsum of the first phalanges, which are joined by the tendons of the Extensor brevis digitorum, Lumbricales, and Interossei; the expansions separate into a central and two lateral slips, which are attached respectively to the middle and terminal phalanges of the toes.

Peroneus Tertius (a separated portion of the preceding).Origin; anterior surface of fibula; intermuscular septum externally. Course; with preceding. Insertion; dorsal aspect of base of fifth metatarsal.

[380] 


\section{LEG AND FOOT.}

Extensor Proprius Hallucis.-Origin; middle three-fifths of front of fibula; corresponding extent of interosseous membrane. Course of tendon; under anterior annular ligament, in a special synovial sheath under the lower part. Insertion; base of terminal phalanx of great toe.

[380]

Extensor Brevis Digitorum.-Origin; impression on upper surface of greater process of os calcis. Course; it forms four fleshy bellies which end in narrow tendons. Insertion; (three outer tendons) expansion of Extensor longus digitorum on dorsum of three middle toes; (innermost tendon) base of first phalanx of great toe.

[380]

Outer Side of Leg.

Peroneus Longus.-Origin; upper two-thirds of outer surface of fibula; intermuscular septa on either side; fascia over it. Course of tendon; around external malleolus and across outer side of os calcis, running under external annular ligament in a common synovial sheath; then around border of cuboid, developing a fibro-cartilage over the tubercle, a bursa intervening; then through peroneal groove on under surface of cuboid and across foot, in a sheath derived from the inferior calcaneocuboid ligaments. Insertion; internal cuneiform; base of first metatarsal.

Peroneus Brevis.-Origin; lower two-thirds of outer surface of fibula; intermuscular septum at anterior border. Course of tendon; over back of external malleolus and across outer side of os calcis, running under external annular ligament in same synovial sheath as preceding. Insertion; base of fifth metatarsal.

[381]

Back of Leg; Superficial Set.

Gastrocnemius.-Origin; (by two heads, inner and outer, with a bursa under each) lateral surface of each femoral condyle; back of knee-joint capsule. Course; two separate bellies. 
Insertion; broad upward expansion of tendo Achillis under deep surface of each belly.

[381]

The tendo Achillis is formed by the union of its two broad membranous expansions upward under the bellies of the Gastrocnemius, connecting their lower parts; narrowing gradually, and thickening, it is inserted (a bursa intervening) in the lower half of the posterior surface of the os calcis.

[382]

Plantaris (inconstant).-Origin; lower inch of external supracondyloid ridge of femur; posterior ligament of kneejoint. Course of tendon; along inner border of tendo Achillis. Insertion; tuberosity of os calcis, or tendo Achillis, or internal annular ligament.

[382]

Soleus.-Origin; posterior surface of head and upper third of shaft of fibula; fibrous arch stretching between tibia and fibula, over popliteal vessels and tibial nerve; oblique line and middle third of inner border of tibia. Insertion; (upper fibres) tendon on superficial aspect, which joins tendo Achillis; (lower fibres) tendo Achillis.

[382]

Back of Leg; Deep Set.

Popliteus.-Origin; rough impression in front of groove on outer aspect of femoral external condyle, by a tendon which passes between the external semilunar cartilage and knee-joint capsule and then pierces the posterior ligament; posterior ligament of knee-joint. Under the tendon is a bursa which communicates with the knee-joint. Insertion; triangular surface on back of tibia above oblique line; fascia over it.

[383]

Flexor Longus Digitorum.-Origin; middle two-fourths of posterior surface of tibia; fascia over it; intermuscular septa on each side. Course of tendon; under internal annular ligament in a special synovial sheath, and across superficial surface of Flexor longus hallucis tendon, from which it receives a band, to sole of foot, where it divides into four tendons. Insertion; bases of terminal phalanges of four outer toes, each tendon en- 


\section{LEG AND FOOT.}

tering the digital sheath, piercing the Flexor brevis digitorum tendon, and being provided with ligamenta accessoria, longa and brevia, as in the hand (see page 171).

[384]

Lumbricales (four small muscles arising from the tendons of the preceding).-Origin; (first lumbrical) tibial side of innermost tendon; (three outer lumbricales) adjacent sides of all four tendons, by two heads each. Course of tendons; to tibial side of corresponding toes. Insertion; dorsal expansion of extensor tendon, metacarpo-phalangeal joint, and base of first phalanx of each of the four outer toes, as in the hand (see page 171). [384]

Flexor Accessorius.-Origin; (outer head) outer border of inferior surface of os calcis; (inner head) inner border of under surface of os calcis. The heads unite in a flattened band. Insertion; upper aspect of Flexor longus digitorum tendons, usually the inner threc.

[384]

Flexor Longus Hallucis.-Origin; lower two-thirds of posterior surface of fibula; fascia over it; intermuscular septa on either side. Course of tendon; under internal annular ligament in a special synovial sheath, and then (grooving back of lower end of tibia, astragalus, and under surface of sustentaculum tali) forward in sole of foot over deep aspect of Flexor longus digitorum tendon, sending a fibrous band to the two inner tendons of the latter. Insertion; base of terminal phalanx of great toe.

[385]

Tibialis Posticus.-Origin; middle three-fifths of fibula, between oblique line and interosseous border; middle third of back of tibia, between vertical line and interosseous border; interosseous membrane; fascia over it, and intermuscular septa on either side. Course of tendon; under internal annular ligament in a special synovial sheath, grooving back of internal malleolus, and then forward deeply into foot, spreading out in three bands. Insertion; navicular and internal cuneiform; second, third, and fourth metatarsals, cuboid, and middle and external cuneiforms; (recurrent slip) inner border of sustentaculum tali.

[385] 
Sole of Foot.

Abductor Hallucis.-Origin; greater tubercle on tuberosity of os calcis; internal annular ligament and plantar fascia. Insertion; inner side of first phalanx of great toe.

[386]

Flexor Brevis Digitorum.-Origin; fore-part of greater tubercle on tuberosity of os calcis; central portion of plantar fascia covering it, and intermuscular septa on either side. Course; forward, giving rise to four tendons which are perforated by the long flexor tendons as in the hand (see pages 170, 171). Insertion; second phalanges of four outermost toes.

[386]

Abductor Minimi Digiti.-Origin; both tubercles on tuberosity of os calcis; plantar fascia and calcaneo-metatarsal ligament. Course; along fifth metatarsal. Insertion; outer side of first phalanx of little toe.

[387]

Flexor Brevis Hallucis.-Origin; inner surface of cuboid; tendon of Tibialis posticus. Course; separating in two parts, between which the Flexor longus hallucis tendon lies. Insertion; both sides of base of first phalanx of great toe, by its two tendons.

[388]

Adductor Obliquus Hallucis.-Origin; sheath of Peroneus longus; heads of third and fourth metatarsals. Insertion; outer side of base of first phalanx of great toc.

[3S8]

Adductor Transversus Hallucis.-Origin; capsules of outer four metatarso-phalangeal joints; transverse metatarsal ligament. Insertion; outer side of base of first phalanx of great toe.

[388]

Flexor Brevis Minimi Digiti.-Origin; sheath of Peroneus longus; base of fifth metatarsal. Insertion; outer side of base of first phalanx of little toe.

[388]

Dorsal Interossei.-Origin; (of all four) shafts of all metatarsals, by two hcads each. Insertion; (first and second) first phalanx, metatarso-phalangeal capsule and dorsal expansion of extensor tendon on sccond toe, on its tibial and fibular sides 


\section{LEG AND FOOT.}

respectively; (third and fourth) same structures on fibular sides of third and fourth toes.

[388]

Plantar Interossei.-Origin; (of all three) tibial side of outer three metatarsals, by a single head each. Insertion; same as Dorsal interossei, on tibial sides of three outer toes.

[389]

\section{NERVES.}

Anterior Crural.-The long (internal) saphenous becomes cutaneous at the inner side of the knee, descends on the leg with the internal saphenous vein, runs in front of the inner ankle, and ends at the middle of the inner border of the foot. Its terminal branches supply the skin on the front and inner side of the leg, and posterior half of the dorsum and inner side of the foot.

[646]

Peroneal or External Popliteal.-Descending with the Biceps tendon in the outer part of the popliteal space over the outer head of the Gastrocnemius, this divides just below the head of the fibula into the recurrent tibial, anterior tibial, and musculo-cutaneous. Branches in popliteal space. The sural pierces the deep fascia over the outer head of the Gastrocnemius and supplies the skin on the upper two-thirds of the outer aspect of the back of the leg. The peroneal communicating descends over the outer head of the Gastrocnemius to the middle third of the leg and usually unites with the tibial communicating branch to form the external (short) saphenous; it may not unite, either replacing the latter or supplying the outer side of the leg, heel, and ankle only.

The recurrent tibial runs forward under the Peroneus longus and Extensor longus digitorum; it divides below the outer tibial tuberosity into branches to the Tibialis anticus, tibiofibular joints, and knee-joint.

[650]

Anterior Tibial.-This descends under the Peroneus longus, Extensor longus digitorum, and Extensor proprius hallucis, lying on the front of the interosseous membrane and lower part 


\section{DISSECTING MANUAL.}

of the tibia; it then runs under the anterior annular ligament and Extensor proprius hallucis tendon and divides on the dorsum of the foot into two terminal branches, internal and external. Collateral branches; muscular to the Tibialis anticus, Extensor proprius hallucis, Extensor longus digitorum, and Peroneus tertius; articular, to the ankle-joint.

[651]

Terminal Branches.-The internal runs to the first interosseous space and divides into two (dorsal digital) branches for the skin on the contiguous sides of the great and second toes, communicating with the musculo-cutaneous; it sends one or two (dorsal interosseous) branches to the tarso-metatarsal, and metatarso-phalangeal joints and First dorsal interosseous. The external runs outward under the Extensor brevis digitorum, ending in a gangliform enlargement from which branches go to the Extensor brevis digitorum and tarsal, tarso-metatarsal and metatarso-phalangeal joints; it may give off four (dorsal interosseous) branches, the two inner to the Second and Third dorsal interossei and the tarso-metatarsal joints, and the two outer to the tarso-metatarsal joints.

[651]

Musculo-cutaneous.-Running below the head of the fibula and under the upper fibres of the Peroneus longus, this descends between the Peronei and the Extensor longus digitorum, in front of the fibula, to the lower third of the leg; it then pierces the deep fascia and divides into two branches, internal and external. It also gives muscular branches to the Peronei, longus and brevis. The internal branch descends over the anterior annular ligament, supplying the lower third of the leg and dorsum of the foot, and divides into three branches; one (internal) to the skin on the dorsum of the foot and inner side of the great toe, communicating with the internal saphenous; one (middle) to the interval between the great and second toes, dividing into two branches which communicate with the anterior tibial; and one (external) to the interval between the second and third toes, dividing in two (digital) branches for the adjacent sides of these toes.

[651] 


\section{LEG AND FOOT.}

The external branch descends over the anterior annular ligament, supplying the lower part of the leg and dorsum of the foot, and divides into two parts, internal and external. These go to the intervals between the third, fourth, and fifth toes, each dividing into two digital branches for their adjacent sides; they communicate with the external saphenous.

Tibial or Internal Popliteal.-Descending mesially in the popliteal space to the lower border of the Popliteus, it then (as the posterior tibial if the upper part is known as the internal popliteal) descends on the back of the leg to the inner ankle, lying on the Tibialis posticus and tibia, and gradually crossing over the posterior tibial vessels from within outward. Under the internal annular ligament it divides into the external and internal plantar.

[652]

Branches in Popliteal Space.-Articular, two to the kneejoint. Muscular; one each to the heads of the Gastrocnemius and to the Plantaris, entering at the border of the popliteal space; one to the Soleus, entering the superficial surface; one to the Popliteus, winding round its lower border to enter the deep surface and also sending branches to the Tibialis posticus, interosseous membrane as far as the lower tibio-fibular joint, upper tibio-fibular joint, and tibia. Cutaneous or tibial communicating; this descends between the heads of the Gastrocnemius and upon the tendo Achillis, pierces the deep fascia in the middle third of the back of the leg, and at once joins the peroneal communicating, forming the external or short saphenous. This runs, with the external saphenous vein, round the back of the external malleolus to the foot; it supplies cutaneous branches to the outer side and back of the lower third of the leg, the ankle and heel, and the outer side of the foot and little toe, as well as articular branches to the ankle and tarsal joints.

Branches in Leg.-Muscular; one each to the Soleus (entering its deep surface), Tibialis posticus, Flexor longus digitorum, and Flexor longus hallucis. Cutaneous or internal 


\section{DISSECTING MANUAL.}

calcanean; to the heel and back part of the sole, piercing the internal amnular ligament. Articular, to the ankle-joint. Medullary, to the fibula.

[653]

Internal Plantar.-Running forward with the internal plantar artery, in the sole beneath the internal annular ligament and Abductor hallucis, to the interval between the latter muscle and the Flexor brevis digitorum, it divides into four terminal branches. Collateral branches; muscular, to the Abductor hallucis and Flexor brevis digitorum; plantar cutaneous, to the inner part of the sole, piercing the plantarfascia between these muscles; articular, to the inner tarsal and tarsometatarsal joints.

Terminal Branches. The first (most internal) pierces the fascia behind the ball of the great toe, and supplies the Flexor hallucis and skin on the inner side of the foot and ball of the great toe; it ends as the plantar digital nerve to the inner side of the great toe. The second, after supplying the First lumbrical, divides into two plantar digital nerves for the adjacent sides of the first and second toes. The third and fourth each divide at the intervals between the second, third, and fourth toes, into two plantar digital branches for the adjacent sides of these toes. The plantar digital nerves supply the whole plantar aspect of the toes, and also their nails and tips dorsally.

External Plantar.-Running forward and outward in the sole with the external plantar artery, between the Accessorius and Flexor brevis digitorum, it divides near the head of the fifth metatarsal into terminal branches, superficial and deep. Collateral branches; muscular, to the Accessorius and Abductor minimi digiti; cutaneous, piercing the plantar fascia at intervals along the external intermuscular septum. The superficial branch (terminal) runs forward between the Flexor brevis digitorum and Abductor minimi digiti and divides in two parts; one (external branch) supplies the Flexor brevis minimi digiti, sometimes one or both Interossei in the fourth space, the skin 


\section{LEG AND FOOT.}

on the sole and the ball of the little toe, and ends as the plantar digital branch to the outer side of the little toe; the other (internal branch) divides at the interval between the fourth and fifth toes into two plantar digital branches for adjacent sides of those toes, and communicates with the internal plantar. The deep branch (terminal) runs inward deeply with the external plantar artery, under the Accessorius and Adductor obliquus hallucis, and supplies (articular branches) the tarsal and tarso-metatarsal joints and (muscular branches) the Adductores, obliquus and transversus, hallucis, outer three Lumbricals, and all the Interossei except, sometimes, those in the fourth space.

[654]

Small Sciatic. - The two sural branches pierce the popliteal fascia and supply the skin on the back of the leg, usually to its middle, but sometimes more or less; they communicate with the external saphenous.

[657]

\section{Arteries.}

The popliteal divides, at the lower border of the Popliteus, into the anterior and posterior tibial. A cutaneous branch (superficial sural) descends in the midline of the calf.

Posterior Tibial.- This runs downward and inward between the superficial and deep muscles of the back of the leg, lying at first on the outer, and then the inner side of the posterior tibial nerve. Under the lower border of the internal annular ligament, midway between the tip of the inner malleolus and most prominent part of the heel, it divides into the internal and external plantar. Branches; muscular; medullary, to the tibia; communicating, to the lower end of the peroneal; cutaneous; internal malleolar, to the inner malleolus; and peroneal.

[864]

The peroneal arises from the posterior tibial about an inch below the Popliteus, descends on the fibula, and divides, about an inch above the ankle-joint, into the anterior and posterior peroneal. Its other branches are muscular; medullary, to the 


\section{DISSECTING MANUAL.}

fibula; and communicating, to the lower end of the posterior tibial. The anterior peroneal runs forward under the lower edge of the interosseous membrane to the dorsum of the foot. The posterior peroneal descends behind the outer malleolus to the outer side of the heel and foot.

[865]

Internal Plantar.-Running forward on the inner side of the foot, between the Abductor hallucis and Flexor brevis digitorum, this joins the plantar digital branch of the dorsalis hallucis to the inner side of the great toe. Three digital branches join the princeps hallucis branch of the dorsalis pedis and the two inner digital branches of the plantar arch, at the roots of the inner three interdigital clefts. Its other branches are muscular, cutaneous, and articular.

External Plantar. - This runs forward and outward between the Accessorius and Flexor brevis digitorum, and then between the latter and the Abductor minimi digiti, to the base of the fifth metatarsal. Then, as the plantar arch, it curves inward, with the convexity forward, across the bases of the metatarsals to join the dorsalis pedis at the outer side of the base of the first metatarsal, completing the arch. Its earlier branches are muscular; cutaneous; and internal calcaneal, to the heel. The branches of the arch are articular, to the tarsal joints; posterior perforating, three in number, passing through the three outer interosseous spaces between the heads of the Dorsal interossei, to join the dorsal interosseous branches of the metatarsal; and digital, four in number. Of the digital, the outermost runs along the outer side of the little toe; the inner three run to the bases of the three outer interdigital clefts and each divides into branches for the sides of the toes; just before dividing they may send (anterior perforating) branches to the dorsal interosseous arteries.

[866]

Anterior Tibial. - This runs forward between the uppermost slips of the Tibialis posticus and above the upper edge of the interosseous membrane. It then descends deeply along the outer border of the Tibialis anticus, resting successively on the 


\section{LEG AND FOOT.}

interosseous membrane, lower part of the tibia, and anterior ligament of the ankle-joint; the Extensor proprius hallucis tendon crosses its lower end. In front of the ankle it becomes the dorsalis pedis.

[867]

Branches.-Superior fibular; arising high up and ascending behind the neek of the fibula. Posterior tibial recurrent; arising high up and ascending in front of the Popliteus to the back of the knee. Anterior tibial recurrent; arising high up and ascending in front of the knee, externally. Muscular. $\mathrm{Cu}$ taneous. Internal malleolar; to the front of the inner malleolus. External malleolar; to the front of the external malleolus.

[868]

Dorsalis Pedis.-Running forward superficially under the anterior annular ligament and along the outer side of the Extensor proprius hallueis tendon, this passes through the base of the first interosseous space, between the heads of the first Dorsal interosseous and joins the end of the external plantar, completing the plantar arch.

[868]

Branches.-Cutaneous. Tarsal, to the outer part of the tarsus. Metatarsal; arising low down and running outward on the bases of the metatarsals, under the tendons: from it three branches (dorsal interosseous) run to the three outer toeclefts, and each divides into two collateral digital branches for the adjacent sides of the toes; the outer dorsal interosseous sends a branch to the outer side of the little toe; each dorsal interosseous sends a branch (posterior perforating) through the back part of the interosseous space, between the heads of the Dorsal interosseous, to join the plantar arch, and another (anterior perforating) through the front of the space to the plantar digital artery. Dorsalis hallucis; running forward to the innermost toe-cleft it divides into collateral dorsal digital branches to the adjacent sides of the toes; it gives off a dorsal ligital branch to the inner sicle of the great toe. Princeps hallucis; arising in the sole, from the termination, it runs forward to the innermost toe-cleft and divides into collateral 


\section{DISSECTING MANUAL.}

digital branches for the adjacent sides of the toes; it gives off earlier a plantar digital branch to the inner side of the great toe.

[869]

\section{VEINS.}

The deep veins are the ven comites which accompany the arteries in pairs and end in the popliteal finally; the latter is single.

[897]

Superficial Veins. - A dorsal digital vein runs along each border of the dorsum of each toe; at the toe-clefts those of adjacent borders unite in four dorsal interdigital veins which join the dorsal venous arch. The arch runs transversely across the metatarsals, uniting externally with the outer dorsal digital vein of the little toe to form the external saphenous, and internally with the inner dorsal digital vein of the great toe to form the internal saphenous. On the sole there is a transverse arch at the roots of the toes, which receives plantar digital veins from the toes and gives off interdigital branches to the dorsal arch.

[900]

The internal or long saphenous begins on the inner side of the foot, runs upward in front of the internal malleolus, and then just behind the inner border of the tibia to the knee; then passing just behind the inner femoral condyle it runs upward and slightly forward to the saphenous opening, where it pierces the cribriform fascia and femoral sheath to join the femoral vein.

[900]

The external or short saphenous begins on the outer side of the foot, runs upward behind the external malleolus, and then along the outer border of the tendo Achillis to the middle of the calf; above this it ascends to the lower part of the popliteal space, pierces the deep fascia, and joins the popliteal. [901]

\section{LYMPHATICS.}

Deep Glands.-A single anterior tibial gland lies near that artery on the upper part of the front of the interosseous membrane.

[916] 






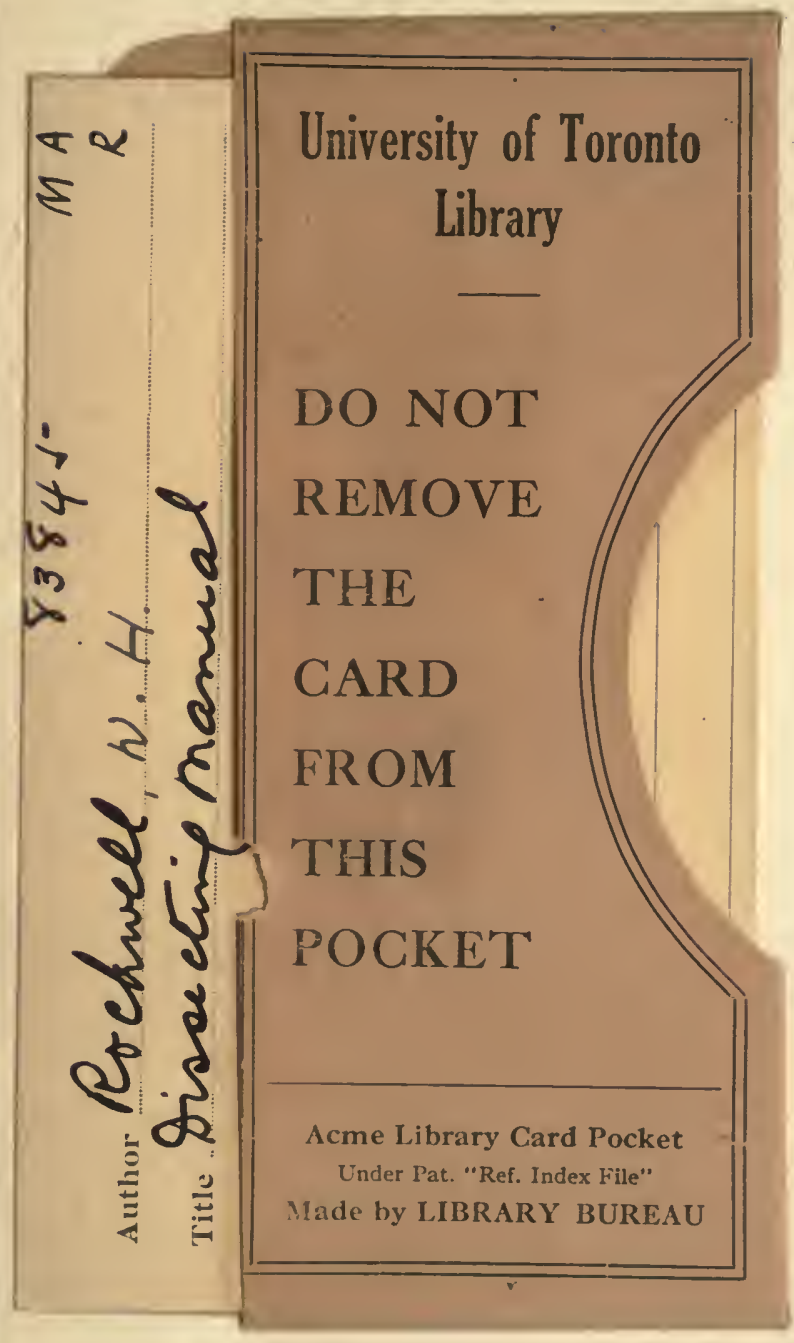


